\title{
0) OECD
}

\section{Towards Improved and Comparable Productivity Statistics}

A SET OF RECOMMENDATIONS FOR STATISTICAL POLICY
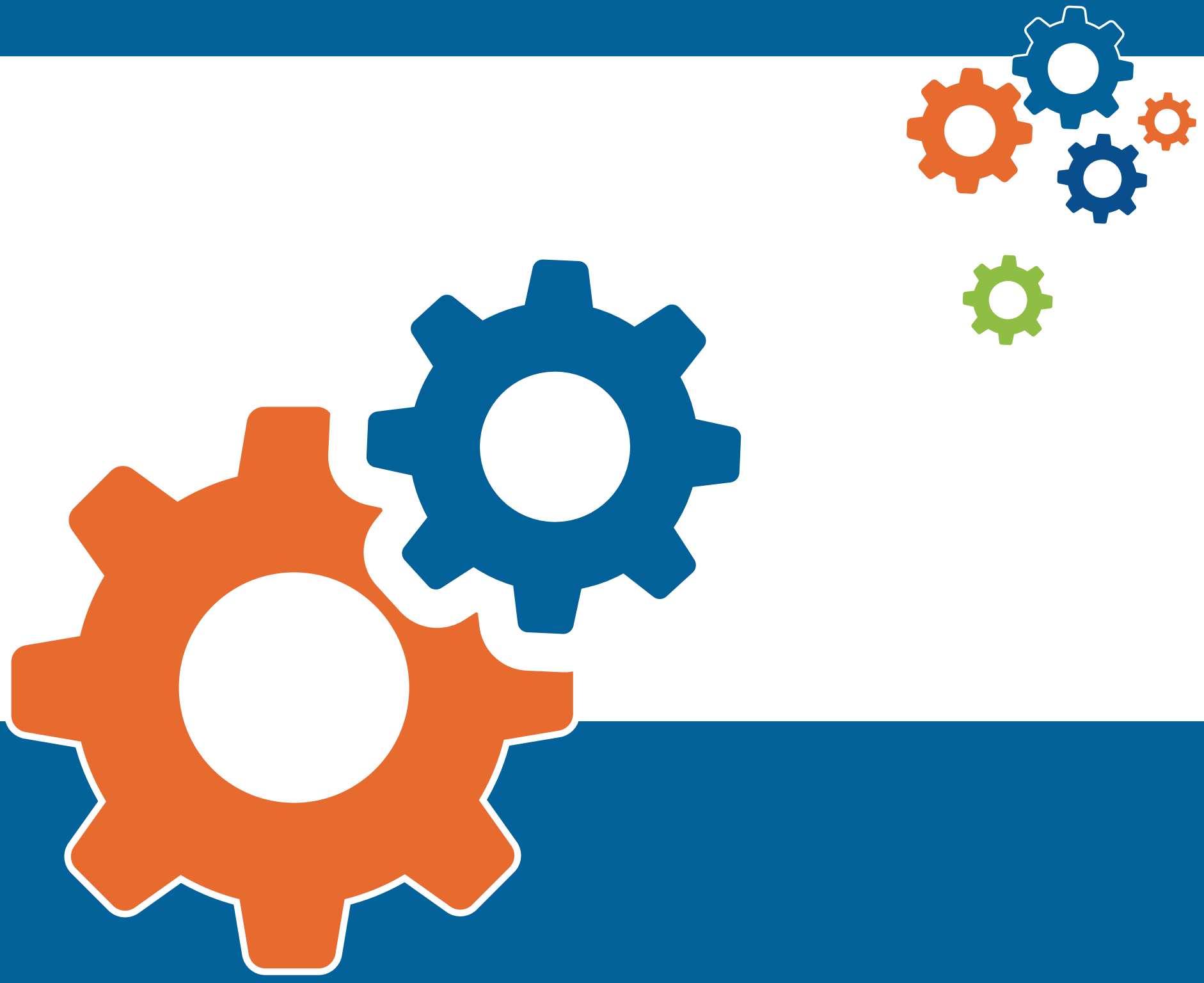

Towards improved and comparable productivity statistics: A set of recommendations for statistical policy 
This work is published under the responsibility of the Secretary-General of the OECD. The opinions expressed and arguments employed herein do not necessarily reflect the official views of the members of the OECD or the APO.

This document and any map included herein are without prejudice to the status of or sovereignty over any territory, to the delimitation of international frontiers and boundaries and to the name of any territory, city or area.

\section{Please cite this publication as:}

APO/OECD (2021), Towards Improved and Comparable Productivity Statistics: A Set of Recommendations for Statistical Policy, OECD Publishing, Paris, https://doi.org/10.1787/1ae0ec74-en. 


\section{Foreword by the Asian Productivity Organization}

Established in 1961 as an intergovernmental organization, the Asian Productivity Organization (APO) contributes to sustainable socioeconomic development in Asia and the Pacific through policy advice and capacity building. It now has 21 members. The national productivity organizations (NPOs) of APO members act as planning and implementing agencies and coordinate productivity projects hosted by their governments.

For the past 60 years, the APO has played a leadership role in productivity growth and long-term socioeconomic development in the Asia-Pacific. Expanding on the APO Vision 2020, which guided activities during 2016-2020, the new APO Vision 2025 addresses new challenges and expectations confronting the region and individual member countries over the 2021-2025 period. Effective productivity policy relies on robust productivity statistics. Evaluation of regional and national performance against the key result areas outlined in the Vison 2025 therefore requires accurate data. The APO has made significant contributions through the APO Productivity Databook and accompanying APO Productivity Database, which represent the most complete measurement efforts of productivity-related data for the region.

In October 2019, the APO and Organisation for Economic Co-operation and Development (OECD) signed a Memorandum of Understanding (MOU) to collaborate in developing improved, more comparable productivity statistics across APO and OECD member economies. This report is the first outcome of that initiative. It explores current practices and challenges in productivity measurement and provides recommendations to national statistics offices, NPOs, and other agencies involved in the compilation and analysis of productivity statistics in APO member economies to improve measurement and cross-country comparability.

The APO looks forward to the next stages of collaboration with the OECD and to continued progress toward the mutual goals of our organizations.

\section{Dr. AKP Mochtan}

APO Secretary-General

$31^{\text {st }}$ January, 2021

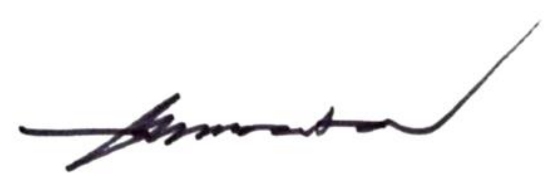




\section{Foreword by the Organisation for Economic Co-operation and Development}

Productivity growth is a central driver of long-term economic growth and living standards but, in recent years, its contribution to growth has declined significantly in most countries. The COVID-19 crisis has exacerbated this decline, from a statistical and a structural perspective, as heightened uncertainty impacts on investment and, despite government support packages, many firms remain closed and jobs are being lost. Reigniting the productivity engine is more important than ever if economies are to build back better, and achieve sustainable, inclusive and resilient growth. To move in this direction, effective policy decisions must rely on evidence-based economic analyses, making the compilation of accurate and comprehensive productivity statistics paramount.

Since its creation in 1961, the Organisation for Economic Co-operation and Development (OECD) has been providing knowledge and advice to inform policy decisions by its member economies in different areas, while offering a unique forum where governments can work together to address economic, social and environmental challenges. The release of the OECD Productivity Statistics database in the early 2000s and the publication of the Measuring Productivity OECD Manual in 2001 and the Measuring Capital OECD Manual in 2009 consolidated its position as an international reference for productivity measurement and analysis.

In October 2019, the Asian Productivity Organization (APO) and the OECD signed a Memorandum of Understanding (MOU), as part of a collaboration to develop improved and more comparable productivity statistics across APO and OECD member economies. The present report is the first outcome of that initiative. It explores current practices and challenges in productivity measurement and provides recommendations to National Statistics Offices (NSOs), National Productivity Organisations (NPOs), and other agencies involved in the compilation and analysis of productivity statistics in APO member economies to improve measurement and cross-country comparability. These agencies are best placed to provide the most reliable inputs for productivity measurement given their access to, and knowledge of, the best data sources in their economy. Therefore, they are the main audience of this report.

The OECD looks forward to the ongoing and productive collaboration with the APO, which we believe has and will continue to deliver significant value to the membership of both organisations.

Paul SCHREYER

OECD Chief Statistician

Director of the OECD Statistics and Data Directorate

$4^{\text {th }}$ February, 2021

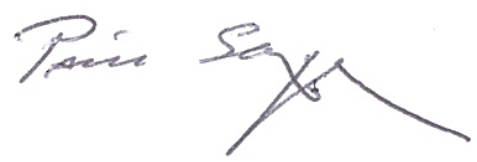




\section{Acknowledgements}

The report is a joint work of the APO and the OECD, and has been prepared in the OECD Statistics and Data Directorate by Ashley Ward and Belén Zinni, who benefited from supervision and comments by Nadim Ahmad and Pierre-Alain Pionnier. Special thanks go to Sehyeon Baek (APO) for his assistance and coordination, Koji Nomura (Keio University) for pointing the authors to useful material, and Miguel Rodríguez Cárdenas and Ivan Hascic (OECD) for fruitful discussions on the measurement of natural capital and environmentally adjusted productivity measures. 
6| P a g e 


\section{Table of contents}

\section{Introduction}

2. Baseline labour productivity measures
a. Measuring output: GDP
b. Measuring labour: population and employment
c. GDP per capita and labour productivity measured as GDP per worker
d. Statistical recommendations

\section{Intermediate productivity measures}
a. Measuring labour: hours worked
b. Labour productivity measured as GDP per hour worked
c. Measuring capital stocks
d. Multifactor productivity accounting for hours worked and net wealth capital stocks
e. Statistical recommendations

\section{Enhanced productivity measures}
a. Measuring labour: composition adjusted labour input (CALI)
b. Measuring capital services
c. Multifactor productivity accounting for labour and capital services
d. Productivity measures accounting for environmental inputs and outputs
e. Statistical recommendations

\section{Conclusions and way forward}

\section{References}


8| P a g e 


\section{Introduction}

Productivity growth is a central driver of long-term economic growth and living standards but, in recent years, its contribution to growth has declined significantly, with higher labour input forming the main engine of growth in most OECD countries. The COVID-19 crisis has exacerbated this decline, both statistically (as governments prioritise health and, indeed, jobs for example through furlough schemes, whilst imposing lockdowns), and structurally, as heightened uncertainty impacts on investment and, despite government support packages, firms are closed and jobs are lost. The aftermath of the 2008-9 financial crisis revealed that the recovery from such shocks can take many years, and the OECD's December 2020 Economic Outlook forecasts that, in many economies, global GDP will only return to pre-pandemic levels at the end of 2021 (OECD, 2020a). Reigniting the productivity engine is more important than ever if economies are to build back better, and achieve sustainable, inclusive and resilient growth.

A pre-requisite for this however is sound measurement of productivity. Effective policy decisions rely on evidence-based economic analyses, making the compilation of accurate and comprehensive productivity statistics paramount.

Many APO member economies are currently able to compile only basic productivity measures at the national level, such as output per employee, which present a skewed and imprecise view of productivity growth and limit the scope for international comparisons. Hours-based labour productivity and multifactor productivity measures that take account of changes in the composition of the workforce and of capital, provide a more accurate view of drivers of economic growth and, so, can better inform the policy debate.

Deriving accurate estimates of productivity, including multifactor productivity, is challenging, especially as many economies have increasingly become services orientated - where price measurement has been notoriously difficult - but recent megatrends, such as globalisation and digitalisation have exacerbated those challenges.

In many APO economies, who have large informal economies the measurement challenges are more severe. Moreover, fast moving trends in Asian labour markets, such as rising female participation, the high incidence of self-employment and the increasing educational levels in the population, reinforce the need to better account for the composition of the workforce in productivity analysis. In addition, rapid structural changes in many economies in the region, driven by the participation in global value chains, require a much better understanding of the underlying capital (and the types of capital) that underpins that transformation.

Addressing these measurement challenges is crucial if economies are to develop sound policies, especially to navigate out of the current crisis, as economies across the globe begin to reassess the impact of the pandemic on their pre-ciris growth strategies. Key to this are productivity measures and their constituent components that are calculated following robust and internationally comparable statistical methods.

This report, using available data, is a first step in that direction. However, as the report illustrates, investment in better data is also needed at the national level, and national statistics offices, who are the primary audience of this report, are strongly encouraged to mainstream the recommendations in 
their dissemination and compliation strategies. These agencies are best placed to provide the most reliable inputs for productivity measurement given their access to, and knowledge of, the best data sources in their economy.

The different productivity indicators in this report are introduced by increasing degree of complexity for statistical measurement. The first substantive chapter of the report discusses the measurement of output, population and employment to compile measures of GDP per capita and GDP per worker, where the latter can be considered as the baseline labour productivity measure. The second substantive chapter introduces baseline measures of capital input and multifactor productivity. The final chapter moves towards the frontier of productivity measurement and describes how to account for the skill-composition of workforce, the composition of produced capital, and some natural assets.

At each stage, the report addresses the measurement challenges brought about by different economic phenomena, focusing on those that are most relevant to the statistical policy agenda of APO member economies and providing specific statistical reccomendations. Much of the discussion speaks to the measurement aspects of the key result areas in the APO Vision 2025. 


\section{Baseline labour productivity measures}

\section{a. Measuring output: GDP}

\section{Conceptual framework}

To measure productivity, we must necessarily compile an accurate measure of the volume of output and build an understanding of how that output is produced. In the context of productivity measurement, the production process can be represented in two main ways.

The first representation relates a measure of gross output to primary and intermediate inputs (OECD, 2001). The primary and intermediate inputs generally considered are Capital, Labour, Energy, Materials and Services, meaning this is often referred to as a KLEMS approach. Gross output refers to the goods or services that are produced within a producer unit. This is a gross measure in the sense that it represents the value of sales and net additions to inventories without, however, deducting purchases of intermediate inputs. The deduction of purchases of intermediate inputs from gross output results in a measure of gross value added, referred to as "gross" because it does not include depreciation but, for convenience, it is typically referred to as value added, which is the approach adopted in this report. The second representation of the production process relates this measure of value added to the primary inputs (i.e. labour and capital).

While the KLEMS approach is considered more appropriate for measuring technical change by industry, as it fully acknowledges the role of intermediate inputs, the significant data burden, as well as the difficulty in communicating inter-industry links and aggregation across industries, makes it more difficult to apply in practice (OECD, 2001). Moreover, value added-based measures of productivity provide a simple conceptual link between industry MFP and aggregate MFP growth, using data that are readily available in official national accounts. These qualities make this approach the default option for many researchers, National Statistics Offices (NSOs) and international organisations.

For the same reasons, this report also adopts the latter approach, which examines how much of an observed rate of change of an industry's volume of value added can be explained by the rate of change in the volume of a single primary input or combined primary inputs. Therefore, it is represented by a value added function that relates the volume of value added produced given a set of primary inputs and technology.

$$
V A(t)=H(A, L, K)=A(t) F(L(t), K(t))
$$

where $V A$ is value added, $A(t)$ represents disembodied technological shifts, and $L(t)$ and $K(t)$ represent the primary inputs, labour and capital, respectively. Productivity change can be defined in terms of a shift of the value added function, i.e. as the relative increase in value added that is associated with technical change. In the representation above, this can be formulated as the difference between the growth rate of the Divisia volume index of value added $\frac{d \ln V A}{d t}$ and the Divisia quantity aggregate index of inputs, $\frac{d \ln X}{d t}=\frac{1}{2}\left(s_{L(t)}+s_{L(t-1)}\right) \frac{d \ln L}{d t}+\frac{1}{2}\left(s_{K(t)}+s_{K(t-1)}\right) \frac{d \ln K}{d t}$, where $s_{L(t)}$ and $s_{k(t)}$ are the weights that correspond to the shares of each input, labour and capital, respectively, in total costs. 


$$
\% \text { change of } V A \text { based } M F P=\frac{d \ln V A}{d t}-\frac{d \ln X}{d t}
$$

Output measures are compiled for a defined economic territory; i.e. a geographic territory administered by a government, within which persons, goods, and capital circulate freely. When measured according to the System of National Accounts (SNA), the output of a country corresponds to the output of its resident economic units. A unit is said to be resident in a country when its "centre of economic interest" is situated in that country's economic territory. Typically, for units where there is some uncertainty over their centre of economic interest, the practical requirement is that the unit has carried out economic activity in the economic territory for more than one year (2008 SNA, para. 2.19).

Implementation of the 2008 SNA

The System of National Accounts (SNA) is the internationally agreed standard set of recommendations on how to compile measures of economic activity in accordance with strict accounting conventions based on economic principles (2008 SNA, para. 1.1). The recommendations are expressed in terms of a set of concepts, definitions, classifications and accounting rules that comprise the internationally agreed standard for measuring such items as gross domestic product (GDP), the most frequently quoted indicator of economic performance. They provide a comprehensive and detailed record of the complex economic activities taking place within an economy and of the interaction between the different economic agents, and groups of agents, that takes place on markets or elsewhere.

The latest standards are the 2008 System of National Accounts (2008 SNA). The 2008 SNA retains the basic theoretical framework of its predecessors, the 1993 and 1968 SNAs. All OECD and most APO member economies have implemented the 2008 SNA.

One of the key material changes between the 1993 SNA and the 2008 SNA regards the enlargement of the productive asset (i.e. capital) base. The 2008 SNA capitalises expenditures in research and development (R\&D) and military weapons systems, bringing them into the asset boundary. Hence, purchases and own-account production of R\&D assets and expenditures in military weapons systems, which were previously recorded as intermediate consumption, are now treated as investments (i.e. gross fixed capital formation) increasing value added and thus GDP (Van de Ven, 2015).

The scale of this change therefore depends on the relative size of a country's military and expenditures in R\&D. Table 2.1 presents the changes to GDP levels in 2010 resulting from the shift to 2008 SNA for OECD countries. The overall impact on the OECD as a whole amounts to 3.1 percentage points, with the capitalisation of R\&D constituting the largest component (2.2 percentage points). Other changes that were introduced in the 2008 SNA - including changes in the way pensions are accounted for, the treatment of special purpose entities, the recording of international trade flows and the measurement of financial services - accounted for 0.6 percentage points of the total impact on OECD GDP. Overall impacts vary across countries, from Poland at 1.2 percentage points to Korea at 5.1 percentage points. 
Table 2.1: The overall impact of switching to 2008 SNA standards on GDP-levels, by type of revision, (\% increase in 2010 GDP levels)

\begin{tabular}{|c|c|c|c|c|}
\hline Country & R\&D & $\begin{array}{l}\text { Military weapons } \\
\text { systems }\end{array}$ & $\begin{array}{l}\text { Other changes } \\
\text { introduced in the } \\
2008 \text { SNA }\end{array}$ & Overall impact \\
\hline Australia* & 1.4 & 0.3 & 2.2 & 3.9 \\
\hline Austria & 2.3 & 0 & 1.4 & 3.8 \\
\hline Belgium & 2.4 & 0 & 0.1 & 2.5 \\
\hline Canada & 1.2 & 0.1 & 0.4 & 1.7 \\
\hline Chile & - & - & - & - \\
\hline Czech Republic & 1.2 & 0.1 & 1.7 & 3.1 \\
\hline Denmark* & 2.6 & 0.1 & 0 & 2.7 \\
\hline Estonia & 0.9 & 0.4 & 0 & 1.4 \\
\hline Finland & 4 & 0.2 & 0 & 4.2 \\
\hline France & 2.2 & 0.2 & 0 & 2.4 \\
\hline Germany & 2.3 & 0.1 & 0.3 & 2.7 \\
\hline Greece & 0.6 & 0.6 & 0.2 & 1.3 \\
\hline Hungary & 1.2 & n.a. & n.a. & 1.6 \\
\hline Iceland & 1.4 & 0 & 0 & 1.4 \\
\hline Ireland & 3.5 & 0 & 0.1 & 3.6 \\
\hline |srael $^{1}$ & 2.2 & 0 & 0.1 & 2.3 \\
\hline Italy & 1.3 & 0.2 & 0 & 1.5 \\
\hline Japan & - & - & - & - \\
\hline Korea & 3.6 & 0.3 & 1.2 & 5.1 \\
\hline Luxembourg $^{2}$ & 0.5 & 0 & 1.2 & 1.6 \\
\hline Mexico*3 & 1.4 & 0 & 0 & 1.5 \\
\hline Netherlands & 1.8 & n.a. & n.a. & 1.7 \\
\hline New Zealand & 1.1 & 0.1 & 0.1 & 1.3 \\
\hline Norway* & 1.4 & 0.2 & 0 & 1.6 \\
\hline Poland & 0.5 & 0.2 & n.a. & 1.2 \\
\hline Portugal & 1.3 & 0.1 & 0.8 & 2.1 \\
\hline Slovak Republic & 0.6 & 0.1 & 1.1 & 1.8 \\
\hline Slovenia & 1.9 & 0.1 & 0 & 2 \\
\hline Spain & 1.2 & 0.2 & 0.2 & 1.6 \\
\hline Sweden & 4 & 0.4 & 0 & 4.4 \\
\hline Switzerland & n.a. & n.a. & n.a. & 3.5 \\
\hline Turkey & - & - & - & - \\
\hline United Kingdom & 1.6 & 0.2 & 0.4 & 2.3 \\
\hline United States ${ }^{4}$ & 2.5 & 0.5 & 0.9 & 4 \\
\hline OECD Totak** & 2.2 & 0.3 & 0.6 & 3.1 \\
\hline
\end{tabular}

Source: Adapted from Van de Ven (2015).

Figure 2.1 shows the progress of APO member economies in the implementation of the 2008 SNA as reported in the APO Databook 2019 (APO, 2019). At the time of the publication of the latter report, only Nepal and Lao People's Democratic Republic (hereafter "Lao PDR") had not yet introduced the 2008 SNA. Fiji, India and the Philippines were relatively early adopters, implementing the 2008 SNA in 2008, 2010 and 2011 respectively. Other APO economies implemented the 2008 SNA much later, with Cambodia and Thailand adopting the standards in 2019 and Viet Nam in 2020. Given the impact of the implementation of the 2008 SNA (as shown in Table 2.1 above) and the commensurate effects on 
international comparisons of GDP and other aggregates, economies whose national accounts are still in line with previous versions are strongly encouraged to implement the 2008 SNA.

Figure 2.1: Implementation of the 1968, 1993, and 2008 SNA in APO member economies

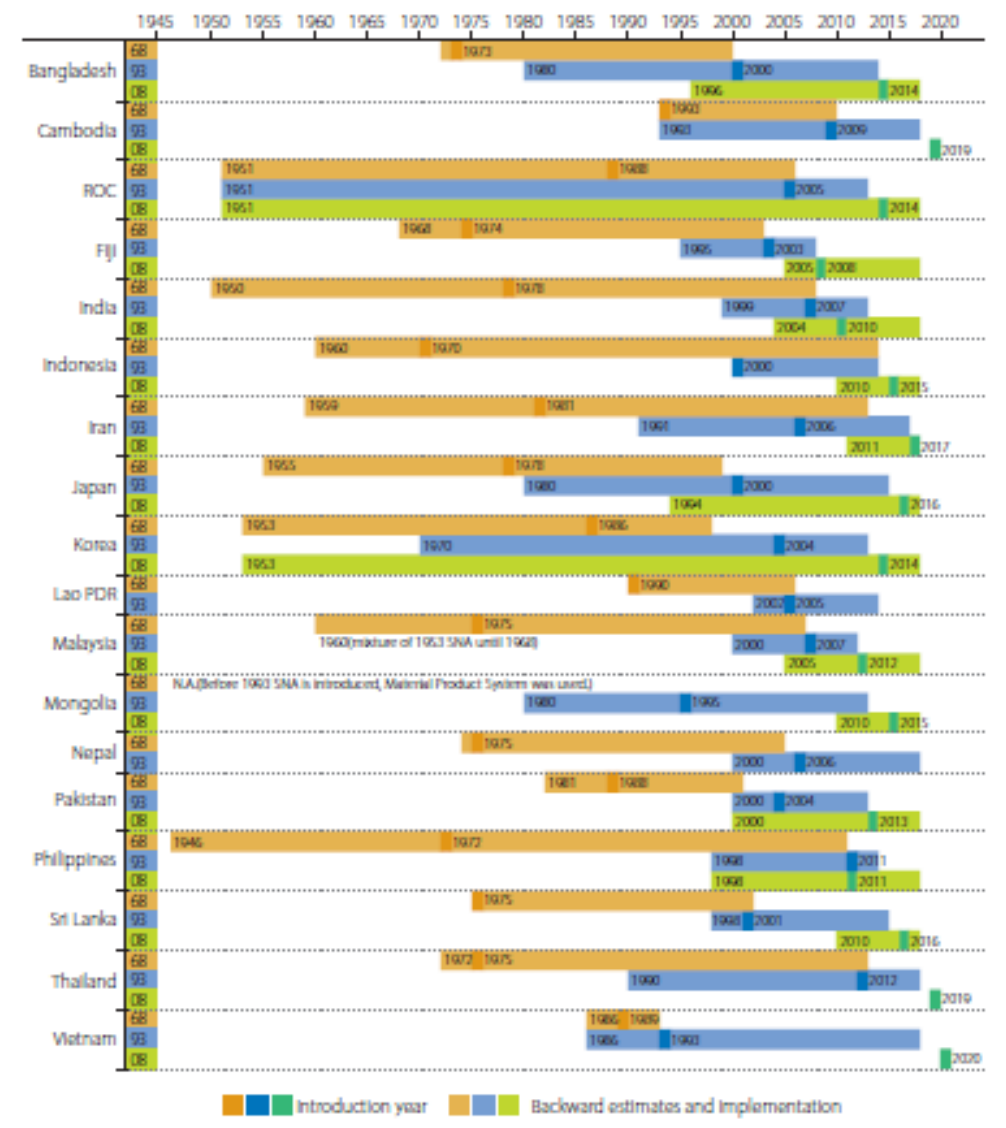

Source: APO Databook (APO, 2019), unmodified Figure 76.

Relative size of economies, GDP growth and economic structure in the APO and OECD areas

Figure 2.2 shows the relative size of economies in the APO and OECD areas and OECD Key Partner economies. ${ }^{1}$ In 2017, the OECD constituted almost half of the GDP of the three groups together, with the APO and the OECD Key Partners making up the remainder in close to equal shares. Each group is dominated by a few very large economies, with the United States (33\%), Japan (9\%) and Germany (8\%) making up half of the OECD's GDP, People's Republic of China (hereafter "China") (57\%) constituting the majority of the OECD Key Partners' GDP, and India (29\%), Japan (17\%) and Indonesia (10\%) making up over half of the APO's GDP.

\footnotetext{
${ }^{1} 2017$ Purchasing Power Parities (PPPs) have been used to convert GDP into a common monetary unit across countries. The World Bank coordinates the International Comparison Programme (ICP), a global statistical initiative established to produce internationally comparable price levels, expenditure values, and Purchasing Power Parity (PPP) estimates. Other international organisations participate in this programme and are in charge of the compilation of PPPs for their region. For example, Eurostat and OECD are jointly in charge of the compilation of PPPs for the Eurostat-OECD region in the context of the ICP. Further information is available here: https://www.worldbank.org/en/programs/icp.
} 
Figure 2.2: Relative size of economies in APO and OECD areas

Share of current price GDP in the total current price GDP of their respective group of economies, 2017 PPPs, 2017

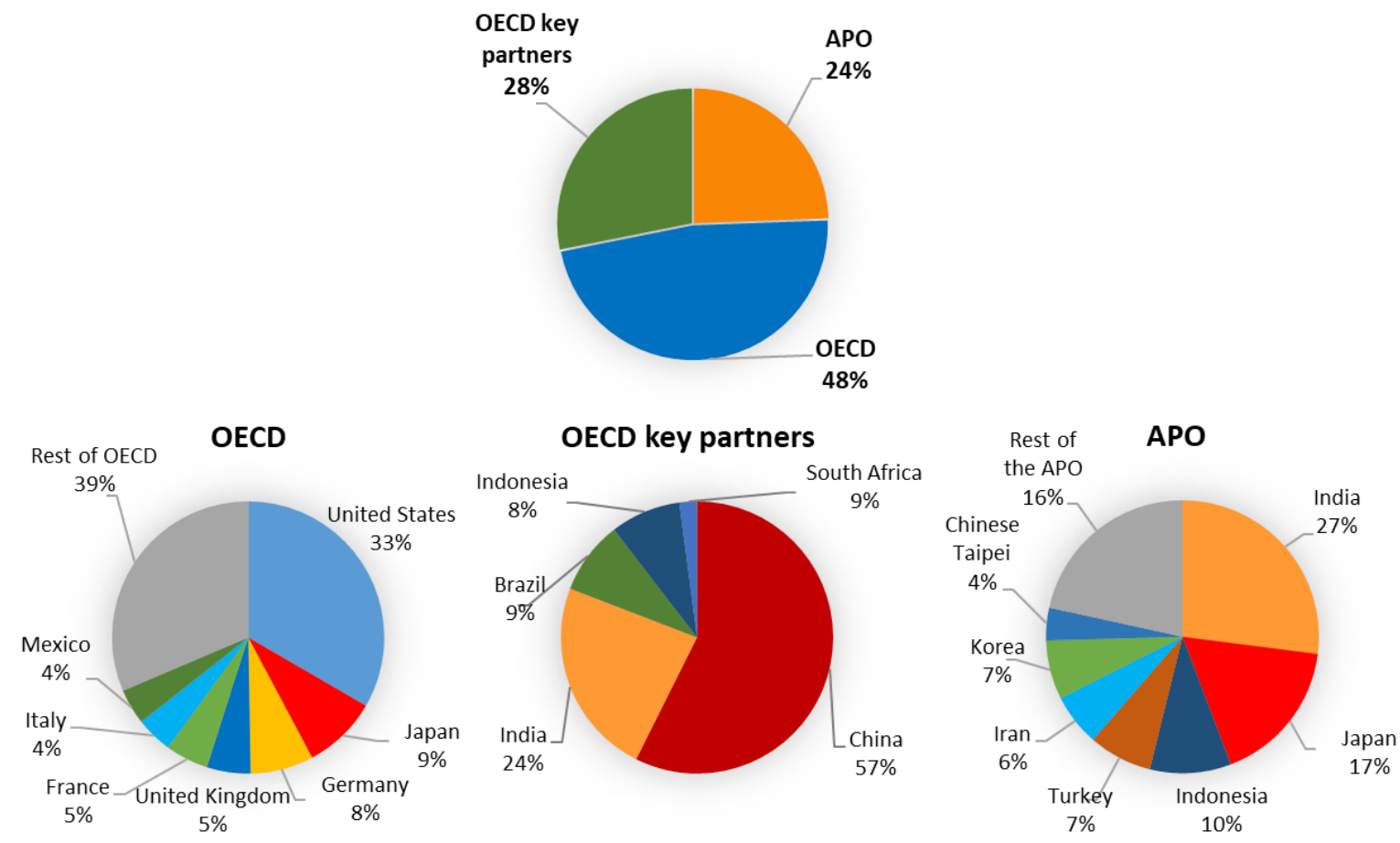

Source: OECD National Accounts Statistics (database), July 2020, and APO Productivity Database 2019, Ver.2 (February 25, 2020).

Note: To present these cross-country comparisons on a comparable base, 2017 Purchasing Power Parities (PPPS) have been used to convert GDP into a common monetary unit across countries. Data for economies with membership in both international organisations (i.e. Japan, Korea and Turkey), and OECD Key Partner countries (i.e. India and Indonesia), are sourced from OECD National Accounts Statistics (database) when available, and when unavailable, from the APO Productivity Database 2019, Ver. 2 (February 25, 2020). Data for these overlapping economies are included in both the OECD and APO shares. For example, Japan is included as both an $O E C D$ and APO economy, and Indonesia is included as both an OECD Key Partner and an APO economy. Access the data.

GDP growth is the main indicator used to evaluate economic growth both within and across economies. Figure 2.3 shows average year-on-year real GDP growth in the APO and OECD in the period 1998-2017. Overall, measured GDP growth is higher in the APO than in the OECD, with growth rates of $4.2 \%$ and $2.6 \%$ per year, respectively. In most APO economies, GDP has grown at a faster pace in the last decade than it did in the 10 years that preceded the 2008-2009 financial crisis, with Indonesia, Turkey and the Philippines being prime examples. The opposite is true for most OECD economies. 
Figure 2.3: GDP growth in APO and OECD areas

Average annual real GDP growth, 1998-2007 and 2010-2017

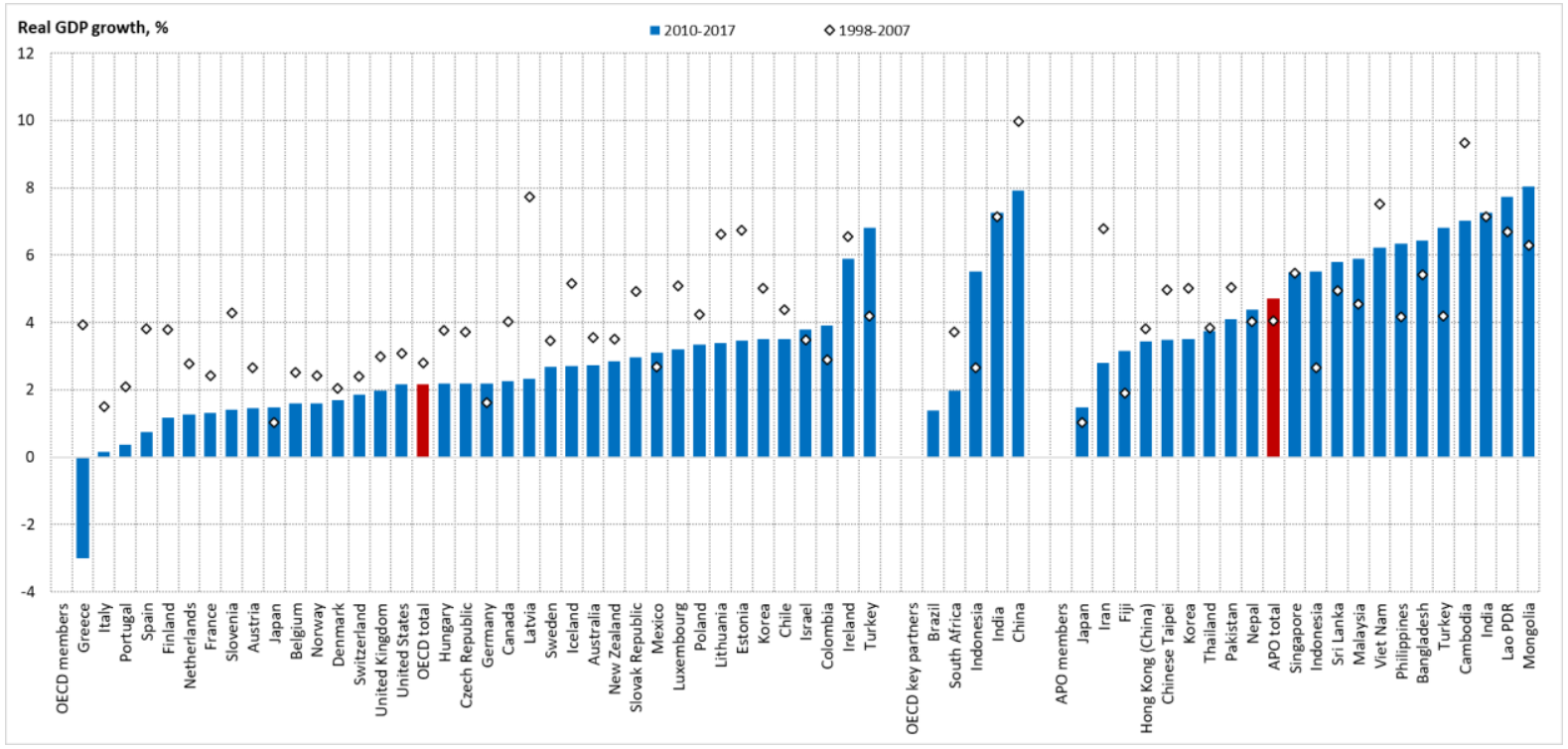

Source: OECD National Accounts Statistics (database), July 2020, and APO Productivity Database 2019, Ver.2 (February 25, 2020).

Note: Data for economies with membership in both international organisations (i.e. Japan, Korea and Turkey), and OECD Key Partner countries (i.e. India and Indonesia), are sourced from OECD National Accounts Statistics (database) when available, and when unavailable, from the APO Productivity Database 2019, Ver. 2 (February 25, 2020). Access the data.

The economic structure, that is, the relative proportions of different economic activities in an economy, typically reveal an economy's stage of economic development. Economies at an earlier stage of development tend to have a larger share of agriculture in their overall output, often with a large proportion of the population engaged in subsistence farming. As economies develop, they tend to shift towards the manufacturing of goods. Many of the most economically developed economies are eventually driven by their service sector, whether that be financial or non-financial services.

Figure 2.4 presents the share of different economic activities in total GDP in 2017, in the APO, the OECD and OECD Key Partner countries. The APO member economies, with Singapore and Hong Kong (China) being notable exceptions owing to their particularly urban focus, tend to have larger shares of agricultural output than their OECD counterparts. The economies with the greatest share of agriculture are Nepal and Cambodia at $27.6 \%$ and $24.9 \%$ respectively. 
Figure 2.4: Economic structure of $A P O$ and $O E C D$ economies

Current price GDP by activity, proportion in total activity, 2017

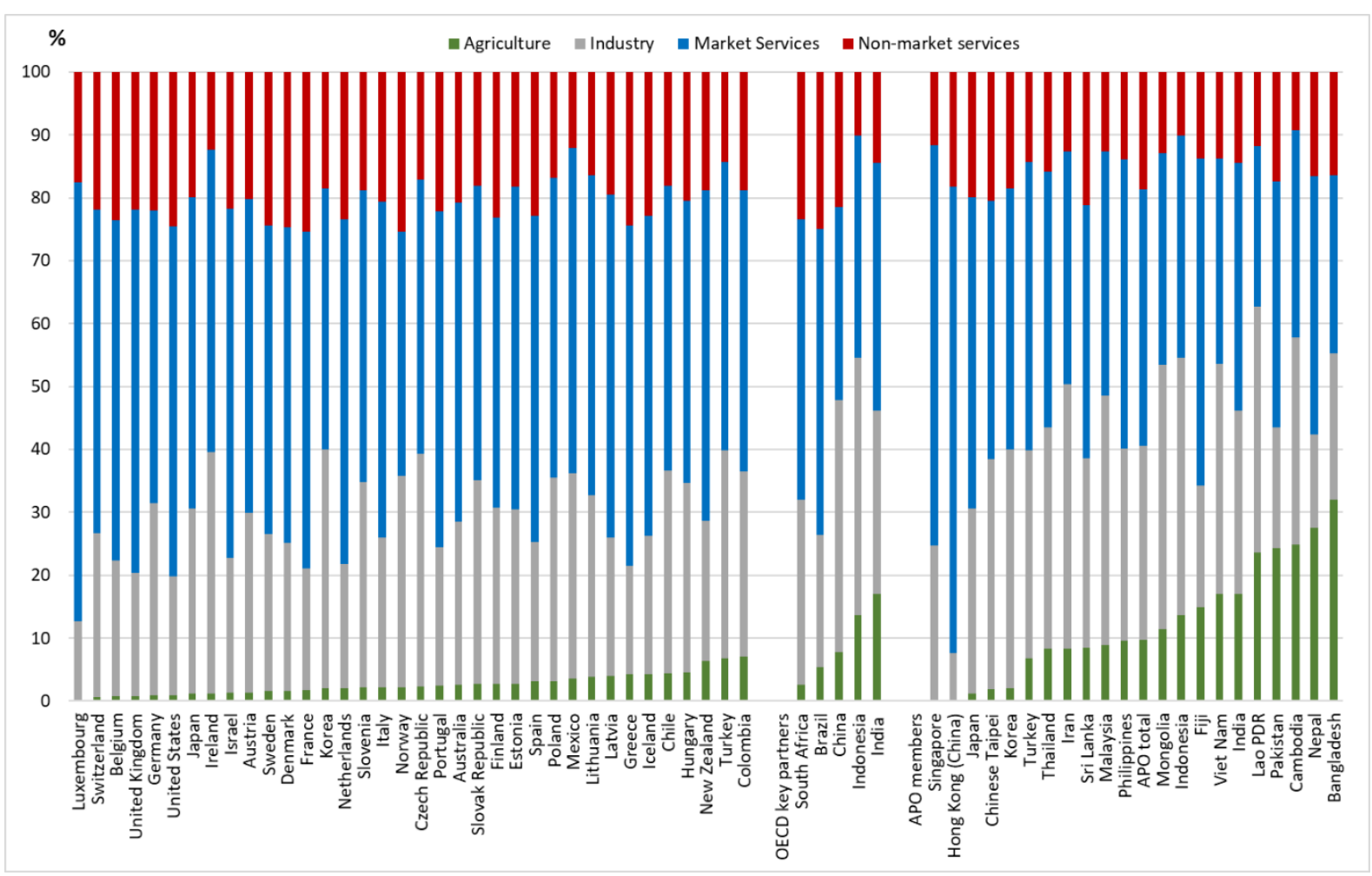

Source: OECD National Accounts Statistics (database), July 2020, and APO Productivity Database 2019, Ver.2 (February 25, 2020).

Note: Data for economies with membership in both international organisations (i.e. Japan, Korea and Turkey), and OECD Key Partner countries (i.e. India and Indonesia), are sourced from OECD National Accounts Statistics (database) when available, and when unavailable, from the APO Productivity Database 2019, Ver. 2 (February 25, 2020). Access the data.

The International Standard for Industrial Classification Revision 4 (ISIC Rev.4.) is the international standard currently used in most OECD countries for the classification of entities according to the activities they carry out. However, some economies continue to report industrial breakdowns of GDP and other macroeconomic variables according to either their own national classification system or, in particular in APO economies, according to the previous standard (e.g. ISIC Rev.3.). This represents a limitation for international comparisons at an industry level and can mask developments in newly developed and/or emerging economic activities all together.

Of particular interest in ISIC Rev.4 is the introduction of industry J - Information and communications, which includes activities from previous ISIC Rev.3 sections D - Manufacturing, I - Transport, storage and communications, $\mathrm{K}$ - Real estate, renting and business activities, and $\mathrm{O}$ - Other community, social and personal service activities, hence strongly impacting comparability with previous ISIC versions (UN, 2008). Information and communications have become increasingly relevant in recent years, making up between $2 \%$ and $12 \%$ of total economy's value added in OECD countries in 2018 (Figure 2.5). The use of previous ISIC versions complicates a comprehensive analysis of these developments. 
Figure 2.5: The growing importance of the information and communications (J) industry Share in gross value added of the total economy, percentage, 2000 vs. 2018

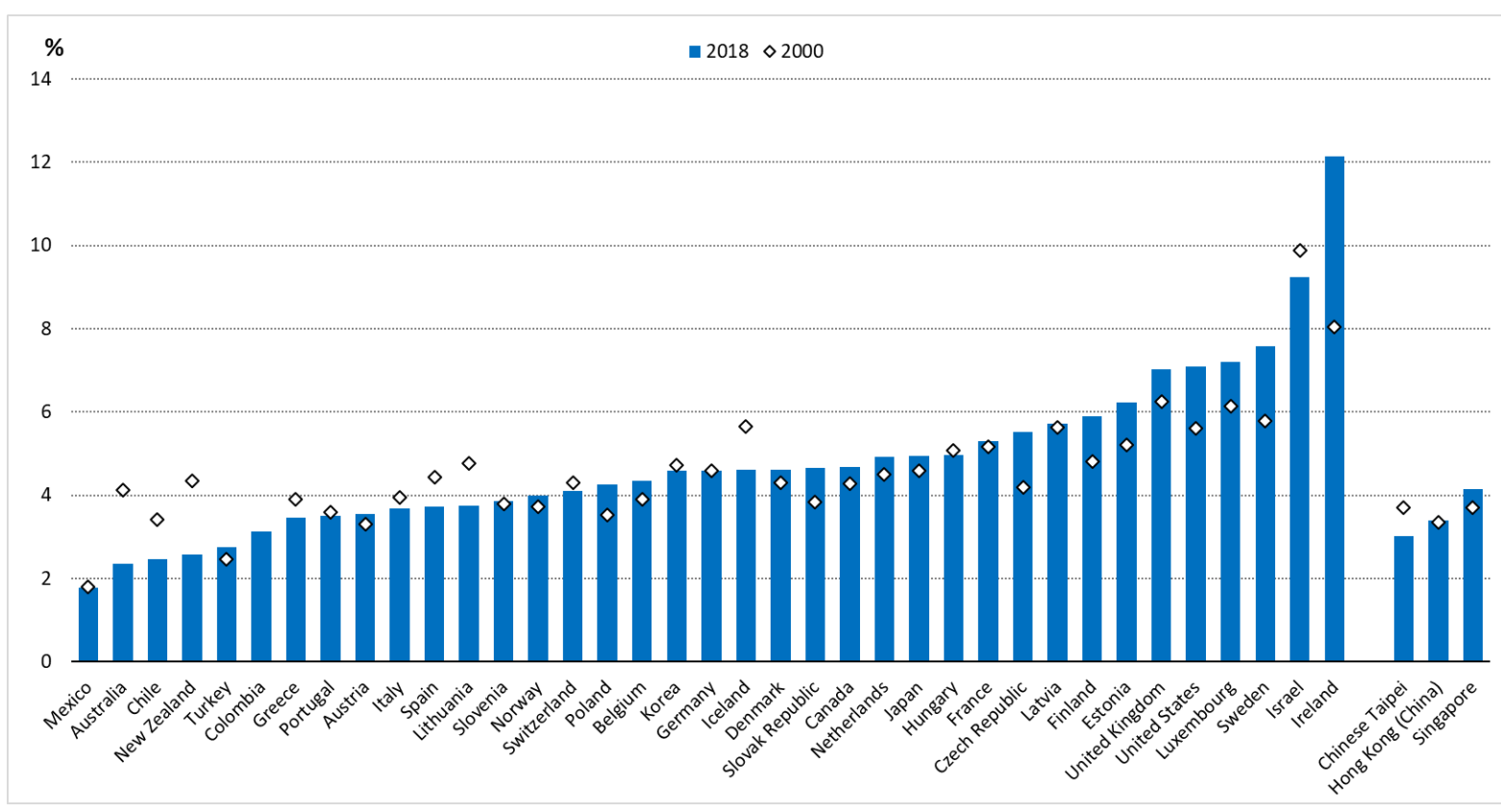

Source: OECD National Accounts Statistics (database), July 2020.

Note: At the time of publication there was no available figure for Colombia in 2000. The 2018 figures for Canada, New Zealand and the United States were unavailable, so were substituted for 2016, 2017 and 2017 numbers respectively. Access the data.

The 2008 SNA notes that while the order of ISIC Rev. 4 should be respected, it may be useful to tailor the level of detail reported to the structure of the specific economy in question (2008 SNA, para. 18.58). For example, in economies with a large subsistence economy, it may be useful to split agriculture into market and non-market production, meanwhile grouping together some of the service sectors that may be less important to the country (2008 SNA, para 18.59). This proposition seems particularly relevant to APO economies and is one of the recommendation put forward by this report.

\section{Non-Observed Economy}

In its endeavour to exhaustively measure all economic activity within its production boundaries, the 2008 SNA predicates that these activities should be measured regardless of whether they are formal or informal. Informal activities often escape traditional data sources and remain unobserved. This part of the economy, along with unobserved but formal activities, is referred to as the Non-Observed Economy (NOE) (2008 SNA, para. 25.2). A vast array of economic policy questions critically depend on measuring and understanding the NOE and related phenomena. An effective accounting for the existence and size of the NOE matters critically for the analysis of economic growth, employment and productivity, possible abuse of social insurance programmes, and erosion of tax revenues (Gyomai and van de Ven, 2014).

The NOE tends to be used as an umbrella term covering a broad spectrum of production Other terms such as informal, underground, grey, black or hidden economy are also regularly used either to describe this concept as a whole, or to refer to some specific aspect. However, for the sake of this 
discussion, and for the rest of this report, the term used will be Non-Observed Economy in line with Measuring the Non-Observed Economy - a Handbook (OECD, 2002). According to this handbook, the NOE covers five major areas:

1. Underground production: activities that are productive and legal but are deliberately concealed from public authorities to avoid payment of taxes or compliance with regulations.

2. Illegal production: productive activities that generate goods and services forbidden by law or that are unlawful when carried out by unauthorised procedures.

3. Informal sector production: productive activities conducted by unincorporated enterprises in the household sector or other units that are unregistered and/or less than a specified size in terms of employment, and that have some market production.

4. Production of households for own-final use: productive activities that result in goods or services consumed or capitalised by the households that produced them.

5. Statistical underground: defined as all other productive activities that should be accounted for in basic data collection programmes but are missed due to deficiencies in the statistical system.

The NOE is particularly prevalent in many APO economies (APO, 2019, Box 2; Blades et al,. 2011. Very few systematic efforts have been made to estimate the size of the NOE within APO economies, but efforts in economies at comparable levels of development suggest that it can be significant. For example, a 2004 study using the "Tabular approach" develop by Eurostat, the statistical arm of the European Commission, revealed that the NOE accounted for $31.4 \%$ of total economic activity in Albania, 11.2\% in Croatia and 14.6\% in Serbia, in 2001, 2002 and 2003 respectively (Ahmad, 2004). Indeed, even in some OECD economies, as shown in Box 2.1 below, the share of GDP generated by the NOE can be significant, accounting for over $20 \%$ Mexico for example.

To account for the NOE, all OECD countries introduce exhaustive adjustments to their official GDP measures. In OECD countries, illegal activities are marginal in macroeconomic terms, with most estimates putting them at less than $1 \%$ of GDP. Estimates for underground production (i.e. legal activities carried out illegally to avoid paying taxes and/or social contributions) range between $2 \%$ and $15 \%$ of GDP in OECD countries (Lequiller and Blades, 2014). Box 2.1 includes additional details on how the French and Mexican national statistical offices measure the non-observed economy in practice.

\section{Box 2.1. Measuring the non-observed economy - Country experiences}

\section{France}

In the case of France, the adjustment for the non-observed economy is around 4\% (Lequiller and Blades, 2014). The French national statistical office, INSEE, define the "underground economy" in terms of three sub-groupings: illegal activities (drug dealing, organised prostitution, etc.); "black" labour (clandestine enterprises); and tax fraud. INSEE make adjustments for only the latter two subgroups and do not try to evaluate illegal activities, which are known to be minimal in macroeconomic 
terms for most OECD economies. They adopt an empirical approach to the measurement of "black" labour, based on official investigations and socio-economic research, picking out sectors where there is a strong presumption of underground work and then estimating, very crudely, sector by sector, the scale of this activity, based on expert opinion. The eventual adjustment to account for "black" labour is roughly $1 \%$ of GDP.

To account for tax fraud and tax evasion, INSEE make an adjustment of around $3 \%$ of GDP, aiming to capture both missing receipts (2.5\%) and unpaid VAT (Value Added Tax) (0.5\%). As regards the dissimulation of receipts, the sources used are official figures from the tax authorities compiled on the basis of sample tax investigations. For unpaid VAT, the source is a comparison between the theoretical VAT amount calculated on recorded taxable transactions, and the VAT actually collected by the government, together with several minor adjustments. In addition to these adjustments, there are accounting adjustments for undeclared gratuities and benefits in kind. Each of these represents roughly $0.5 \%$ of GDP.

\section{$\underline{\text { Mexico }}$}

INEGI, the Mexican NSO, regularly compiles national accounts aggregates for the informal sector and other modalities of informal activities (INEGI, 2013). For the informal sector, INEGI compiles the production and income accounts, and estimates the number of paid and unpaid jobs. Regarding the other modalities, they compile the income account and count the number of paid and unpaid jobs, including informal jobs in the formal sector, informal jobs the farming sector, un-registered workers performing housekeeping activities, and persons employed in own-account production. For these purposes, they rely on many different data sources, such as their economic census, in particular, on the information this collects for establishments with 0 to 5 employees, the National Survey on Micro-Businesses (ENAMIN), the National Survey on Household Income and Expenditure, the National Survey on Occupation and Employment (ENOE), and information on employment provided by the Mexican Institute of Social Security (IMSS).

The first step in their process is the construction of the Husmanns Matrix, a matrix elaborated in the XVII ICLS in 2003 as an answer to the requirements of the Delhi Group ${ }^{2}$, among them, planning to shape more precisely the concept of informality in the economic sector. The matrix follows a building-block approach to dissagregate total employment according to two dimensions: type of production unit and type of job. The type of production unit (rows of the matrix) is defined in terms of legal organisation and other enterprise-related characteristics, and includes three groups: formal sector enterprises, informal sector enterprises, and households. The type of job (columns of the matrix) is defined in terms of status in employment and other job-related characteristics, and classifies jobs into own-account workers, employers, contributing family workers, employees, and members of producers' cooperatives.

\footnotetext{
2 This was a UN group of experts set up in 1997 and active until 2010, as an international forum to exchange experiences in the measurement of the informal sector, document the datacollection practices, including definitions and survey methodologies followed by member countries, and recommend measures for improving the quality and comparability of informal sector statistics. See https://unstats.un.org/unsd/methodology/citygroups/delhi.cshtml.
} 
Once the labour matrix is computed, INEGI determines the income per capita for workers in each cell and proceeds to the estimation of the production and income accounts by industry in line with the NAICS industrial classification.

In compiling the production account, INEGI estimates the value added generated as sum of compensation of employees and gross mixed income received by workers engaged in the informal sector or under informal conditions in the activities aforementioned. To do this, they follow the guidelines provided by the Delhi Group, in particular, the labour input method (or indirect approach), which involves three steps: (a) obtaining estimates of labour input in the informal sector by economic activity using household surveys; (b) deriving estimates of value added per unit of labour input following the same economic activity breakdown used for enterprises belonging to the non-observed sector; and (c) multiplying the labour input estimates by the per unit productivity norm to obtain the value added of the informal sector by economic activity (ILO, 2013). INEGI also estimates the intermediate consumption of these businesses as the sum of the purchases of goods and services and changes in the inventories of fuels and materials.

According their current estimates, the informal economy, i.e. the informal sector and workers employed in the activities aforementioned under informal conditions, accounted for $23 \%$ of total economy value added in 2019.

The impact of the inclusion of the Non-Observed Economy in GDP is expected to be even more significant in less developed economies. Therefore, NSOs should be encouraged to exploit all available data sources to effectively evaluate the scale of their NOE, utilising a "tabular approach", similar to that developed by Eurostat, wherever possible (Ahmad, 2004). This is by no means a simple endeavour, making open discussions between countries key in order to exploit synergies and share best practices. In this respect, the APO could serve as a body to facilitate discussions between its member economies on best practices with regards to adjusting their output and productivity statistics for the non-observed economy.

\section{Measuring the digital economy}

The past two decades have brought with them new and disruptive technologies, with new forms of intermediation, service provision and consumption (Ahmad and Schreyer, 2016). Digitalisation has drastically changed the way people interact, consume and work. These innovations were expected to stimulate a new wave of productivity growth, similar to that seen following electrification and the invention of internal combustion engines at the end of the 1800's or, more contemporaneously, the Information and Communication Technology (ICT) boom of the 1990s. However, these gains from digitalisation have not yet materialised, with productivity growth in most of the world having been relatively subdued since the 2008 financial crisis or even prior to this, raising a number of open questions, regarding potential lagged effects of these new technologies, structural versus cyclical factors and, of course, measurement. While a growing body of evidence suggests that measurement, or rather "mis-measurement", is not the primary cause (Syverson, 2016; Byrne, Fernald and Reinsdorf, 2016; Ahmad et al., 2017; Reinsdorf and Schreyer, 2019), many challenges remain in the practical measurement of the digital economy, including its inclusion in both GDP and productivity. 
One of the core manifestations of the digital economy has been peer-to-peer transactions facilitated by online intermediaries in the corporate sector. These services come in a variety of forms, but can be generally placed into four categories: i) Dwelling services (e.g. AirBnB), ii) Business and transportation services (e.g. Uber, Lyft, Bolt), iii) Distribution services (e.g. Amazon, eBay) and iv) Financial intermediation services (e.g. GoFundMe, Kickstarter). It should be noted that the underlying transactions which make up the sharing economy aren't in themselves new, with households having long engaged in peer-to-peer transactions such as the provision of rental services, taxi services, often unlicensed, and the sale of second-hand goods.

On the conceptual side, all of these peer-to-peer transactions fall within the national accounts' production boundary, and should be captured by GDP. However, digitalisation has changed the scale of these transactions, facilitated by new types of intermediaries. Therefore, while these transactions sit within the conceptual boundary of GDP, the question is whether the compilation practices currently employed to measure peer-to-peer transactions, and which were designed to measure low-scale, relatively insignificant, sums, are sufficiently robust to accurately measure them at much larger scale. However, the very cause of the increased size of the problem (the new intermediaries) may also be a source of the solution, in that they provide potential access to new administrative data or business accounts that record what were previously largely invisible (non-observed) transactions. This could not only contribute to solving the current compilation question, but also illuminates information on previously non-observed transactions. Wherever possible, NSOs should be encouraged to engage with these intermediaries and explore new data sources.

Other forms of digitalisation have also become an established feature in many economies. One such incarnation is the increasing role of consumers as own-account producers, with widespread internet access allowing more and more households to provide services to themselves that used to be produced by private companies. For example, households are now able to use search engines and travel websites to book flights and plan holidays, while this would previously have required a dedicated travel agent. Other examples include the self-check in at airports, self-service payment at supermarkets, and on-line banking. These examples all suggest that households are increasingly involved in activities previously included in GDP. Conceptually, this is not new to the system of national accounts, as it joins the traditional discussion regarding unpaid household activities, such as childcare, the preparation of meals, and gardening. Own-account production of services, with the exception of owner-occupied housing services, is excluded from the national accounts' production boundary given the importance of the third-party criterion used in the accounts and the importance that GDP retains its primary focus as a tool to guide macro-economic policy making, as well as valuation difficulties. For example, valuing households' own-account production at replacement costs (based on market prices for comparable products) as opposed to an alternative valuation based on opportunity costs (based on the foregone salary of households when they produce this output) can lead to very different results (Ahmad and Koh, 2011). Hence, even though the substitution of own-account production for market production has the potential to distort cross-country and temporal comparisons of GDP and to affect the output and productivity of some industries, solving this issue by imputing a value for households' own-account production could make the measurement issue even worse. The recommended solution is therefore to monitor the development of households' own account production in a satellite account rather than in the central framework of national accounts. 
Free and subsidised consumer products, such as free mobile phone applications or search engines, may be considered as other possible sources of GDP underestimation. These products are usually financed through advertising, and/or through the collection of data generated by users of these digital products. So far, national accountants value the production of these service providers based on the advertising revenues they generate and treat this production as an intermediate consumption of advertising agencies. Exactly the same accounting treatment is applied to radio and TV service providers. While the national accounts community is currently discussing the potential to treat (part of) the output of these service providers as final rather than intermediate consumption, the limited size of advertising services in GDP means the resulting effect on the value of output is expected to be small (Byrne et al., 2016; Ahmad et al., 2017).

Finally, digitalisation and the rapid pace at which ICT products (e.g. computers, mobile phones etc.) are renewed over time creates significant challenges for the price and volume measurement of output and investment. The large share of new ICT products introduced every period requires that price statisticians rely on efficient quality adjustment methods to measure price inflation for these products. The NSOs of APO members are encouraged to keep abreast of the statistical literature on the price measurement of ICT products and to compare their deflators with those used in OECD countries. Since these goods are largely traded across countries, there should only be limited differences in their price levels and evolutions. Therefore, any significant difference in ICT price deflators across countries should be analysed with great care.

Ahmad et al. (2017) estimate the potential scale of mismeasurement in ICT price changes and its impact on GDP measures in selected OECD countries. They start by selecting the lowest average annual growth rate ("lower bound") in national price indices of ICT equipment, computer software databases and communications services across the selected countries over the period 2010-2015. In the next step, they replace each country's own price index for each of the three products, adjusted for the differences in general inflation rates, by the selected "lower bound" growth in assets' prices and estimate the impact on measured GDP depending on whether the affected products are used for final or intermediate use and on whether they are imported or domestically produced. Figure 2.6 shows the results of this exercise, and presents the counterfactual GDP growth rates for the selected OECD countries between 2010 and 2015. The authors consider three scenarios to test the sensitivity of the results to variations in the use (final or intermediate) and origin (domestically produced or imported) of these assets. The results indicate that adjustments for potential mismeasurement of prices of ICT products can be expected to add on average $0.2 \%$ per annum to GDP growth rate across the selected OECD countries. Adjustments are larger if ICT products are domestically produced and used for final demand because in such cases the mismeasurement of ICT prices directly affects GDP.

While Ahmad et al. (2017) show that the mismeasurement of ICT prices is unlikely to severely bias output and productivity measures in OECD countries, further work is needed to determine the impact on non-OECD economies, as the extent of potential ICT price mismeasurement could be more severe and, for many, the contribution of ICT production and exports more significant (OECD, 2018e; OECD, 2019d). 
Figure 2.6: Aggregate impact on GDP growth from adjustments in the ICT asset prices Average annual growth rate in percentage, 2010-2015 (or latest available year)

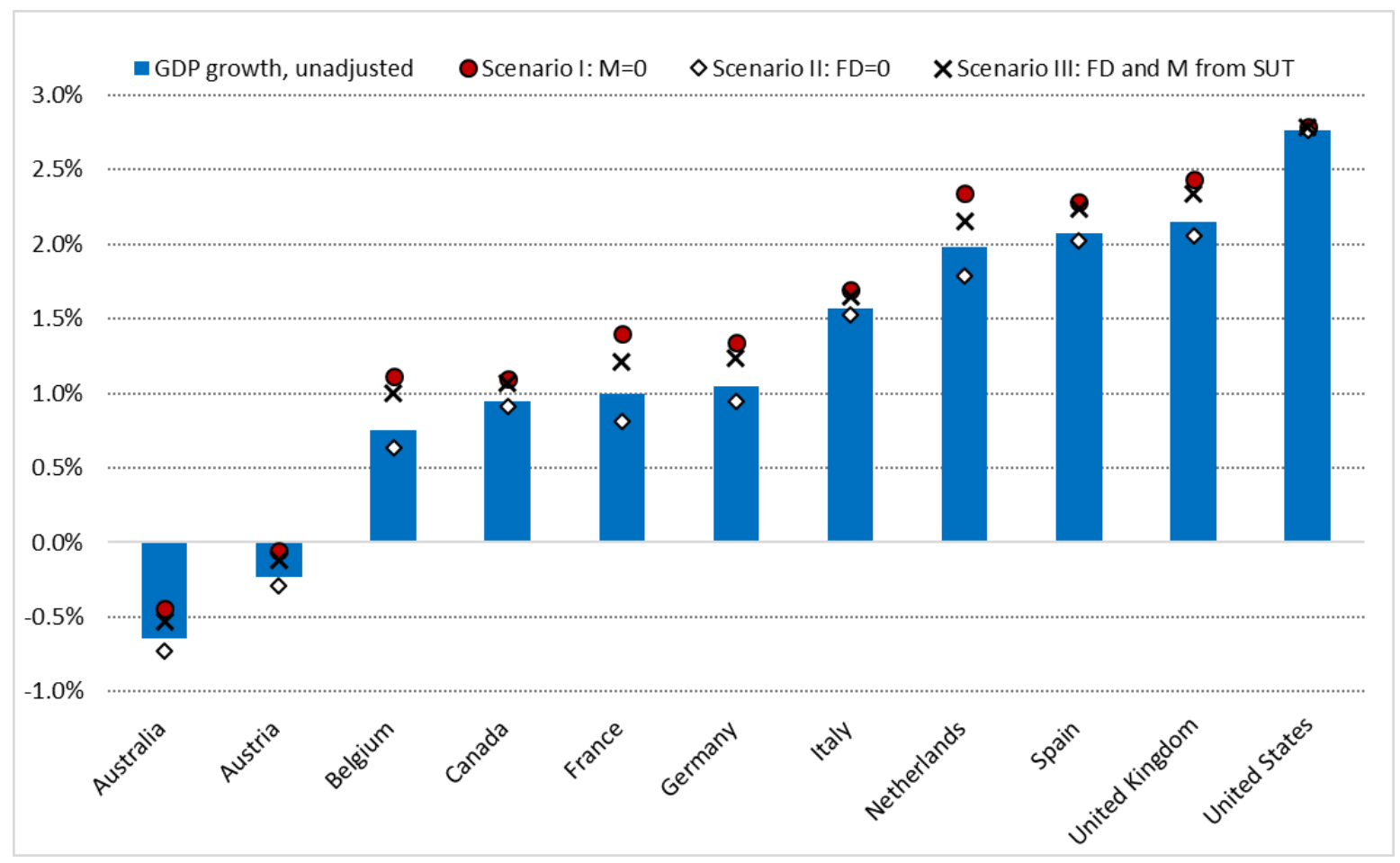

Source: Table 2.4, Ahmad et al. (2017).

Note: Scenario I assumes that there are no imports of the ICT assets ( $M=0$ in the graph) and the adjustment flows through to final demand (maximum counterfactual GDP growth estimate); scenario II assumes that there is no final demand for these ICT assets (FD=0) and the adjustment flows through to imports of these goods (minimum counterfactual GDP growth estimate); in scenario III the information on final demand and imports of these ICT assets is sourced from national supply and use tables (SUT) (central counterfactual GDP growth estimate). Access the data.

\section{b. Measuring labour: population and employment}

Labour is the single most important input to many production processes. This section will focus on two basic labour input measures that most countries' National Statistics Offices (NSOs) release on a regular basis: population and employment.

\section{Population}

The 2008 SNA defines a country's population as all those persons who are usually resident in the country. This more closely resembles a de jure definition of population, as opposed to a de facto definition whereby the population is measured as a count of those persons present in the economic territory of the country at a specific time (usually at the time of the census). As a general rule, any person resident in a country for a period of a year or more should necessarily be included in a de jure measure. Annual population estimates are commonly compiled using data from population censuses, which are usually conducted every five or ten years. For the intervening year's census, figures can be updated using sources of information on births, deaths and net migration (2008 SNA, para. 19.9). 
For productivity analysis, given its broad availability across countries, population measures provide a convenient, albeit very imperfect, denominator to construct the output-input ratio. Indeed, while measures of GDP per capita are closely related to the concept of labour productivity, they can only account for the average available resources (or domestic production) per head of population. Measures of labour input should be consistent with the production boundary of national accounts and include those individuals contributing to that production. The population of a country, however, includes individuals such as children, the retired, the unemployed and those in institutions such as prisons, who rarely participate in the production process. The inclusion of these individuals in the labour input measure depresses productivity levels measured on this basis, but also affects the analysis of derived growth rates wherever the rate of employment or working time patterns change over time or differ across countries.

Figure 2.7 presents the share of the population in the APO, OECD and OECD Key Partners, along with the proportions of the members in each area or group. A few large economies account for a substantial share of the total population agglomerated in these groups, notably India ( $49 \%$ of total population in the APO), the United States (23\% of total population in the OECD), and China ( $43 \%$ of total population in OECD Key Partner countries). However, a large population does not necessarily confer commensurate output, as differences in country's working age population, employment rates, hours worked, the skills of workers and available capital, among other factors, influence the productive capacity of an economy. For example, India accounts for almost half of the APO population, but just over a quarter of APO output, whereas the United States constitutes around a third of the OECD's total output (33\%) and less than a quarter of total OECD population (23\%). This highlights the need for productivity comparisons and analyses that account for all the aforementioned factors. 
Figure 2.7: Relative size of populations in APO and OECD areas

Share of population in the total population of their respective group of economies

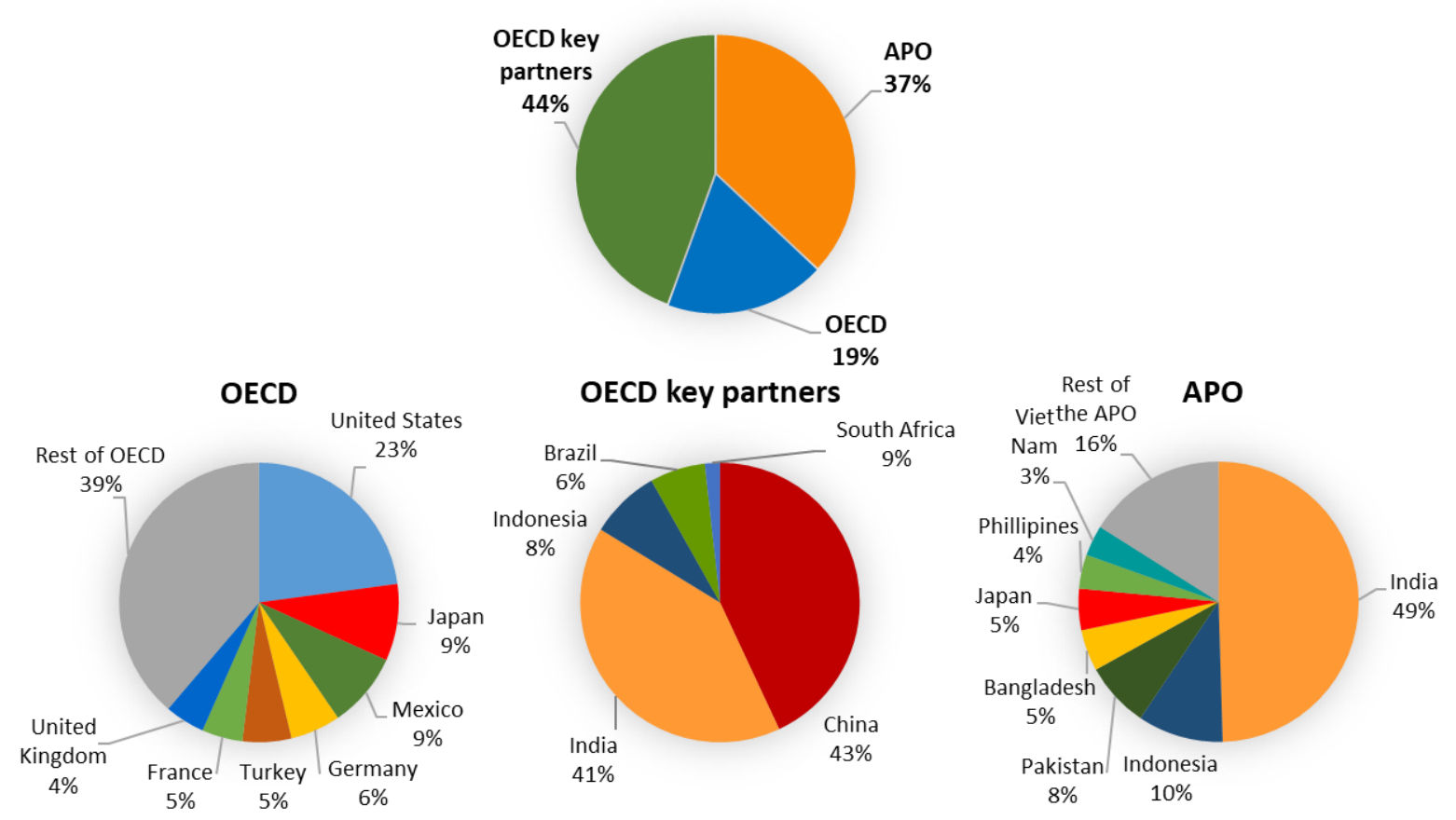

Source: OECD National Accounts Statistics (database), July 2020, and APO Productivity Database 2019, Ver.2 (February 25, 2020).

Note: Data for economies with membership in both international organisations (i.e. Japan, Korea and Turkey), and OECD Key Partner countries (i.e. India and Indonesia), are sourced from OECD National Accounts Statistics (database) when available, and when unavailable, from the APO Productivity Database 2019, Ver. 2 (February $25,2020)$. Data for these overlapping economies are included in both the OECD and APO shares. For example, Japan is included as both an OECD and APO economy, and Indonesia is included as both an OECD Key Partner and an APO economy. Access the data.

Population growth has varied greatly across OECD and APO economies in recent years. Figure 2.8 shows the annualised population growth in the period 1995-2017. All economies experienced positive population growth, with the exception of Latvia, Lithuania, Estonia and Hungary. The OECD population as a whole grew by $0.7 \%$ per year between 1995 and 2017, with growth in the APO population being $1.4 \%$ per year over the same period. The greatest population growth occurred in Israel (2.1\% per year), Pakistan and Singapore (both $2.2 \%$ per year). 
Figure 2.8: Population growth in APO and OECD regions

Average annual population growth, 1995-2017

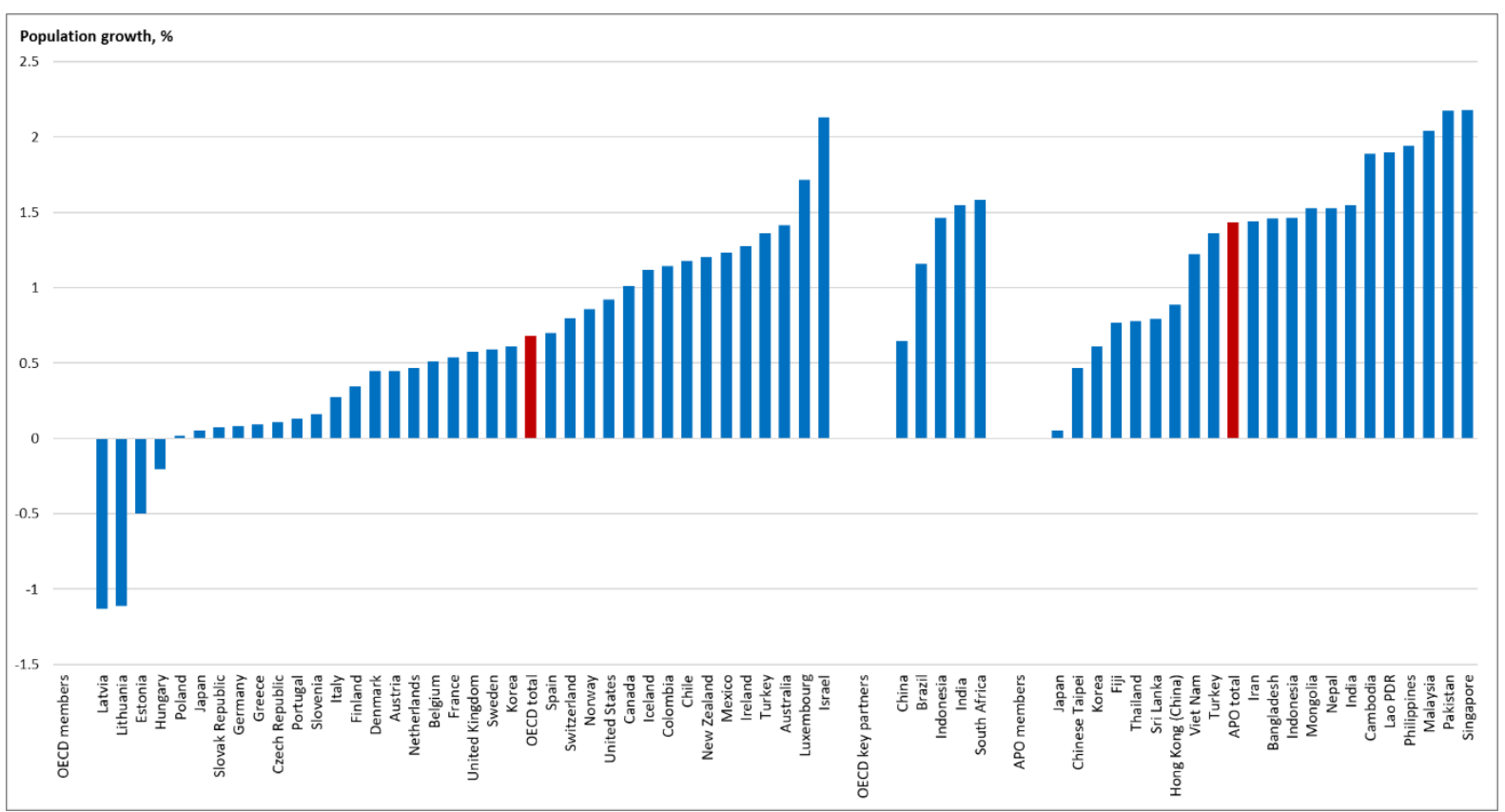

Source: OECD National Accounts Statistics (database), July 2020, and APO Productivity Database 2019, Ver.2 (February 25, 2020).

Note: Data for economies with membership in both international organisations (i.e. Japan, Korea and Turkey), and OECD Key Partner countries (i.e. India and Indonesia), are sourced from OECD National Accounts Statistics (database) when available, and when unavailable, from the APO Productivity Database 2019, Ver. 2 (February 25, 2020). Access the data.

\section{Employment}

Moving from a population measure to one of employment means discounting those that are not engaged in production, creating a labour input measure that includes only those persons working in the domestic units that produce goods and services. Employment ${ }^{3}$ in the 2008 SNA is indeed defined as all persons, both employees and self-employed, engaged in some productive activity that falls within the production boundary of national accounts and that is undertaken by a resident institutional unit.

A number of measurement issues affect the international comparability of employment data across countries. The most important challenges and differences come from the measurement of employment in terms of persons employed or job counts, measuring the self-employed, the type or variety of data sources used, and the extent to which employment measures align with national accounting principles (Ward et al., 2018).

\section{Persons in employment versus job counts}

\footnotetext{
3 Importantly, this differs from the concept of labour force, which includes employees of resident and non-resident institutional units, the self-employed and unemployed individuals (2008 SNA, para. 19.17).
} 
Employment can be measured according to different units and is compiled by countries in their national accounts as the number of jobs, or the number or persons who are employed or selfemployed. ${ }^{4}$ Most countries choose to report the number of persons in employment. The two measures differ wherever multiple job holdings exist, meaning that the number of jobs generally exceeds the number of persons in employment. This can cause important discrepancies when comparing employment across countries. Moreover, measures of employment growth only remain valid if the share of people holding multiple jobs remains stable. Multiple job holdings are a significant feature in many APO member economies. For example, a relatively high proportion of workers in Indonesia (19.9\%), Viet Nam (19.7\%) and Lao PDR (12.9\%) have more than one job, as compared to the relatively low share in the United States (4.9\%) (ILO, 2018). Because substantial differences between job counts and number of persons can exist, NSOs should provide appropriate metadata with regards to the unit of measure. Analysts should be cautious in their interpretation of cross-country comparisons of employment and GDP per worker, as the unit of measurement of employment may differ.

For the purposes of productivity analysis both units of measure provide an imperfect accounting of labour input, as they neglect to account for changes in working patterns and the extent of full-time and part-time work. A comprehensive measure of labour input accounting for changes in working time can only be achieved through a measure of total actual hours worked (see Section 3.a), or, even better, through a composition adjusted measure of hours worked (see Section 4.a).

\section{Measuring the self-employed}

Regardless of the unit of measure used, both employees and self-employed workers/jobs should be included in the compilation of employment measures. Figure 2.9 shows how the ratio of self-employed to total employment (i.e. employees plus self-employed) varies across APO and OECD member economies. For most OECD countries, self-employed workers constituted $5 \%$ to $20 \%$ of total employment in 2017, a proportion that has generally decreased since 1995. APO economies have also experienced a general decrease in the incidence of self-employment between 1995 and 2017, but from a much higher base. In fact, the APO average (59\%) was almost twice that of the highest OECD country (33\%) in 2017. Given the scale of self-employment in many economies, especially in the APO area, accurately accounting for self-employed persons is paramount, otherwise omitting, in many cases, the majority of employment.

\footnotetext{
${ }^{4}$ To the extent that one person can have two jobs in different industries, at the industry level job counts are deemed to be more consistent with value added than persons, as value added is normally measured through enterprise surveys.
} 
Figure 2.9: Differences in the incidence of self-employment across APO and OECD areas Ratio of self-employed to total employment, 1995 and 2017

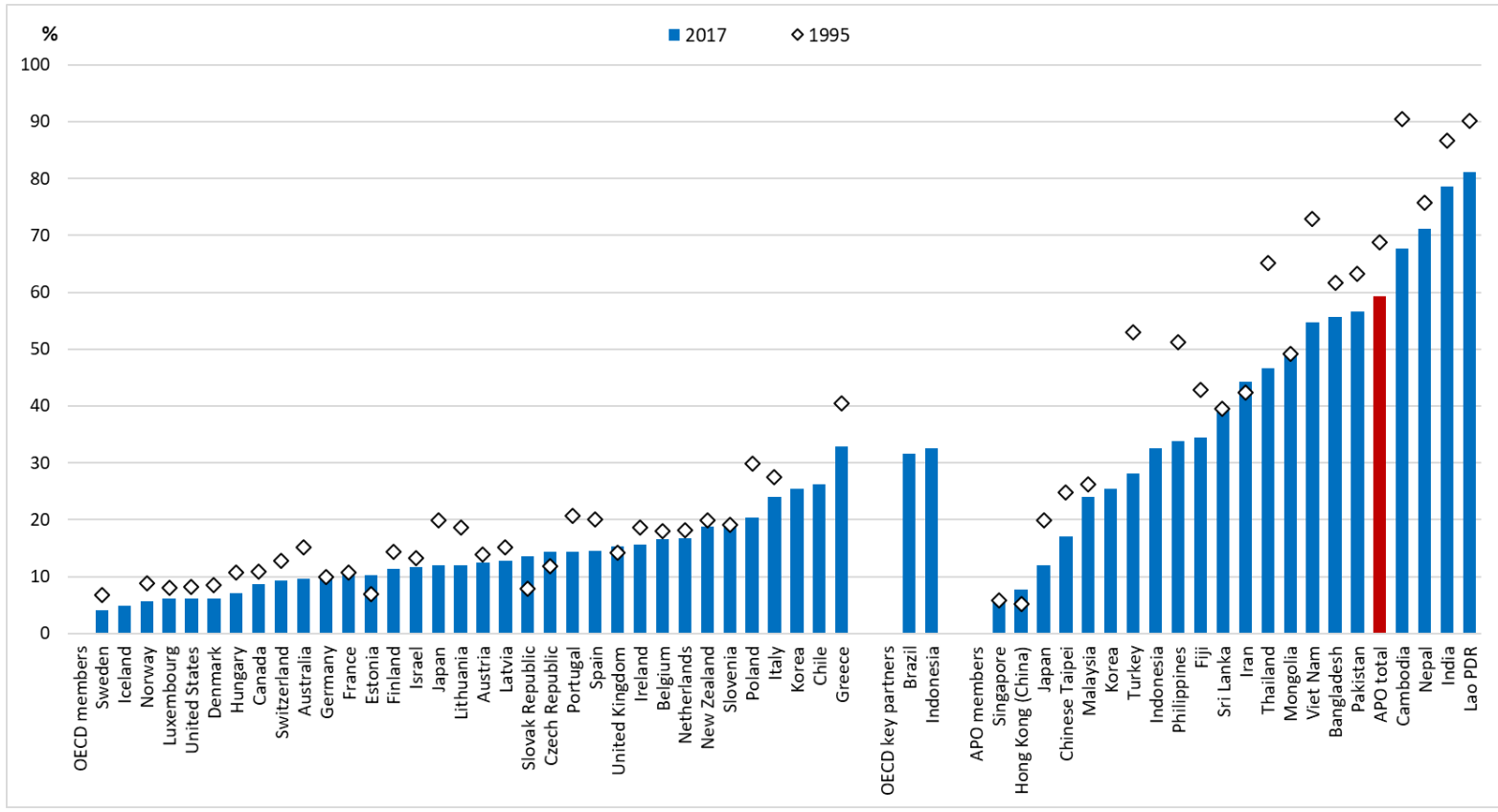

Source: OECD National Accounts Statistics (database), July 2020, and APO Productivity Database 2019, Ver.2 (February 25, 2020).

Note: Data for economies with membership in both international organisations (i.e. Japan, Korea and Turkey), and OECD Key Partner countries (i.e. India and Indonesia), are sourced from OECD National Accounts Statistics (database) when available, and when unavailable, from the APO Productivity Database 2019, Ver. 2 (February 25, 2020). Access the data.

The prevalence of self-employment varies widely across activities, with certain activities clearly being more or less conducive to the presence of large employers. Figure 2.10 highlights these differences in OECD countries, presenting the ratio of employees to total employment in agriculture, manufacturing and trade, transport, accommodation and food services in 2017. In the United States, for example, around a third of workers in agriculture are self-employed, compared with manufacturing where less than $2 \%$ of workers are self-employed and distributive trade, transport, accommodation and food services where less than $5 \%$ of workers are self-employed. Countries for which agriculture accounts for a significant share of economic activity, for example, Indonesia and Brazil in Figure 2.10, tend to observe a greater share of self-employment across all types of activity. For these economies, which constitute many of the APO member economies, self-employed workers play a more significant role in the labour market, underlying the need for the accurate measurement of the self-employed. 
Figure 2.10: Incidence of self-employment in different activities

Ratio of self-employed to total employment, activities A, C \& G-I, 2017

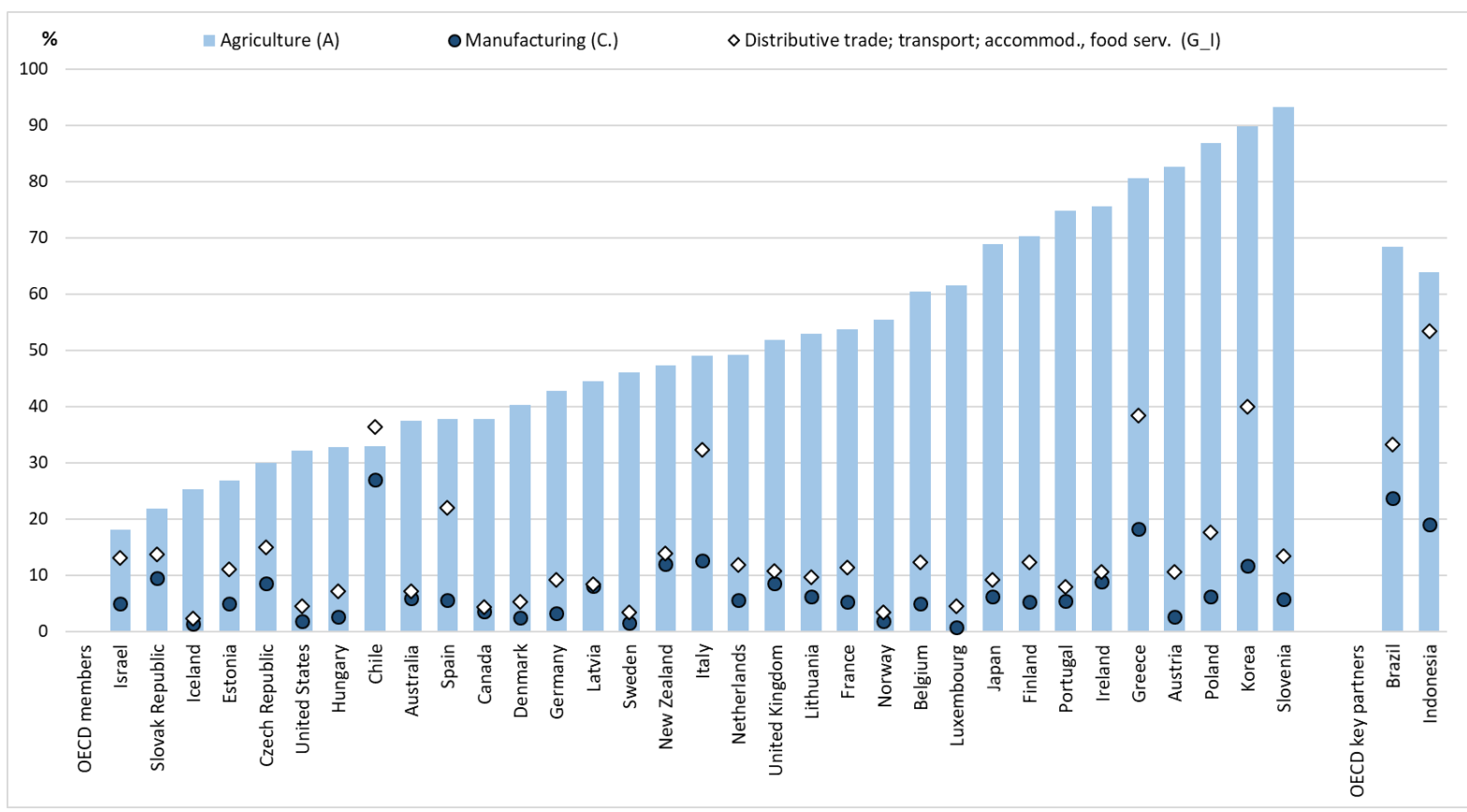

Source: OECD National Accounts Statistics (database), July 2020.

Note: Access the data.

\section{Data sources used to compile employment measures}

Countries generally rely on household surveys (mostly labour force surveys, LFS), population census, and/or establishment surveys (including statistical business registers) to compile estimates of employment, with some countries also exploiting administrative sources (see Box 2.2 for details of these sources). No single source provides a flawless measure of employment. Employment data collected through the LFS, for example, may have definitional differences with the national accounts framework due to the inclusion of resident persons working in non-resident institutional units and exclusion of non-resident persons working in resident institutional units, as well as the exclusion of military personnel, individuals living in collective households and workers outside the age range covered by the survey. On the same note, business statistics are unlikely to provide an accurate accounting of employment in isolation, primarily as they typically do not include records for selfemployed or for workers in non-sampled institutions or certain economic activities. 


\section{Box 2.2. Sources commonly used to construct employment and hours worked in national accounts}

A wide variety of primary data sources are used to estimate employment and hours worked in line with the national accounts production boundary. In practice, these vary substantially across countries, as revealed by the 2018 OECD/Eurostat survey on national accounts labour input measures, reflecting their applicability and use within each country with regards to coverage, reliability, timeliness, and purpose of analysis. The most widely used primary data sources are labour force surveys, population census, business statistics and administrative sources. While the first two are commonly used to monitor the "supply-side" of the labour market, the latter two provide a "demand-side" perspective.

Labour force survey - The labour force survey (LFS) is the most comprehensive and well-established source for information on the composition and characteristics of the labour force. International harmonisation is achieved by complying with definitions set out by the International Labour Organisation (ILO, 1982 and 2013), although sample selection, survey techniques, survey responses and the implementation of ILO concepts may vary between countries. An advantage of the LFS is that it covers a broad range of employment situations, including the selfemployed, unpaid family workers and informal employment, as well as collecting information on multiple-job holdings, hours usually and actually worked, and paid and unpaid overtime. Moreover, it provides information on the structure of employment in terms of age, sex, education level and professional status. Its main limitation from the perspective of national accounting, and hence, productivity analysis, is the often limited consistency with output and value-added measures, in particular, by industry, as the LFS is a household survey for which the stratification process may not adequately capture the homogenous strata required in productivity analysis. For example, in the LFS, industry coding is often conducted on the basis of information given by the respondent about the type of product, service or function provided by his/her place of work, which may not align with the industry coding of that firm in the business register, and hence national accounts (although in some countries this alignment is improved by matching respondents information, such as the name and address of the firm with equivalent information on the business register). In addition, in many countries, the LFS does not cover some groups of the population such as persons below or above certain age thresholds (which varies by country), those living and working in communal establishments (such as prisons or long-term care facilities), collective households (such as religious institutions) and the armed forces, all of whose output is included, at least in theory, in estimates of GDP. In addition, the sampling structure of LFS is based on the population usually residing in the country and includes workers in non-resident production units, whereas non-resident cross-border workers working in resident production units are excluded. There may also be biases in LFS responses, reflecting the self-reporting nature of LFS, and these biases, that may also be cultural, appear to be significant with respect to responses on hours actually worked. For example, in some countries, certain categories of workers, such as managers, professionals, and some selfemployed may over-report their hours actually worked. On the other hand, despite reassurances that the LFS is purely for statistical purposes, there may be a tendency to hide or under-report hours actually worked by those working in the grey or informal economy. 
Population census - The population census (PC) is a comprehensive source covering the whole population of a country, making it a useful tool to benchmark household surveys, including the LFS. The main disadvantages are the low frequency of data collection, which is typically carried out every five or ten years, and the possibility that unregistered migrants may not be captured.

Business statistics - Business statistics (BS) include establishment and/or enterprise surveys, business census, and dedicated labour cost surveys. Another important data source is the statistical business register (SBR) which is typically sourced from multiple primary data sources, including business surveys and a variety of administrative data. ${ }^{5}$ BS typically provide detailed data on employment and hours worked following a detailed industrial classification of firms that is generally consistent with their classification in national accounts output and value-added data - indeed structural business statistics are an important input to, and building block for, the national accounts. One of the main limitations of BS, however, is that they sometimes exclude establishments or enterprises below a certain employment or turnover threshold and certain categories of firms, such as unincorporated businesses, self-employed persons and informal labour. A further limitation of some business statistics, such as dedicated labour cost surveys, is that they often provide information on hours paid or contractual hours only, and not information on absences from work and unpaid overtime, and, so, do not align with the concept of hours actually worked required to measure labour input in productivity analysis.

Administrative data sources - Administrative data sources (AS) are typically collected by government bodies - but also increasingly by private data providers (e.g. associations for specific groups) - based on some form of statutory or voluntary registration. For example, statistics from social security institutions and tax administrations can provide information on all persons required to pay income tax or social insurance contributions. Social security records, tax registers, compulsory business registration systems, resident permit registers, migration statistics, and statistics on the armed forces, are the administrative sources most commonly used by countries in compiling estimates of labour input. AS may include information on wages, entrepreneurial income, taxes, etc. as well as a series of demographic variables describing age, gender, and family ties. The main advantage of AS is that they are generally comprehensive, at least with regards to the population that they purport to cover, and do not entail additional collection costs to the national statistical offices (NSOs) as compared to surveys. Like BS however, AS often struggle to capture informal labour.

Other sources - Statistical offices may use other complementary sources to estimate labour input that do not fall neatly into any of the above categories. Among others these can include time-use surveys, surveys on households' living conditions, tourism surveys, and surveys of insurance companies. In some ways, these sources are similar to administrative sources and so, for simplicity, and without prejudicing the analysis and results presented here, this paper groups AS and these other sources together.

Source: Ward et al. (2018).

${ }^{5}$ There is ongoing work to harmonise Statistical Business Registers (SBR) via both the UN Wiesbaden Group on Business Registers, the UN Committee of Experts on Business Statistics, and the joint UNECE-Eurostat-OECD expert group on business registers. 
In 2018, Eurostat and the OECD surveyed their combined member countries, and selected nonmember countries, regarding their data availability, sources and methods used to compile labour input data in the national accounts (Ward et al., 2018). All countries surveyed produce data on employment at a whole economy level and by industry, most commonly breaking employment down to at least a partial two-digit industry level. Figure 2.11 shows the main and secondary/supplementary sources used to compile data on the numbers of employees and self-employed. The evidence reveals that the most commonly used main data source for employment is the LFS, this being even more prevalent for the estimation of the number of self-employed, which are often not included in other primary data sources. Business statistics and administrative sources are also regularly used as main sources by countries, particularly for employees, and administrative sources are the most commonly used second or supplementary source. Many of the countries with the most robust compilation methods looked to multiple primary data sources, weighing up the relative benefits of each, in order to produce a representative and reliable estimate of total employment.

Figure 2.11: Sources used for employment

The sources used by countries, main original sources and other sources, to construct estimates

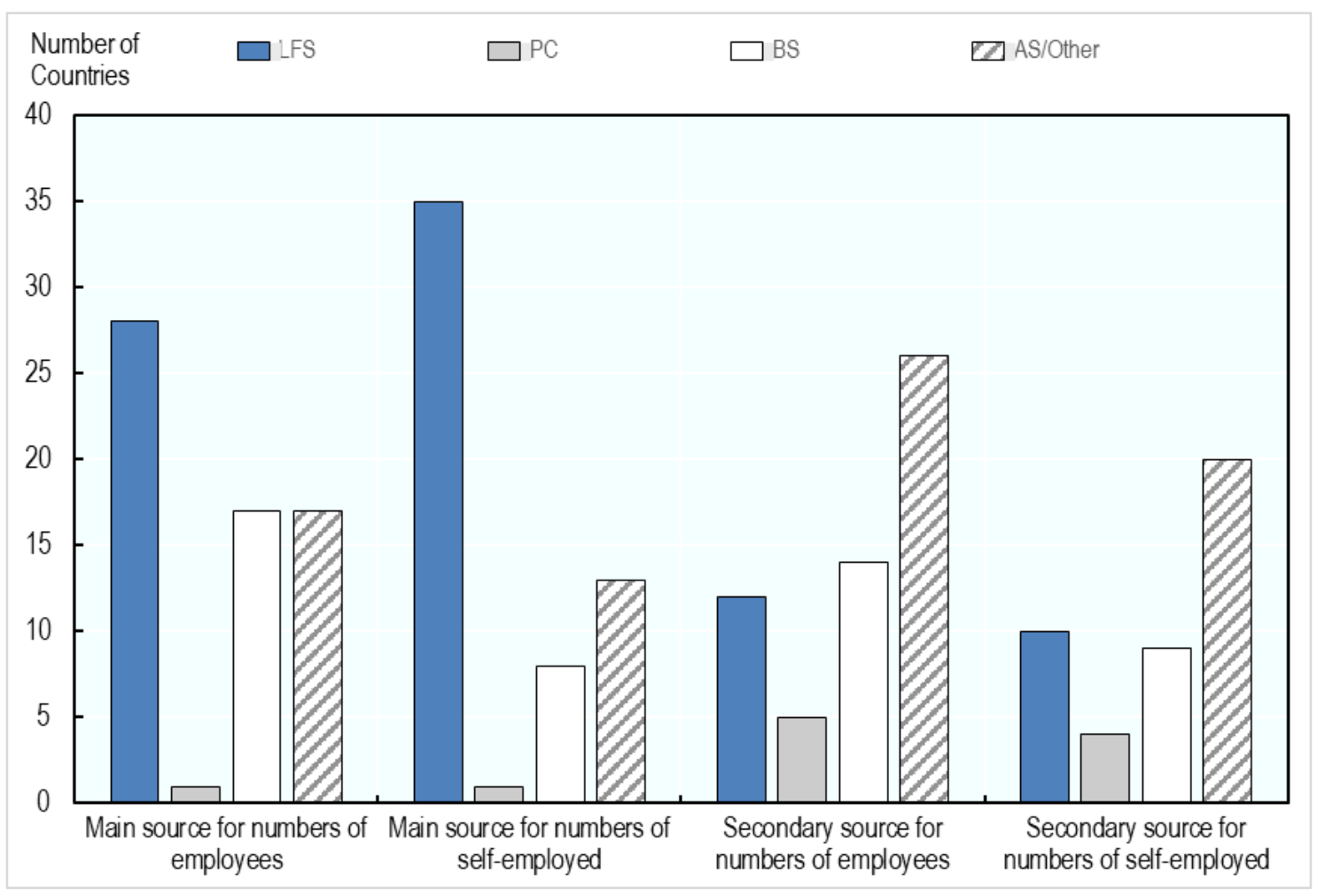

Source: Ward et al. (2018).

Notes: LFS refers to Labour Force Surveys, PC refers to Population Census, BS refers to Business Statistics and AS refers to Administrative Sources. Other sources can include academic studies, time-use surveys and other household surveys, among others. Access the data.

While the type of data source/s used to compile employment measures are of great importance the significance of the quality and the international comparability of the underlying data is not to be underestimated. For example, many countries rely largely on their LFS to measure employment, but the nature of a country's LFS, and issues therein, can vary widely across countries. These differences include, but are not limited to, differences in the definitions of employment, sample sizes, sampling 
procedures and the coverage of geographic areas and/or activities (Eurostat, 2020). It is the domain of each country's NSO to maintain robust data collection and processing procedures to ensure the consistency and quality of their surveys and available administrative data. With this aim, it is recommended that the NSOs adhere to internationally accepted standards in order to facilitate reliable cross-country comparisons.

\section{Adjustments to align with national accounts}

Depending on the choice of the main primary data source(s), there are likely to be necessary adjustments to ensure the coherence of the resulting employment estimates with the national accounts (for a detailed description see Box 2.3). Such adjustments are mostly to cover all employed or self-employed persons contributing to the GDP of a given country (see Table 2.2).

Table 2.2: Individuals Included and Excluded from National Accounts Consistent Total Employment

\begin{tabular}{|l|l|}
\hline \multicolumn{1}{|c|}{ INCLUDED } & \multicolumn{1}{c|}{ EXCLUDED } \\
\hline $\begin{array}{l}\text { Non-resident cross-boarder and seasonal workers, working in } \\
\text { resident units. }\end{array}$ & $\begin{array}{l}\text { Resident border or seasonal workers, that is, who work as } \\
\text { employees in another economic territory. }\end{array}$ \\
\hline $\begin{array}{l}\text { Members of a country's armed forced stationed in the rest of } \\
\text { the world and conscripted forces regardless of location. }\end{array}$ & $\begin{array}{l}\text { Members of the armed forces working with international military } \\
\text { organisations located on the geographic territory of the country. }\end{array}$ \\
\hline $\begin{array}{l}\text { National scientific staff, employees of general government } \\
\text { bodies, or diplomatic staff, placed outside of the geographic } \\
\text { territory of the country. }\end{array}$ & $\begin{array}{l}\text { Nationals working in foreign scientific bases established in the } \\
\text { economic territory. }\end{array}$ \\
\hline $\begin{array}{l}\text { Members of the crews of fishing boats, other ships, aircraft and } \\
\text { floating platforms operated by resident units. }\end{array}$ & $\begin{array}{l}\text { Nationals who are members of the crews of fishing boats, other } \\
\text { ships, aircraft and floating platforms operated by non-resident } \\
\text { units. }\end{array}$ \\
\hline $\begin{array}{l}\text { Resident workers living in an institutional household (such as a } \\
\text { religious institution or a prison). }\end{array}$ & $\begin{array}{l}\text { The personnel of international civilian organisations located } \\
\text { within the geographic territory of the country (including local } \\
\text { employees directly recruited). }\end{array}$ \\
\hline $\begin{array}{l}\text { Resident workers under the age limit defined for measurement } \\
\text { of the labour force who work for resident institutional units. }\end{array}$ & $\begin{array}{l}\text { Residents who are employees of foreign government agencies } \\
\text { located on the geographic territory of the country. }\end{array}$ \\
\hline
\end{tabular}

Source: 2008 SNA para. 19.32-19.34.

Box 2.3. Common adjustments needed to align employment and hours worked estimates with the national accounts

Persons to jobs / jobs to persons - Original data sources may provide information on employment in terms of persons and/or jobs. Whenever the units of measure used in the original data source and those referred to in the presentation of a country's national accounts differ, an adjustment from persons to jobs or vice versa is required.

Residence - A number of adjustments are necessary to ensure alignment of estimates of workers with the residence of the economic unit in which they work. For example, adjustments are needed to capture non-resident persons working in domestic (resident) production units and to exclude those in the resident population that work in non-resident units (e.g. foreign embassies, consulates and foreign military bases within the reporting country or work abroad). Adjustments are also needed to ensure the inclusion of subsets of the resident population not covered in the original data source(s): in the case of the LFS, this may refer to military and 
conscripts, collective households and workers in territories not covered by the LFS but that are within the country's economic territory; in the case of business statistics, the subsets of resident population typically not covered include the selfemployed and unpaid family workers, as well as workers in economic activities such as public administration, education, health and other non-market services (although the latter are generally well covered by administrative data).

Unobserved economy - By their nature, business statistics and administrative data sources typically miss information on employment and hours worked in the unobserved economy. Whenever this is the case, adjustments to capture employment and hours worked are required to ensure consistency with the production boundary of output measures. Depending on the country and the original data sources, these adjustments may be more relevant in some economic activities, such as construction, trade, catering and personal services.

Digital economy - The digital economy has increased the importance of peer-topeer transactions, with the emergence of platforms intermediating, for example, the provision of taxi services, by households to other households. The emergence of the gig economy, and with it "gig workers", has contributed significantly to the growth in part-time self-employment we have seen over the past decade (OECD, 2017b). While, in principle, the measurement framework used by national accountants covers the output of these activities, the increase in the scale of these activities by, typically, the 'occasionally self-employed' may require an examination of methods (and sources) currently used to measure both output and labour input (Ahmad et al., 2016; Ahmad et al., 2017).

Periodicity - National accounts are generally compiled on a quarterly and annual basis. However, original data sources can have different periodicities and so adjustments to original source data - ranging from simple arithmetic averages of higher-frequency data (e.g. annual figures are obtained as the arithmetic mean of quarterly values) to interpolations based on information from additional data sources - are required. The latter are often used to extend series backwards, as the periodicity of original data sources has increased over years.

Other adjustments - Many countries introduce additional adjustments to the data obtained from original sources to comply with national accounts concepts. These include adjustments for working students, workers engaged in production undertaken entirely for their own final consumption or own capital formation either individually or collectively, working prisoners, workers below or above age thresholds covered by original data sources, and, for estimates of labour productivity at the industry level, adjustments may be needed to ensure that persons employed in temporary employment agencies are included in the industry of the agency and not in the industry of the enterprise for which they actually work (2008 SNA, para. 19.21). In addition, albeit with marginal impact on actual estimates of labour input, when the original data source is the LFS, a common adjustment is the reclassification of owners of corporations and quasi-corporations working in their companies as employees rather than as self-employed persons, which is often how they classify themselves (see also 2008 SNA, para. 19.21).

Source: Ward et al. (2018). 
In practice, the necessary adjustments vary as much as the primary data sources chosen and their scale can range from minimal to pronounced. The 2018 Eurostat/OECD survey on labour input measurement revealed that the majority of countries make some type of adjustment to their original source data to align with the national accounts production boundary or for other data source specific requirements (Ward et al., 2018).

The conversion of employment data from jobs to persons, or vice versa, is often not required, but in some cases can constitute a substantial adjustment. For example in Japan, where the unit of measure for employment data in the national accounts is jobs, estimates of persons sourced from the LFS are adjusted upwards by approximately $2.3 \%$ for employees and $13.4 \%$ for self-employed to produce job count metrics (Ward et al., 2018).

Adjustments to align with the residence principle are particularly large for smaller countries with high levels of cross-border working and that use LFS as their main data source. For example, the Slovak Republic makes a downwards adjustment of $-4.8 \%$ for employees as many residents work abroad, and Switzerland makes an upwards adjustment of $8.9 \%$ for employees as it hosts many cross-border workers. Almost all countries make some explicit adjustment to align with the national accounts' residence principle; however, Chile, Croatia, New Zealand, and the United Kingdom (in its national accounts) make none, despite all four using the LFS, which, by definition, provides information on the national concept ${ }^{6}$ of employment. Sources such as international passenger surveys, migration statistics, business surveys and income tax records may provide information on country of residence and help countries, currently unable to make these adjustments, to assess the scale and direction of their cross-border worker flows. Such adjustments must be applied symmetrically across countries, meaning there is significant scope, if not necessity, for international organisations, including the APO and the $\mathrm{OECD}$, to play a role in coordinating the exchange of country practices and experiences across NSOs.

Employment measures on the basis of both the national and domestic concept are available in the OECD National Accounts Statistics (database). Figure 2.12 presents the ratio of the national to the domestic concept in order to highlight differences in the measures. For the majority of countries, these measures differ by less than 3\%. However, Luxembourg, Switzerland, Israel and the Slovak Republic are notable exceptions with the domestic concept diverging from the national concept by $40.4,7.4$, 7.2 and $-6.7 \%$ respectively. As a general rule, the countries which show the greatest differences tend to be small countries which have multiple or particularly large neighbours. For example, in Singapore there were 3.6 million employed persons in 2019, however, there were only 2.2 million employed residents (Singstat, 2020). For such countries, a robust methodology to adjust employment for crossborder workers is particularly important.

\footnotetext{
${ }^{6}$ The national concept of employment refers to all resident persons in employment, regardless of the place of residence of the institutional unit by which they are employed. The domestic concept of employment refers to all persons employed in resident production units irrespective of the place of residence of the employed person.
} 
Figure 2.12: Differences in national and domestic concept employment estimates
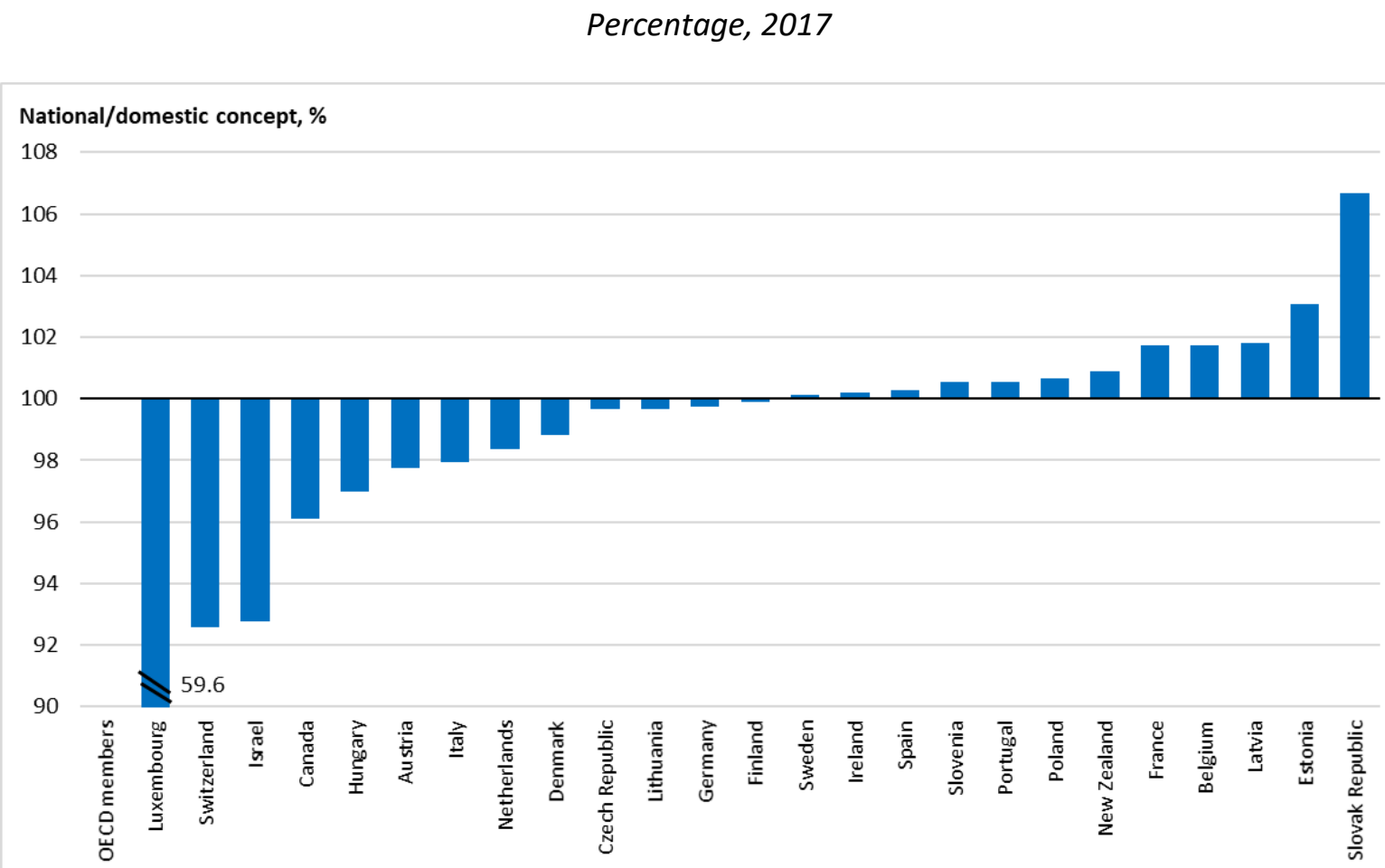

Source: OECD National Accounts Statistics (database), July 2020.

Note: Multiple countries are omitted from this chart as, for one reason or another, they report only one concept or the recorded concepts are equal. For Australia, Japan and Korea only the domestic concept is reported. For the United States only the national concept is reported. For the United Kingdom employment data by industrydomestic concept are benchmarked to those in population and employment by industry-national concept, and hence are identical. Access the data.

The scale and direction of adjustments necessary to fully align with the national accounts definition of employment differ by country. Figure 2.13 shows, for selected countries, the breakdown of adjustments made to the source data for employees in order to get to the figures recorded in the country's national accounts. Each of the countries presented employ multiple adjustments, without which their estimates could diverge from the national accounts' value by up to $10 \%$ of the data reported in the original main data source. This highlights how important measurement can be, with the adjustments applied playing a significant role in determining the final estimate. The impact of a country not applying the necessary adjustments could be substantial, not only for the interpretation of employment levels, but also for productivity and economic analyses relying on their accuracy. NSOs can play a fundamental role in this regard, as they are likely to have access to more detailed information and data sources than any international organisation or external researcher, facilitating the most comprehensive and accurate set of adjustments. 
Figure 2.13: Adjustments made to estimates of employees

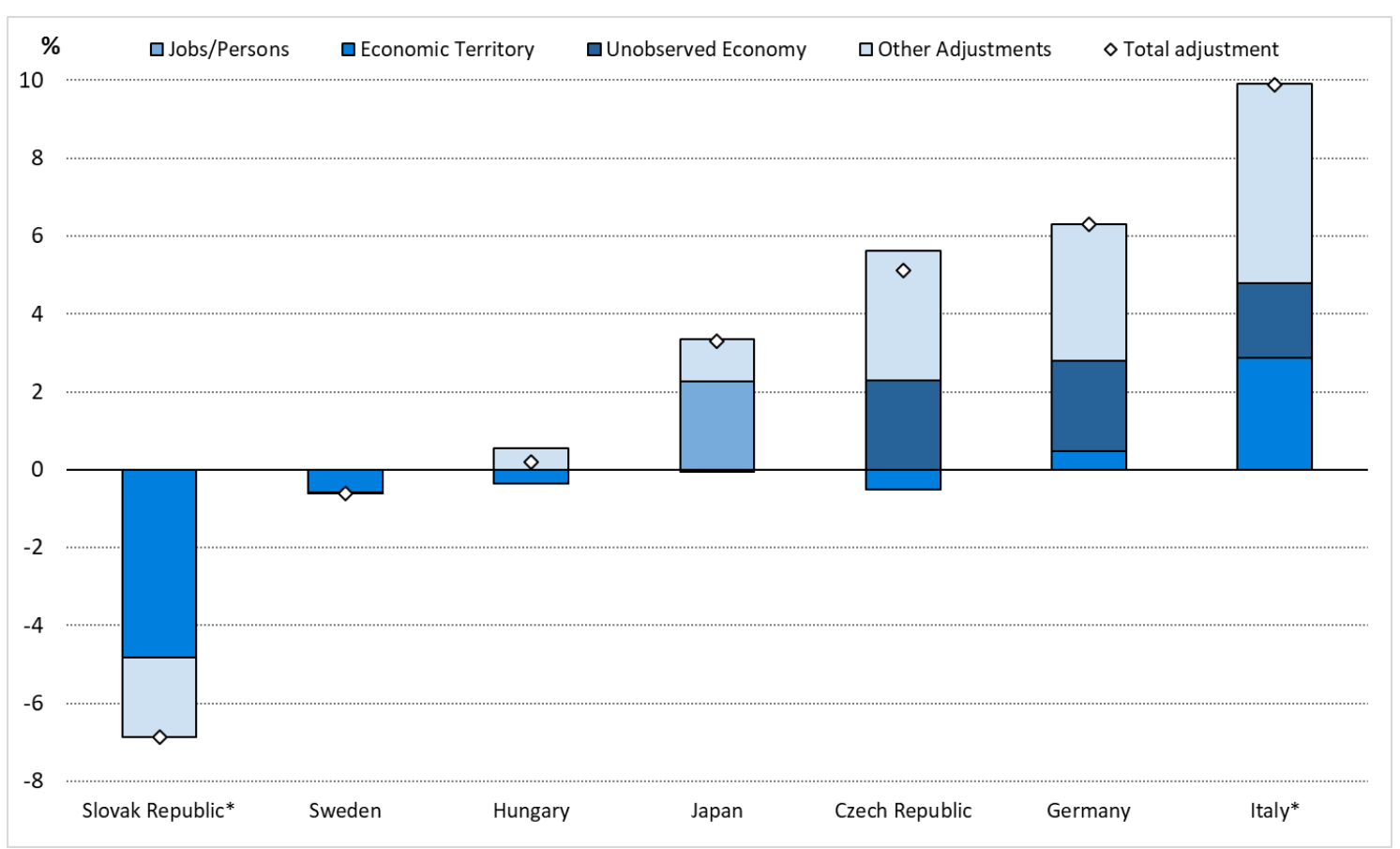

Source: Data from Ward et al. (2018) and author calculations.

Note: *Report adjustments for total employment only. Access the data.

As discussed at length in the section on output, the national accounts endeavour to be exhaustive in their coverage of economic activity. This includes not only that production recorded by traditional surveys and administrative sources, but also production in the non-observed economy (NOE) (see full definition in Section 2.a. above). Productive activities in the non-observed economy benefit from the labour services provided by workers who may be in all or in part unobserved. In addition, enterprises or employers in the formal sector may engage workers in their productive activities through informal jobs. It is important to understand the scope of the non-observed economy and ensure the effective measurement of workers:

- in the illegal economy, who either produce and sell illegal goods and services or sell legal goods without necessary authorisation;

- in the underground or concealed economy, who produce goods and services that are legal when performed in compliance with relevant regulations but who conceal those activities (often to avoid paying certain taxes or meeting specific employment regulations);

- in the informal economy, working in unincorporated enterprises in the household sector or other units that are unregistered and/or below a specific employment threshold;

- in households producing goods or services consumed or capitalised by that household; and

- in the statistical underground, who are missed due to deficiencies in the statistical system.

To maintain the coherence between employment and output measures in the national accounts and for the purposes of productivity measurement, countries must adjust their measures of employment (and of compensation of employees) whenever necessary to account for these non-observed workers and for those in the formal sector but informally employed (2008 SNA, para. 19.35). It is worth noting that the necessary adjustments to output and employment may not be proportionate. For example, 
the part of employment that is unobserved can be higher or lower than the unobserved part of the related output. Therefore, applying the same adjustment to both output and employment could distort the resulting productivity measures. The measurement of informal employment is not a simple endeavour and is covered in detail in Box 2.4, with case studies presented in Box 2.5.

The scale of informal employment varies across economies, but is generally more prevalent in developing economies. Across Latin America, as well as South Africa and Turkey, informal workers account for a significant share of employment, in particular among those who are self-employed (Figure 2.14, Sorsa et al., 2020). These examples further highlight the importance of accounting for informal workers in the employment measurement framework, with these workers making up the majority of the workforce in some economies.

Figure 2.14: Share of employees and self-employed workers in informal employment Selected countries, 2007 and 2017

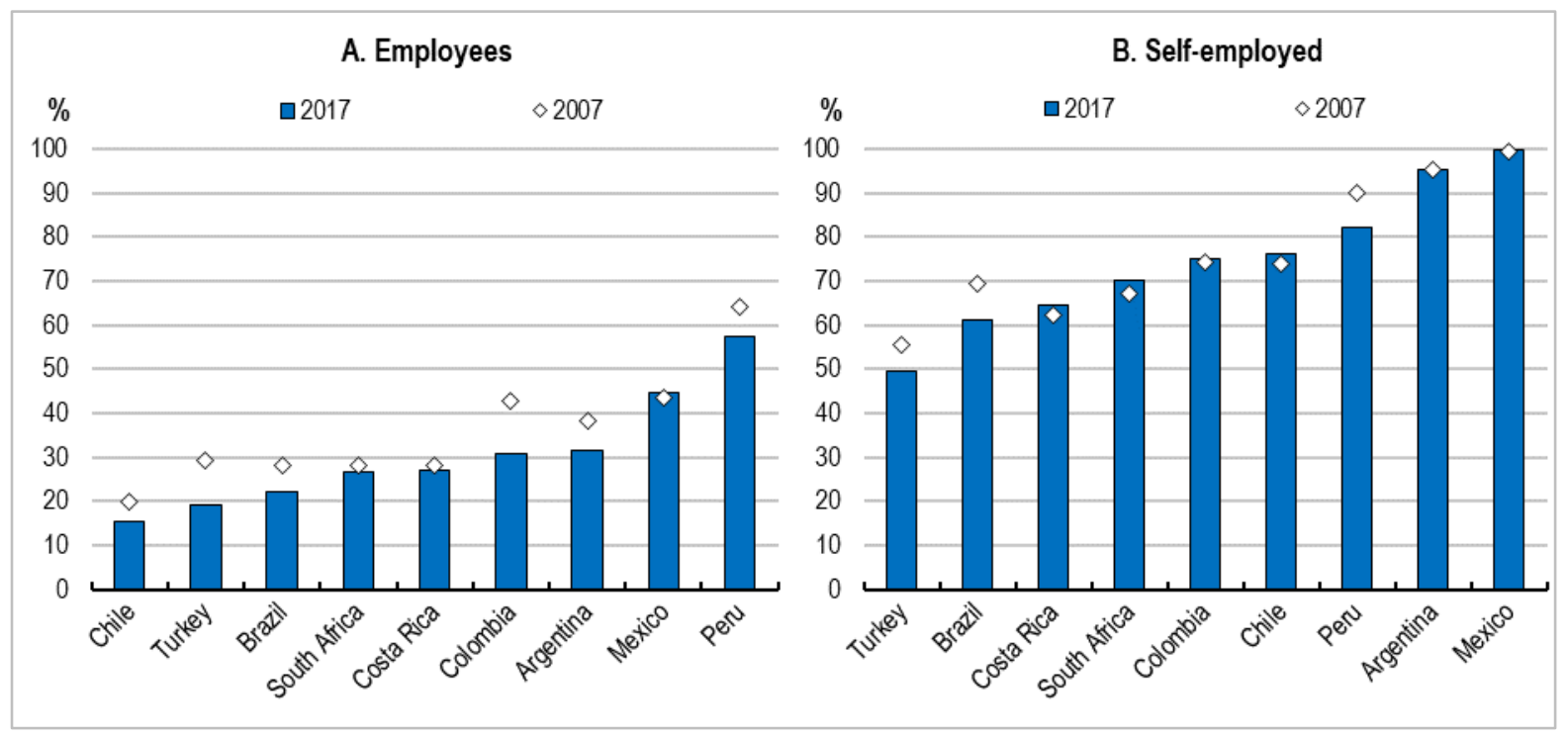

Source: Sorsa et al. (2020).

Note: Informality is defined to include: i) employees who do not pay social security contributions; and ii) selfemployed who do not pay social security contributions (Brazil, Chile and Turkey), or whose business is not registered (Argentina, Colombia, Costa Rica, Mexico, Peru and South Africa). Data for Turkey refer to persons aged 15 and more. Data for Argentina refer to selected urban areas (according to the National Statistical Authority (INDEC), LFS series published after the first quarter of 2007 and until the fourth quarter of 2015 must be considered with caution). Access the data.

\section{Box 2.4. Measuring informal employment}

The ILO definition of informal workers includes two groups: i) all workers in the informal sector and ii) all informal workers outside of the informal sector (ILO, 1993; ILO, 2003).

Informal sector enterprises satisfy a specific set of criteria: 
- Unincorporated - It is not a legal entity separate from its owners, it is owned by one or multiple households and it is not a quasi-corporation (i.e. it does not have a complete set of accounts including balance sheets);

- Market enterprise - It sells at least some of the goods or services it produces;

- The number of persons employed on a continuous basis is below the country threshold for the definition of an enterprise;

- and/or the enterprise is not registered and/or the employees of the enterprise are not registered (i.e. there is no contract which commits the employer to pay relevant taxes and social security contributions on behalf of the employees, or which make the employment relationships subject to standard labour legislation).

Informal employment outside of the informal sector includes workers where their main or secondary jobs are:

- own-account workers engaged only in the production of goods exclusively for the final consumption of their own household, if such production comprises an important contribution to the total consumption of the household and as such they are considered self-employed (ILO, 1982);

- contributing family workers, whether they are remunerated or not, and contributing unpaid workers as long as they do not have employment contracts subject to standard labour legislation;

- or in informal jobs with formal sector enterprises, such that they are not subject to national labour legislation, income taxation, certain social protection or certain employment benefits.

The intersection between the type of production unit and the type of job can present a significant challenge when attempting to capture all of informal employment. Table 2.3 represents this intersection, showing types of production units in rows and types of job in columns, highlighting the potential overlap across measures of informal employment, employment in the informal sector and informal employment outside of the informal sector (ILO, 2013).

Table 2.3: Conceptual framework for informal employment (1 $7^{\text {th }}$ ICLS guidelines)

Production units by type

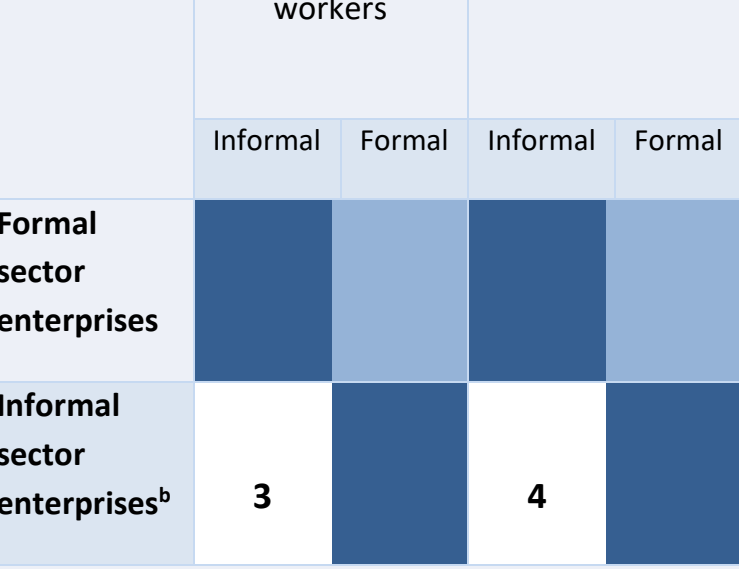

Jobs by status in employment

\begin{tabular}{|c|c|c|c|c|}
\hline $\begin{array}{c}\text { Own-account } \\
\text { workers }\end{array}$ & Employers & $\begin{array}{c}\text { Contributing } \\
\text { family } \\
\text { workers }\end{array}$ & Employees & $\begin{array}{c}\text { Members of } \\
\text { producers' }\end{array}$ \\
\hline Informal Formal & Informal Formal & Informal & Informal Formal Informal Formal \\
\hline
\end{tabular}




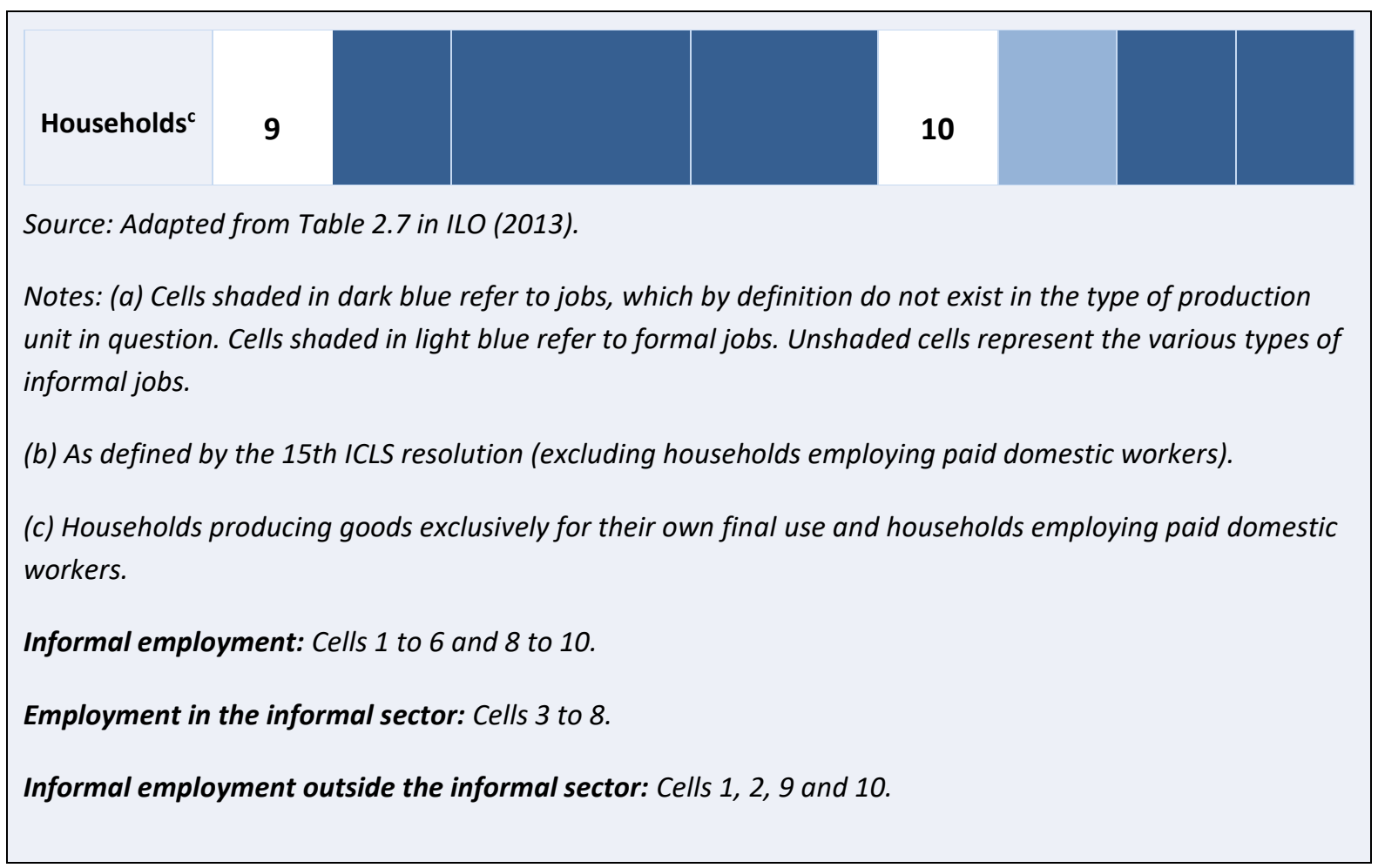

\section{Box 2.5. Measuring informal employment: Case studies}

\section{India}

In 2017, the ratio of persons employed to the working age population in India - i.e. the employment rate - was around 58.3\%, well below other Asian BRIICS (China, $76.8 \%$; Indonesia, $68.4 \%$ ) and the overwhelming majority of those in employment (around $89 \%$ of total employment) was in the informal economy (OECD, 2019a).

Kulshreshtha (2011) provides an overview of the measurement of the informal economy in India, in particular of employment and net domestic product. The term "informal" is not used in the Indian national accounts, with the term "unorganised" taking its place; even so, the definitions are similar. Data on the non-agricultural parts of the unorganised sector are covered by the regular survey program of the National Sample Survey Organisation (NSSO), which is the data collection agency conducting large scale sample surveys in diverse fields, and the follow-up surveys organised by the agency that coordinates statistical activities in the country, the Central Statistical Organisation (CSO), after each Economic Census. Each specific activity in the unorganised economy - i.e. manufacturing, trade, transport, hotels and restaurants, and other services - is covered once in five years as part of the quinquennial program of follow-up surveys to the Economic Census.

Employment in the informal sector can be measured either directly or indirectly (Kulshreshtha, 2011). The direct approach relies on survey data to identify unorganised enterprises and count the persons they employ. However, the quality of the data on the informal sector collected directly from the primary data sources 
is a serious issue, as sources differ in their coverage and methods, providing notably different estimates of the workforce. For this reason, an indirect method has been used to estimate informal employment starting with the 1993-1994 series of national accounts statistics. The worker-population ratios are taken from the latest round of the NSSO Employment and Unemployment Survey (EUS) and used with the latest population projections to create an estimate of the workforce broken down by rural/urban area, sex and region. These totals are then apportioned to one-digit activities using NSSO work participation rates and then to two and three-digit levels using the proportions observed in the Population Census, with adjustments made to account for multiple job holdings. These estimates of the total workforce, including data on both formal and informal employment, are then combined with data on the formal sector from the Director General for Employment and Training (DGE\&T) to derive an estimate of the size of the informal sector by activity.

Estimates presented in Kulshreshtha (2011) highlight the scale of India's unorganised sector, showing that in the period 1990-2000 unorganised workers made up $88 \%$ of manufacturing employment, $98 \%$ of employment in trade, $97 \%$ of employment in hotels and restaurants, $87 \%$ of transport employment, $39 \%$ of employment in the post and communication sector and $73 \%$ of employment in other services.

The OECD's 2019 Economic Survey of India concludes that complex labour market regulations discourage firms from growing and creating quality jobs, with it being far easier to avoid these regulations by employing informal workers. The introduction of simpler and more flexible labour legislation, removing the disincentives to create jobs, would encourage firms to engage workers in formal jobs and shrink the size of the informal workforce (OECD, 2019a). The elaboration of reliable statistics on informal employment is thus not only useful for productivity analysis, but also to contribute to the economic policy debate more generally.

While informal employment is particularly prevalent in India, the same likely holds true for other APO members, which creates issues not only for measurement but also for human capital development and for the expansion of the tax base. In any case, the experience of the Indian statistical system in accounting for informal employment may be useful for the NSOs of other APO member economies as well.

\section{Other country practices}

Many countries make adjustments for the non-observed employment, and NSOs in different countries address this challenge in different ways (Ward et al., 2018). For example, France estimates work in illegal activities using previous studies on the non-observed economy in national accounts (Louvot, 2011) and data from the French Monitoring Centre for Drugs and Drug Addiction (OFDT). Hungary estimates the number of employees and self-employed persons in drug trafficking based on the approximate income available from this activity and criminal statistics, and the number of workers in prostitution based on information from the Association of Hungarian Sex Workers (Eurostat, 2018d). Israel estimates the number of foreign illegal workers using data from border controls and assumes that tourists not leaving the country shortly after expiry of their tourist visa become undocumented workers (Eurostat, 2018f). Italy integrates information from many different sources to make a thorough assessment of employment in the unobserved economy, including an 
estimate for domestic work using its Multipurpose Survey on Households, the number of potential jobs in the transport of goods and persons derived from administrative data on circulating vehicles, and an estimate for undeclared work performed by residents and non-residents resulting from the integration of LFS data with administrative sources (LFS-ADMIN), data from the Ministry of Interior and data elaborated by private research institutions monitoring immigration (Eurostat, 2018g). Similarly, Slovenia uses data from the Ministry of Interior and the National Institute for Public Health, among other sources, to produce estimates of illegal trafficking of drugs and prostitution, and the number of alternative doctors, babysitters, teachers providing private tutoring and persons providing assistance to elderly people (Eurostat, 2018e). The United States, for productivity measurement, does not adjust for unobserved activities, but the Bureau of Economic Analysis (BEA) does make adjustments when preparing employment estimates for the BEA/BLS integrated production accounts. Finally, Croatia adds a fixed number workers, about 10,000 people, every quarter (since 2008) to its LFS totals (Eurostat, 2018a).

\section{Data and comparisons}

Employment growth is one indicator of a country's increasing/decreasing labour input, one component of the production function, and an important driver of GDP growth (OECD, 2019e). Figure 2.15 presents the annual growth in employment in APO, OECD member and Key Partner economies between 1996 and 2017. While APO economies have experienced higher average employment growth over the period (1.5\%) than OECD countries (1\%), growth varies substantially across members of both organisations. Only two countries, Lithuania and Latvia, experienced negative employment growth over the period at $-0.4 \%$ and $-0.2 \%$ per year respectively. Conversely, the greatest annual increase in employment occurred in Cambodia (3.3\%), Luxembourg (3.2\%) and Malaysia (2.9\%). 
Figure 2.15: Employment growth in APO and OECD regions

Average annual employment growth, 1996-2017

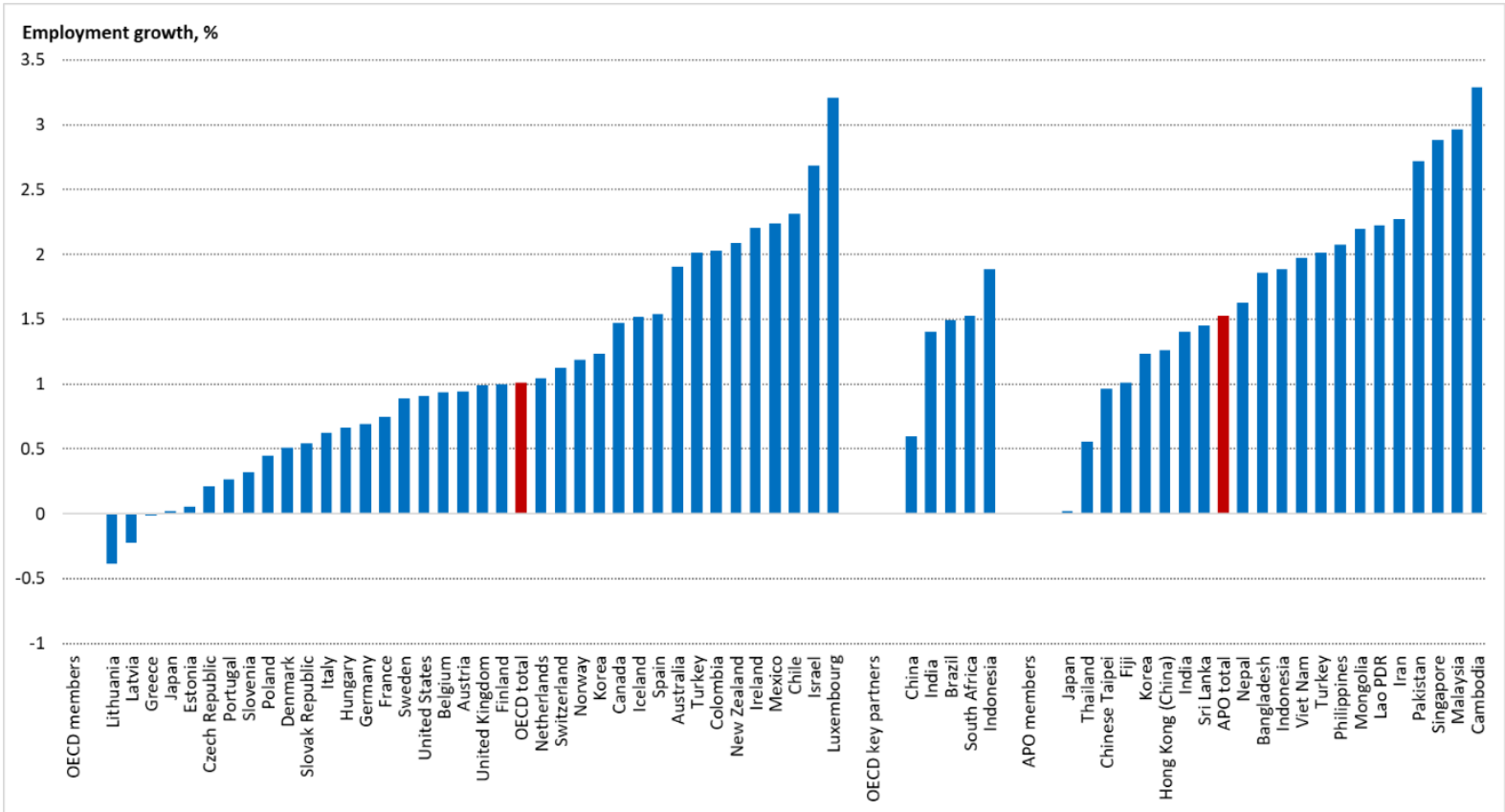

Source: OECD National Accounts Statistics (database), July 2020, and APO Productivity Database 2019, Ver.2 (February 25, 2020).

Note: Data for economies with membership in both international organisations (i.e. Japan, Korea and Turkey), and OECD Key Partner countries (i.e. India and Indonesia), are sourced from OECD National Accounts Statistics (database) when available, and when unavailable, from the APO Productivity Database 2019, Ver. 2 (February 25, 2020). Access the data.

Employment growth in the economy as a whole tells only part of the story. For economic analysis, it is also necessary to account for the distribution of employment across economic activities, as this yields an understanding of the productive structure of an economy and eventually contributes to a more detailed analysis of the productivity dynamics. The structure of employment by activity, as illustrated in Figure 2.16, shows stark differences between the OECD and APO member economies. The most obvious difference is the much larger share of employment engaged in agriculture in APO economies. In the APO area, $44 \%$ of employment is devoted to agricultural production as compared with under $3 \%$ in the OECD, where the majority of labour is utilised in services $(76.2 \%)$ and the remainder in industry and construction (20.8\%). This share of employment in agriculture is far greater than the share of output accruing to agriculture, reflecting, in large part, subsistence farming. The APO Databook 2018 highlighted that less developed economies tend to have a larger agricultural sector as measured by the sector's share in total value added, finding a broad negative correlation between the value-added share of agriculture and GDP per capita (APO, 2018). 
Figure 2.16: Differences in economic structure in $A P O$ and $O E C D$ areas

Employment by activity, proportion in total activity, 2017

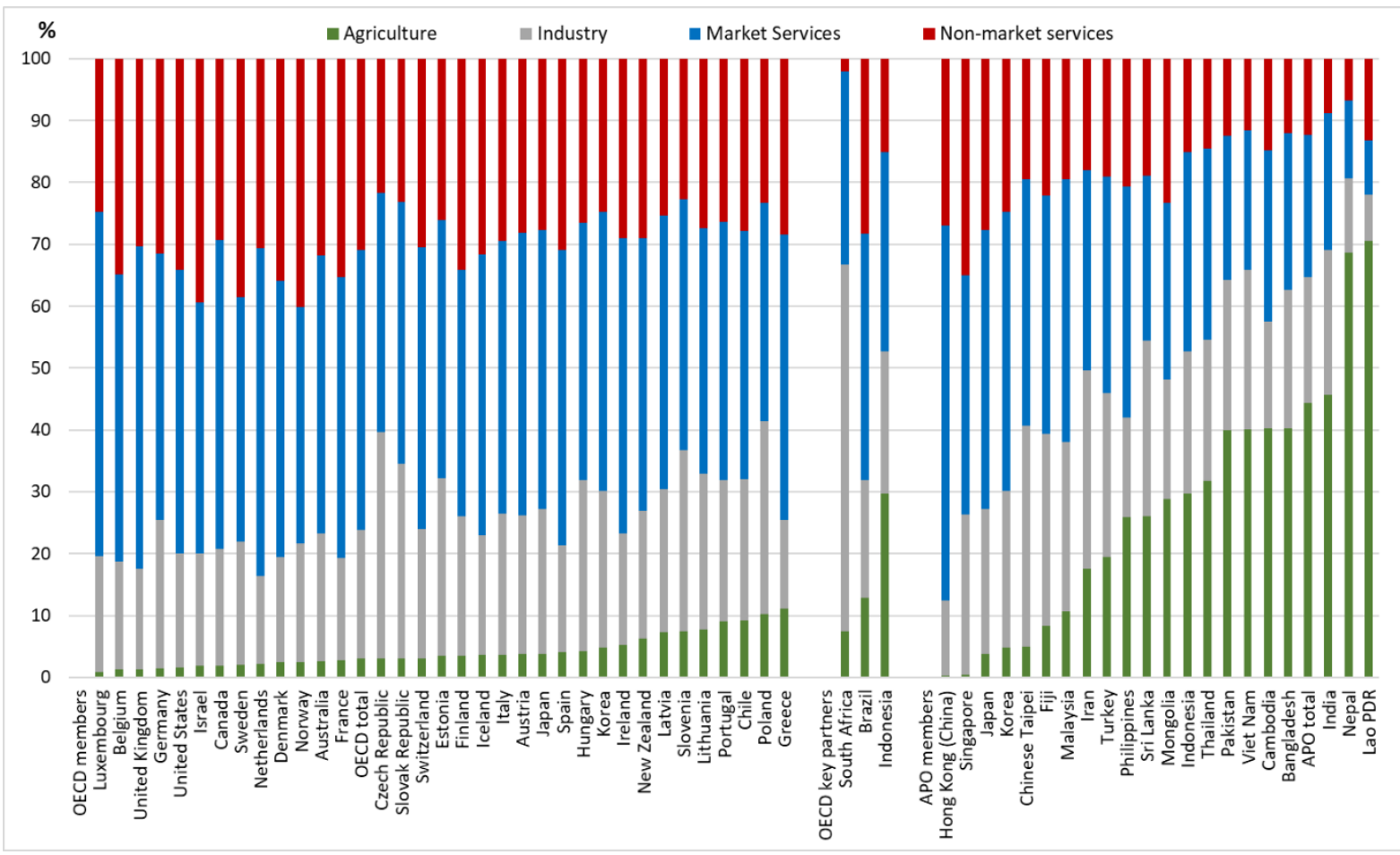

Source: OECD National Accounts Statistics (database), July 2020, and APO Productivity Database 2019, Ver.2 (February 25, 2020).

Note: Data for economies with membership in both international organisations (i.e. Japan, Korea and Turkey), and OECD Key Partner countries (i.e. India and Indonesia), are sourced from OECD National Accounts Statistics (database) when available, and when unavailable, from the APO Productivity Database 2019, Ver. 2 (February 25, 2020). Access the data.

The productive capacity of a country - i.e. the maximum possible output of an economy - depends on the effective allocation of the available resources. With regards to the labour input, this can be partly measured by the relative "utilisation" of the working age population, or the employment rate. Figure 2.17 shows employment rate varies across APO and OECD member economies. The employment share of the working age population was notably higher in the OECD as compared with the APO, at $75 \%$ and $61 \%$ respectively in 2017 . This disparity may be partially explained by challenges associated with measuring the non-observed workforce, but may also relate to cultural differences regarding female participation. Female participation is generally low in APO economies, ${ }^{7}$ but has been increasing over the past few decades (OECD, 2018a; OECD, 2019b; OECD, 2019c). Between 1995 and 2017 almost every $\mathrm{OECD}$ member experienced a rise in their employment rate, averaging an increase of 6.2 percentage points. Conversely, notwithstanding substantial increases in rates in countries such as

\footnotetext{
${ }^{7}$ The gender-pay gap in APO economies tends to be relatively high compared with the OECD average (Korea, for example, presents among the highest gaps in the OECD; OECD, 2018a), with women often more likely to be working part-time or informally. One of the key contributing factors to this gender-pay gap relates to women withdrawing entirely from the labour market after having children or returning in a reduced capacity, meaning women with children are less likely to achieve their full earning potential in the labour market (OECD, 2018a).
} 
Singapore (12.2 percentage points) and Japan (11.8 percentage points), the employment rate for the APO members fell ( -5.9 percentage points), largely driven by India, containing around half of the APO's population (Figure 2.7), which saw a fall of 8.6 percentage points over the period.

Figure 2.17: Employment rates in the $A P O$ and $O E C D$ areas

Employment as a share of the working age population (15-64), all persons, 1995 and 2017

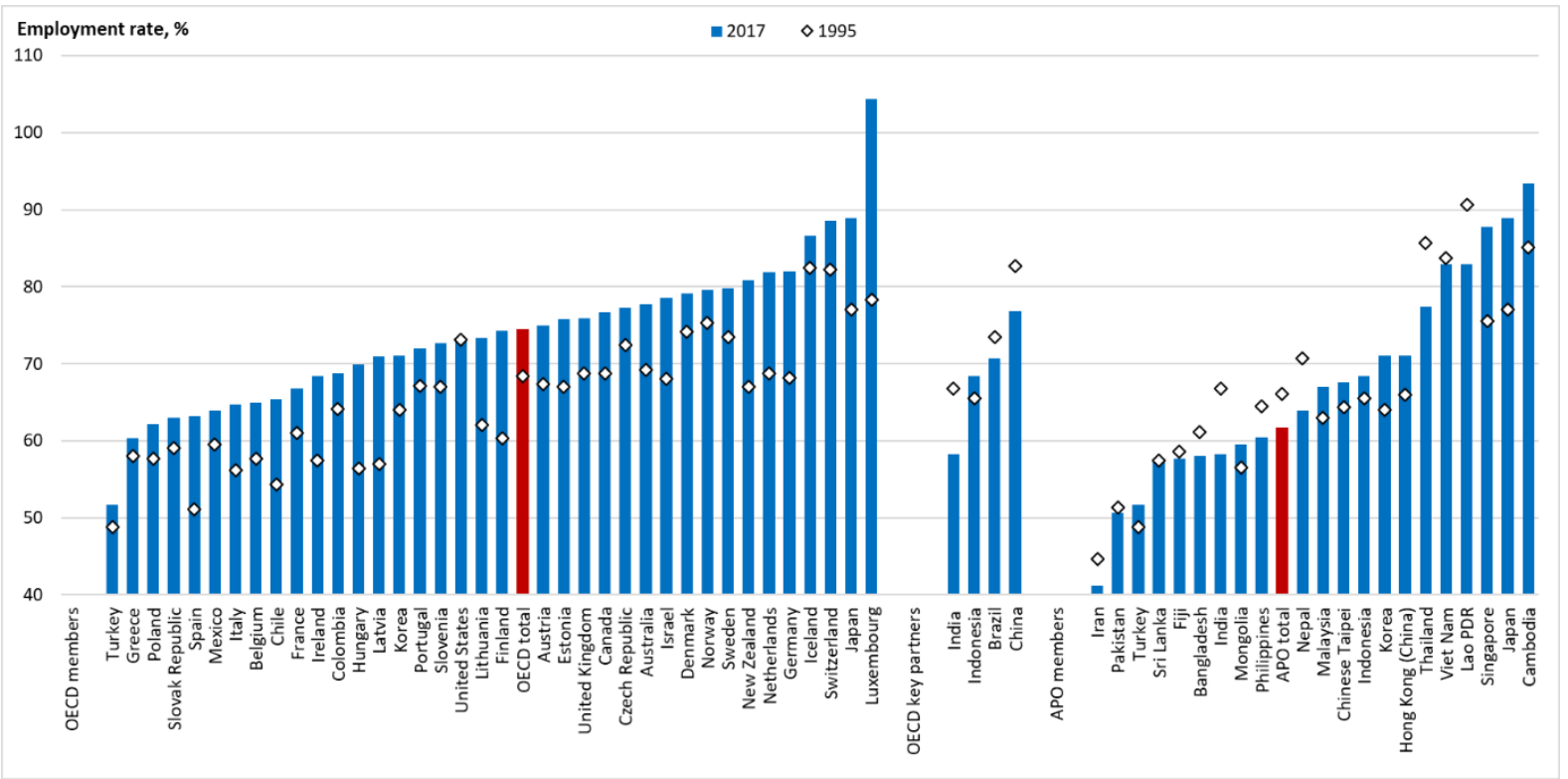

Source: OECD National Accounts Statistics (database), July 2020, and APO Productivity Database 2019, Ver.2 (February 25, 2020).

Note: Data for economies with membership in both international organisations (i.e. Japan, Korea and Turkey), and OECD Key partner countries (i.e. India and Indonesia), are sourced from OECD National Accounts Statistics (database) when available, and when unavailable, from the APO Productivity Database 2019, Ver. 2 (February 25, 2020). Access the data.

However, changes in the employment rate are only one of the drivers for changes in labour utilisation, which is typically better captured by hours worked per capita (the measurement of hours worked is discussed in detail in Section 3.a) (Figure 2.18). In the period following the crisis, shown in Panel (a), while the employment rate generally increased in the OECD there was a decline in the working age population for most countries, many of which experienced a demographic shift reflecting an ageing population. The challenges of an ageing population are projected to be compounded in the coming decades, with the ratio of individuals 65 and over to those of working age (28 per 100 of working age in 2015) expected to double by 2050 (OECD, 2017c). The pattern observed for the APO is more mixed, with a some economies experiencing growth in their working age population share, notably Bangladesh ( $0.73 \%$ annually) and Nepal (1.03\% annually), and others, such as Japan (-0.8\% annually) and Hong Kong, China (-0.44 annually), observing a reduction in the working age population. Overall, the APO saw a substantial decrease in average hours worked per person (-0.36\% annually), in line with the general trend of falling working hours in Asia and around the world. 
Figure 2.18: Evolution of labour utilisation in APO and OECD areas

Average annual growth in hours worked per capita, average hours worked per person, employment rates, and working age population, 2010-2017 and 2000-2010

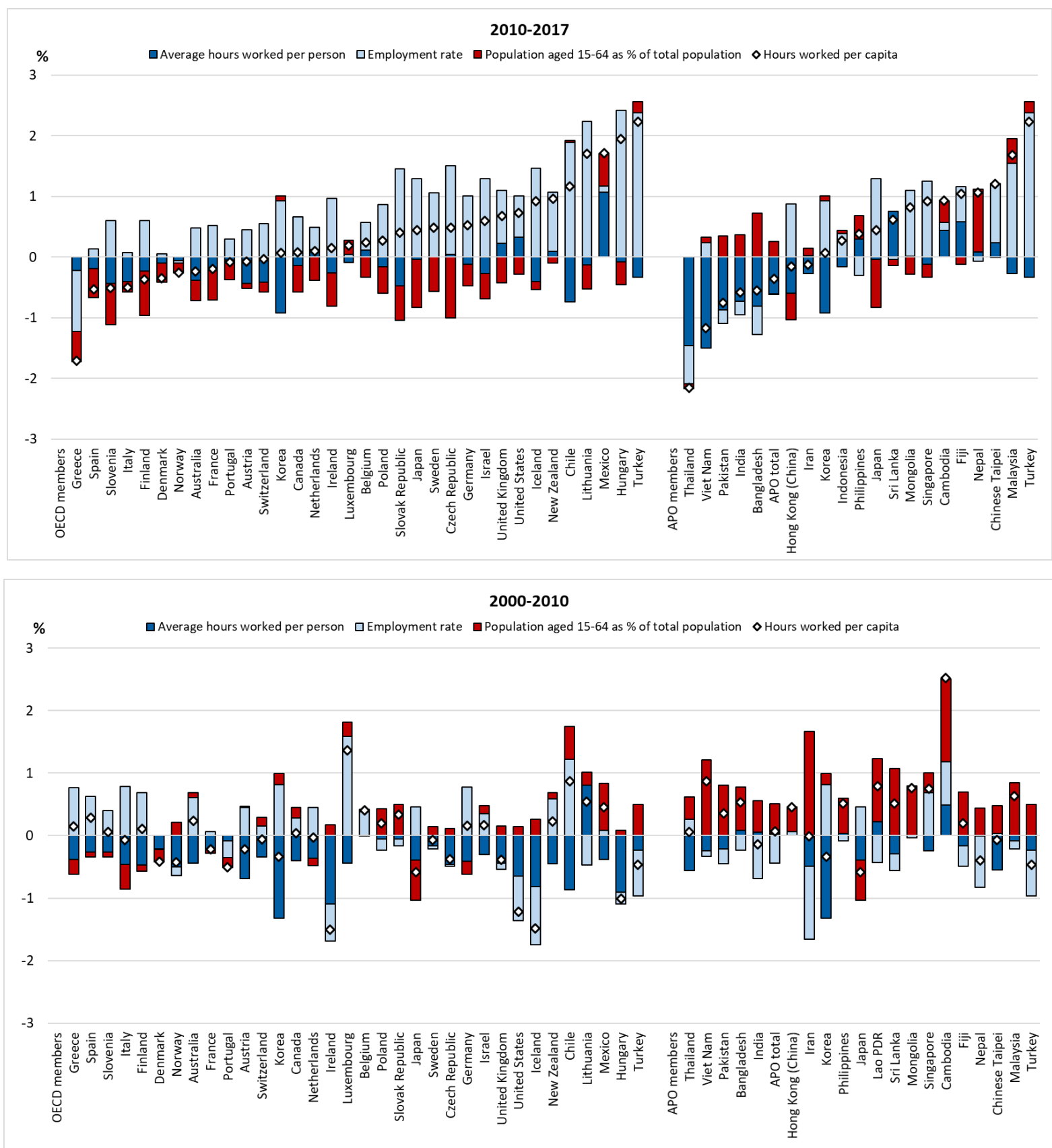

Source: OECD National Accounts Statistics (database), July 2020, and APO Productivity Database 2019, Ver.2 (February 25, 2020).

Note: Data for economies with membership in both international organisations (i.e. Japan, Korea and Turkey), and OECD Key Partner countries (i.e. India and Indonesia), are sourced from OECD National Accounts Statistics (database) when available, and when unavailable, from the APO Productivity Database 2019, Ver. 2 (February 25, 2020). Access the data. 


\section{c. GDP per capita and labour productivity measured as GDP per worker}

GDP per capita and GDP per worker constitute the most basic indicators used for productivity measurement. Levels of GDP per capita and GDP per worker show how much the average citizen or worker contributes to output, with their growth rates pointing to the improvement (or worsening) in economic performance through time. This allows the user to view GDP growth through an adjusted lens where the growth accruing to additional labour input can be accounted for separately. However, labour productivity only partially reflects the productivity of labour in terms of the personal capacities of workers or the intensity of their effort. The ratio between output and labour input also depends to a large degree on the presence of other inputs.

Both GDP per capita and GDP per worker utilise data that are widely available across both the OECD and APO member economies, making them relatively simple from a compilation perspective. However, they are far from perfect as they make broad assumptions regarding the proportion of the population engaged in the labour force and about the working time of those in employment.

\section{GDP per capita}

Evidently, the quality of measures of GDP per head of the population will be necessarily affected by the accuracy with which GDP and population are estimated, as highlighted in the previous subsections.

Despite some recognised shortcomings, GDP per capita is a core indicator of economic performance, commonly used as a broad measure of average living standards or economic well-being. From a compilation perspective, and from a cross-country comparison perspective, this indicator has its advantages, as it relies on two of the most commonly available and regularly updated indicators compiled by the NSOs worldwide. While it shares some characteristics with measures of labour productivity, and is also occasionally used as such, due to data constraints, it is a weak measure at best. Indeed, GDP per capita ignores changes in the employment rate of a country, changes in the share of the working-age population - disregarding the impact of population ageing - as well as changes in working time, working patterns and the composition of the labour force. Consequently, this indicator neglects changes in a country's population structure, labour market structure and labour policy, and captures only changes in births, deaths, migration patterns and, of course, value added.

Figure 2.19 presents GDP per capita levels converted to US dollars using purchasing power parities (PPPs). In 2017, GDP per capita averaged USD 43,300 in the OECD area and USD 11,500 on average for the APO members, i.e. $25 \%$ the OECD average level. The evidence also shows large disparities in GDP per capita levels across members within each of these areas. Within the OECD, Colombia's GDP per capita is only $34 \%$ of the OECD average, while Ireland's is $180 \%$ of the average. The disparities are even wider in the APO, with Nepal's GDP per capita equivalent to $25 \%$ of the APO average, and Hong Kong, China (527\%) and Singapore's (818\%) GDP per capita over five times and eight times the average respectively. As demonstrated in Figure 2.20, the APO economies have shown signs of catch-up between 1995 and 2017, with almost all of the APO members reporting an increase in GDP per capita of over $50 \%$ over the period, with less than half of OECD economies showing similar gains. 
Figure 2.19: GDP per capita in the APO and OECD areas

GDP in current prices and current PPPs, 2017

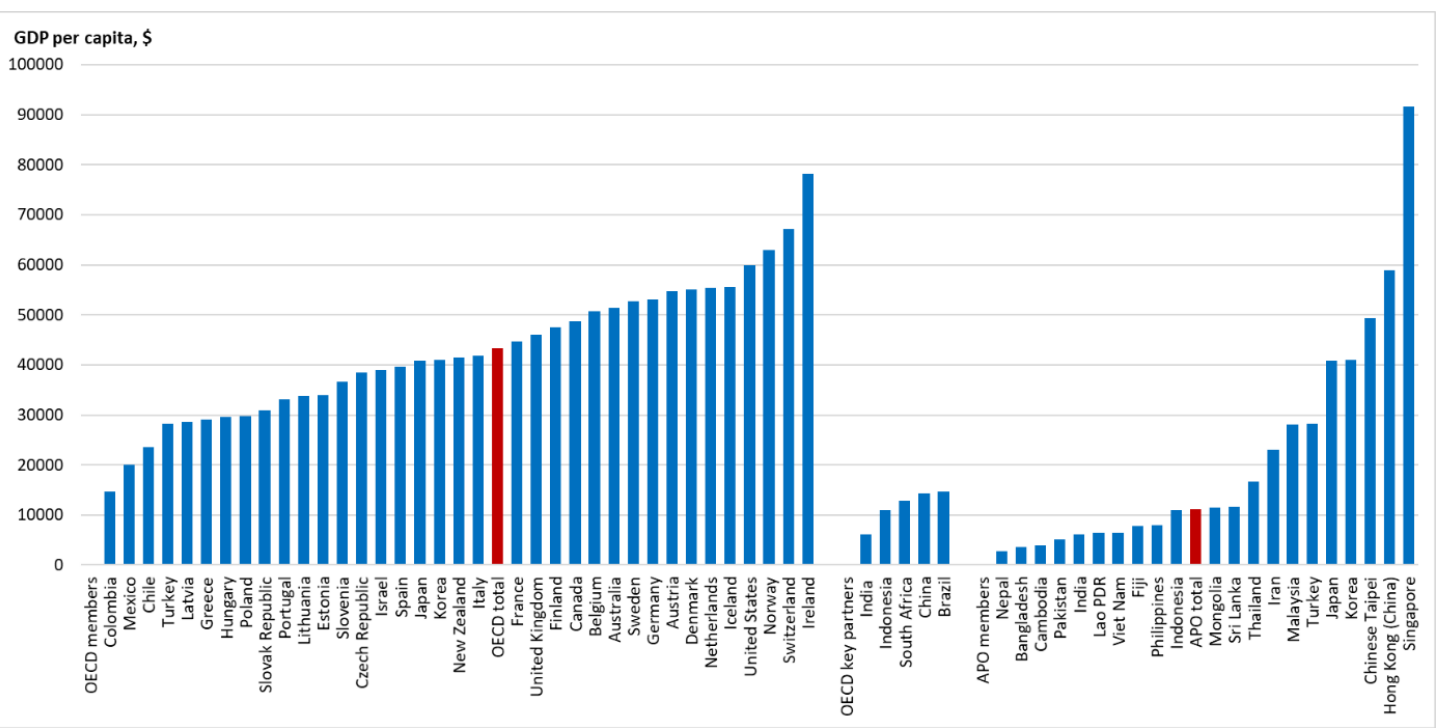

Source: OECD National Accounts Statistics (database), July 2020, and APO Productivity Database 2019, Ver.2 (February 25, 2020).

Note: Data for economies with membership in both international organisations (i.e. Japan, Korea and Turkey), and OECD Key partner countries (i.e. India and Indonesia), are sourced from OECD National Accounts Statistics (database) when available, and when unavailable, from the APO Productivity Database 2019, Ver. 2 (February 25, 2020). Access the data.

Figure 2.20: GDP per capita growth in the APO and OECD areas GDP in constant prices (2015), 2005 and 2017

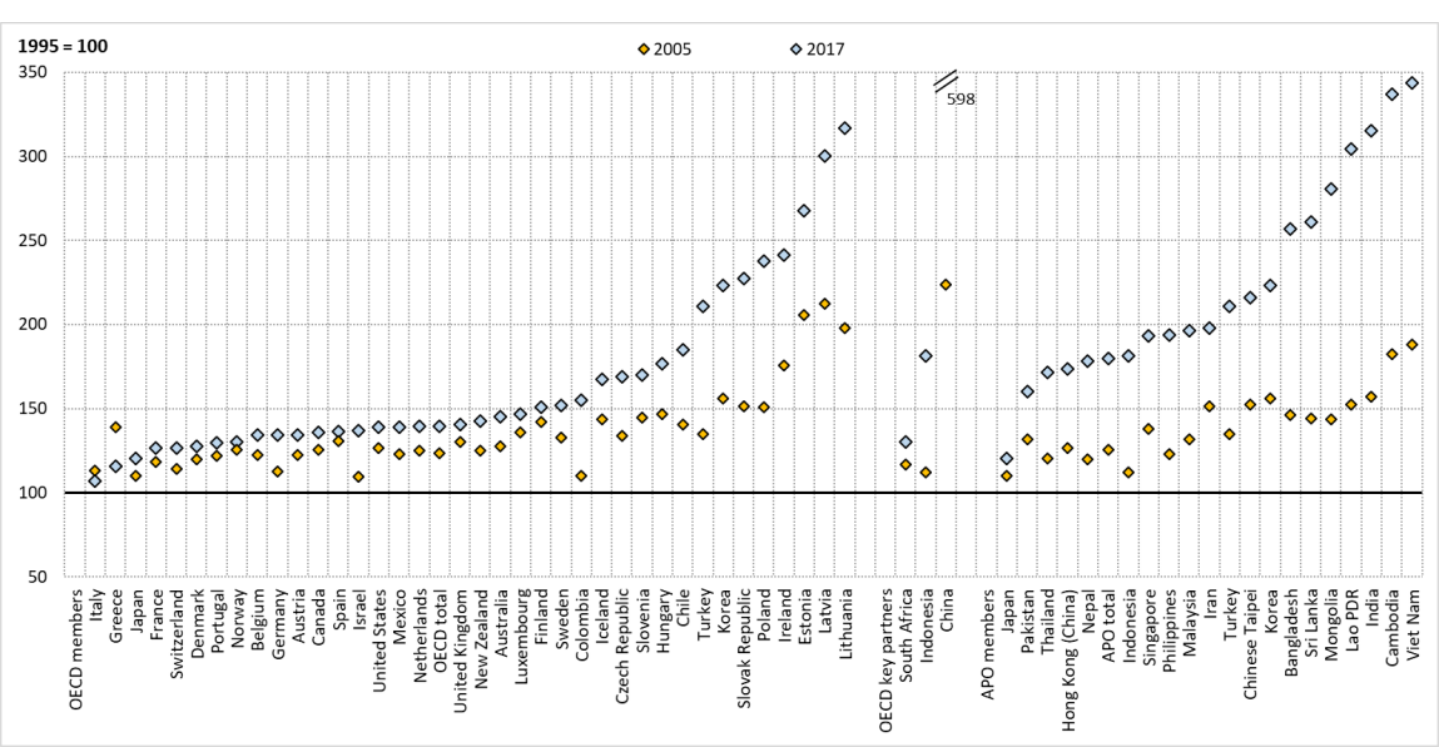

Source: OECD National Accounts Statistics (database), July 2020, and APO Productivity Database 2019, Ver.2 (February 25, 2020).

Note: Data for economies with membership in both international organisations (i.e. Japan, Korea and Turkey), and OECD Key Partner countries (i.e. India and Indonesia), are sourced from OECD National Accounts Statistics (database) when available, and when unavailable, from the APO Productivity Database 2019, Ver. 2 (February 25, 2020). Access the data. 


\section{GDP per worker}

Combining data on GDP and employment allows for the compilation of a measure of labour productivity: GDP per worker.

As with GDP per capita, GDP per worker is widely used to evaluate a country's economic performance, either when this is constructed as GDP per person employed, or as GDP per employee (i.e. excluding the self-employed from the denominator). The latter version is convenient in some cases, as it can be calculated using information from business surveys, which typically collect information only on employees. However, GDP per employee will present a skewed picture when comparing labour productivity levels across countries, as this will overstate labour productivity levels in countries with higher rates of self-employment. For comparisons of labour productivity developments over time (i.e. growth), using GDP per employee instead of GDP per person employed would have a more limited impact as long as the share of self-employed in total employment remains broadly stable.

The OECD multi-dimensional review for Thailand and the economic survey for Malaysia both target stronger productivity growth as key priority, and both measure labour productivity through GDP per employee (OECD, 2018c; OECD, 2019b). However, the APO Databook 2019 shows that the share of self-employed in Malaysia and Thailand were $24 \%$ and $47 \%$ respectively in 2017 , which, while below the APO average, are well above that for Japan (12\%) and Korea (19\%), as well as the OECD average (12\%). For both economies, the share of self-employed workers has decreased significantly since 1970 (from $42 \%$ in Malaysia and from $87 \%$ in Thailand), presenting significant challenges in the interpretation of GDP per employee measures over time.

Figures 2.21 and 2.22 highlight the differences between GDP per person employed and GDP per employee in levels and growth rates, respectively. The level of GDP per employee is, by definition, always greater than the level of GDP per person employed, but the difference depends entirely on the scale of self-employment in each country, which can differ markedly and is more prevalent in APO economies. The growth rates of GDP per person employed and GDP per employee paint a different picture, with trends through time differing substantially for the two measures and in different directions depending on the country. For example, as derived from the APO Productivity Database 2019, Cambodia experienced 4.9\% annual growth in GDP per person employed over the period 20112017, but a fall of 3.4\% annually in GDP per employee, thus indicating a decrease in the share of selfemployed workers in this country. Chile, instead, saw greater growth in GDP per employee (2.1\%) than GDP per person employed (1.0\%). 
Figure 2.21: GDP per person employed and GDP per employee in APO and OECD areas Current prices and current PPPS, 2017

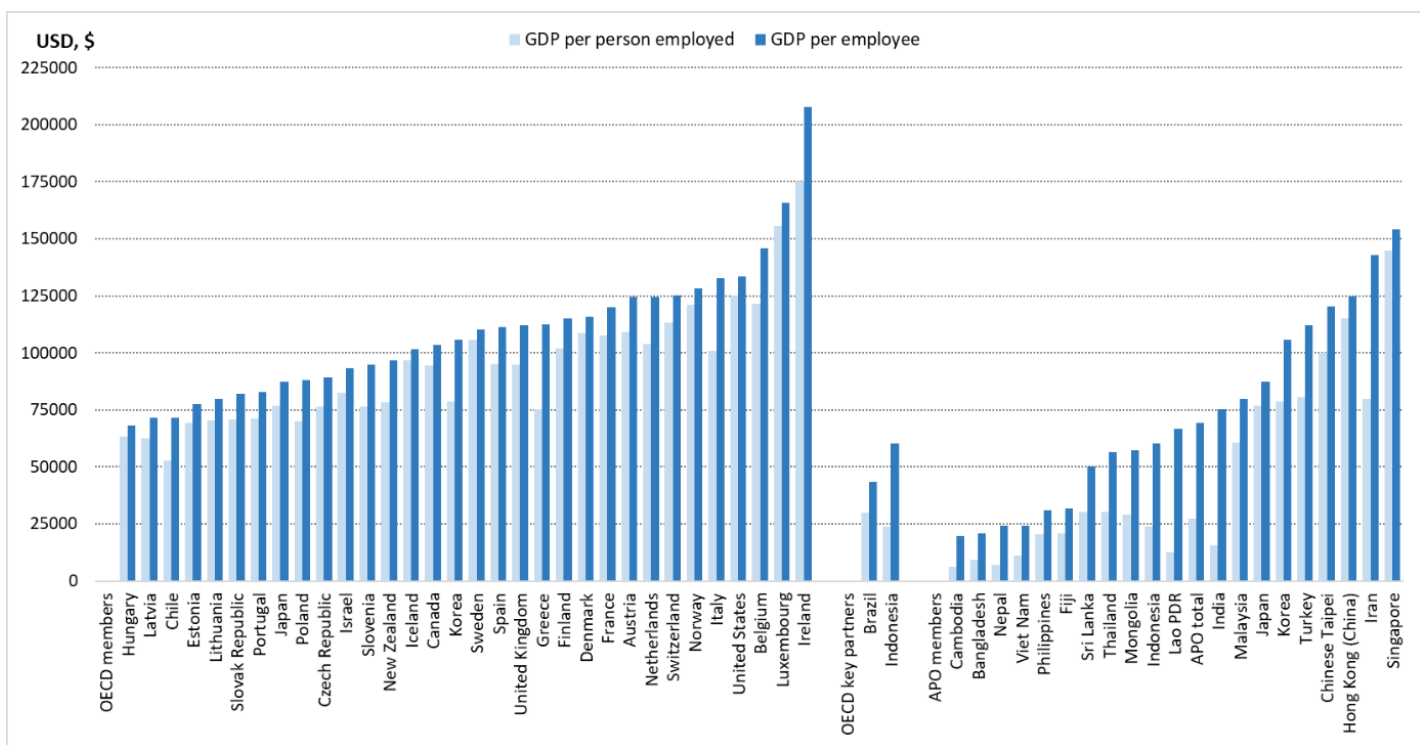

Source: OECD National Accounts Statistics (database), July 2020, and APO Productivity Database 2019, Ver.2 (February 25, 2020).

Note: Data for economies with membership in both international organisations (i.e. Japan, Korea and Turkey), and OECD Key Partner countries (i.e. India and Indonesia), are sourced from OECD National Accounts Statistics (database) when available, and when unavailable, from the APO Productivity Database 2019, Ver. 2 (February 25, 2020). Access the data.

Figure 2.22: GDP per person employed and GDP per employee growth in APO and OECD areas Constant prices (2015), 2011-2017

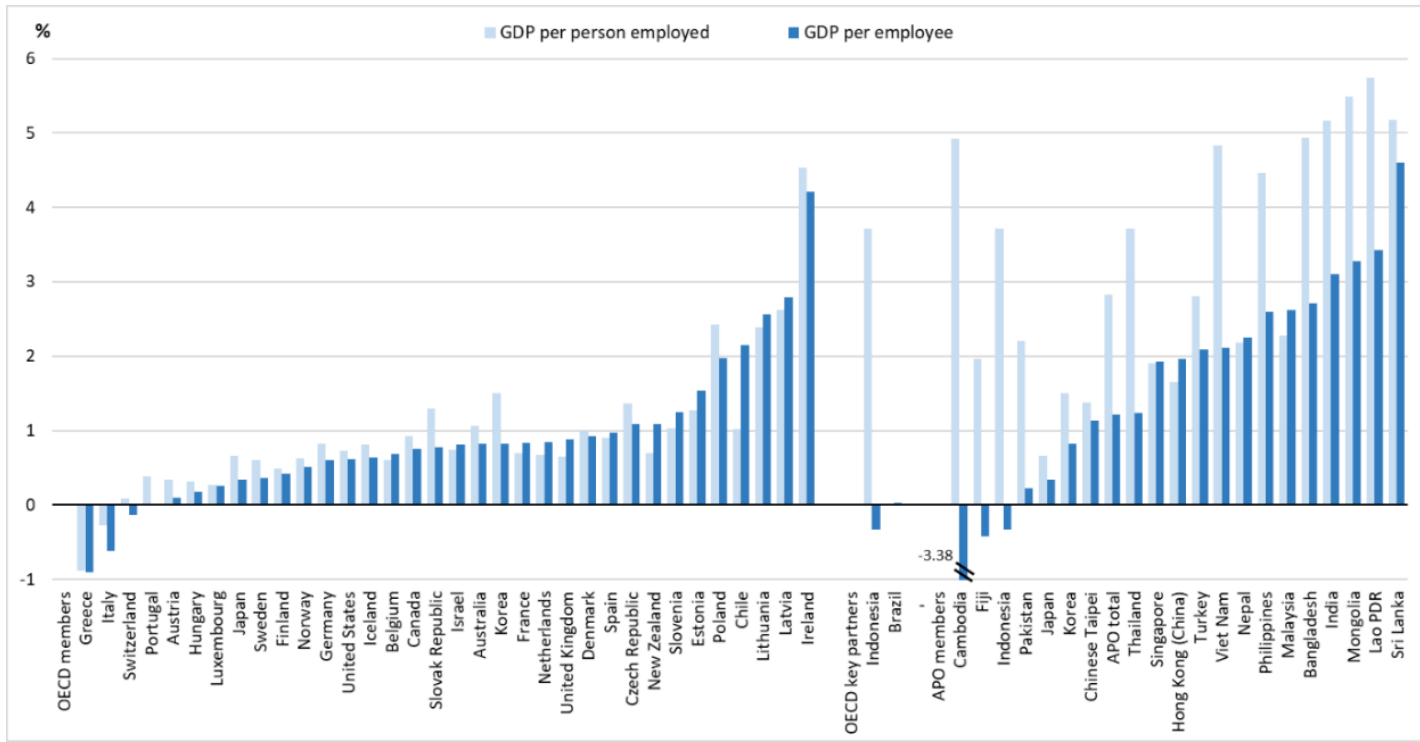

Source: OECD National Accounts Statistics (database), July 2020, and APO Productivity Database 2019, Ver.2 (February 25, 2020).

Note: Data for economies with membership in both international organisations (i.e. Japan, Korea and Turkey), and OECD Key Partner countries (i.e. India and Indonesia), are sourced from OECD National Accounts Statistics (database) when available, and when unavailable, from the APO Productivity Database 2019, Ver. 2 (February 25, 2020). Access the data. 
The labour productivity gap between the OECD and APO members persists when this is measured on a GDP per person employed basis instead of GDP per capita, as the average GDP per person employed level across APO members (USD 27,600, current PPPs) amounts to only $30 \%$ of the OECD average (USD 94,700, current PPPs) in 2017 (Figure 2.23). GDP per person employed grew substantially over the period 1995-2017 in most APO economies with India, by far, the largest APO economy, more than doubling its GDP per person employed levels over that period (Figure 2.24).

Figure 2.23: GDP per person employed in the APO and OECD areas

GDP in current prices and current PPPs, 2017

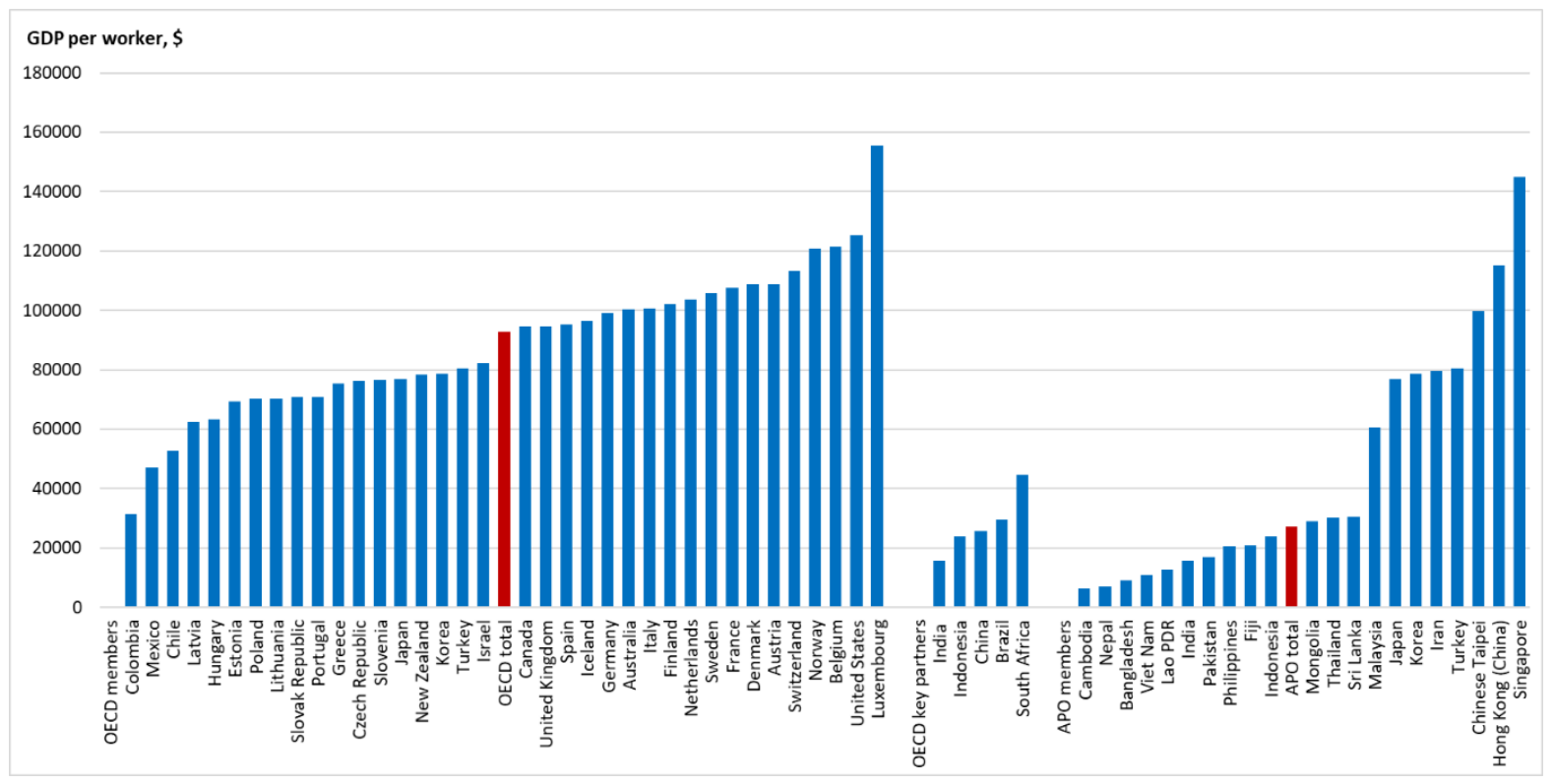

Source: OECD National Accounts Statistics (database), July 2020, and APO Productivity Database 2019, Ver.2 (February 25, 2020).

Note: Data for economies with membership in both international organisations (i.e. Japan, Korea and Turkey), and OECD Key Partner countries (i.e. India and Indonesia), are sourced from OECD National Accounts Statistics (database) when available, and when unavailable, from the APO Productivity Database 2019, Ver. 2 (February 25, 2020). Access the data. 
Figure 2.24: GDP per person employed growth in the APO and OECD areas

GDP in constant prices (2015), 2005 and 2017

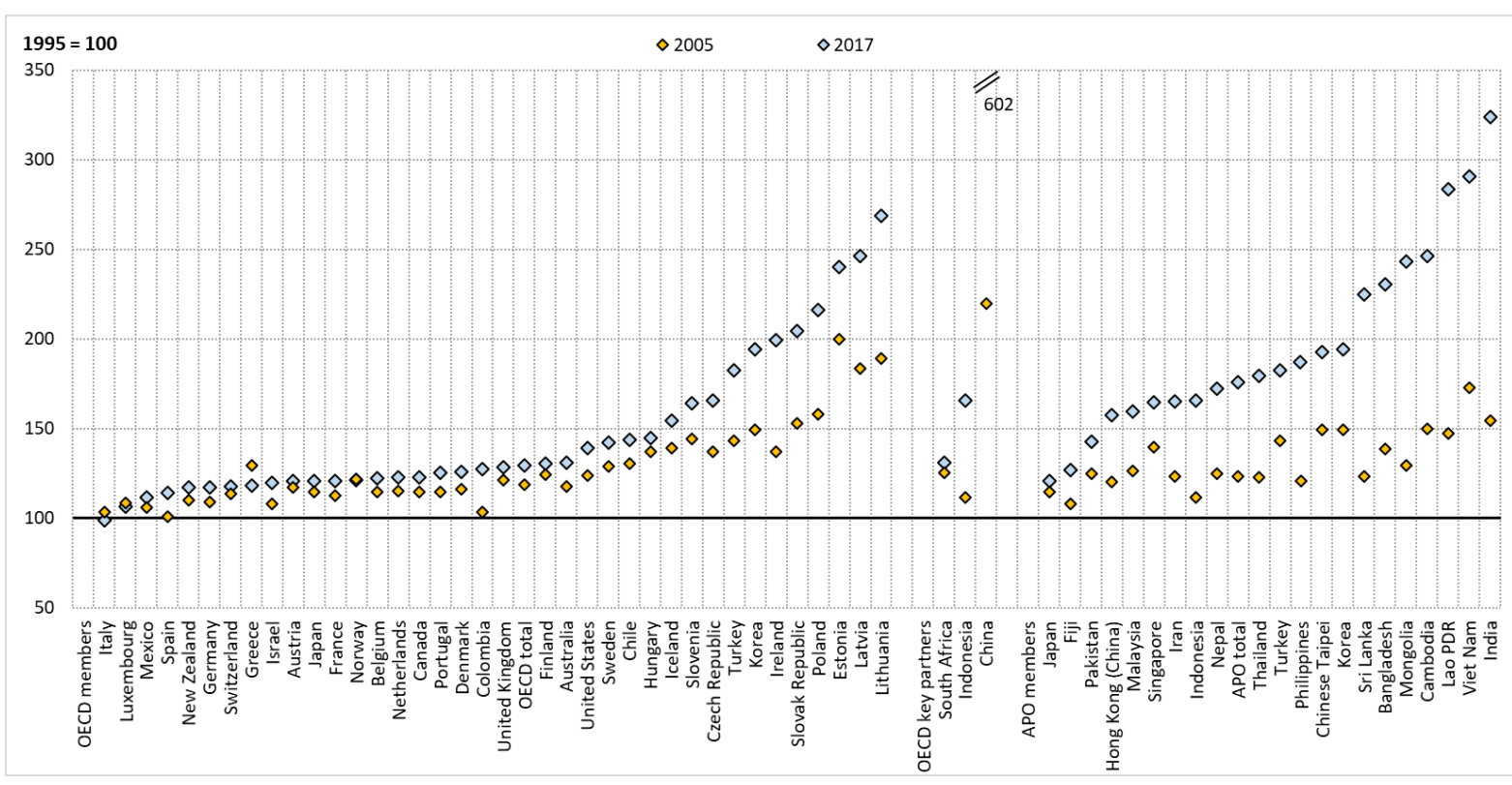

Source: OECD National Accounts Statistics (database), July 2020, and APO Productivity Database 2019, Ver.2 (February 25, 2020).

Note: Data for economies with membership in both international organisations (i.e. Japan, Korea and Turkey), and OECD Key Partner countries (i.e. India and Indonesia), are sourced from OECD National Accounts Statistics (database) when available, and when unavailable, from the APO Productivity Database 2019, Ver. 2 (February 25, 2020). Access the data.

\section{d. Statistical recommendations}

\section{KEY MEASUREMENT CHALLENGES STATISTICAL RECOMMENDATIONS}

\section{Measuring output}

All OECD and most APO member economies have implemented the 2008 SNA. However, at the time of writing this report, Nepal and Lao PDR have not yet made the transition from SNA 1993 to 2008 SNA (APO, 2019). This presents comparability issues across economies, as expenditures in R\&D and military weapon systems were capitalised for the first time in 2008 SNA.

The share of the Non Observed Economy (NOE) in GDP is highly variable across economies, but is likely very high in less-developed economies. Many economic policy questions critically depend on the measurement of the NOE, including: analyses of economic growth, employment and productivity; possible abuse of social insurance programmes; and erosion of tax revenues (Gyomai and van de Ven, 2014).

The last two decades have seen a dramatic increase in the use of information and communication technologies (ICT), but the lack of expected productivity gains has raised questions around the conceptual coverage of the digital economy in economic measurement. The two most significant challenges for NSOs are related to the coverage of all peer-to-peer transactions facilitated by online intermediaries in the corporate sector (e.g. AirBnB, eBay,
Given the known impact on GDP level of introducing the 2008 SNA (between 1 and 5 percentage points for OECD countries), and the commensurate effects on international comparisons of GDP and other aggregates, countries should faithfully and comprehensively implement the 2008 SNA if not done already.

Given the potential scale of the NOE, countries cannot afford to ignore its incidence in their measurement of output and value added. NSOs should exploit the full range of data at their disposal in order to estimate of the size of the NOE as accurately as possible. They are best placed to do so. Nevertheless, the APO could serve as a body to facilitate discussions between its member economies on best practices with regards to adjusting their output and productivity statistics for the non-observed economy.

While many of the peer-to-peer transactions brought on by digitalisation sit within the conceptual boundary of GDP, most compilation practices currently employed were designed to measure low-scale, relatively insignificant, sums, and may not be sufficiently robust to accurately measure them at a larger scale. However, these new intermediaries may contribute to their measurement, in that they can provide access to data related to these transactions (e.g. number of days per year an apartment is 
Uber, GoFundMe etc.) and to the measurement of price deflators for ICT products.

Some countries have not yet implemented a classification of economic activities in line with ISIC Rev.4 in their national accounts, instead still reporting on the basis of classifications that are in line with previous versions such as ISIC Rev.3. This brings important challenges for international comparisons and for the use and interpretation of data within the country. An important concern is that economic activities driven by and/or relying on the digitalisation of the economy might be obscured in older industrial classification standards. rented out via AirBnB and at what price). Wherever possible, countries should engage with these intermediaries, explore and eventually exploit any available data sources to capture these activities. Regarding the measurement of price deflators for ICT products, NSOs are encouraged to keep abreast of the statistical literature on the price measurement of ICT products and to compare their deflators with those used in OECD countries. Any significant difference in ICT price deflators across countries should be analysed with great care.

Countries should apply a classification of economic activities in line with ISIC Rev.4 in their presentation of data by activity. While the order of ISIC Rev.4 should be respected, it may be useful to tailor the level of detail reported to the structure of the specific economy in question (2008 SNA, para. 18.58). For example, in economies with a large subsistence economy, it may be useful to split agriculture into monetary and non-monetary production, meanwhile grouping together some of the service sectors that may be less important to the country (2008 SNA, para 18.59).

\section{Measuring population and employment}

A single primary data source can rarely provide a comprehensive measure of population or employment, consistent with the national accounts.

Many primary data sources used to measure employment, such as business surveys, do not cover the self-employed. In some countries, particularly developing ones, self-employed workers can make-up the majority of total employment, especially in agriculture.

Countries use different units of measure for employment, persons and/or job counts, in their national accounts. This may complicate cross-country comparisons of employment. Levels of jobs and persons will differ to the extent of multiple job holdings in a country and growth rates will differ as the propensity of the working population to hold multiple jobs changes through time.

Regardless of the primary data source used to measure employment, it is likely that some adjustments will be necessary in order to align with the national accounts. For many countries the necessary adjustments are significant, sometimes amounting to up to $10 \%$ of the data reported in the original main data source. This highlights the importance of measurement, with the adjustments applied playing a significant role in determining the final estimate.

Non-observed employment (i.e. illegal, informal, underground, household and statistically underground employment) is a major measurement and policy issue in many economies, especially in developing economies. For example, in India, around 8 out of 9 workers are in the non-observed economy.

Regardless of the type of data source used for the measurement of population and employment, the quality and the international comparability of the underlying data can represent significant challenges. For example, many countries rely largely on their
NSOs have access to many data sources, e.g. population census, labour force surveys, administrative data, business statistics, and should consult the full range to which they have access, weighing up the relative benefits of each to produce a representative and reliable estimate of total population and total employment in their national accounts and for the purposes of productivity measurement.

It is of the utmost importance for NSOs to capture the selfemployed in their measurement of employment. Labour force surveys, population census and some administrative sources include the self-employed and can be used to complement business surveys or other primary sources omitting these workers.

NSOs should be clear in their metadata with regards to the unit of measure used and analysts should be careful in their interpretation of cross-country comparisons of productivity indicators where the unit of measurement differs across countries.

In their compilation of total employment, NSOs should apply the full range of adjustments to align with national accounting standards. In doing so, they should ensure they have covered all persons working for resident economic units, including those not covered in the primary data source (typically, the self-employed, those in non-sampled institutions, and non-residents working in domestic institutional units) and excluding those working in nonresident units (e.g. resident persons who commute to work in a different country).

NSOs should exploit all available data, such as bespoke studies on non-observed employment and administrative sources, in order to add non-observed workers to their estimates. They should use a "Tabular approach", similar to that developed by Eurostat, wherever possible (Ahmad, 2004). An accurate accounting of the scale of non-observed employment can facilitate informed policy solutions, which can help to better serve and protect these workers. This is demonstrated in India, where the government has introduced more generous health and retirement insurance schemes for informal workers (OECD, 2019a).

It is the domain of each country's NSO to maintain robust data collection and processing procedures to ensure the consistency and quality of their surveys and available administrative data. With this aim, it is recommended that the NSOs adhere to international 
labour force survey (LFS) to measure employment, however, country's LFS can differ in the definitions of employment, sample sizes, sampling procedures and the coverage of geographic areas and/or activities. statistical standards in order to facilitate reliable cross-country comparisons.

\section{Measuring GDP per capita and per worker}

The quality of the input series (i.e. GDP, population and NSOs are in the best position to measure GDP and labour and are employment) will dictate the quality of the labour productivity measure, so due care and attention should be paid to the accurate measurement of output and labour input. encouraged to produce these estimates in line with the recommendations made above. They should also comply with international standards, specifically the UN Fundamental Principles of Official Statistics, usefully complemented by the Recommendation of the OECD Council on Good Statistical Practice (independence of NSOs, etc.). Analysts should be prudent when bringing together these data from multiple countries, noting and being transparent about cross-country differences in definitions and the quality of data sources.

GDP per capita is a weak measure of labour productivity as it ignores changes in the employment rate of a country, as well as changes in working time, working patterns and the composition of the labour force. Consequently, this indicator neglects changes in a country's population structure, labour market structure and labour policy, and captures only changes in births, deaths, migration patterns and, of course, value added.

GDP per employee is often used as a measure of labour productivity measure, especially when it is difficult to capture the self-employed. It may provide a very different picture to GDP per person employed, in terms of both levels and growth rates, and will present a non-comparable view for economies with different levels of self-employment.
GDP per capita is more appropriate as a measure of relative income levels across countries, accounting for the relative inequalities therein, and may only be used as a measure of labour productivity if no alternative is available. Analysts should approach this measure with caution and present it along with the relevant caveats for its interpretation.

NSOs should endeavour to include the self-employed in their measurement of labour productivity wherever possible, with GDP per person employed measures preferred to those of GDP per employee. Analysts should be careful in their interpretation of GDP per employee measures, especially in cross-country comparisons of economies with different incidence of self-employment. 
56 | P a g e 


\section{Intermediate productivity measures}

\section{a. Measuring labour: hours worked}

From the perspective of productivity measurement, ignoring the composition of the workforce for the moment, the most appropriate measure of labour input is the number of total hours actually worked by all persons employed (OECD, 2001; 2008 SNA, para. 19.47). The advantage of such a measure, as compared with population or employment, is that it captures variations in the incidence of part-time work, absences from work and shifts in normal working hours, and hence, bears a closer relation to the amount of productive services (labour input) actually provided by workers in the production of goods and services. This alleviates the lack of precision associated with the use of population measures for productivity measurement, which include those who are not in employment (i.e. unemployed, and children, retired, and others not looking for a job imprisoned etc.), and issues related to differences and changes in working patterns across countries over time, which are associated with the use of measures of persons employed.

The measurement of hours worked constitutes a major policy question, as these reflect variations in working time and related employment legislation. Figure 3.1 compares average hours worked per person across OECD member countries, OECD Key Partner countries and APO economies for the year 2017. Workers in Asian economies tend to work longer hours than the average worker in the OECD area, with the average APO country worker working 2066 hours per year, as compared to the average OECD country worker who works 1670 hours per year. All of the OECD economies have seen a reduction in average hours of work, with the OECD as a whole experiencing a fall of $5.3 \%$ between 2000 and 2017, as social trends and labour legislation have shortened the working day and driven towards a more equitable work-life balance (OECD, 2019c). While the APO also observed an overall fall in average hours worked of minus $2.1 \%$ between 2000 and 2017, the picture varies significantly across economies. Thailand and Korea ${ }^{8}$ both saw significant reductions, from a high base, constituting a $16.4 \%$ and $16.2 \%$ fall, respectively. However, the relatively small APO economies of Cambodia, Lao PDR and Fiji observed increases in average hours ranging from $3 \%$ to $8 \%$, with some larger economies like India and Indonesia reporting smaller increases of around $2 \%$. In the case of Japan (1680 annual hours), the role played by socio-institutional context has been highlighted, with social norms and overwork culture, rather than public policy and legislation, appearing as the root cause of long working hours (Ono, 2018). The OECD has recommended strict enforcement of the new 360 hour annual limit on overtime in order to improve work-life balance and workers wellbeing in Japan (OECD, 2019c).

${ }^{8}$ Between 2004 and 2011 the standard working week was reduced from 44 to 40 hours, contributing to this fall. More recently, the Korean government has targeted a reduction in annual hours of work to 1800 through a reduction of the statutory limit on weekly working hours from 68 to 52 (OECD, 2018a). 
Figure 3.1: Average annual hours worked per person in the APO and OECD areas 2000 and 2017

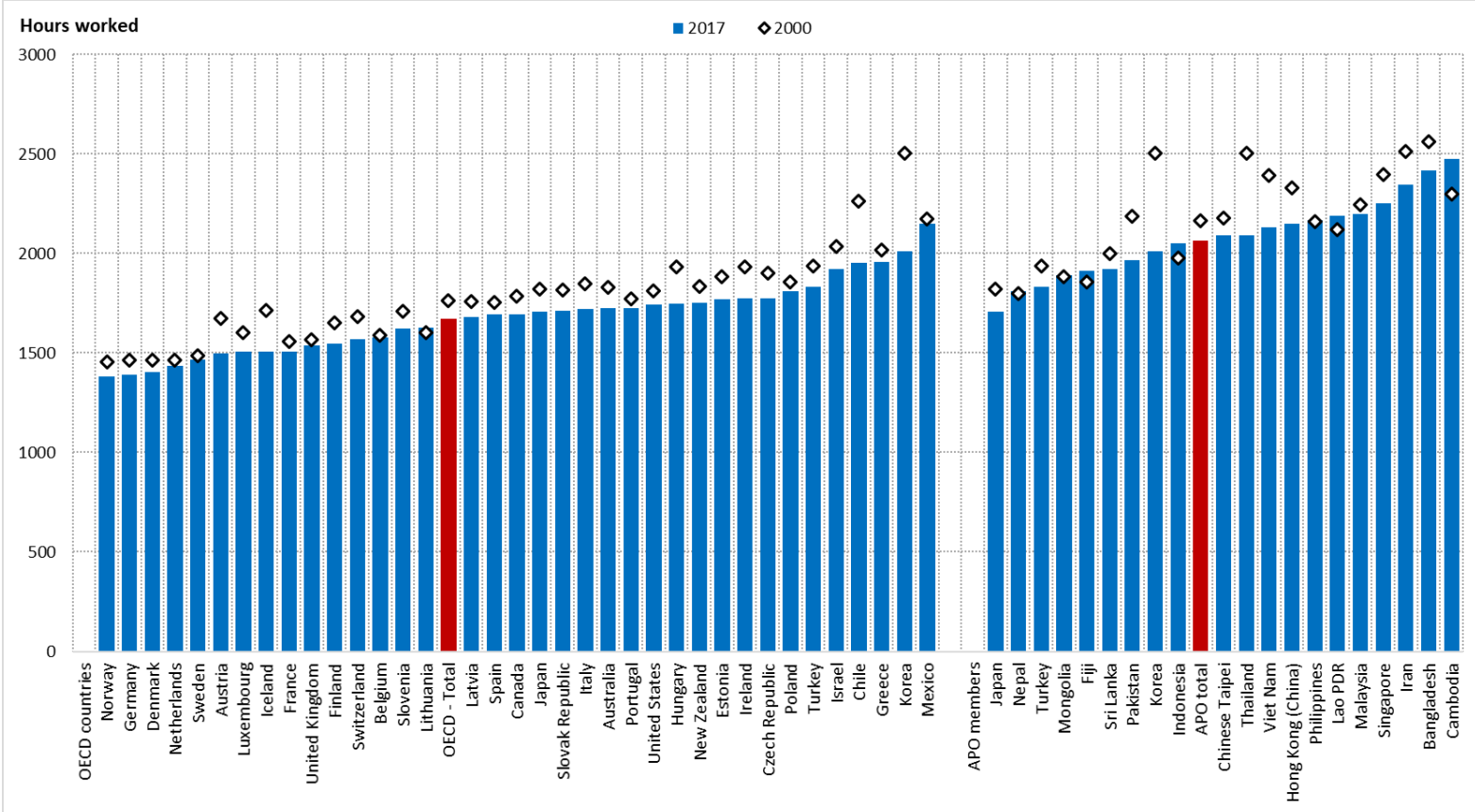

Source: OECD Productivity Statistics (database), January 2021, and APO Productivity Database 2019, Ver.2 (February 25, 2020).

Note: Data for economies with membership in both international organisations (i.e. Japan, Korea and Turkey), and OECD Key Partner countries (i.e. India and Indonesia), are sourced from OECD National Accounts Statistics (database) when available, and when unavailable, from the APO Productivity Database 2019, Ver. 2 (February 25, 2020). For Austria, Estonia, Finland, Greece, Latvia, Lithuania, Poland, Portugal, Sweden and the United Kingdom, average actual hours worked data calculated in country's national accounts are replaced with estimates produced at the OECD using the OECD simplified component method, which relies on the EU-LFS and complementary sources. This reflects conclusions from the OECD Statistics Working Paper International Productivity Gaps: Are Labour Input Measures Comparable?, which shows that the use of a direct method for the estimation of average hours worked creates systematic upwards bias, weighing down on productivity levels please refer to the paper itself for a more detailed account. Access the data.

Although these differences in average hours worked per person reflect, in part, real structural differences across countries, the results from the 2018 Eurostat/OECD survey on the measurement of labour input suggest that the sources and methods used to measure hours worked can play a substantial role and may introduce an important bias into international comparisons of labour productivity (Ward et al., 2018).

\section{Defining hours worked}

The International Labour Organisation (ILO, 2008) and the 2008 SNA define total hours actually worked as follows:

- hours spent directly on carrying out the tasks and duties of a job regardless of the amount of working time agreed contractually between employers and employees; 
- hours spent in activities in relation to them, including maintenance time, cleaning time, training time, waiting time, time spent on call duty, travelling time between work locations;

- time spent in between these hours when the person continues to be available for work, which includes periods where a person cannot work for reasons that are either inherent to the job or due to temporary interruptions; and

- short resting time.

Conversely, hours actually worked exclude:

- all types of leave (annual, public holidays, sick leave, maternity and parental leave, etc.);

- longer breaks from work (e.g. meal breaks);

- commuting time when no productive activity is performed;

- educational activities other than on-the-job training time.

The evidence collected in the 2018 Eurostat/OECD survey on the measurement of labour input indicates that all OECD countries produce hours worked for the whole economy, and most of them do so for a subset of industries (normally one-digit or partial two-digit industry breakdown, according to national industrial classifications) (Ward et al., 2018). While Japan compiled national accounts data on hours worked by employees, at the time of the survey they did not generate similar figures for the self-employed. The majority of non-OECD countries that participated in the survey also produced hours worked data for the whole economy in the national accounts framework (e.g. Bulgaria, Croatia, Cyprus, Malta, Peru, Romania, Russian Federation and South Africa), with the exception of Argentina, Brazil and Costa Rica.

\section{Data sources used compile hours worked measures}

Similarly to employment, countries compile hours actually worked as part of their national accounts using data from household surveys, establishment surveys, administrative records, or some combination of the three (Ward et al., 2018). Figure 3.2 shows the main and secondary/supplementary sources used by countries to compile hours worked by employees and the self-employed. The most commonly used main source by countries for hours worked compilation is the LFS, particularly for hours worked by the self-employed. Business sources are the next most frequently used main source, especially for employees, as these sources often contain records of hours paid or contractual hours for those workers in the payroll. Administrative sources, i.e. data collected not for the purpose of statistics but instead for some separate administrative reason such as tax registration or social security records, are the most frequently used secondary source for both employees and the self-employed, partly reflecting the fact that hours worked in activities or by persons not included in the main source, such as armed forces personal, are often recorded in administrative databases. 
Figure 3.2: Sources used for hours worked estimates

The sources used by countries, main original sources and other sources, to construct estimates

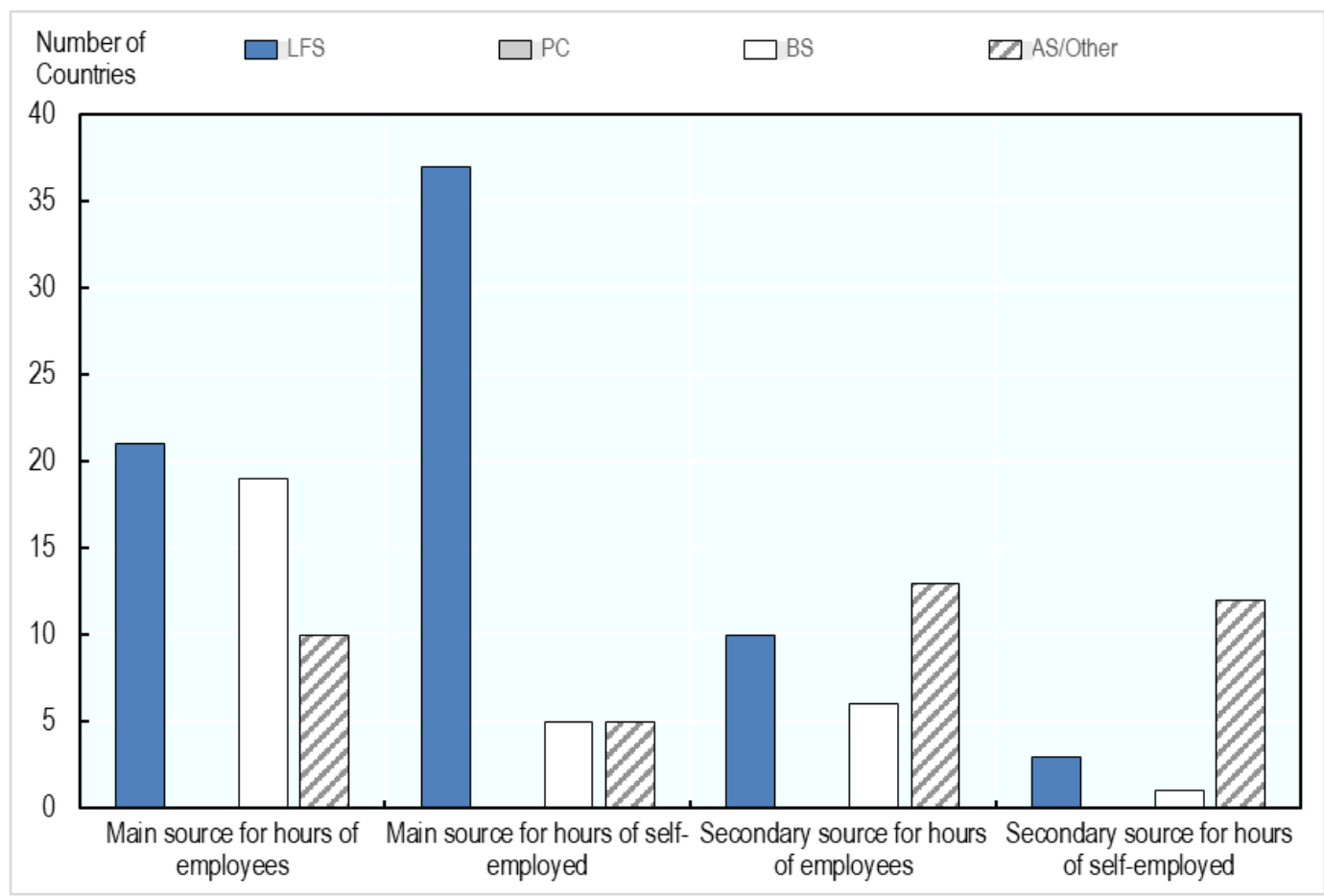

Source: Ward et al. (2018).

Notes: LFS refers to Labour Force Surveys, PC refers to Population Census, BS refers to Business Statistics and AS refers to Administrative Sources. Other sources can include academic studies, time-use surveys and other household surveys, among others. Access the data.

In practice, countries adopt one of two methods to estimate average hours worked for productivity estimates. One of these methods is commonly known as the direct method, which takes actual hours worked reported by respondents in surveys, generally the LFS. The second is typically referred as the component method, which starts from contractual, paid or usual hours per week from establishment surveys, administrative sources or, indeed, the LFS, and introduces adjustments for absences, overtime and other adjustments that are necessary to align with the concept of output in the national accounts. While the direct method has major practical advantages in that it (typically) uses a singular data source and simple calculations, estimates of working time derived directly from the LFS often require adjustments for over-reporting of hours worked (compared with hours worked reported in time use surveys), in particular for those working long hours, like managers and professionals, but also because respondents are likely to underestimate absences from work due to public holidays and annual leave. Accordingly, and to facilitate an accurate application of working time definitions by data producers, LFS also collects responses for usual hours worked, as well as for absences and overtime though these data can also be subject to the same brand of self-reporting bias as hours actually worked. It is for that reason, among others, that establishment surveys and administrative sources have a certain appeal, as information on working time from these data sources generally correspond to hours paid or contractual hours, which then need to be adjusted to account for hours paid but not worked (i.e. absences due to holiday or sickness) and for hours worked but not paid (i.e. unpaid overtime). See Box 2.2 for a comprehensive overview of the types of data sources used to construct hours worked. 


\section{Adjustments made to align with the national accounts}

Whichever the choice of original data source and the resulting working-time concept, adjustments remain necessary to align the latter with the national accounts definitions and maintain internal consistency with national accounts output and employment estimates. To calculate a measure of total hours actually worked, NSOs combine information on average hours worked per person and total employment. The measurement of average hours worked should then correspond directly to those persons or jobs included in the previously defined measure of employment. As such, despite the deficiencies of the employment metrics alone for productivity measurement, this is an essential component in the calculation of labour input for productivity analysis.

The approach of the data producer and the modifications to be made to the source data will necessarily depend on the original data source chosen. Adjustments to align with the concept of actual hours worked in national accounts and to maintain consistency with employment estimates most often include the following:

- passing from hours per job to hours per person, or vice versa, which is necessary wherever the unit used in source data for hours worked differs from the unit used in employment estimates;

- the subtraction of annual leave and holidays, which is essential when departing from a measure of usual or paid hours where these hours are included but not worked;

- the subtraction of sickness leave, again crucial when using usual or paid hours as a starting point;

- the subtraction of hours for strikes or temporary lay-offs;

- the addition of overtime, whether paid or unpaid, where this is not included in the reported usual or paid hours;

- adjustments for under or over-reporting, which are particularly important for estimates of hours worked extracted from LFS;

- and the addition of hours worked for those in the non-observed economy (i.e. accounting for the hours worked by those non-observed workers included in national accounts employment estimates).

In practice, countries differ in their approach to, and comprehensive coverage of, adjustments made to hours worked (Ward et al. 2018). The majority of the 36 countries covered in the 2018 Eurostat/OECD survey on the measurement of labour input reported making some adjustment to the hours worked obtained from the original source. There were however six countries that made no adjustment to hours worked sourced from the primary data sources, those being Chile, Ireland, Lithuania, New Zealand and the United Kingdom for both employee and self-employed; and Israel for the self-employed only.

Adjustments for absences (i.e. holidays, annual leave and sickness) were found to be applied by all countries that begin with a measure of paid, contractual or usual hours, and by a few that extract actual hours from their original source. These working time components constitute the second most important factor, after usual/normal hours, in explaining differences in actual working time (Figure 3.1). Adjustments for the hours worked in the unobserved economy are also very common, with most countries that use business or administrative sources making such adjustments. Most countries that 
do not adjust for hours worked by the non-observed workers use the LFS as their main source and assume that either the LFS accurately captures these workers, or that the hours worked by such workers are not considerably different from those in the observed economy. In practice, while LFS are declared to be confidential, the results are likely to suffer from under-reporting of hours worked on non-observed activities, and so these assumptions may be deemed weak. Adjustments for under and/or over-reporting, notably with respect to under-reporting by the self-employed, are applied in Bulgaria, Colombia, Italy, Luxembourg and Norway, which apply the component method, and in the United States (for employees only).

Other adjustments specific to countries and data sources are widespread across countries independently of the method and source(s) used and can vary substantially in nature. These include, among others: adjustments to fit hours worked by industry to total economy figures; inclusion of hours worked by groups of workers excluded from the original main source(s) such as farmers, loggers and military personnel; addition of hours worked in secondary jobs; and adjustments for the underestimation of domestic paid housework.

Figure 3.3 presents, as an example, the scale of adjustments that France and Germany make in order to align their source data with the definition of actual hours worked and with the national accounts production boundary. France and Germany are ideal case studies as they each have a long standing measurement framework, employing multiple data sources and applying a full range of adjustments, serving as an example for APO economies (Eurostat, 2018b; Eurostat, 2018c). Downward adjustments for annual leave, holidays and leave due to sickness clearly constitute the most important adjustments made by both countries, with much smaller upward adjustments for other components. The overall impact of these adjustments was $-18.8 \%$ of total hours worked for France and $-12.4 \%$ of average annual hours worked for Germany. If a country were to measure total hours using usual or paid hours, without adjustment, they would be introducing a significant upward bias into their hours worked indicators and a downward bias in their measurement of output per hour. 
Figure 3.3: Adjustments made to estimates of employees hours worked

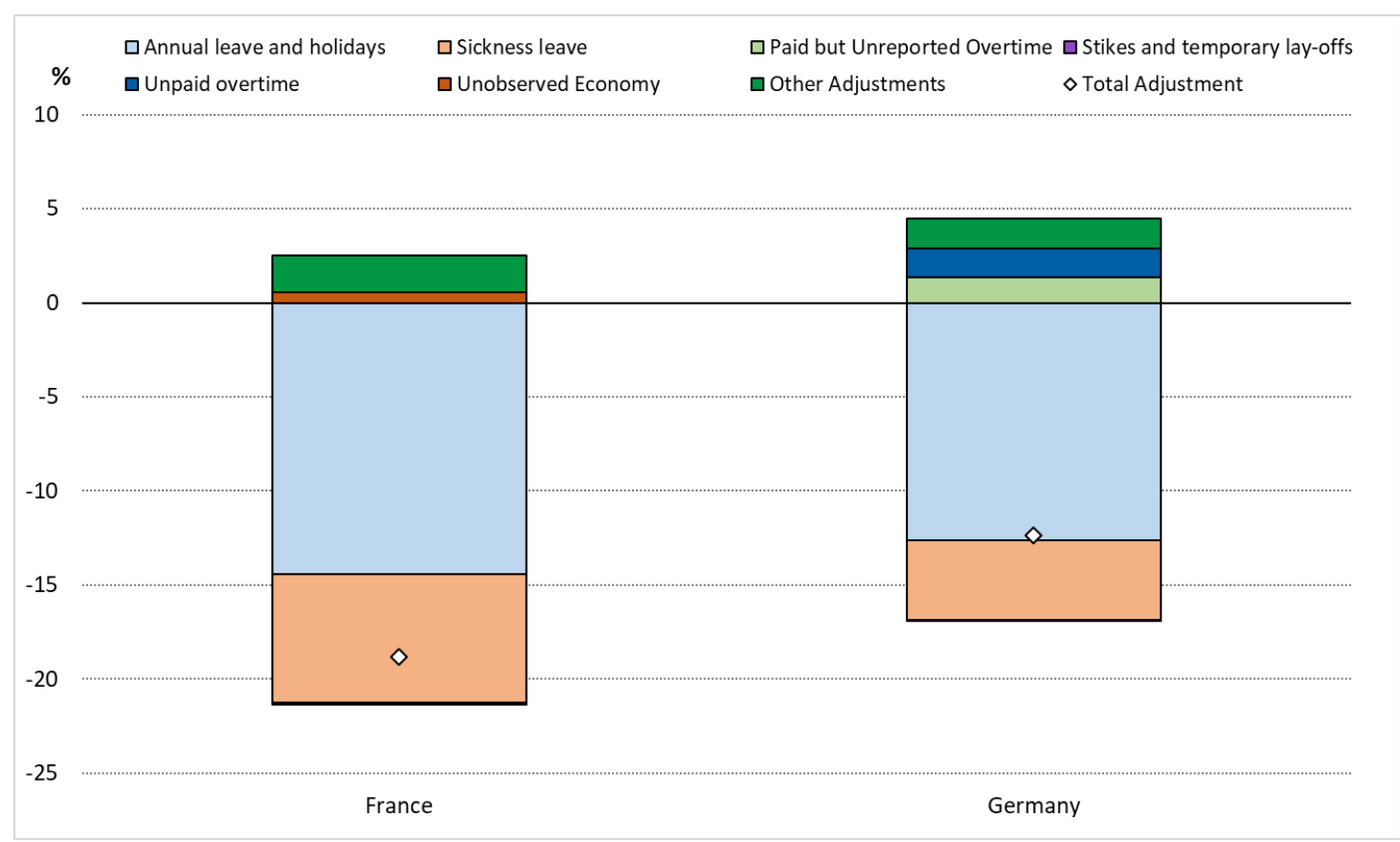

Source: Data from the 2018 Eurostat/OECD survey on labour input measurement, with author calculations.

Note: Data for France refer to adjustments to total hours worked, whereas data for Germany refer to adjustments to average annual hours worked. Access the data.

Direct vs. component method for the estimation of hours worked: What does it change in practice?

The use of different methods for the calculation of actual hours worked can yield marked differences in results. In practice, most countries adopt one of the two methods described above to estimate average hours worked for productivity analysis: the direct method or the component method.

The direct method has some advantages in that it generally uses a single data source, and if using the LFS can draw directly on responses for actual hours worked. However, as previously discussed, the LFS has its own drawbacks, particularly as it regards over-reporting of hours worked and under-reporting of absences. The component method presents a more accurate picture to the extent that a given approach is able to properly adjust for the components of working time and for national accounts concepts.

Ward et al. (2018) provided strong evidence that response bias and a lack of exhaustive adjustments to align with the national accounts production boundary, lead to a systematic upwards bias in the estimates obtained with the direct method as compared with those resulting from a "simplified" component approach. ${ }^{9}$ Direct method estimates are systematically higher than estimates compiled using a simplified component method for the same country. Figure 3.4 presents national accounts

\footnotetext{
${ }^{9}$ The authors referred to this as a "simplified" component method as they use LFS data available to them and statutory leave entitlements and public holidays, rather than actual leave taken. This "simplified" component method is very much a second best to national efforts making use of all available data sources to align with the national accounts and to address reporting bias.
} 
estimates of average hours worked per person across countries adopting different methods in their calculation. Countries using a direct method end up with average hours worked estimates that are substantially higher than those countries adopting a component method. The OECD simplified component method calculation for these countries, using the LFS as a single source, indicates that estimates of hours worked would be far lower if the component method were to be adopted by those countries.

Figure 3.4: Average hours worked per person in 2016, methods comparisons

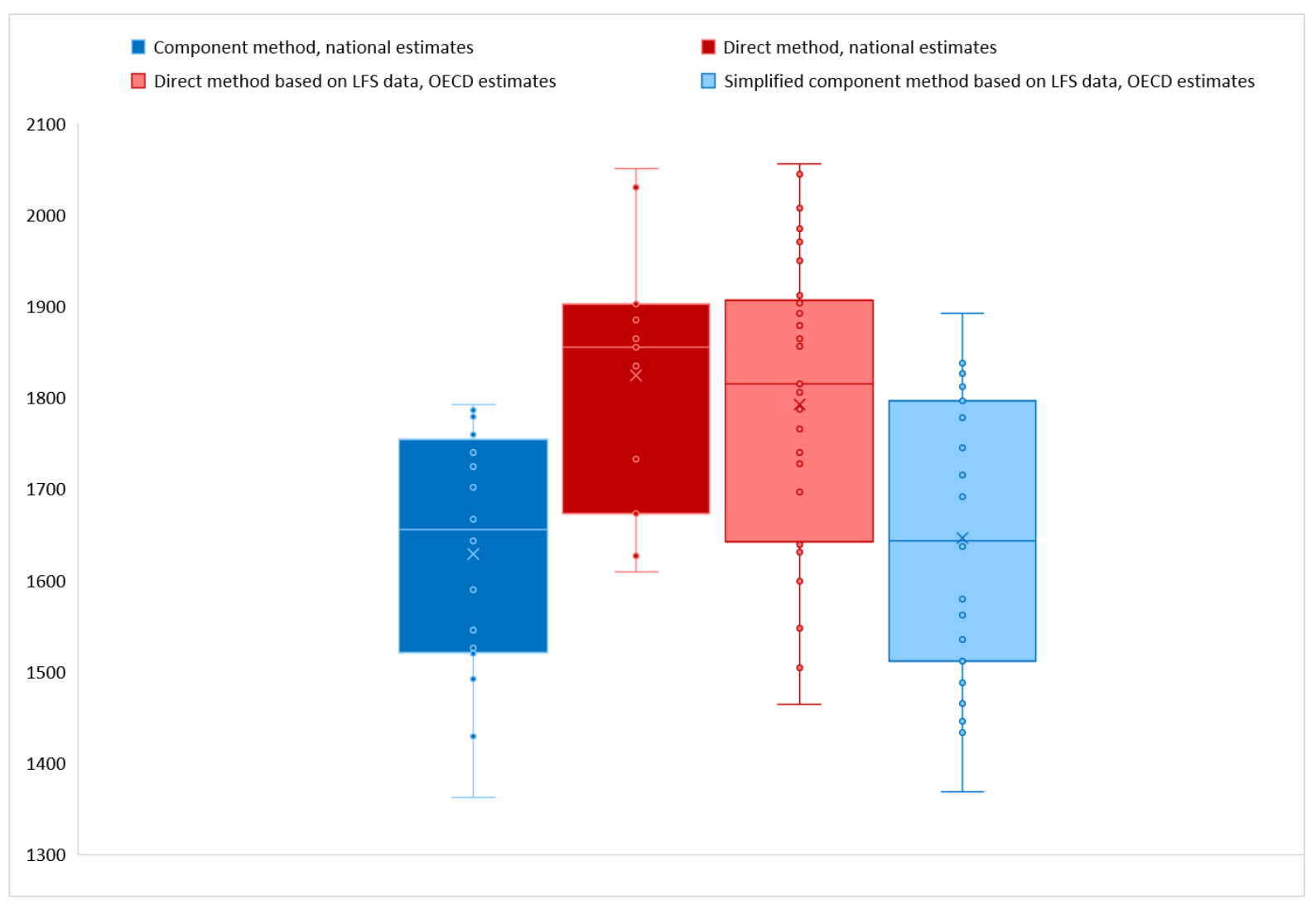

Source: Authors' calculations based on Ward et al. (2018).

Note: Access the data.

\section{b. Labour productivity measured as GDP per hour worked}

Output per hour is calculated as GDP divided by total hours worked, which is derived from average hours worked per worker and total employment. Therefore, the quality of hours worked data, both in terms of consistency with national accounts and comparability across countries - driven by the aforementioned differences in data sources and methods utilised - as well as the accuracy of employment estimates, dictates the quality of output per hour comparisons. Changes in these measures are, of course, affected by changes in output or labour input, but can also be affected by shifts in capital input or the composition of the workforce.

Figure 3.5 presents productivity levels in output per hour terms from the OECD and APO productivity databases. Labour productivity levels in 2017 varied widely across the OECD and APO alike, ranging 
from USD ${ }^{10} 22$ (Mexico) to USD 103 (Luxembourg) per hour in the OECD and from USD 3 (Cambodia) to USD 64 (Singapore) per hour in the APO. While there is a persistent labour productivity gap between OECD (average of USD 56 per hour in 2017) and APO (average of USD 13 per hour) economies, APO economies have seen higher growth rates in labour productivity over the last two decades. Figure 3.6 presents the change in output per hour over the period 1995-2017 (1995=100), showing that most APO economies experienced significant improvements in productivity performance, more pronounced than the OECD countries, with Fiji (22\%) and Japan (32\%) growing the slowest and Viet Nam (219\%) and India (224\%) showing the fastest productivity growth over the period.

Figure 3.5: GDP per hour worked in the APO and OECD areas

GDP in current prices and current PPPs, 2017

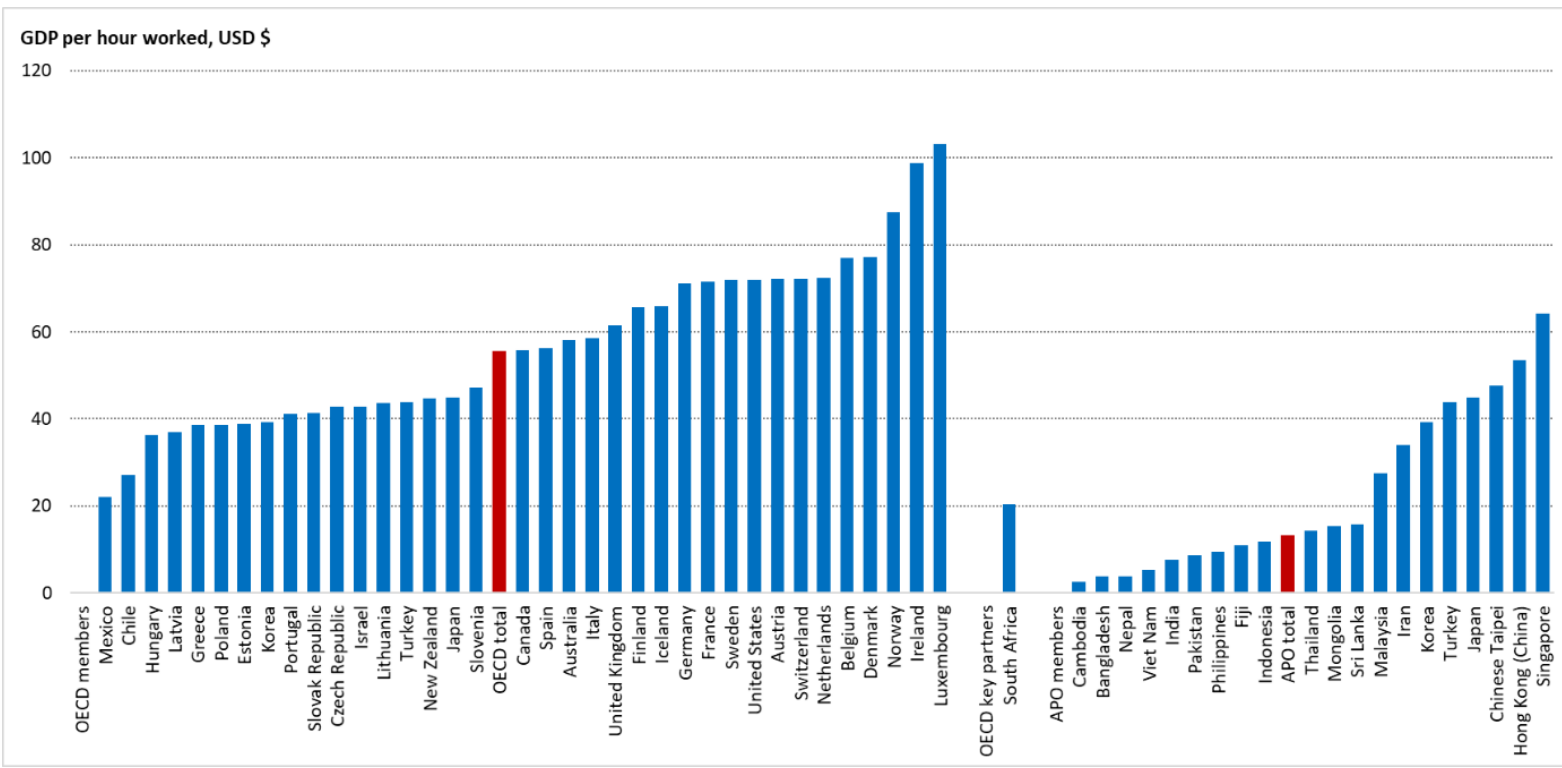

Source: OECD Productivity Statistics (database), July 2020, OECD National Accounts Statistics (database), July 2020, and APO Productivity Database 2019, Ver.2 (February 25, 2020).

Note: Data for economies with membership in both international organisations (i.e. Japan, Korea and Turkey), and OECD Key Partner countries (i.e. India and Indonesia), are sourced from OECD National Accounts Statistics (database) when available, and when unavailable, from the APO Productivity Database 2019, Ver. 2 (February 25, 2020). For Austria, Estonia, Finland, Greece, Latvia, Lithuania, Poland, Portugal, Sweden and the United Kingdom, average actual hours worked data calculated in country's national accounts are replaced with estimates produced at the OECD using the OECD simplified component method, which relies on the EU-LFS and complementary sources. This reflects conclusions from the OECD Statistics Working Paper International Productivity Gaps: Are Labour Input Measures Comparable?, which shows that the use of a direct method for the estimation of average hours worked creates systematic upwards bias, weighing down on productivity levels please refer to the paper itself for a more detailed account. Access the data.

${ }^{10}$ Purchasing power parities (PPPs) are used to convert GDP data in national currencies into US Dollars for cross-country comparisons. 
Figure 3.6: GDP per hour worked in the APO and OECD areas GDP in constant prices (2015), 2005 and 2017

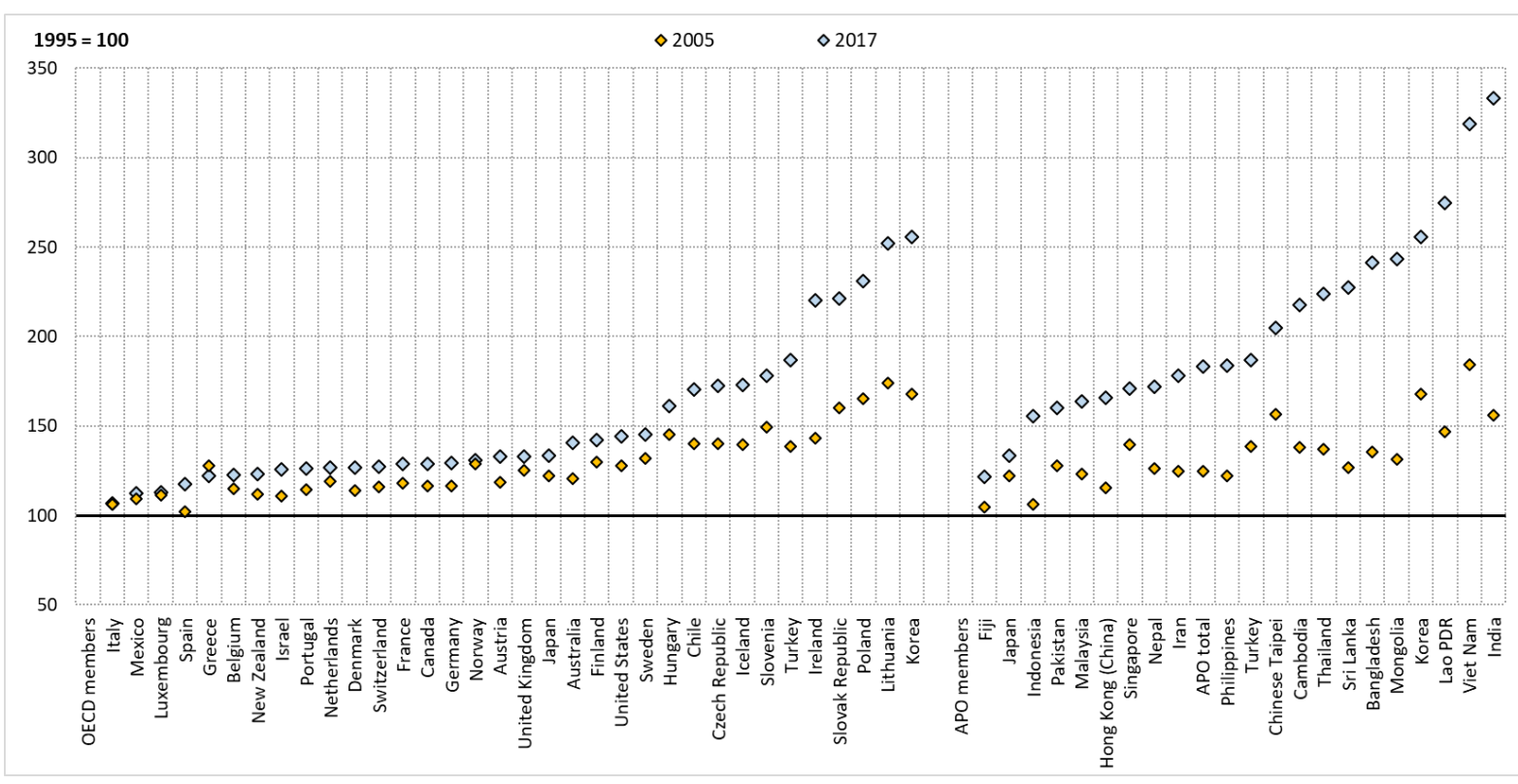

Source: OECD National Accounts Statistics (database), July 2020, and APO Productivity Database 2019, Ver.2 (February 25, 2020).

Note: Data for economies with membership in both international organisations (i.e. Japan, Korea and Turkey), and OECD Key Partner countries (i.e. India and Indonesia), are sourced from OECD National Accounts Statistics (database) when available, and when unavailable, from the APO Productivity Database 2019, Ver. 2 (February 25, 2020). Access the data.

The measurement of labour productivity as output per hour makes a material difference in crosscountry comparisons (Ahmad et al., 2003). Figure 3.7 compares the levels of output per capita, output per person employed and output per hour worked in 2017, relative to the OECD average. For example, while GDP per capita in Spain and Italy is below the OECD average, measures of GDP per person employed and GDP per hour worked, exceed the respective average levels in the OECD area. Chinese Taipei and Hong Kong, China show significantly greater GDP per capita and GDP per person employed levels than GDP per hour worked, reflecting their relatively high levels of average annual hours worked per worker (see Figure 3.1; 2093 for Chinese Taipei and 2148 for Hong Kong, China in 2017). 
Figure 3.7: Comparing measures of labour productivity levels GDP per hour worked, GDP per person employed and GDP per capita, 2017, OECD average $=100$

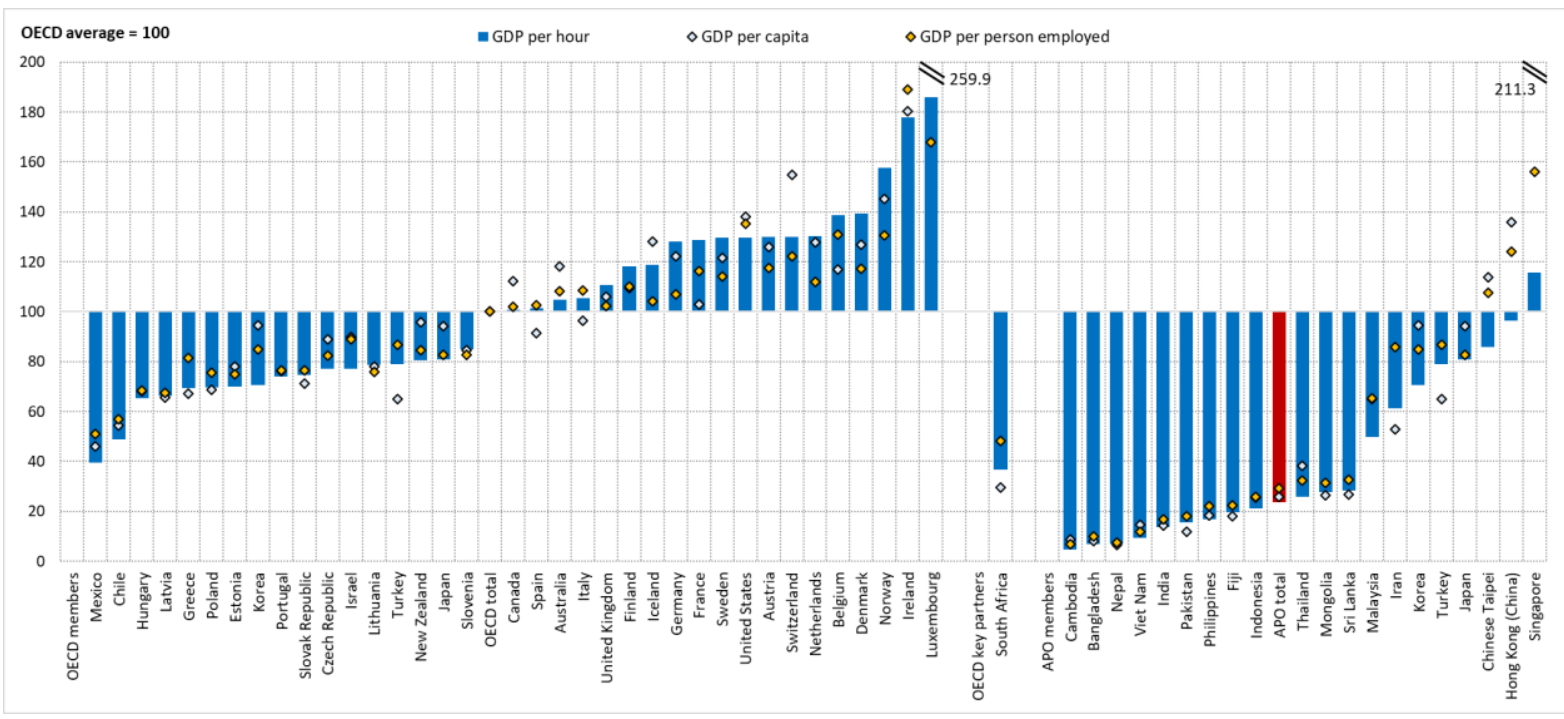

Source: OECD Productivity Statistics (database), July 2020, OECD National Accounts Statistics (database), July 2020, and APO Productivity Database 2019, Ver.2 (February 25, 2020).

Note: Data for economies with membership in both international organisations (i.e. Japan, Korea and Turkey), and OECD Key Partner countries (i.e. India and Indonesia), are sourced from OECD National Accounts Statistics (database) when available, and when unavailable, from the APO Productivity Database 2019, Ver. 2 (February 25, 2020). Access the data.

The choice of the labour productivity measure also makes a clear difference in cross-country comparisons of growth rates, as demonstrated in Figure 3.8. Regardless of the measure used, APO labour productivity growth is significantly higher than in the OECD over the period. In general, measured labour productivity growth would be lower if based on output per person employed as opposed to output per hour worked. The order of countries shifts markedly when comparing labour productivity measures with measures of GDP per capita. For example, measures of GDP per capita place Israel seven places higher than hours-based labour productivity measures, shift Ireland four places downwards and Turkey four places upwards. 
Figure 3.8: Comparing measures of labour productivity growth

GDP per hour worked, per person employed and per capita, 2000-2017

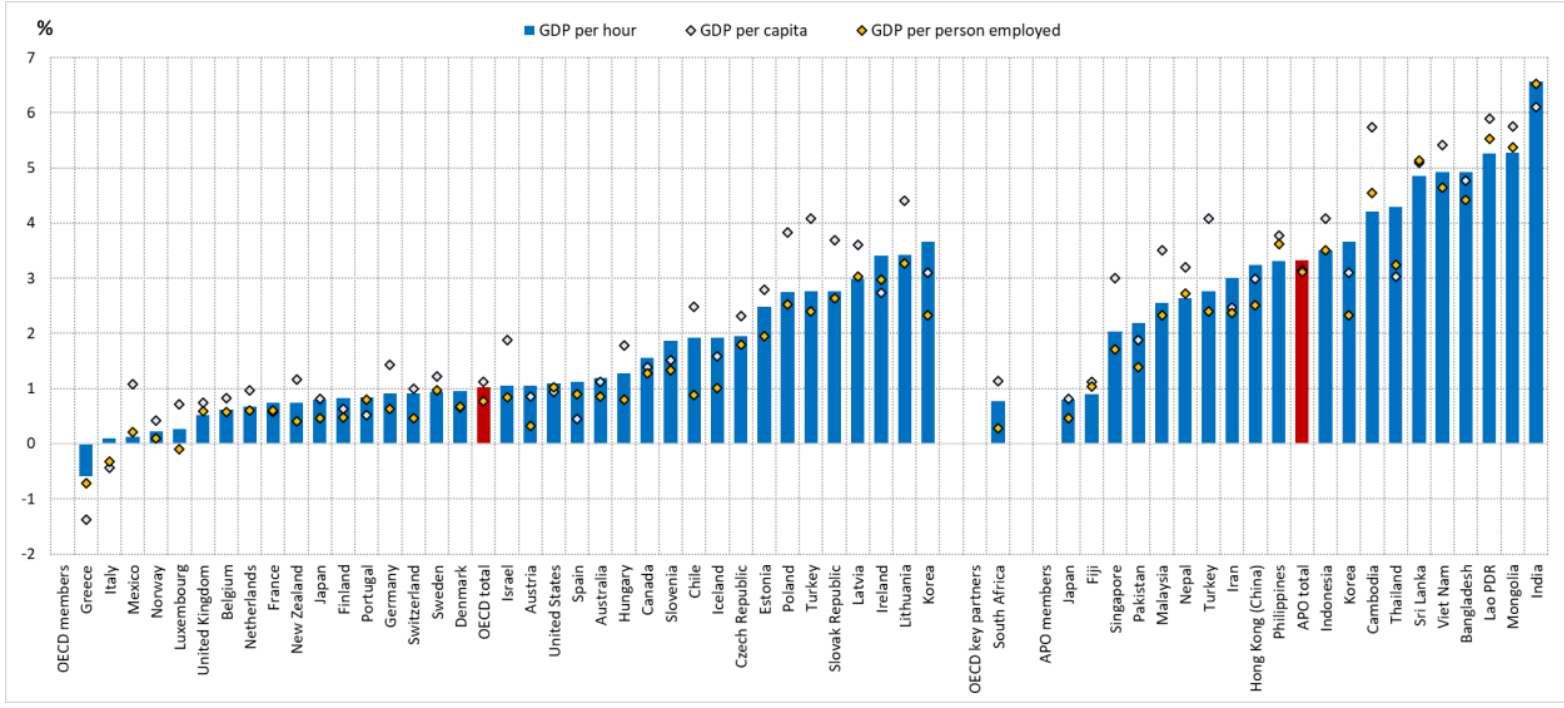

Source: OECD Productivity Statistics (database), July 2020, OECD National Accounts Statistics (database), July 2020, and APO Productivity Database 2019, Ver.2 (February 25, 2020).

Note: Data for economies with membership in both international organisations (i.e. Japan, Korea and Turkey), and OECD Key Partner countries (i.e. India and Indonesia), are sourced from OECD National Accounts Statistics (database) when available, and when unavailable, from the APO Productivity Database 2019, Ver. 2 (February 25, 2020). Access the data.

As discussed in the section on hours worked, the method used in the compilation of hours worked estimates can make a significant difference in measured hours worked and, in turn, labour productivity levels. Figure 3.9 presents labour productivity levels for selected OECD countries (referenced to the United States), using hours worked estimates compiled with the OECD simplified component method alongside those derived using national direct method estimates of hours worked. For all countries using a direct method, using the OECD simplified component method to estimate hours worked results in an improvement in their output per hour levels relative to the United States. The use of a component method can have a significant impact, closing the labour productivity gap with the United States by up to $10 \%$ in the case of Sweden.

While the approach recommended in Ward et al. (2018) clearly highlights the current bias in international comparisons of productivity levels across OECD countries, it does not follow that the same holds for international comparisons of productivity growth rates. Growth rates would only be distorted if the impact of the adjustments required showed significant disproportional change over time. Indeed, the authors find that the implementation of the simplified component approach reveals no systematic bias in growth rates of hours worked, and hence, labour productivity. 
Figure 3.9: Accounting for differences in estimation methods in GDP per hour worked Comparing official estimates with those based on the OECD's simplified component method (red diamond) for countries using a direct method, 2016, United States $=100$

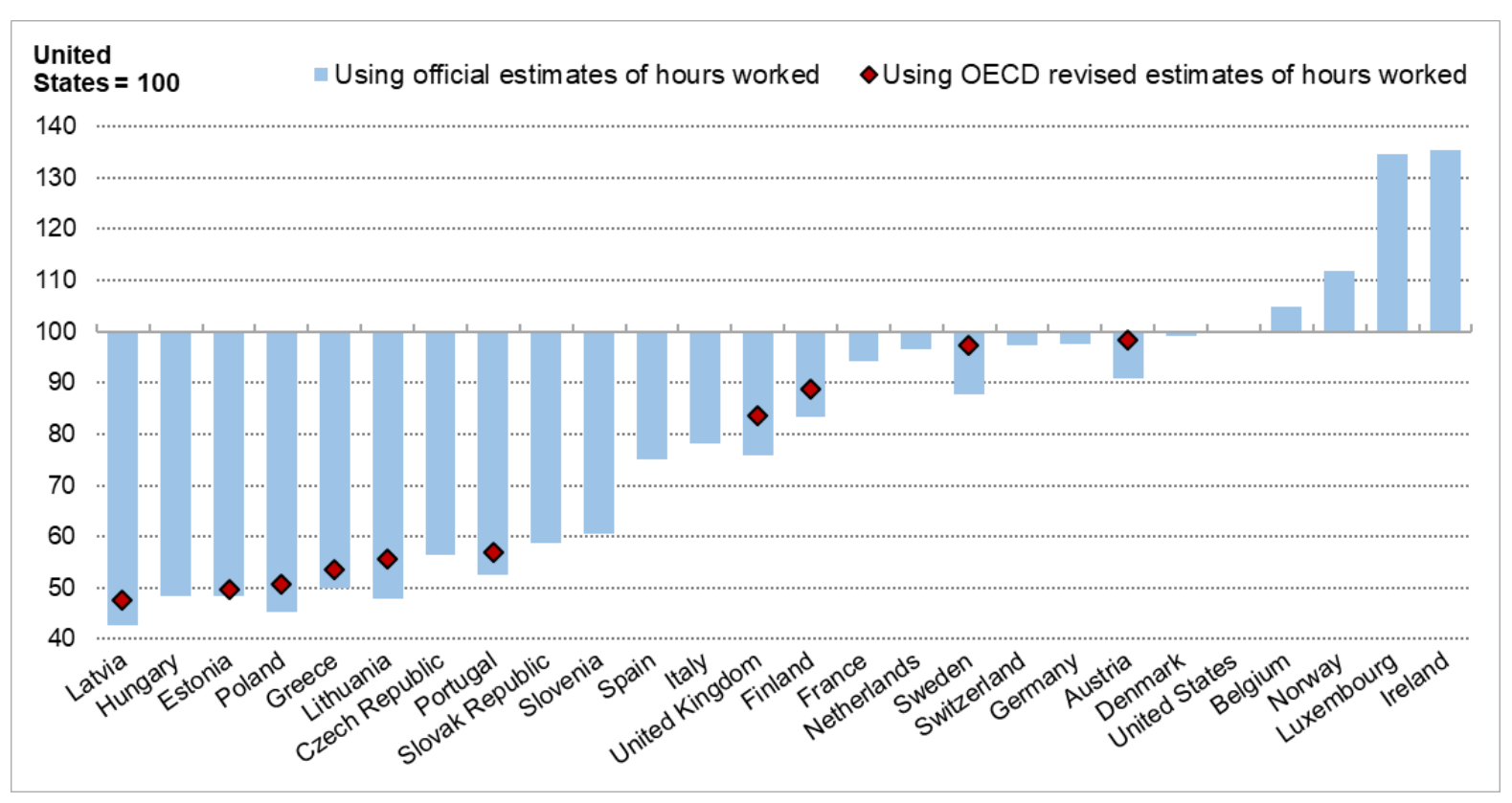

Source: Ward et al. (2018).

Note: Access the data.

\section{c. Measuring capital stocks}

\section{Motivation}

The measurement of capital stocks is key to both the national accounts and productivity measurement (OECD, 2009). Capital stocks feature at two key points in the national accounts, as part of the compilation of balance sheets and as a tool to derive estimates of depreciation/consumption of fixed capital (CFC). Capital stocks are also a core component in the productivity measurement framework, constituting an input into the construction of capital services (Section 4.b), which in turn enter into the growth accounting framework as a measure of capital input and therefore in the estimation of multifactor productivity (MFP) as a residual. Capital stocks, therefore, have a dual nature, both as a storage of wealth as presented in balance sheets, and as a source of capital services in analysis of production and productivity. As shown in Table 3.1, the former are referred to as net wealth capital stocks (the topic of this section) and the latter as productive capital stocks.

This section discusses the measurement of net wealth capital stocks and the related challenges. This measure is not ideal for the purpose of productivity measurement where the interest is in capital's productive potential (i.e. productive capital stocks), as opposed to the market value of the capital stock. Indeed, the change in the market price of an asset does not necessarily translate to an equal change in the productive capacity or efficiency of that asset, especially at the beginning of an asset's life. However, net wealth capital stocks are produced as part of the national accounting framework in most countries. 
Table 3.1. Two aspects of capital

\begin{tabular}{|c|c|c|}
\hline & $\begin{array}{l}\text { Income and wealth } \\
\text { perspective }\end{array}$ & $\begin{array}{l}\text { Production and productivity } \\
\text { perspective }\end{array}$ \\
\hline Basic flow & Investment & Investment \\
\hline $\begin{array}{l}\text { Aggregation across assets of } \\
\text { different age based on }\end{array}$ & Depreciation profile (Age-price profile) & Age-efficiency profile \\
\hline $\begin{array}{l}\text { Resulting stock for each class } \\
\text { of assets }\end{array}$ & Net capital stock by asset type & Productive stock by asset type \\
\hline Derived flow & $\begin{array}{l}\text { Depreciation (consumption of fixed } \\
\text { capital) }\end{array}$ & Capital services by type of asset \\
\hline $\begin{array}{l}\text { Aggregation across different } \\
\text { classes of assets based on }\end{array}$ & Market prices & Price of capital services \\
\hline Resulting stocks & Total net capital stock & $\begin{array}{l}\text { Productive stock for each type of } \\
\text { asset }\end{array}$ \\
\hline Derived measures & $\begin{array}{l}\text { Balance sheet entry, national wealth, } \\
\text { net measures of income }\end{array}$ & $\begin{array}{l}\text { Capital services, multifactor } \\
\text { productivity }\end{array}$ \\
\hline
\end{tabular}

Source: Adapted from the Measuring Capital Manual: Second Edition (OECD, 2009).

\section{Estimation methods}

The second edition of Measuring Capital OECD Manual (OECD, 2009) discusses two main ways to measure the net capital stock:

- from company or business surveys

- through the direct application of the perpetual inventory method (PIM), as the sum of past investments, weighted by a combined age-price/retirement profile.

Because the net capital stock is conceptually similar to some balance sheet items in company accounts, information from company records can, in principle, be used to gauge the level of the net stock of fixed assets. However, while notionally convenient, statisticians have to overcome some practical issues before the information can be used for the compilation of balance sheets in national accounts. One important issue is valuation, as data on company assets may be valued at historical costs whereas national accounts balance sheet items must be valued at current prices (i.e. the price of the assets in the market on the date to which a balance sheet relates, rather than the price at which the asset was acquired in the past). Another concern is whether the depreciation patterns used by companies to derive the net value of assets are broadly compatible with national accounts principles, in particular whether the depreciation pattern approximates a loss in the market value of the asset as it ages. Sometimes fiscal considerations or fiscal rules, such as accelerated depreciation, influence the value of a company's net capital stock without being representative of market values.

Given the practical issues surrounding the use of company and business surveys, the most widely used method across NSOs for the measurement of capital stocks is the direct application of the Perpetual Inventory Method (PIM). The PIM allows for the estimation of the net or productive capital stocks from the associated investment flows. It does this by accumulating past purchases of capital assets (i.e. gross fixed capital formation - GFCF), adjusted for retirement, and using an age-price profile (when the aim is to estimate the net wealth stock), or an age-efficiency profile (when the aim is to estimate productive capital stocks). 
The starting point for any computation of the net wealth stock using the PIM is therefore the construction of a combined age-price/retirement profile for a particular asset group. While the retirement pattern is determined by a probability distribution indicating the likelihood of retirement (and survival) of a cohort of assets at each given age, the age-price profile indicates the loss in value of an individual asset in the cohort as it ages, conditional on its survival. In practice, this can be determined in different ways. It can be directly estimated using empirical information about depreciation patterns, which typically rely on second-hand asset prices, average service lives and assumptions on the functional forms of the age-price and retirement profiles. Alternatively, the combined age-price/retirement profile can be derived from a combined age-efficiency/retirement profile, which depicts the decline in the productive capacity of the asset as it ages. Indeed, the ageefficiency profile and the age-price profile are closely related and cannot be determined separately (OECD, 2009).

\section{Data requirements}

The stock of assets surviving from past periods, and corrected for depreciation (i.e. corrected for both retirement and loss in asset value due to ageing), constitute the net wealth capital stock (OECD, 2009). The net wealth capital stock is valued as if the capital good (used or new) were acquired on the date to which a balance sheet relates, and, as such, it is designed to reflect the wealth of the owner of the asset at a particular point in time. Hence, the notion of "wealth" stock is sometimes considered a more precise terminology than "net" capital stock, as there exist other forms of "net" capital measures, for example, the productive capital stock, which is 'net' of efficiency losses resulting from its use in the production process.

The principle data requirement for the compilation of capital stocks in a PIM approach is the availability of long series of GFCF (i.e. investment), ideally reaching as far back as the intended length of the capital stock series, plus the maximum service life of the asset. Because investment undertaken in different years needs to be aggregated while adjusting for asset price changes over time, all capital stock figures resulting from the PIM are expressed in "constant prices". These prices may be the prices of the current year, in which case past expenditures are adjusted to the current year price level, or may be expressed at the prices of a given year, usually the one that is the base year for constant price series in the country's national accounts.

The estimation of capital stocks relies on a minimum level of detail in the asset breakdown of GFCF data, such that the asset groupings reported are relatively homogenous in terms of asset prices, ageprice profiles and retirement patterns. ${ }^{11}$ Table 3.2 presents the standard asset breakdown recommended in the 2008 SNA, and followed in the OECD National Accounts Statistics Database ${ }^{12}$ and the APO Databook. ${ }^{13}$ Due to data limitations, some NSOs are not able to compile and/or publish GFCF

11 In defining the retirement patterns for an homogeneous group of assets the statistician necessarily makes an assumption about their average service life.

12 The breakdown of N112. Other buildings and structures into N1121. Buildings other than dwellings, N1122. Other structures and N.1123. Land improvements is not available in the OECD National Accounts Statistics database.

13 While the NSOs of some APO member economies do compile GFCF at a sufficiently disaggregated level, with some even producing estimates of net capital stocks in-house (e.g. Chinese Taipei), many do not, due to data limitations or otherwise. As such, the APO Databook 
series for all assets or at such a disaggregated level, while other NSOs, such as the United States' Bureau of Economic Analysis (BEA) and Statistics Canada, are able to produce a much greater asset breakdown in their national estimates.

Table 3.2. 2008 SNA asset breakdown

\begin{tabular}{|c|c|}
\hline 2008 SNA code & Produced fixed assets \\
\hline N111 & Dwellings \\
\hline N112 & Other buildings and structures \\
\hline N1121 & Buildings other than dwellings \\
\hline N1122 & Other structures \\
\hline N1123 & Land improvements \\
\hline N11M & Machinery and equipment and weapons systems \\
\hline N1131 & Transport equipment \\
\hline N1132 & ICT equipment \\
\hline N11321 & Computer hardware \\
\hline N11322 & Telecommunications equipment \\
\hline N110 & Other machinery and equipment and weapons systems \\
\hline N115 & Cultivated biological resources \\
\hline N117 & Intellectual property products \\
\hline N1171 & Research and development \\
\hline N1172 & Mineral exploration and evaluation \\
\hline N1173 & Computer software and databases \\
\hline N1174 & Entertainment, artistic and literary originals \\
\hline N1179 & Other intellectual property products \\
\hline
\end{tabular}

In general, the greater the level of investment detail for which separate deflators and depreciation rates are available, the more reliable and precise will be the estimates of net capital stocks and, hence, the estimates of consumption of fixed capital (OECD, 2009). Indeed, the disaggregation of assets allows for the tailored treatment of different assets in the PIM. For example, the treatment of Machinery and equipment and weapons systems (N11M) in Table 3.2 as a single asset group would mean treating its four sub-categories uniformly, therefore assuming the same average service life for assets as diverse as as transport equipment - generally considered to have an average service life ranging between 10 and 25 years - and computer hardware - generally considered to have a 5 to 7 year average service life.

Figure 3.10 shows net wealth capital stock estimates in four different scenarios, where different initial asset breakdowns of investment series are used for the estimation of capital stocks. The asset breakdown underlying the PIM calculations increases in detail from scenario 1 (less detailed) to 4 (greater detail). For the three selected countries, the results indicate that more detailed asset breakdowns of investment yield higher net capital stock estimates, partly reflecting the use of asset-

relies on commodity flow analysis, supply and use tables and available national accounts statistics to produce GFCF series with a sufficient breakdown of assets for all countries (Annex A3; APO, 2019). 
specific price indices. For example, in scenario 4, the PIM is applied at the level of detailed ICT assets such as computer hardware and telecommunications equipment, for which prices have declined considerably over time, hence increasing investment volumes and consequently the net capital stocks of these assets.

Figure 3.10: Capital stock estimates by asset type in 2018, excluding real estate assets Estimates normalised to scenario 1 (scenario $1=1$ )

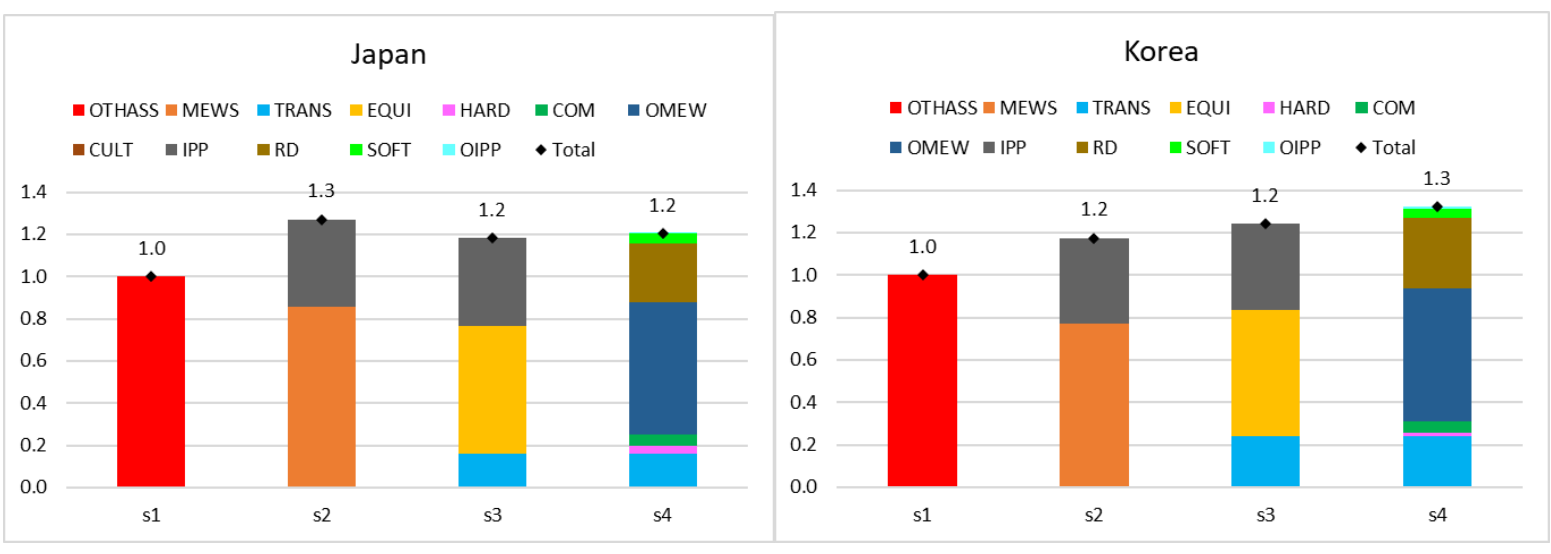

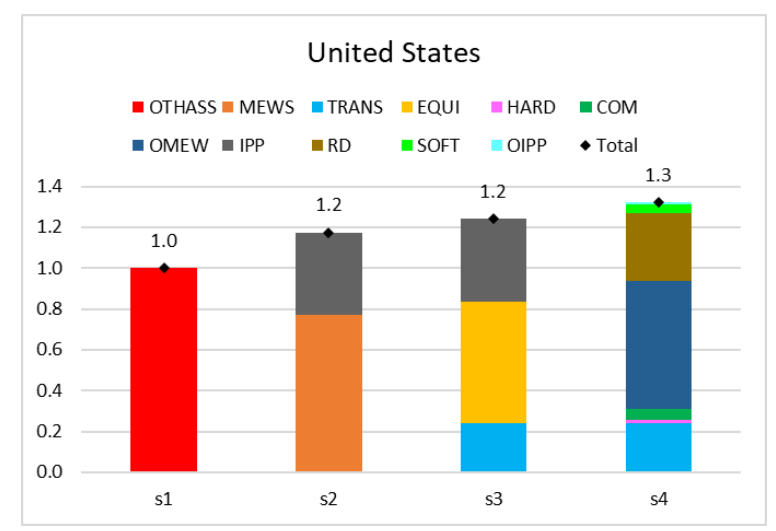

Source: OECD calculations based on OECD Productivity Statistics database, November 2020.

Note: The asset breakdown assumed under the different scenarios is as follows: Scenario 1 (s1) uses a single asset category: Other assets (OTHASS) than dwellings and other buildings and structures; Scenario 2 (s2) uses three asset categories Machinery and equipment and weapons systems (MEWS), Cultivated biological resources (CULT) and Intellectual property products (IPP); Scenario 3 (s3) uses four asset categories - Transport equipment (TRANS), Other equipment and weapons systems (EQUI), Cultivated biological resources (CULT) and Intellectual property products (IPP); Scenario 4 (s4) uses eight asset categories: Transport equipment (TRANS), Computer hardware (HARD), Telecommunications equipment (COM), Other machinery and equipment and weapons systems (OMEW), Cultivated biological resources (CULT), Research and development (RD), Computer software and databases (SOFT), and other intellectual property products (OIPP). The estimates are normalised to the value of the net capital stock of non-real estate assets estimated under scenario 1 (i.e. its value is set equal to 1).It turns out that the net capital stock under scenario 4 for the United States is 1.3 times higher than the estimate obtained under scenario 1. Cultivated biological resources were excluded for Korea and are not available for the United States. Access the data.

For these reasons, many countries compile investment series, and consequently net capital stocks, with a more disaggregated asset breakdown than the one presented in Table 3.2. For example, as demonstrated by the 2013 Eurostat-OECD Survey of National Practices in Estimating Net Stocks of Structures (Eurostat-OECD, 2016), countries may apply different assumptions for one/two-unit and 
multi-unit dwellings and/or across dwellings constructed with different materials (e.g. wooden or nonwooden in the case of Japan). The survey also revealed that most countries differentiate across different types of non-residential buildings (e.g. offices, factories, retail buildings, schools, hospitals) and structures (e.g. roads and bridges, railroad structures, sewage and waste disposal constructions, mining structures, air transportation structures), while only a few countries treat buildings other than dwellings and other structures as single asset types, albeit using different assumptions across industries when applying the PIM. Similarly, countries typically differentiate across different types of transport equipment (e.g. passenger cars, trucks, trains, ships, aircrafts), and/or identify different types of machinery and equipment other than transport and IT equipment and weapons systems when conducting their PIM calculations (Schmalwasser and Schidlowski, 2006; ISTAT, 2019; Statistics Netherlands, 2019; Office for National Statistics, 2019). In addition, some countries distinguish GFCF and net capital stocks of pre-packaged, customised and own-account computer software (Giandrea et al., 2018), in line with the recommendations of the Joint Eurostat-OECD Task Force on Land and Other Non-financial Assets (Eurostat-OECD, 2019). Many also split R\&D into R\&D in natural sciences and engineering (CPA 721) and R\&D social sciences and humanities (CPA 722), ${ }^{14}$ into basic and applied research and experimental development, or into purchased and own-account produced R\&D. ${ }^{15}$

A detailed asset breakdown is essential not only for the application of the PIM, but also in its own right to inform policy dialogues centred around specific types or groups of assets. It facilitates investigations into new developments in the measurement of capital assets, and the increasing prevalence of "intangible assets" or intellectual property products (IPP), such as R\&D and computer software and databases, and ICT equipment, including computer hardware and telecommunications equipment.

Furthermore, a sufficient asset breakdown is necessary for a robust and critical assessment of a country's infrastructure, which is an essential instrument for economic development. For example, Bennett et al. (2020) exploited data in the national accounts of the United States to show that some important types of basic infrastructure have barely, or have not, kept pace with depreciation and population growth in recent decades. Many studies have built the analysis of infrastructure using GFCF data sourced from countries' national accounts, constructing measures of infrastructure investment using different GFCF sub-components, and therefore benefitting, when available, from GFCF data cross-classified by detailed asset type, and/or industry and institutional sector (Revoltella et al. 2016; Asian Development Bank, 2017; Bennett et al. 2020). As such, a lack of detail in GFCF sub-components by type of asset (such as residential and non-residential buildings, civil engineering works, and machinery and equipment) and the institutional sector/industry in which the asset is used makes it difficult to readily distinguish, and therefore evaluate, investments in infrastructure. Moreover, as the nature of infrastructure evolves, the analysis of networks, connectivity, alternative-energy systems and digital and intangible infrastructure becomes central to more and more policy debates, increasing the pressure to produce and disseminate GFCF series, and net capital stocks, at the most detailed asset breakdown possible.

\footnotetext{
${ }^{14}$ CPA is the Statistical Classification of Products by Activity in the European Community, link.

15 The final report on the measurement of Intellectual Property Products recommended to distinguish between own-account and purchased (pre-packaged plus customised) software when compiling estimates of GFCF (Eurostat-OECD, 2019).
} 
In light of the above, NSOs in APO economies are encouraged to compile and disseminate investment series with detailed breakdowns by asset type. Admittedly, crude assumptions can always be applied to break down investment series by asset type, but given their access to original data sources, NSOs are likely in a better position than external researchers to provide high-quality detailed investment series for their country. In the end, the achieved level of detail will make a difference for the measurement of capital stocks (e.g. infrastructure capital), capital services, and multifactor productivity.

\section{Key measurement challenges}

The application of the PIM comes with a series of measurement challenges, including the choice of age-price profiles, retirement patterns, asset prices (in particular for ICT assets, see below and Section 2a), and the calculation of the initial capital stock. Many NSOs struggle to choose among alternative assumptions in their capital stocks measurement framework, making a critical evaluation of current practices essential, including empirical assessments of the underlying assumptions, sensitivity analysis and the sharing of best practices.

\section{Age-price profiles}

An important element in the estimation of capital stocks (and consumption of fixed capital) is the choice of the age-price (or depreciation) profile. This profile depicts the loss in value of a capital good as it ages, and can be illustrated by the pattern followed by the relative prices for different vintages of the same (homogenous) capital good. The form of the age-price profile depends on several factors, including the rate of loss of productive capacity and the remaining asset service life.

There are several ways of determining the appropriate functional form of the age-price profile, including the following:

- Starting from empirical information about assets' service lives, and making an additional assumption about the functional forms of the individual asset depreciation and retirement patterns.

- Using information on depreciation implicitly derived from information on used asset prices and exploited econometrically;

- Deriving age-price and depreciation patterns from age-efficiency profiles;

In the first approach, typically, the depreciation pattern is assumed to follow one of two different forms: straight-line or geometric. Under the straight-line or linear model of depreciation, the asset losses a constant amount of value every period, which is equal to $1 / T$, where $T$ represents the service life of the asset. Under the geometric model, the value of the asset declines at a constant rate $(\delta)$. The most important challenge in the estimation of depreciation patterns by adopting a given functional form is the choice of the functional form itself and the values of certain parameters, such as the service lives $(T)$ or depreciation rates $(\delta)$. Ideally, these choices should be supported by empirical evidence.

The second approach, which in its nature often acts to support assumptions made in the first, gathers econometric studies of depreciation drawing on price observations on new and used assets for several periods, distinguishing the prices of a particular class of assets by the age, vintage and time of purchase. These studies typically estimate a constant (geometric) depreciation rate $(\delta)$ using 
information from second-hand asset prices. Many of these empirical studies of used asset prices originate in the United States. However, similar studies have been also carried out in Canada (Statistics Canada, 2007; Baldwin et al., 2015), and Japan (Suga and Nomura, 2018). In general, there are two main conclusions that can be drawn from these studies (OECD, 2009). First, different kinds of assets exhibit a very wide range of age-price profiles. If price is plotted on the vertical axis and age horizontally, studies have found age-price profiles adopting a wide variety of functional forms (concave to the origin, horizontal lines, falling straight line and convex to the origin). Second, by far the most prevalent age-price profile is a function which falls over time with some convexity towards the origin (Hulten and Wykoff, 1981). This is almost always the case for machinery and equipment and is generally the case for buildings. Some studies have tested whether their observed age-price profiles follow one of two simple models - geometric, or straight-line. Even though statistical tests almost invariably reject both of these simple models, the geometric model is often considered as a reasonable approximation of combined age-price and retirement profiles (Hulten and Wykoff, 1981; OECD, 2009).

The third approach, derives age-price from age-efficiency profiles. Indeed, age-price and ageefficiency profiles are conceptually linked by the asset market equilibrium condition. In equilibrium, the price of an asset equals the expected sum of its discounted future rentals, which are themselves closely related to the age-efficiency profile of the asset. Given an age-efficiency profile for a cohort, and given a real rate of return, a consistent age-price profile can be computed. Note that with geometric age-efficiency profiles, age-price profiles inherit the same shape. Otherwise, the derivation of age-price profiles from age-efficiency profiles is more involved and requires to estimate or assume a rate of return for capital investments (see OECD 2009 for additional technical details).

The above describes the various approaches towards the estimation of age-prices profiles. The choices made by NSOs in these domains should be informed by the empirical evidence and point to a detailed asset classification. Whenever possible, advice from experts, researchers and businesses, as well as comparisons of national results with those obtained in other countries should be used as a sense check for these assumptions.

\section{$\underline{\text { Asset service lives }}$}

The accuracy of capital stock estimates derived using the PIM is crucially dependent on information on service lives, which indicate the time-span that assets are retained in the capital stock, whether in the stock of the original purchaser or in the stocks of producers who purchase them as second-hand assets. In this context, it is the economic service life that matters, hence prevailing over the physical or mechanical notion, meaning that even assets in relatively new condition can be retired when a more productive and/or cheaper asset appears.

Services lives need to be assumed or estimated based on empirical evidence. The main sources for estimating service lives are the following:

- Tax codes - In most countries, the tax authorities specify the number of years over which the depreciation of various types of assets may be deducted from profits before calculating tax liabilities. Many countries make some use of these, either where no other information is available, or as a sense check of service lives obtained through other methods. It should be noted that the reliability of these estimates depends largely on the method used by the 
specific tax authority to derive these service lives in the first place and that statisticians may apply an upward or downward correction factor before using them in the PIM (Schmalwasser and Schidlowski, 2006; OECD, 2009). ${ }^{16}$

- Company accounts - Company accounts often include information on the service lives that enterprises use to depreciate assets. They almost always record stocks of assets at historic (or "acquisition") values, and while this is a disadvantage for many purposes, it does not necessarily prevent them from being used to estimate asset service lives.

- Statistical surveys - Two kinds of surveys are relevant for the estimation of asset service lives: those which ask producers about the discard (retirement or disposal) of assets during a previous accounting period, and those which ask respondents to give the purchase dates and expected remaining lives of assets currently in use. For example, the Netherlands has been carrying out a discards survey since 1991 (van Rooijen-Horsten et al., 2008; Eurostat-OECD, 2016), while the Economic and Social Research Institute (ESRI) in Japan has been conducting a survey on capital expenditure and disposals since 2006 (Suga and Nomura, 2018). Similarly, the Bank of Korea derived average service lives for machinery and intellectual property assets using a retirement survey (Cho et al., 2012). In Canada, the Capital and Repair Expenditures Survey undertaken by Statistics Canada asks enterprises not only for the prices and age at which assets are sold but also for estimates of the expected length of life of the assets at the time of the initial investment (Baldwin et al., 2015).

- Administrative records - For some assets, government agencies maintain administrative records that can be used to estimate service lives. For example, most countries maintain registers of the construction and demolition of dwellings and non-residential buildings. Vehicle registration records track the service lives of road vehicles, and aircraft and ships are often subject to similar controls. Regulatory bodies in energy power industries, railways and telecommunications are also a possible source of information.

- Expert advice - Most countries tend to base at least some of their asset lives on expert advice. This may involve seeking advice from a panel of production engineers familiar with conditions in a representative cross-section of industries, from personnel working in different ministries with direct access to relevant information, or from researchers and academics in different relevant fields (Schmalwasser and Schidlowski, 2006; Statistics Netherlands, 2019, RinconAznar et al., 2017; Office for National Statistics, 2019).

- Other countries' estimates - Most countries periodically review estimates used by other countries to ensure that their own estimates are not too far out of line with those of neighbouring or similar countries. However, there is a danger that if countries systematically copy other countries, an impression is created that there is a well-based consensus on the matter when in fact few countries have actually investigated service lives in their own economies. As stated in the Measuring Capital OECD Manual (OECD, 2009), asset service lives are strongly influenced by country-specific factors such as the relative prices of capital and labour, interest rates, climate and government investment policies. Other countries' estimates may provide a broad sense check, but should not be adopted without question.

\footnotetext{
${ }^{16}$ For example, governments may use various systems of accelerated depreciation to promote investment, in which case tax-lives are likely to need a correction for their use by the NSO in capital stock estimation.
} 
Errors in service life assumptions affect the reliability of capital stock estimates, as the use of too long (too short) service lives will lead to an overestimation (underestimation) of the capital stock, with a more or less important impact on its growth rates and estimates of the consumption of fixed capital. The accuracy of average service lives used in the PIM are then key to the production of reliable estimates of asset holdings and unbiased measures of depreciation, which subsequently inform businesses and policy makers in their decisions.

\section{Retirement functions}

When identical asset types are purchased at the same point in time, they form a cohort. However, it is unlikely that all assets in a cohort will reach the end of their theoretical service life and be retired simultaneously. A retirement or mortality profile is required to model the retirement process of assets over time, to describe the probability of the retirement of an asset in that cohort in each period of time, with the maximum probability at the average service life.

Therefore, a key parameter within the retirement profile is the average service life of the assets, which indicates the average length of time an asset remains in the capital stock, thus having implications for the level and growth rate of the capital stock for an individual asset and of the total capital stock. There are many potential retirement patterns that can be applied to different asset classes depending on their characteristics. One of the simplest versions of a retirement profile is "simultaneous exit", whereby all assets in a given group and cohort are retired at their average service life. In reality, however, it is implausible to expect that all assets of the same type and vintage will be withdrawn from the capital stock at the same moment. Some assets will be discarded before they reach the average service life because they are overworked or poorly maintained, while others will continue to provide good service several years beyond their average life expectancy. A similarly simplistic approach is to apply a linear, or delayed linear, retirement profile, whereby assets are retired with the same probability at any point along the distribution. A more reasonable assumption is a bell-shaped retirement profile, meaning that the majority of assets are retired at their average service life, with some assets being retired shortly after purchase or long after their average service life. Bell-shaped retirement profiles come in a variety of forms, including log-normal, normal, gamma, Winfrey and Weibull functions, and a complete description of these and other retirement profiles can be found in the Measuring Capital Manual (2009). Most OECD countries assume a bell-shaped retirement profile to represent the retirement pattern of assets for their capital stock estimates. For example, Germany uses a gamma function, Belgium, France and Ireland apply a log-normal distribution; the United Kingdom assumes a normally distributed retirement pattern (Office for National Statistics, 2019); Australia, Korea, and New Zealand account for retirement using Winfrey curves (Australian Bureau of Statistics, 2015; Cho et al., 2015; Statistics New Zealand, 2014); and the Netherlands uses a Weibull distribution (Statistics Netherlands, 2019). ${ }^{17} 18$ While bell-shaped retirement profiles are widely used,

\footnotetext{
17 See methodological notes available on NSOs websites for Belgium (http://www.nbb.be/doc/dq/e method/m sec2010d2 en.pdf) and Ireland (https://www.cso.ie/en/media/csoie/methods/estimatesofthecapitalstockoffixedassets/Estim ates of the Capital Stock of Fixed Assets Methodology.pdf), and Cabannes et al. (2013) for France.

${ }^{18}$ The Bank of Korea initially developed its capital measurement program based on log-normal retirement functions. In the process of unifying their own programs, however, the Bank of Korea and Statistics Korea agreed in 2013 to represent the retirement of assets using Winfrey
} 
the choice of the functional form should have some empirical support and replicate the discard patterns observed in the country.

\section{Prices of ICT assets}

A price index is constructed by comparing prices of a sample of products between two periods of time. In order to ensure the accuracy of the price index, the products in the sample should be representative of the whole asset group and they should be comparable over time. When the quality and specification of the underlying products change very rapidly, which is the case for Information and Communication Technology (ICT) products, these two conditions are difficult to fulfil, and there is a risk that the resulting price index reflects not only variation in asset prices over time but also changes in quality and product specification. A price index that captures quality changes may affect the distinction between price and volume changes and consequently estimates of capital stocks, capital services and value added (Section 2.a above).

Different techniques have been used by statisticians to construct constant-quality deflators for ICT assets. Price estimates of a new model in a previous period of time and of an old model in a future period have been estimated on the basis of expert advice, option pricing, transactions in second-hand markets, and/or hedonic methods (Schreyer, 2002). Wyckoff (1995) was one of the first to point out large differences in the deflators of value added in the computing machinery industry across a sub-set of OECD countries, and concluded that they were more likely a reflection of the differences in statistical methods to deflate value added than true differences in price changes over time. A recent survey measuring the impact of the digital economy on price indices conducted by the IMF and the OECD in 2017 revealed that while most OECD countries apply quality adjustments when constructing price indices for high-tech products, the techniques used vary across countries and include both explicit (e.g. hedonic models) and implicit (overlap and bridge overlap methods) approaches. Recent studies have found evidence of overestimation of price changes in official price indices for ICT assets and have revived discussions on price mismeasurement (Byrne, Oliner and Sichel, 2015; Byrne, Fernald and Reinsdorf, 2016; Byrne and Corrado, 2017).

To carry out meaningful analysis and international comparisons of the economic effects of ICT investment on productivity, both the OECD Productivity Statistics database and the APO Databook apply a common methodology for the deflation of ICT investment across countries developed in Schreyer (2000) and Schreyer and Colecchia (2001). This method relies on the assumption that the growth differential between the price of an ICT asset and that of non-ICT assets is expected to be equal across countries and then refers to relative changes between ICT and non-ICT prices of a country applying robust quality adjustments. Once the reference country is selected, they obtain the "harmonised" ICT deflators in three steps. While the reference country in OECD productivity estimates is the United States, Japan is selected as reference country in the APO Databook.

The OECD (for its Productivity Statistics database) and the APO (for the APO Databook and the APO database) first compute the ratio of each ICT asset price to the non-ICT assets prices in the reference country and calculate the year-on-year change in this ratio. Second, they regress the latter series on

distributions. The difference between stocks from log-normal functions and from Winfrey curves turned out to be minor (Cho et al., 2015). 
time using a polynomial regression to smooth the changes in the relative ICT-to-non-ICT assets prices. Finally, from the predicted (smoother) series of changes in the relative prices, they obtain a smoother series of the ratio of the ICT asset's price to non-ICT asset prices for the reference country and multiply these ratios by the non-ICT price indices in all other countries to obtain the "harmonised" ICT price indices. Figure 3.11 shows differential growth between ICT asset prices and the non-ICT price index, confirming the pattern of divergences across countries and hence, potential mismeasurement. Figure 3.12 shows the impact on growth rates of ICT capital stocks when replacing national deflators with the "harmonised" deflators computed as described above and taking the United States as the reference country. As harmonised ICT deflators aim to remove quality changes potentially captured in national price indices, capital stocks of ICT assets grow faster when harmonised ICT deflators are applied.

While this methodology removes cross-country differences in the relative price evolution of ICT and non-ICT products, where differences are often thought to be caused by measurement, some of these differences may actually reflect the reality. Therefore, NSOs in APO economies are encouraged to keep abreast of the statistical literature on the price measurement of ICT products and to compare their deflators with those used in OECD countries. Remaining differences in ICT price deflators across countries should be analysed and documented with great care (see Section 2.a).

Figure 3.11: Differential growth between ICT price indices and non-ICT price index Average annual change, 1995-2019 (or latest available year)

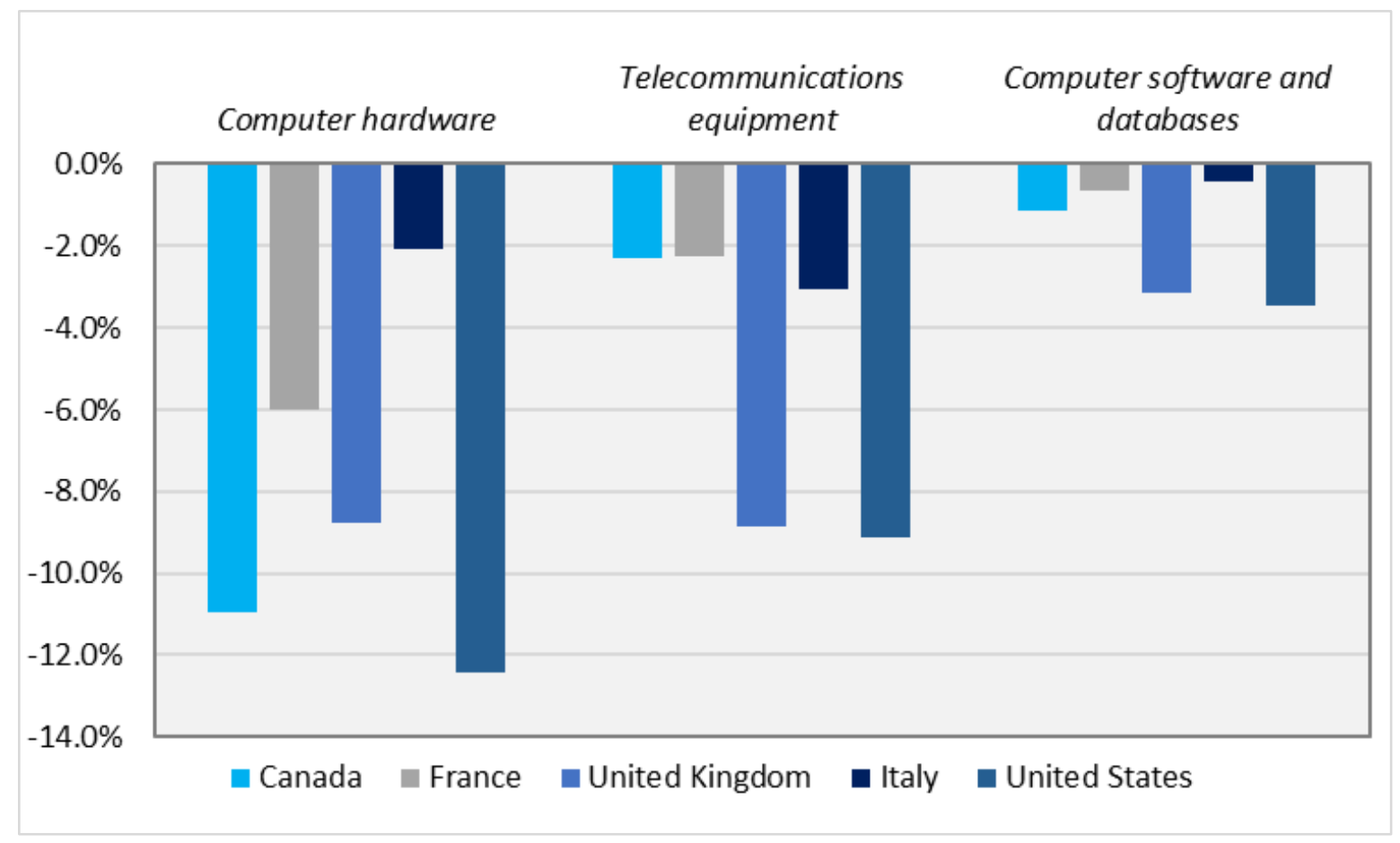

Source: OECD calculations based on OECD Productivity Statistics database, November 2020.

Note: Access the data. 
Figure 3.12: Growth in ICT capital stock using national and harmonised deflators Average annual change, 1995-2019 (or latest available year)

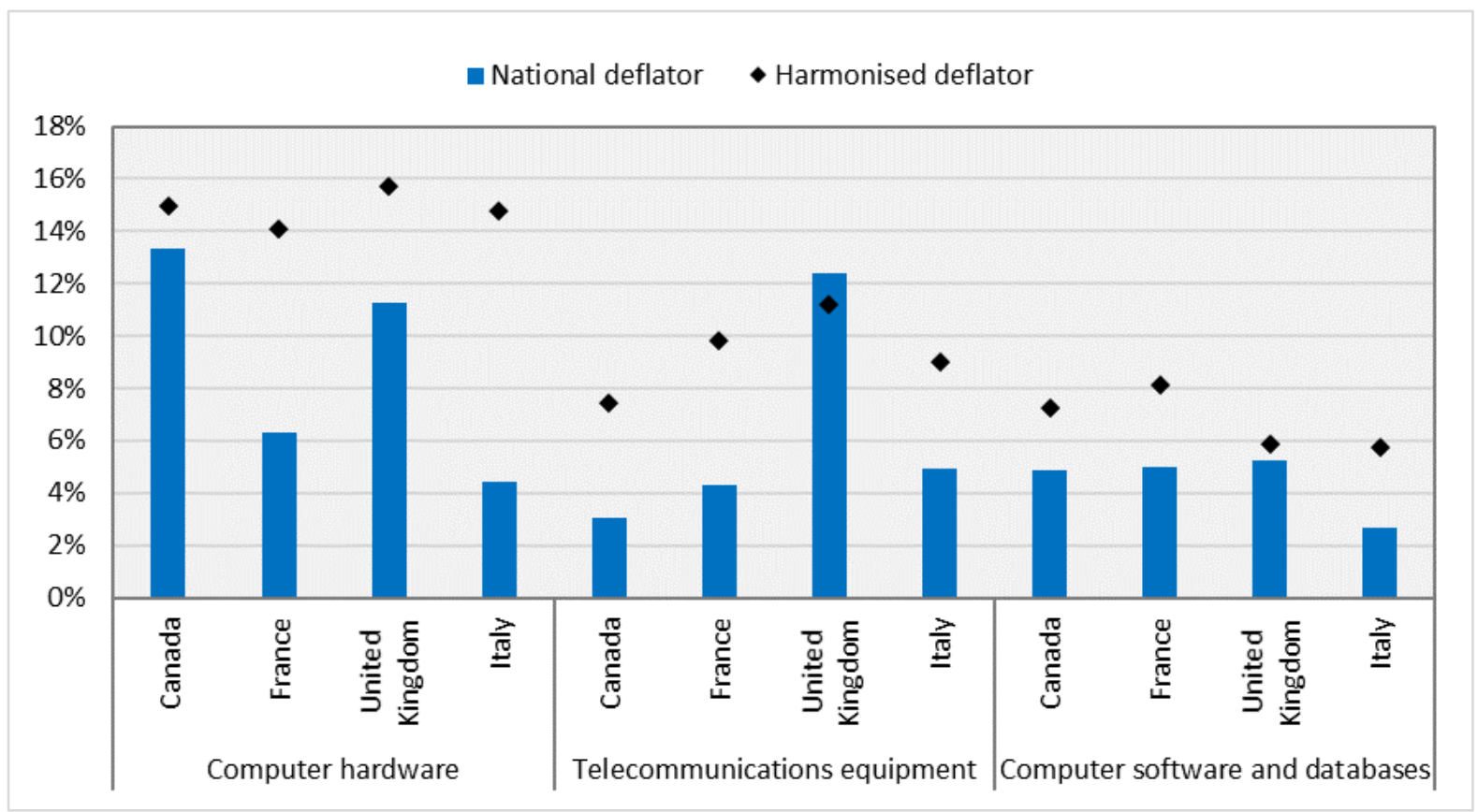

Source: OECD calculations based on OECD Productivity Statistics (database).

Note: Access the data.

$\underline{\text { Initial capital stocks }}$

As discussed previously, the PIM relies on long GFCF time series for each asset. In theory, the required GFCF time series for each asset should be as long as the intended capital stock time series, plus the maximum service life for this asset. This may not always be possible, as the longest living assets, usually dwellings and/or buildings and structures, often have an average service life above 60 years, and up to 100 years in some cases.

There are various ways to address this issue. One possibility is to construct a benchmark estimate on the basis of sources other than long investment series, including wealth surveys, population and housing census, administrative property records on the construction, demolition and stock of dwellings and other buildings, fire insurance records, and companies' accounts and balance sheets. The benchmark estimate derived from these sources will be an approximation of the true initial capital stock in a given year, with the impact of potential errors diminishing over time as the initial year becomes more distant and the initial stock gets depreciated.

A different approach consists in estimating the initial capital stock with some variant of the PIM under the assumption that the depreciation profile follows a geometric pattern. The latter implies that the net capital stock at the beginning of period $t$ is equal to the weighted sum of past investments, where the weights result from the geometric depreciation profile: $K_{t}=\sum_{t=0}^{\infty}(1-\delta)^{i} I_{t-1}$. In this case, the growth rate of the net capital stock between two consecutive periods is given by $\theta_{t}=\frac{K_{t}-K_{t-1}}{K_{t-1}}=$ $\frac{I_{t-1}}{K_{t-1}}-\delta$. If a plausible assumption about the long-run growth rate of capital stocks $(\theta)$ can be made, 
e.g. taking it equal to the long-run growth rate of volume GDP or GFCF, then the initial capital stock at the beginning of period $(\mathrm{t}-1)$ can be estimated as $K_{t-1}=\frac{I_{t-1}}{\theta+\delta} \cdot{ }^{19}$

Another option when a long GDP time series exists is to backcast the GFCF time series based on an econometric relationship between investment and GDP (OECD, 2009). The resulting longer GFCF series can then be used in the PIM to compute an estimate of the initial capital stock.

Regardless of the chosen approach, the estimation of initial capital stocks remains one of the most important challenges for capital measurement. Any attempt to estimate initial capital stocks in the absence of sufficiently long time series of investment should rely on the construction of benchmark estimates based on other sources than GFCF series (i.e. value of stocks sourced from census, surveys and administrative records) and some variant implementation of the PIM with the use of plausible assumptions about the long-run growth rate of capital stocks or investment. While the assumptions build in some circularity, their impact decreases significantly over time, especially for short-loved assets. A sensitivity analysis of the results obtained using alternative approaches is needed in any case.

\section{d. Multifactor productivity accounting for hours worked and net wealth capital stocks}

\section{Definition}

Multifactor productivity (MFP), sometimes referred to as total factor productivity (TFP), is a measure of the remaining output or value added growth when contributions from key inputs into the production process have been taken into account. ${ }^{20}$ In this respect, MFP is measured as a residual. In the present report, the focus is on capital-labour MFP indices, which show the time profile of how productively combined labour and capital inputs are used to generate value added (OECD, 2001). ${ }^{21}$ Traditionally, MFP is seen as a measure of technical change but, in fact, technical change can also be embodied in factor inputs, e.g. improvements in design and quality between two vintages of the same capital asset. In practice, MFP only captures disembodied technical change, e.g. network effects or spillovers from production factors, the effects of better management practices, organisational change and improvements in general knowledge. Moreover, MFP picks up other factors such as adjustment costs, economies of scale, effects from imperfect competition, variations in capacity utilisation (if not captured by the capital input measures) and errors in the measurement of output, inputs and input weights. For instance, increases in educational attainment or a shift towards a more skill-intensive production process, if not captured in the form of composition adjusted labour input (i.e. labour

\footnotetext{
${ }^{19}$ For a discussion on the estimation of the long-run growth rate of volume GDP or volume investment see Berlemann and Wesselhöft (2014).

20 Total factor productivity (TFP) is used as a synonym for multifactor productivity (MFP). This report follows the Measuring Productivity OECD Manual (OECD 2001) and uses the term MFP to signal a certain modesty with respect to the capacity of capturing all factors' contribution to output growth.

${ }^{21}$ The KLEMS multifactor productivity shows the time profile of how productively combined labour, capital and intermediate inputs (energy, materials and services) are used to generate gross output. The KLEMS approach is not adopted in this report.
} 
services, see Section 4.a) will end up in measured MFP. Therefore, an accurate estimation of output and input measures is key for the appropriate measurement of MFP.

MFP growth can be presented as the difference between the rate of change of value added (VA) and the weighted sum of growth rates of labour $(L)$ and capital $(K)$ inputs, where weights correspond to the current-price shares of each factor in total costs and sum to unity:

$$
\frac{d \ln M F P}{d t}=\frac{d \ln V A}{d t}-\left(\frac{1}{2}\left(s_{L}^{t}+s_{L}^{t-1}\right) \frac{d \ln L}{d t}+\frac{1}{2}\left(s_{K}^{t}+s_{K}^{t-1}\right) \frac{d \ln K}{d t}\right)
$$

The MFP measure defined in this section relies on the quality of the value added, hours worked and net (wealth) capital stocks data discussed in previous sections. Still, even if these data were of the highest quality, they constitute only the minimum inputs for the calculation of a baseline measure of MFP. ${ }^{22}$ An ideal and comprehensive measure of MFP should account not only for the volume, but also for the composition (or "quality") of both labour and capital inputs, as well as for both produced and natural capital. These developments are addressed later in this report.

\section{Measurement challenges}

An important aspect of the measurement of MFP growth is the construction of the labour and capital cost shares in total costs of production. Many studies and international organisations that compile MFP measures define the labour cost share as the ratio of labour compensation of total employment (i.e. employees and self-employed) to value added at basic prices and define the capital cost share as one minus the labour share. This is based on a number of assumptions that are discussed in Section 3.c.

In APO economies, however, estimates for the compensation of employees are not always available in the official national accounts (Appendix 6; APO, 2019). At the time the APO Databook 2019 was written, the national accounts of Bangladesh, Bhutan, Cambodia, Indonesia, Iran, the Lao PDR, Myanmar, Pakistan, and Viet Nam did not contain official and/or sufficiently frequent estimates of compensation of employees. In such cases, the APO Databook 2019 relies on an estimation or extrapolation of compensation of employees based on the Asia QALI Database.

An additional but related measurement issue pertains to the measurement of labour compensation received by self-employed and contributing family workers. National accounts show the total income received by self-employed workers as mixed income, without providing any distinction between the returns from their work effort (labour) and their capital returns as business owners. Two main approaches to split mixed income exist in the literature. Under the "labour basis" approach, the most frequently used of the two approaches, labour income received by the self-employed is assumed to be equal to the average labour compensation of employees working in the same industry (Pionnier and Guidetti, 2015; Cho et al., 2017). ${ }^{23}$ Under the "asset basis" approach, capital income accruing to

\footnotetext{
22 Timmer et al. (2010) refer to a "crude" MFP measure in this case.

${ }^{23}$ The reader should note the relevance of measuring average labour compensation per hour worked as opposed to per job or per person.
} 
the self-employed is calculated by assuming that the return to capital is the same for self-employed workers and corporations (Elsby et al., 2013).

The APO Databook 2019 derives labour compensation of non-salaried workers using estimates from the Asia QALI Database, in which common assumptions across economies are applied, except for economies where reliable data are available. Specifically, the Asia QALI Database assumes a wage differential ratio (WDR), i.e. a ratio between the hourly wages of self-employed workers and those of employees, of 0.5 for Cambodia, Hong Kong (China), Japan, Korea, Lao PDR, Chinese Taipei, Singapore and Viet Nam, and 0.2 for all other economies in the database.

\section{Box 3.1. The role of capital and MFP measures for estimating potential output and output gap}

Measures of potential output and output gap are crucial in many areas of economic policy. Potential output is generally understood to measure the medium-to-longterm level of sustainable real output in the economy, i.e. the maximum output an economy can sustain without generating a rise in inflation. As such, it measures an economy's productive capacity. The output gap is defined as the deviation of the actual level of output from the potential level (i.e. potential output). It measures the degree of utilisation of production factors in the economy and provides a key benchmark to assess inflationary pressures. Measures of potential output and output gap are used to derive additional indicators, such as cyclically adjusted government budget balances, which are used to assess fiscal sustainability. However, neither potential output nor the output gap can be directly observed, and they need to be inferred from existing data using statistical and econometric methods.

The measurement of potential output relies on a mathematical representation of the production process, i.e. a production function whereby GDP (output) results from the combination of productive inputs, typically labour and capital, and MFP. For practical purposes, most approaches rely on a constant-returns-to-scale CobbDouglas function (below), which is a special case of the constant elasticity substitution (CES) function where the elasticity of substitution between labour and capital is equal to one (European Commission, 2014; Chalaux and Guillemete, 2019).

$$
G D P=E L^{\alpha} K^{1-\alpha}
$$

In the OECD framework, GDP corresponds to GDP volume, E represents labouraugmenting efficiency, $L$ denotes total employment sourced from national accounts, $\mathrm{K}$ measures the whole-economy stock of capital excluding residential structures, and $\alpha$ denotes the share of national income accruing to labour, assumed to be 0.67 and constant in all countries. Total employment (L) is further decomposed into the combination of measures of the size of the working age population (WAP), the labour force participation rate (LF / WAP) and the unemployment rate (U / LF).

$$
L=W A P * \frac{L F}{W A P} *\left(1-\frac{U}{L F}\right)
$$


The level of potential output is then estimated by introducing (2) into (1) and substituting each variable by its trend component (with the exception of the capital stock), as indicated by the superscript TR in equation (3):

$$
G D P^{T R}=\left[E^{T R} * W A P^{T R} * \frac{L F}{W A P}^{T R} *\left(1-\frac{U}{L F}^{T R}\right)\right]^{\alpha} K^{1-\alpha}
$$

All trend components are obtained by applying a Hodrick-Prescott filter, with the exception of the trend unemployment rate (NAIRU), which is estimated using a Kalman filter within the context of a Phillips curve equation with anchored inflation expectations. The capital stock remains unadjusted under the assumption that it reflects its maximum potential contribution to the economy and full utilisation.

This brief description of the potential output estimation method used at the OECD emphasises the importance of an accurate measurement of output, labour, capital and MFP. Certainly, the method used to de-trend all variables also plays an important role for the estimation of potential output and output gap.

Figure 3.13 presents OECD estimates of MFP growth and the contributions to GDP growth from labour volume (hours worked) and capital volume (net capital stock) for selected OECD countries. The measures of factor inputs used in this framework account for changes in the volume of inputs, ignoring any change in their composition (or "quality"). As a result, changes in the skills of workers or in the capital quality are captured by MFP measure.

Figure 3.13 MFP growth accounting for hours worked and net wealth capital stocks Average annual growth, percentage, 2010-2019 (or latest available

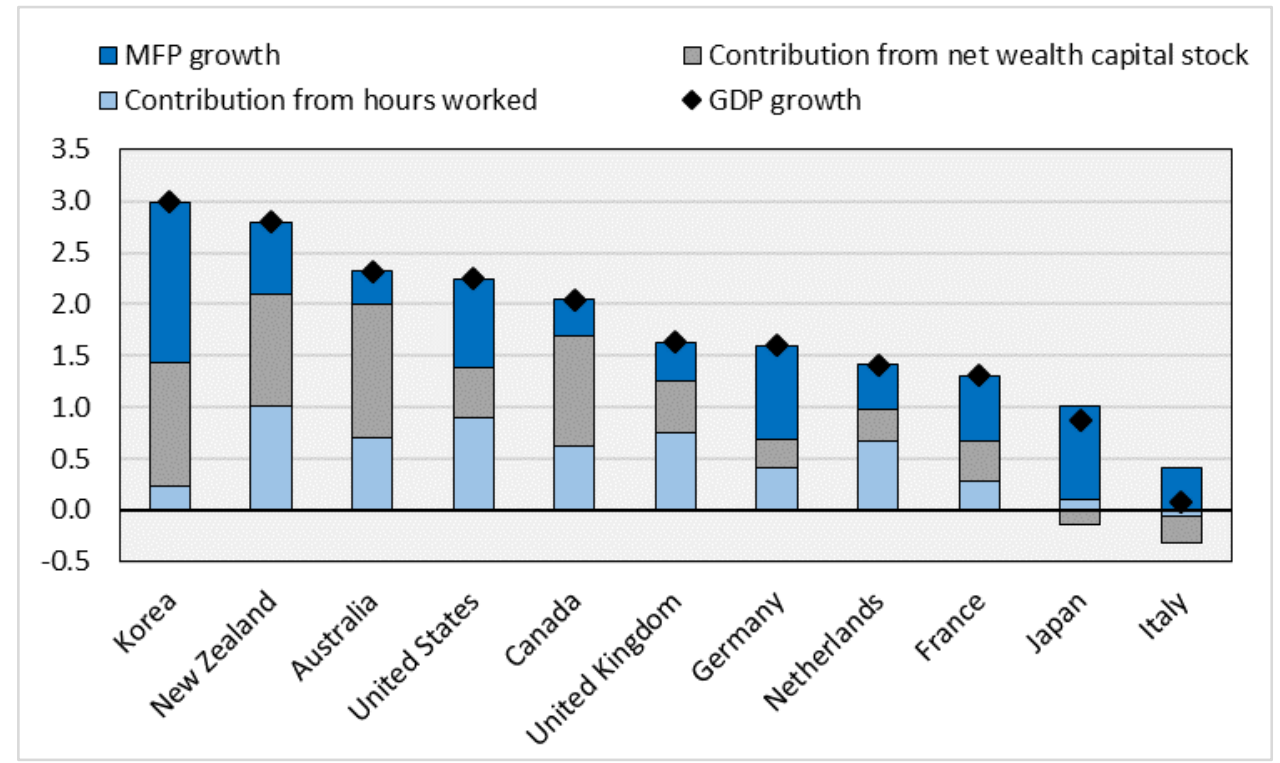

Source: OECD estimates based on the OECD Productivity Statistics database, November 2020.

Note: These estimates are based on the assumption that the depreciation of net capital stocks follows a geometric pattern. The labour income of the self-employed is assumed to be equal to that of employees and the capital cost share is derived as one minus the labour cost share, which in turn is calculated as total labour income as a share of GDP. Access the data. 
The measurement of MFP is especially important for APO economies, where for much of their recent history there has been a pattern of relatively weak MFP growth, with the principal contributions to output growth coming from factor inputs. The prime example is Thailand, which followed a similar path to other East Asian emerging economies, and where productivity gains made during its early industrialisation came primarily from the reallocation of under-utilised rural labour from agriculture to labour-intensive manufacturing, supported by capital accumulation and imported technology embodied in foreign direct investment (OECD, 2018c). Thailand's 12th National Economic and Social Development Plan sets a target of over $2.5 \%$ annual growth both for labour productivity and MFP, a target enshrined in Thailand 4.0 and to be achieved through innovation, human capital development, regulatory reform and infrastructure development. An accurate accounting of MFP, and by extension, of its fundamental components, constitutes a key piece of evidence and a "yardstick" for country specific policies in the direction of improved productivity performance.

In Turkey, capital formation has contributed more to GDP growth over the longer term than in comparable catching-up countries (OECD, 2018b). The extensive revisions to the national accounts in 2016 made this even more evident. Analysis by the IMF also concluded that, since 2012, aggregate investment has exceeded its expected level (IMF, 2018). However, overall, the quality of capital formation has been falling short. In particular, the contributions of MFP and information technology to economic growth remain below those observed in comparable countries (OECD, 2018b).

Another example is Malaysia, which since the mid-1990s has embarked on a programme to promote innovation and productivity to transform the country from an input-driven to a knowledge-based economy (EPU, 2015). Despite the intensity of public investment and initiatives aiming to boost productivity, Malaysia's productivity levels remain weak and economic growth in the country is largely driven by factor inputs, especially capital increases in residential and non-residential buildings (OECD, 2019b).

In India, as a counterpoint, the analysis of contributions to GDP growth reveals that MFP has been driving potential GDP growth over the last two decades, while the contributions from both labour and capital inputs have been declining over the last ten years. Lifting investment, addressing infrastructure shortages and sustaining job creation is key to boost productivity and growth (OECD, 2019a).

All previous examples taken from OECD Economic Surveys clearly show the importance of accurate measures of factor inputs and MFP for economic analysis and to provide support for policy recommendations. 


\section{e. Statistical recommendations}

\section{KEY MEASUREMENT CHALLENGES}

STATISTICAL RECOMMENDATIONS

\section{Measuring hours worked}

The appropriate measure of labour input for productivity measurement, ignoring the composition of the workforce, is the number of total hours actually worked by all persons employed. Unlike measures of population or employment, such a measure captures variations in the incidence of part-time work, absences from work and shifts in normal working hours, and hence, bear a closer relation to the amount of productive services (labour input) actually provided by workers in the production of goods and services.

Different NSOs use different data sources and methods in their measurement of total hours actually worked by all persons employed. This has implications for cross-country comparisons of hours worked and productivity. In particular, an upwards bias has been identified in direct method estimates of hours worked based on labour force surveys, as compared with approaches using a component method.
NSOs are encouraged to follow ILO (2008) and 2008 SNA guidance on the compilation of measures of total hours actually worked by all persons employed and to prefer the use of hours worked rather than persons or job-counts.

When measuring hours actually worked, NSOs should, where possible, apply a component method exploiting their full range of data sources in order to capture deviations from paid/usual hours worked (i.e. annual and sick leave, overtime, over or underreporting etc.) and avoid the self-reporting bias that affects direct method estimates.

\section{Measuring net wealth capital stocks}

The measurement of net capital stocks relies on long series of GFCF with a minimum level of detail in the asset breakdown. This is to ensure asset groupings are adequately homogenous, such that they can be treated with the same age-price and retirement profiles. However, some countries do not yet produce such a breakdown, and many countries still struggle to measure relatively new asset classes such as different types of ICT equipment and intellectual property products. the perpetual inventory method (PIM). Assumptions must be made regarding the form of the age-price and retirement profiles for each group of assets. Each and any of these assumptions may have a substantial impact on the eventual estimate of net capital stocks and the other figures derived on their basis.

Asset service lives are strongly influenced by country-specific factors such as the relative prices of capital and labour, interest rates, climate and government investment policies. Errors in service lives assumptions affect the reliability of net capital stock estimates, as the use of longer (shorter) service lives than the actual ones will lead to an overestimation (underestimation) of the capital stock.

The PIM relies on long GFCF time series for each asset. In theory, the required GFCF time series for each asset should be as long as the intended capital stock time series, plus the maximum service life for this asset. This may not always be the possible, as the longest living assets, usually dwellings and/or buildings and structures, often have an average service life above 60 years, and up to 100 years in some cases. Therefore, it is often the case that countries must estimate an initial capital stock from which their PIM can begin.
NSOs are encouraged to compile and disseminate GFCF with detailed breakdowns by asset type. In general, the greater the level of investment detail for which separate deflators and depreciation rates are available, the more reliable and precise will be the estimates of net capital stocks and, hence, the estimates of consumption of fixed capital (OECD, 2009). Admittedly, crude assumptions can always be applied to break down investment series by asset type, but given their access to original data sources, NSOs are likely in a better position than external researchers to provide high-quality detailed investment series for their country. A detailed asset breakdown is essential not only for the application of the PIM, but also in its own right to inform policy dialogs centred around specific types or groups of assets (e.g. ICT assets, or infrastructure assets).

The choices made in the PIM should be based on and supported by empirical evidence. To guide themselves, NSOs should look at the different studies that have derived depreciation profiles, service lives, and retirement patterns from empirical evidence. Whenever possible, advice from experts, researchers and businesses, as well as comparisons of national results with those obtained in other countries should be used as a sense check for these assumptions.

Asset service lives should be chosen carefully and on the basis of the most robust available data. Various potential sources exist to form the decision on asset service lives including: tax authorities, company accounts, statistical surveys, administrative records, expert advice and other country estimates. While other countries' estimates may provide a broad sense check, given the country specific factors at play, they should not be adopted without question.

Any attempt to estimate initial capital stocks in the absence of sufficiently long time series of investment should rely on the construction of benchmark estimates based on other sources than GFCF series (i.e. value of stocks sourced from census, surveys and administrative records) and some variant implementation of the PIM, for example, relying on plausible assumptions about the long-run growth rate of net capital stocks or investment. A sensitivity analysis of the results obtained using alternative approaches is needed in any case. 
Accurate price indices for groups of assets are essential for the calculation of net capital stocks. When the quality and specification of the underlying products change very rapidly, as is the case for ICT assets, the products underlying the construction of the price index are likely not to be representative of the whole asset group and/or comparable over time. For this reason there is a risk that the resulting price index reflects not only variation in asset prices over time but also changes in quality and product specification.
In order to address the risk that ICT price indices pose in the calculation of net capital stocks, NSOs should attempt to construct constant-quality deflators for ICT assets. NSOs in APO economies are encouraged to keep abreast of the statistical literature on the price measurement of ICT products and to compare their deflators with those used in OECD countries. Remaining differences in ICT price deflators across countries should be analysed and documented with great care.

\section{Measuring GDP per hour worked and baseline multifactor productivity (MFP)}

As with the other measures of labour productivity, the quality of output per hour estimates rely on the quality of the input series, in this case: GDP and total hours actually worked. Of particular importance in this case is consistency between the coverage of these input series.

NSOs should work carefully to compile accurate estimates of GDP, employment and hours worked in line with international standards (i.e. 2008 SNA, ILO 2008 etc.). Particular care should be taken with regard to consistency between those series. For example, if informal output is included in estimates of GDP, informal workers should be included in employment estimates and the variation in hours worked between formal and informal workers should be accounted for in estimates of average hours actually worked.

\section{Measuring multifactor productivity (MFP) accounting for hours worked and net capital wealth stocks}

While the net (wealth) capital stock is an important indicator for economic analysis, it is not the most suitable measure of capital input for growth accounting and productivity analysis. In this case, capital input measures should capture the productive capacity of capital as opposed to its market value. Indeed, the change in the market price of an asset does not necessarily translate to an equal change in the productive capacity or efficiency of that asset, especially at the beginning of an asset's life.
Net capital stocks should only be used in the calculation of MFP if there is no viable measure of productive capital stocks and capital services. Guidance on the calculation of productive capital stocks and capital services is provided in Section 4.b. Capital services are the ideal measure of capital input for productivity analysis and the appropriate target for NSOs. 


\section{Enhanced productivity measures}

\section{a. Measuring labour: composition adjusted labour input (CALI)}

\section{$\underline{\text { Introduction }}$}

Traditional measures of labour input, such as employment or hours worked, account only for the volume of labour. These measures treat the labour input of all workers equally, ignoring heterogeneity among workers with potentially vastly different skills and different contributions to output and productivity changes. Indeed, workers with different skills are not fully interchangeable and firms treat them as distinct inputs by paying different rates. The need to account for not only the volume of hours worked, but also the skills and characteristics of the workforce was laid out in the Measuring Productivity OECD Manual (OECD, 2001), and subsequently in the System of National Accounts 2008 (2008 SNA). The measure of labour input used in the growth accounting framework should properly account for the heterogeneity of labour, necessarily differentiating between hours worked by persons with different characteristics. Measuring labour input through only the volume of hours worked foregoes some of the explanatory power of one of the factor inputs, often resulting in the underestimation of the contribution of labour to real output growth and the overestimation of growth in multifactor productivity (MFP). An accurate accounting of both the volume and composition of hours worked, that is a measure of Composition-Adjusted Labour Input (CALI) or labour services ${ }^{24}$, provides policy makers and analysts with a more accurate view of the sources of economic growth and more accurate measures of MFP.

Taking into account the composition of workers in the growth accounting framework is particularly important as it provides analysts and policy-makers with a clearer perspective on the sources of growth, and, in this case, away from the residual productivity growth and towards the contribution of human capital. In fact, a comparison of adjusted and unadjusted measures - i.e. comparing growth in composition-adjusted labour input with growth in total hours worked - affords a better view of pure compositional change in the workforce, one important aspect of human capital accumulation. In recent decades, most countries have experienced some improvement in the general level of education of their population, with citizens staying in school longer and more people achieving a higher level of educational attainment. Figure 4.1 shows the growth in the average years of schooling 25 in both OECD and APO member economies across the period 1970-2010. Starting from a lower base, the APO economies have experienced greater growth in their average years of schooling, implying improvements to the general skill level of their workforce. Given the fast progress in their education

\footnotetext{
${ }^{24}$ The terms composition-adjusted labour input and labour services are synonymous and refer to the same concept for the purposes of this report. They will be used interchangeably to describe labour input measures that account for both the volume and the composition of labour used in production. CALI measures are also referred in the economic literature as qualityadjusted labour input (QALI).

25 It should be noted that years of schooling are not necessarily the most accurate or comprehensive measure of overall human capital improvement. It has been acknowledged for some time that while most measures of schooling account only for "quantity", there is also substantial variation in the "quality" of education, creating some bias in traditional estimates (Behrman \& Birdsall, 1983).
} 
institutions, a measure of productivity that incorporates the changing composition of the workforce is a sensible aspiration, even with the associated data burdens.

Figure 4.1: Average years of schooling in the APO and OECD areas $1970,1980,1990,2000$ and 2010

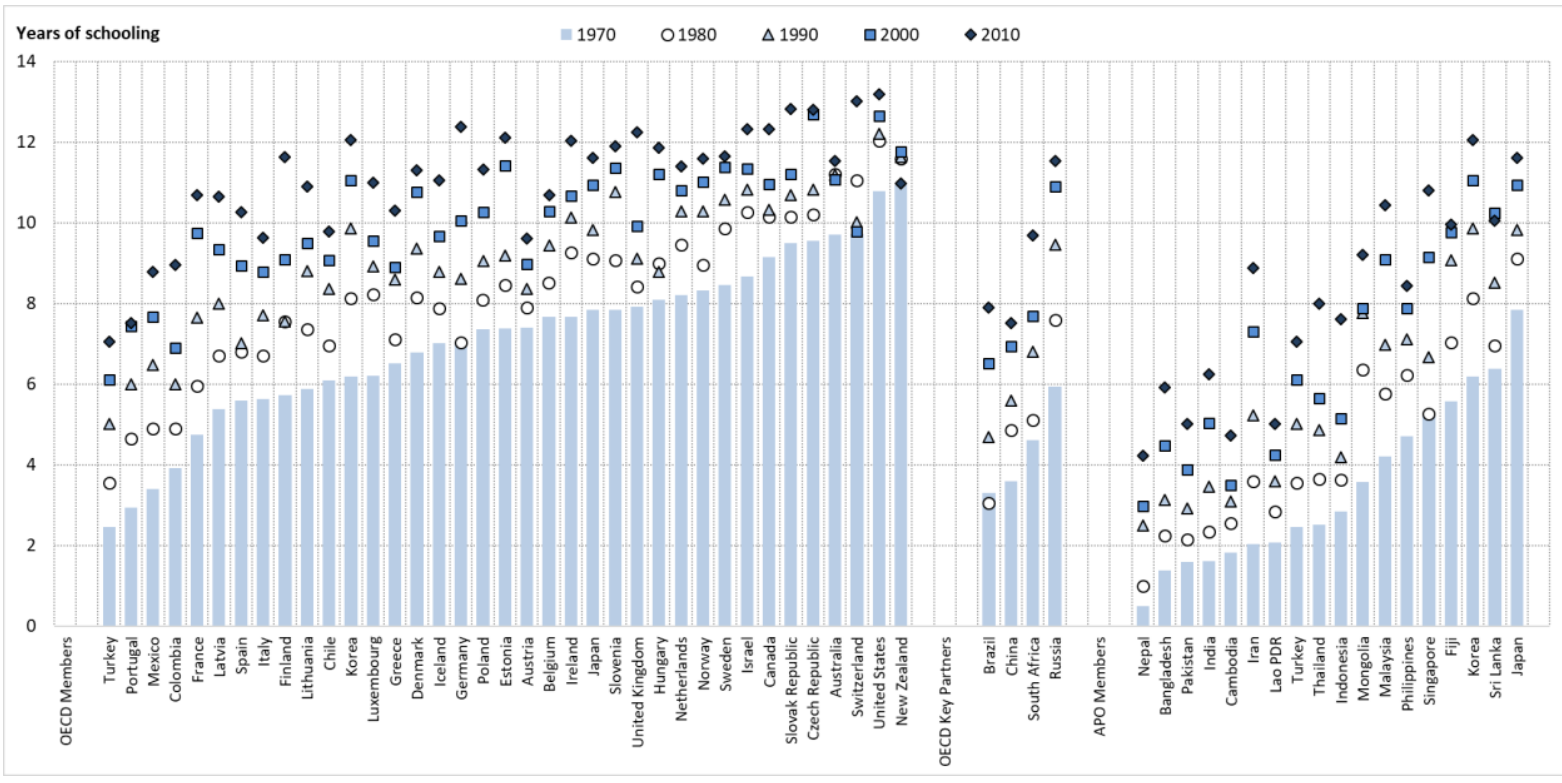

Source: Barro and Lee (2014).

Note: Access the data.

\section{Methodology}

Most approaches, past and present, to the estimation of labour services rely on the same conceptual and measurement basis as the earlier work of Jorgenson and Griliches (1967). In the compilation of labour services, the volume measure of hours worked must first be divided between different groups of workers. Workers are generally split, at a minimum, by educational attainment, as a proxy for skills, and by age, as a proxy for experience. Some approaches also break down workers by a range of other dimensions, including employment status, sex, industry and occupation.

In order to meaningfully re-aggregate the volume of hours worked by different groups of workers, each group is then weighted by their relative productivity. While each group's productivity is not directly observed, the theory of the firm stipulates that, under specific conditions - i.e. competitive input and product markets - labour of a certain type will continue to be hired up until the point where the cost of an additional unit of labour is exactly equal to the additional revenue that this unit generates. As such, most approaches to adjusting labour input for changes in its composition, weight the hours worked of each cross-classified group of workers by their respective wage shares, specifically by each group's share in total labour compensation. ${ }^{26}$

\footnotetext{
${ }^{26}$ Wages are an imperfect proxy for marginal productivity for various reasons. For example, For example, important differences in labour market regulations across countries may drive relative differences in wages of workers with different characteristics, introducing differences in relative wages that do not reflect differences in productivity (Eurostat, 2016). In addition,
} 
As endorsed in OECD (2001), most approaches use the Törnqvist index to create the aggregated growth rate of labour services, which is the weighted average of the growth rate of hours worked by each group of workers, where the weight assigned to each is their share in total labour compensation. Formally, the growth rate in labour services can be calculated as:

$$
\ln \left(\frac{L S E R_{t}}{L_{S E R_{t-1}}}\right)=\sum_{i=1}^{N} \frac{1}{2}\left(v_{i, t}+v_{i, t-1}\right) \ln \left(\frac{H R S_{t}}{H R S_{t-1}}\right)
$$

Where,

$L S E R_{t}$ is the volume of labour services in year $t$

$H R S_{t}$ is the total number of hours worked by all persons in employment in year $t$

$N$ is the number of groups of workers

$v_{i, t}=\frac{w_{i, t} H R S_{i, t}}{\sum_{i=1}^{N} w_{i, t} H R S_{i, t}}$ is the share of labour costs of group $i$ in year $t$ in total labour costs in year $t$

And the growth rate of labour quality alone $(L Q)$ is derived by removing the growth of the volume of hours worked from the total growth in labour services:

$$
\begin{aligned}
\ln \left(\frac{L Q_{t}}{L Q_{t-1}}\right)=\ln \left(\frac{L S E R_{t}}{L S E R_{t-1}}\right)-\ln \left(\frac{H R S_{t}}{H R S_{t-1}}\right) \\
=\sum_{i=1}^{N} \frac{1}{2}\left(v_{i, t}+v_{i, t-1}\right) \ln \left(\frac{H R S_{t}}{H R S_{t-1}}\right)-\ln \left(\frac{H R S_{t}}{H R S_{t-1}}\right)
\end{aligned}
$$

\section{Literature review}

The principle modifications between different approaches to the compositional adjustment of labour input are in the characteristics by which they divide workers. This is, in part, due to conceptual differences, but also heavily depends on the availability of data and the sample sizes therein. Table 4.1 details the methods used by NSOs and other research bodies to compute CALI measures, including the data sources used in each approach. Some approaches venture to account for several workers' traits. Jorgenson et al. (1987), for example, used up to five categories (age, education, employment class, occupation and sex) to cross-classify workers in each of 51 industries in the United States, with the resulting composition measure reflecting both the contribution of each characteristic and the interactions between them. More recent approaches, such as that of the Asia QALI project (Nomura and Akashi, 2017), which builds upon earlier work for Singapore (Nomura and Amano, 2012) and for Japan (Nomura and Shirane, 2014), also account for numerous factors, those being educational attainment, age, sex and employment class. Other approaches, such as those of EUKLEMS (Stehrer, 2019), INSEE (Cabannes et al., 2013), as well as those currently applied by the Australian Bureau of

discrimination in the labour market presents a particular constraint/challenge for this core assumption, as gender pay gaps and differences in wages may not be driven by differences in workers marginal productivity. 
Statistics (ABS, 2015), the Office for National Statistics (ONS) in the United Kingdom (Sgaravatti, 2020), and the Bureau of Labour Statistics (BLS) in the United States (BLS, 2007), rely on a slightly slimmeddown subset of categories, namely age, education and sex, at a more or less detailed industry breakdown. ${ }^{27}$ Other approaches differentiate between an even smaller number of characteristics, such as Eurostat's QALI database (Eurostat, 2016) that use only education and age to classify workers in each industry, or the Conference Board's Total Economy Database (TED), which differentiates workers based only on educational attainment (Vries and Erumban, 2017).

Given the nature of the operation, requiring micro-data on hours worked and earnings, together with national accounts aggregates to benchmark these against, the calculation of a CALI index is rarely approached using a single data source. As highlighted by Table 4.1, most approaches use some combination of household surveys (most often labour force surveys (LFS)), administrative sources, enterprise earnings surveys and population censuses, occasionally, in combination with national accounts. Both Eurostat's QALI Database and the data held in the EUKLEMS project use the EU-LFS, EU-SES and national accounts as the foundation of their approach, each providing information on at least all of the 27 EU member countries (Eurostat, 2016; Stehrer, 2019). The BLS approach utilises information from the Current Employment Survey (CES), the Current Population Survey (CPS) and the National Compensation Survey (NCS) (BLS, 2007); the United Kingdom's QALI index builds on information from the National Labour Force Survey (LFS), the Annual Survey of Hours and Earnings (ASHE) and data on hours worked from the ONS productivity accounts (Sgaravatti, 2020); and the Asia QALI database exploits different sources for each country, using mostly population and housing census' and labour force surveys (LFS) (Nomura and Akashi, 2017).

The data burden presented by the estimation of labour services reinforces the argument for the calculation of these measures at the national level. NSOs have access to the necessary data, and the detailed knowledge of their own data sources, to generate high quality estimates of CALI. Therefore, they are encouraged to produce their own CALI estimates for productivity analysis.

\footnotetext{
${ }^{27}$ The exercise carried out at INSEE classifies workers according to their age (4 categories), sex ( 2 categories) and the qualification of their job (3 categories, namely "non-qualified", "qualified" and "highly qualified").
} 


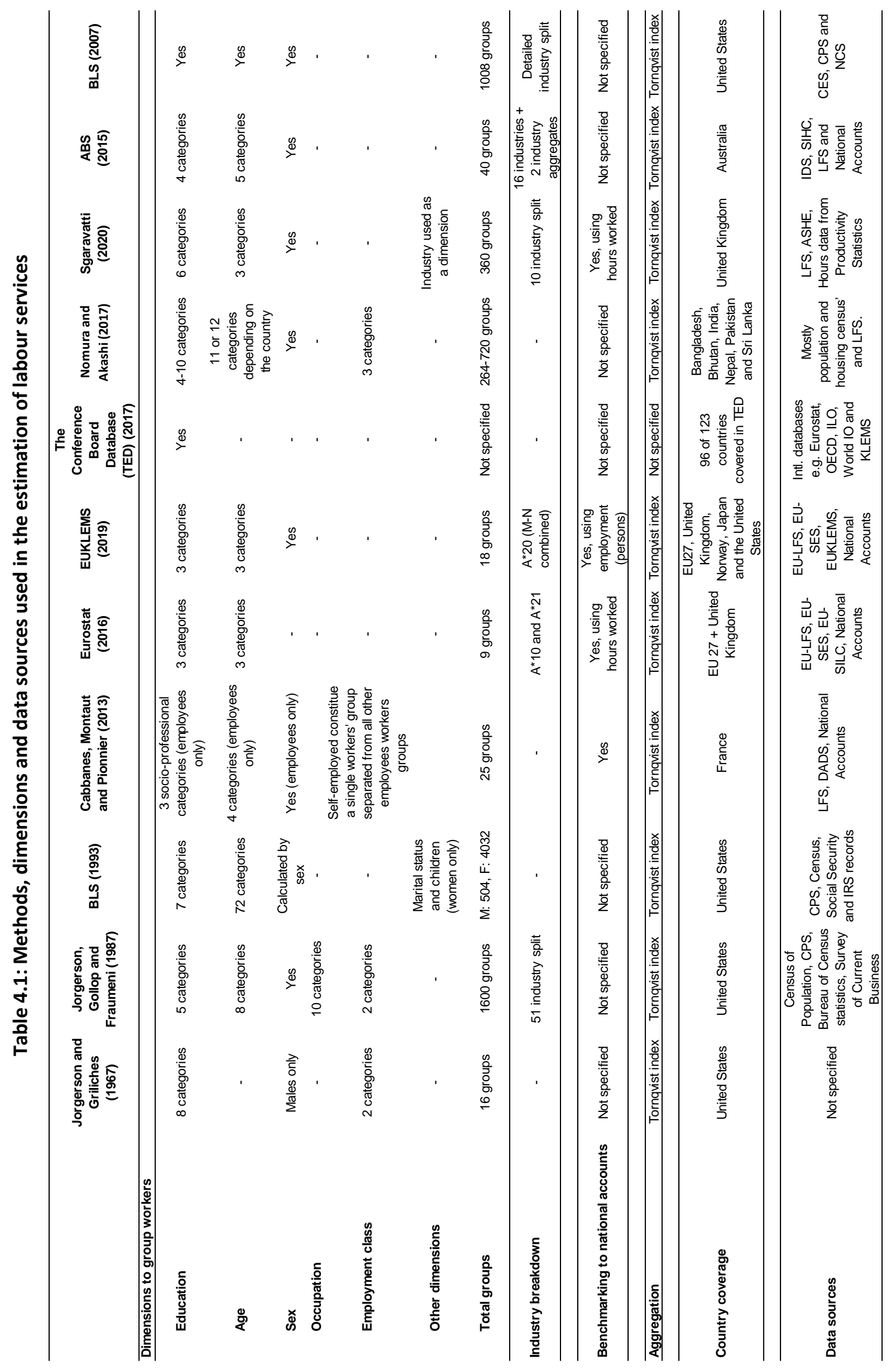


Notwithstanding estimates produced at the national level, the Asia QALI Database takes a novel approach to the estimation of cross-country comparisons of labour services (Nomura and Akashi, 2017; APO, 2019). For each of Bangladesh, Bhutan, India, Nepal, Pakistan and Sri Lanka, they calculate bespoke adjusted labour input measures using country-specific data sources:

- Bangladesh - Population and Housing Census (PHC) and the Labour Force Survey (LFS).

- Bhutan - Population and Housing Census of Bhutan (PHCB) and Labour Force Survey (LFS).

- India - Census of India (COI) and Employment and Unemployment Survey (EUS).

- Nepal - National Population and Housing Census (NPHC) and the Labor Force Survey (LFS)

- Pakistan - Population Census (PC), and the Labour Force Survey (LFS).

- Sri Lanka-Census of Population and Housing (CPH) and the Labour Force Survey (LFS).

The Asia QALI Project extends to all APO member economies, as detailed in the APO Databook (Appendix 7; Table 7). In most cases, with the exception of the Philippines, more than one data source is used to generate the estimate of labour services. For additional economies they use a range of data sources, including: population and housing Census'; labour force surveys; socio-economic surveys; statistical yearbooks; employment and unemployment surveys; and surveys on wages and salaries. The Asia QALI Project, for each country, makes use of the best data available to researchers. However, the potential of measures created at the level of the NSO should not be discounted. Such an effort, possibly in coordination with the Asia QALI Project, might benefit from access to additional or more detailed data sources, as well as from specific technical knowledge relating to those sources.

As mentioned previously, this approach divides workers into cross-classified groups by education, age, employment status and sex. However, unlike other approaches in the literature, the number of groups within each dimension for each country is not uniform and is instead defined by the data sources used. Table 4.2 shows, for selected countries, the number of groups delineated for each worker classification, as well as the total. For all countries included in the table, employment status is split into three groups, generally employees/employers, own account workers/self-employed, and unpaid family workers/casual labour, and sex is divided into two groups, female and male. Most countries workers' are split into 11 age groups, with the exception of Bangladesh and Sri Lanka, where they are split into 12 groups. Countries workers' are broken down into four groups in the case of Pakistan and ten groups in the case of Bangladesh (from 2003-2015).

Table 4.2: Dimensions used in the Asia QALI Database for Bangladesh, Bhutan, India, Nepal, Pakistan and Sri Lanka

\begin{tabular}{|c|c|c|c|c|c|}
\hline & Education & Age & Employment status & Sex & Total groups \\
\hline Bangladesh & $\begin{array}{c}5 \text { groups } 1970- \\
2003 \& 10 \text { groups } \\
2003-2015\end{array}$ & 12 groups & 3 groups & $F \& M$ & $\begin{array}{l}360 \text { groups } 1970- \\
2003 \& 720 \text { groups } \\
2003-2015\end{array}$ \\
\hline Bhutan & 7 groups & 11 groups & 3 groups & $F \& M$ & 462 groups \\
\hline India & 7 groups & 11 groups & 3 groups & $F \& M$ & 462 groups \\
\hline Nepal & 5 groups & 11 groups & 3 groups & $F \& M$ & 330 groups \\
\hline Pakistan & 4 groups & 11 groups & 3 groups & $F \& M$ & 264 groups \\
\hline Sri Lanka & 5 groups & 12 groups & 3 groups & $F \& M$ & 360 groups \\
\hline
\end{tabular}

Notes: OECD elaboration made based on Nomura and Akashi (2017). 


\section{Measurement challenges}

Many approaches, including that of the Asia QALI Database, incorporate sex as a dimension to divide workers. However, while men and women constitute part of the heterogeneity of the workforce of in a country, implementing sex as a dimension presents a unique problem owing to the way that the productivity of each group of workers is approximated in the estimation of labour services. As detailed previously, the hours worked by each cross-classified group of workers are weighted by their respective wage shares. In large part, differences in the wages of different groups of workers should reflect variations in their relative productivity. In theory, firms should hire workers only up to the point where their remunerations are equal to the value they create for the firm. However, in reality, relative wage differences may reflect other factors, including conscious or unconscious bias against specific types of workers, as demonstrated, for example, by the gender-pay gap present in many countries across the world (OECD, 2012). As a result, in the presence of such a gender-pay disparity, a measure of labour services incorporating sex as a dimension would show a reduction in labour services, in reaction to increased female participation in the labour market. These signals are misleading and do not represent, all other things being equal, any real change in the skills or productivity of the workforce.

Female participation is generally low in APO economies, and while it has been increasing over the past few decades, substantial inequality remains in terms of the working patterns, types of jobs and wages for women. In Japan, for example, female participation rates have increased in recent years, but the share of women in part-time work is high and the share in management positions is low relative to the OECD average (OECD, 2019c; OECD, 2020b). The gender wage gap in Japan (25\%) and Korea (35\%) are among the highest in the OECD area (Figure 4.2). In Korea, this is driven by women withdrawing from the labour market after having children, partially reflecting deficiencies in early education and childcare (OECD, 2018a). Admittedly, as the CALI approach controls for other worker characteristics such as education or occupation and within each category, the gender wage gap is likely smaller than the one shown in Figure 4.2. Nevertheless, given the typically large wage gaps in Asia, taken together with increasing female participation, statisticians should consider that the inclusion of sex as a dimension in labour services measures for the Asian economies would likely bias the results, providing misleading conclusions. Notwithstanding the importance of gender differentiated data more generally, which is crucial to build a better understanding of gender-pay gaps and other forms of bias based on gender, it is not recommended to include gender as a dimension in measures of CALI. 
Figure 4.2: Gender wage gaps in the OECD

2000 and 2019 (or latest year)

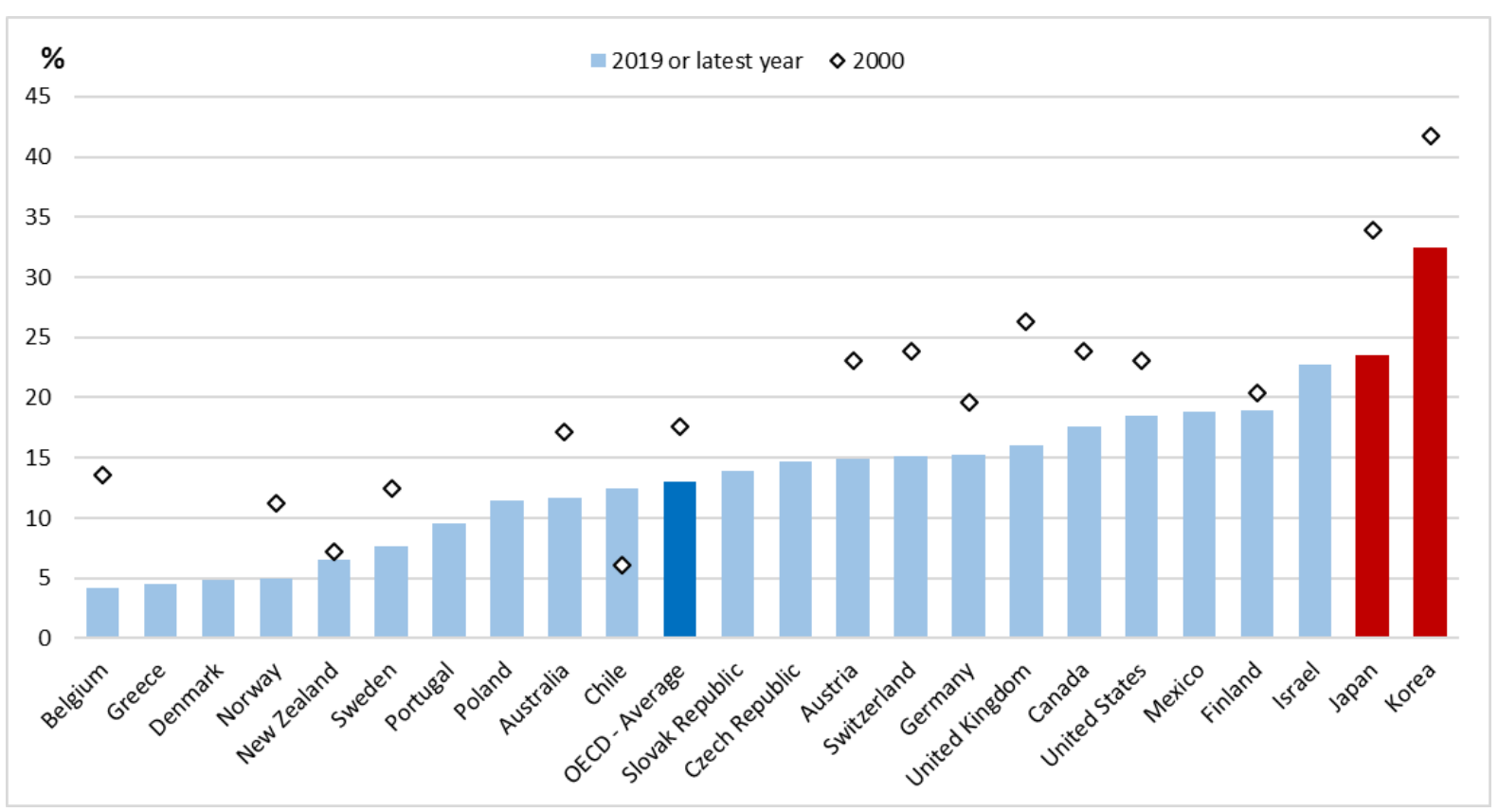

Source: OECD Employment Database, November 2020.

Notes: Data for Australia, Austria, Denmark, Finland, Germany, Greece, Israel, Poland, Portugal, Switzerland and the OECD average refer to 2018. Data for Belgium and Chile refer to 2017. Note that the gender wage gap in this Figure is not corrected for differences in observable characteristics (e.g. education, occupation) between men and women that may partly explain it. However, to account for gender differences in working hours and parttime employment, the gap is based where possible on wages for full-time employees only. Access the data.

Data on labour compensation are regularly available from business surveys and administrative sources, however, these sources often do not include the self-employed, making their inclusion in labour services estimates, for many countries, difficult or impossible. In many cases, an assumption must be made in order to include the self-employed. For example, in the case of the Asia QALI Database a country-common assumption is applied, with exceptions for economies where reliable data are available. Specifically, the Asia QALI Database assumed a wage differential ratio (WDR), i.e. the ratio between the hourly wages of non-employees to hourly wages of employees, in each elementary group of workers of 0.5 for Cambodia, Hong Kong (China), Japan, Korea, Lao PDR, Chinese Taipei, Singapore and Viet Nam, and 0.2 for all other economies in the database.

\section{$\underline{\text { Results }}$}

Countries at different stages of development, and with differing policies relating to their educational institutions and labour markets, are expected to show different trends in their estimates of labour services. Figure 4.3 shows how the rate of QALI growth varied across the European and Asian economies between 2003 and 2017, using the Eurostat and Asia QALI databases respectively. ${ }^{28}$ The

${ }^{28}$ It should be noted that the Eurostat and Asia QALI databases are constructed using different data sources and differing assumptions, meaning that cross-country comparisons should be treated with the appropriate caution. Specifically, they differ in the dimensions used to split the 
APO member economies tended to experience substantially greater growth in labour services over the period than their European counterparts. With a few exceptions, namely three of the highest income APO members (Japan, Hong Kong (China) and Korea), the majority of the APO economies experienced labour services growth of over 2\% between 2003 and 2017, while all European countries covered observed less than $2 \%$ annual growth.

Figure 4.3: Labour services growth in the $A P O$ and $O E C D$ areas Average annual QALI growth, 2003-2017

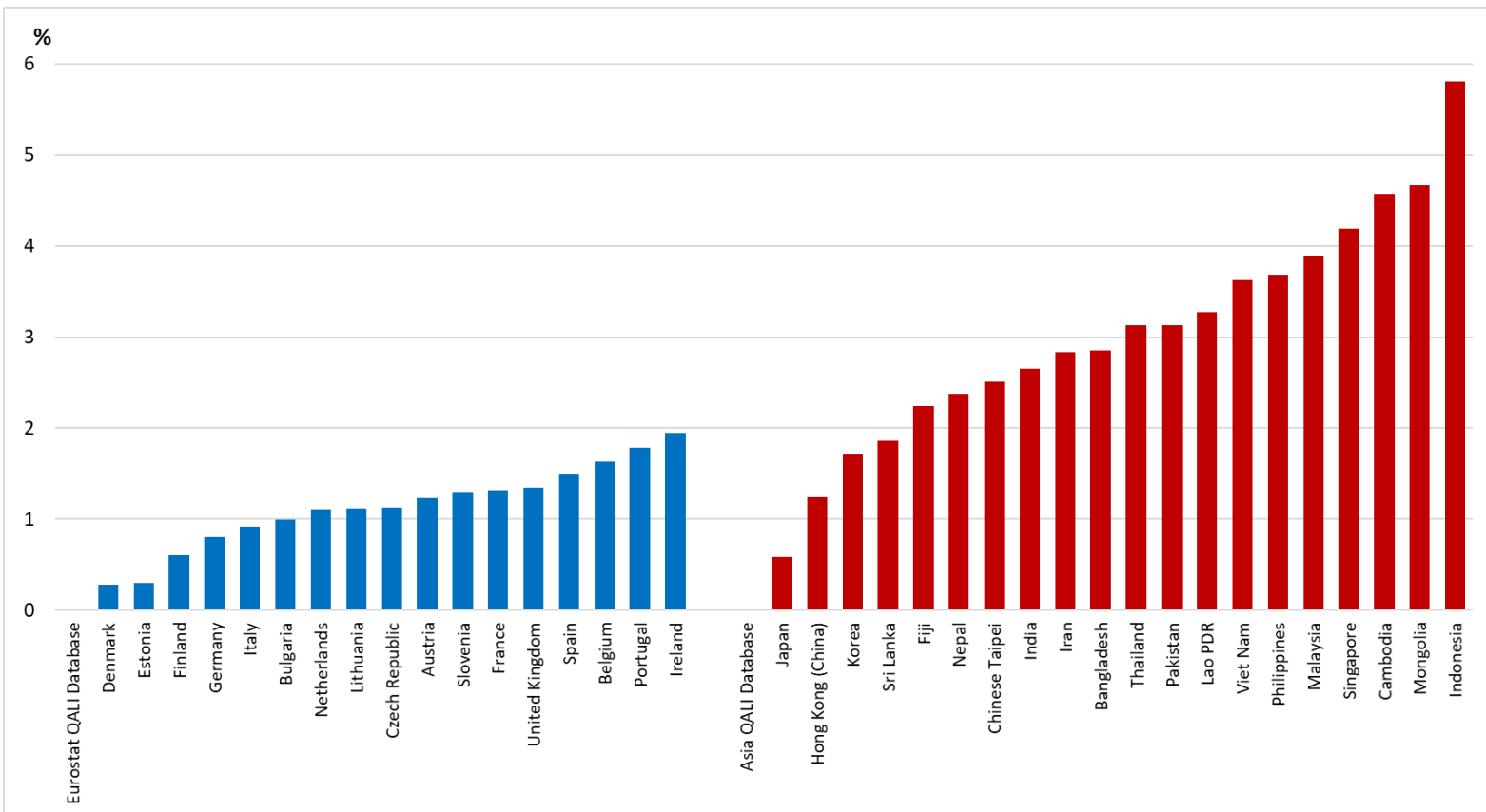

Source: Eurostat QALI Database and APO Productivity Database 2019, November 2020.

Note: Access the data.

Decomposing labour services into a volume and composition component provides a view of changes in the accumulation of human capital in an economy. Figure 4.4 shows the annual average growth in labour services in the APO economies alongside its constituent components, i.e. growth in the volume of hours worked and changes in the composition of labour, between 2003 and 2017. The evidence indicates that growth in the composition of labour (or labour quality) made a positive contribution to labour services in almost all economies over the period. The greatest contributions from changes in labour composition are observed in Indonesia, Thailand and Mongolia, where the labour composition component grew by $3.7 \%, 3.5 \%$ and $2.2 \%$, respectively. Even for the higher income APO member economies where labour services growth has been much slower, such as Japan and Korea, composition has still seen improvements. It is important to note that this period includes the 20082009 recession, which had a substantial impact on labour markets globally. During a recession, the compositional effect generally points to an increase in the average skill level of those in employment 
(i.e. an increase in labour quality), as firms are likely to shed labour and/or reduce hours worked among lower-skilled workers, and to hoard higher-skilled individuals.

Figure 4.4: Breaking down labour services growth

Average annual growth in the volume and composition of hours worked, 2003-2017

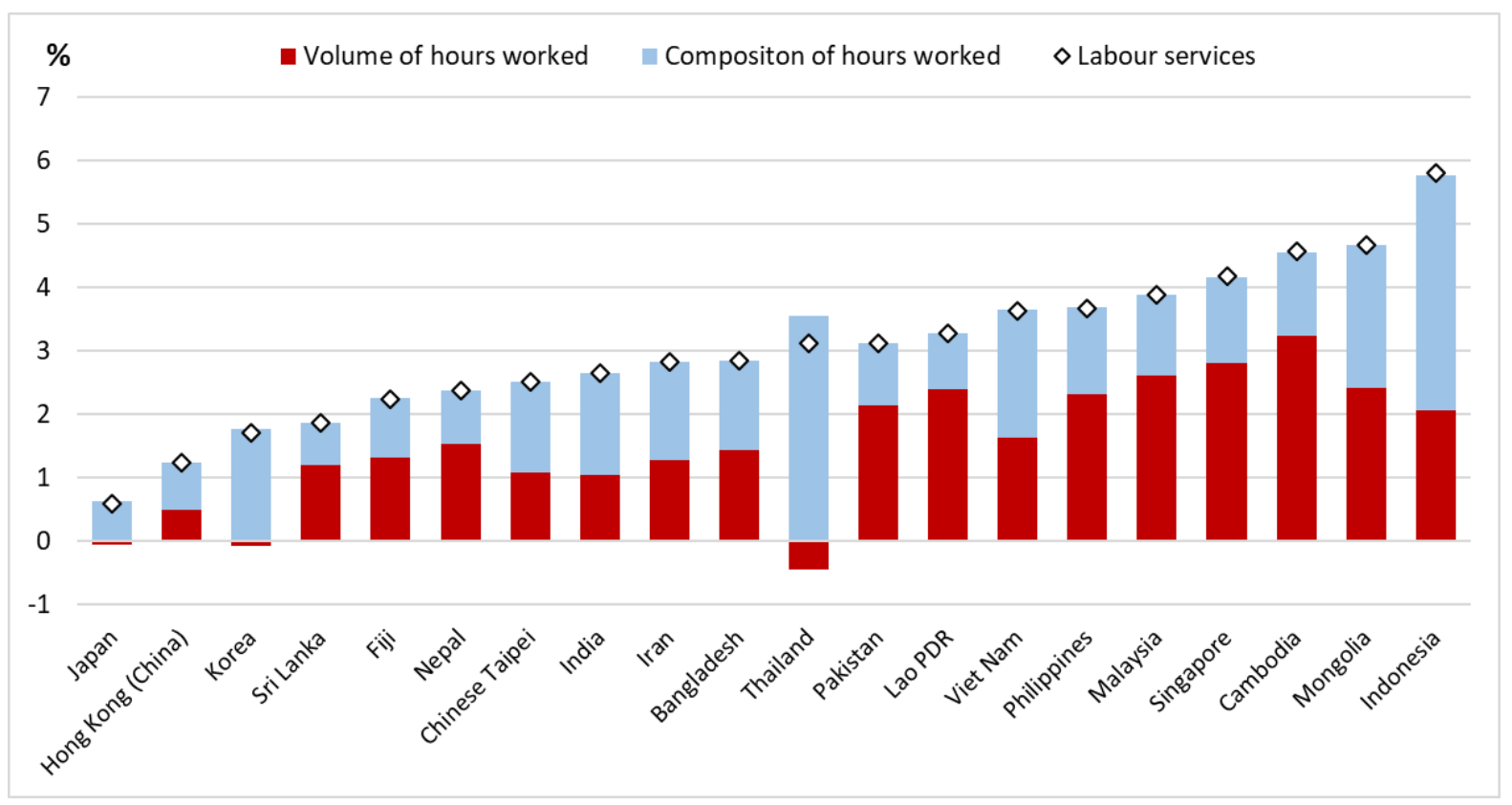

Source: OECD estimates based on data from the APO Productivity Database 2019.

Note: Access the data.

\section{Policy relevance}

Reliable and accurate estimates of labour services facilitate the effective monitoring of the evolution of the composition of the labour force and are a prerequisite for a comprehensive approach towards MFP measurement. These estimates of labour services can also be directly applied to labour market and education policy implementation and evaluation. Indeed, the building blocks for labour services measurement - i.e. the hours worked and wages of the workforce disaggregated by education, age, employment class, and other characteristics - are informative for economic policy in their own right.

NSOs should learn from and capitalise on the work of other countries and projects in this domain. They should be encouraged to produce their own estimates at a national level, following the generally accepted methods described above, and exploiting all the data sources at their disposal. These national estimates are expected to be superior to those produced centrally for all countries. However, the Asia QALI Project, and other cross-country approaches, are a rich source of data and experience, and should be built upon. Collaboration between country-specific NSOs and existing centralised projects may well be the ideal path towards the development and improvement of labour services measures. 


\section{b. Measuring capital services}

Section 3.c discussed many aspects of capital measurement related with the capacity of capital goods to act as a storage of value or wealth. As highlighted previously, a fundamental characteristic of capital relies on its dual nature, by which, depending on the purposes of the analysis, the capital measure will reflect the market value of assets in the balance sheets or the source of productive services provided by capital goods to the production process. This section discusses the latter, focusing on the major challenges to assess capital's productive capacity and, hence, capital measures (that should be) used in activity and production analyses.

The analysis of this second nature of capital goods relies on the concepts of "productive capital stock" and "capital services". To better understand these concepts, one can conceive that for any given type of asset (e.g. trucks, computers, R\&D) there is a flow of productive services drawn from the cumulative stock of past investments. This cumulative sum of past investment volumes, adjusted for retirement and losses in efficiency (as opposed to losses in market value used in the measurement of net wealth capital stocks), constitutes the productive capital stock of the asset. The flow of productive services drawn from productive capital stocks is commonly known as capital services, which constitute the appropriate measure of capital input for production and productivity analysis (OECD, 2009).

Conceptually, this concept of capital is analogous to measures of labour input. Capital goods that are purchased or rented by a firm are seen as carriers of capital services that constitute the actual input in the production process. Similarly, employees hired for a certain period can be seen as carriers of stocks of human capital and therefore repositories of labour services. Differences between labour and capital arise because producers usually own capital goods. Unlike labour therefore, when the capital good "delivers" services to its ultimate user and owner, no market transaction is recorded. The measurement of these implicit transactions - the quantity of services drawn from the capital stock during a period and the price of those services - is one of the challenges of capital measurement for productivity analyses (OECD, 2001).

Key measurement challenges and differences with net wealth capital stocks

\section{Age-efficiency profiles}

As for the net wealth capital stock, the estimation of the productive capital stock relies on the application of the PIM. As such, the estimation of productive stock comes with the same challenges affecting the measurement of wealth stock, including the need for long GFCF series broken down by asset type, the estimation of initial capital stocks, and assumptions about the retirement profile and the price of ICT assets. However, in the implementation of the PIM at the individual asset level, there exist an important difference between the two capital stock concepts, related to the use of an ageprice profile when the aim is to estimate net wealth capital stocks, or an age-efficiency profile if the purpose is to estimate productive capital stocks.

Nonetheless, the choices of age-efficiency and age-price profiles for groups of assets come in pairs, and although they may be different, they are not independent from each other. Indeed, declines in the productive capacity of an asset, i.e. in its ability to produce a stream of productive services over time, are closely related with declines in its economic value. Whichever the starting point, age-price or age-efficiency, the choice of the functional form should be made based on empirical evidence 
regarding the group of assets, or otherwise based on sound logical reasoning about the depreciation or efficiency decline based, for example, on experts' advice. However, age-efficiency profiles are rarely observed directly, and indirect methods for inferring asset efficiency profiles are necessary (Hulten, 1980).

When it comes to the choice of the age-efficiency profile, in principle, three functional forms are typically analysed: linear, hyperbolic and geometric (Hulten, 1991; Biatour et al., 2007; Statistics Canada, 2007; OECD, 2009). The linear age-efficiency profile assumes that productive efficiency declines by a constant absolute amount every period. The derived age-price profile is more or less convex to the origin. While this profile is simple in presentation, it is not necessarily the most plausible form of efficiency loss of an asset (OECD, 2009). Indeed, the other two forms, hyperbolic and geometric profiles, are more frequently used across OECD countries as they tend to be supported by empirical evidence and/or intuitive reasoning.

The hyperbolic age-efficiency profile assumes that an asset loses productive efficiency at a slow rate in the first years of its service life and at increasingly faster rates towards the end of its service life. Such an age-efficiency profile gives rise to a convex age-price profile. The Australian Bureau of Statistics (ABS), Statistics Netherlands, Statistics New Zealand and the Office for National Statistics (ONS) of the United Kingdom assume that declines in productive efficiency of capital assets follow a hyperbolic function and derive thereof an age-price profile to estimate net wealth stocks and consumption of fixed in their national accounts (ABS, 2015; Statistics Netherlands, 2019; Statistics New Zealand, 2014; ONS, 2019). Similarly, the Bureau of Labour Statistics (BLS) in the United States (BLS, 2017) and the OECD Productivity Statistics database (Schreyer et al. 2003) assume a hyperbolic age-efficiency profile to derive productive capital stocks for the estimation of capital services.

The geometric age-efficiency profile postulates that the efficiency of a cohort of assets declines at a constant rate. In this case, both the age-efficiency and age-price profiles decline at the same constant rate and are identical. Since the empirical evidence suggests that the combined age-price and retirement profiles of assets tend to follow a geometric pattern (Hulten and Wykoff, 1981), the geometric profile has significant practical advantages. Statistics Canada (Statistics Canada, 2007; Baldwin et al., 2015) and the United States Bureau of Economic Analysis (BEA) (BEA, 2003) assume a geometric age-price profile to compile estimates of capital stocks and consumption of fixed capital in their national accounts. Similarly, a geometric age-efficiency profile is assumed in the APO Databook since its 2019 edition for the estimation of net stocks of fixed capital assets and the capital services derived thereof (Annex 3 in APO, 2019) ${ }^{29}$. Since geometric profiles tend to be "empirically supported, conceptually correct and easy to implement" (OECD, 2009), NSOs in APO economies with little empirical information on the evolution of asset prices and productive capacity over time are encouraged to use such profiles to measure asset depreciation in their national accounts.

\section{The price of capital services: user costs of capital}

Conceptually, capital services reflect a "quantity" or "physical concept", not to be confused with the market value, or price concept, of capital discussed in the previous chapter. To illustrate this, take the example of a taxi. The capital services provided by the taxi relate to the number of trips, distance

\footnotetext{
${ }^{29}$ Before the 2019 edition, the APO Databook assumed a hyperbolic age-efficiency profile with the same parameters across all countries (Annex 3 in APO Databook 2018).
} 
driven, and comfort of the taxi, rather than the market value of the vehicle, which would instead relate to the net wealth capital stock concept (OECD, 2019e). As a result, the price of the capital services that the vehicle provides to the taxi owner when used in the production of transport services differs from the market value of the vehicle. The measurement of the price of capital services, i.e. the user cost of capital, is the core difference between aggregate measures of net wealth stocks and capital services.

The methodology underlying aggregate measures of capital services relies on the work of Jorgenson (1963) and Jorgenson and Griliches (1967). In their framework, the volume of capital services provided by a given asset is assumed to be proportional to the asset's productive capital stock. With a timeinvariant proportionality factor, at the individual asset level, the growth rate of the asset's capital services is equal to growth rate of the asset's productive capital stock. The next step towards the construction of total capital services is to aggregate across different asset types (and industries). The aggregation process relies on the construction of asset-specific weights.

The aggregation of net wealth capital stocks across asset types (and industries) is based on the market value of each asset. In contrast, an aggregate measure of capital services is computed by aggregating the volume change of capital services of all individual assets using asset-specific user cost shares as weights. Ideally, statisticians would use observed rental prices of capital goods, i.e. the price paid in the market to use capital good for one period. In practice, most capital goods are owned by their users and rental transactions are not observed. In such cases, rental prices have to be imputed as the implicit rent that capital goods' owners "pay" to themselves. This implicit rent is estimated as the user cost of capital.

The user cost of capital is the minimum price at which the owner of the capital good would be willing to rent the asset during one period of time. It corresponds to a fraction of the purchase price of a new asset where the percentage share is computed as the sum of three components. The first component is a nominal rate of return representing the opportunity cost of the financial capital tied up to the asset. The choice of the nominal rate of return is an important decision in the construction of user costs and is discussed in Box 4.1. The second component is the depreciation rate of a new asset. It is derived from the combined age-price/retirement profile of the asset. The third component is the expected change in the price of the asset during the period where it is used as a factor of production. ${ }^{30}$ This reinforces the need for an accurate measurement of changes in asset prices, which, as described in the previous chapter, is particularly challenging for ICT assets. Further details about the construction of user costs of capital are available in OECD (2009).

\footnotetext{
${ }^{30}$ If the capital owner expects an increase (decline) in the asset price, he will charge a lower (higher) rental price. For this reason, the expected change in the asset price enters with a negative sign in the user cost formula.
} 


\section{Box 4.1. Estimating nominal rates of return for the estimation of user costs of capital}

The choice of a suitable nominal rate of return for the construction of the user cost of capital is linked to the question of whether the value of capital services should correspond exactly to the measure of gross operating surplus plus the capital element of mixed income (GOS) available in national accounts. In other words, the question is whether the fixed assets included in the measure of capital services are the sole factors of production remunerated through GOS.

In practice, this question relates to the approaches adopted by productivity analysts in estimating nominal rates of return: the endogenous and the exogenous approach. Each approach comes with its advantages and drawbacks.

The endogenous approach is the most frequently used method in empirical applications of capital measurement. Under this approach, the rate of return is computed based on the assumption that the estimated value of capital services (i.e. the total user cost of capital) equals GOS plus capital taxes on production. This is the approach currently used in the APO database for the estimation of capital services and MFP (APO, 2019; Appendix 5). This approach has the advantage that the nominal rate of return is produced by a system that is fully integrated and where all elements are interrelated. However, this set up assumes that all assets contributing to production are observed and measured (OECD, 2009). If other unmeasured assets actually provide capital services, the estimated rate of return overestimates its true value. The same is true if there are residual profits such as those arising in the presence of market power, or non-constant returns to scale (Schreyer, 2010).

Under the exogenous approach, the nominal rate of return is chosen to reflect economic agents' expectations about the required return from investment. The nominal rate of return is then derived on the basis of interest rates with different maturities, such as long-term government bond yields and treasury bill rates. The OECD currently adopts this approach because the theoretical assumptions justifying this approach are less demanding than those underlying the endogenous method (OECD, 2009). Indeed, Schreyer (2010) showed that exogenous rates can co-exist with occurrences of non-observed/measured assets, imperfect competition and non-constant returns to scale. As a result, MFP measures resulting from the growth accounting approach when using exogenous rate of returns for the measurement of capital services will combine effects of technical change, unobserved inputs, nonconstant returns to scale and deviations from perfect competition in products and inputs markets.

Inklaar (2010) compares the impact of these two approaches using industry data for the United States. He finds that exogenous rates of return usually lead to lower costs of capital than endogenous ones. He also advocates the use of exogenous rates of return because the endogenous ones can magnify measurement errors in the underlying data and lead to wrong conclusions when a limited number of assets are covered. 
The user cost of capital of asset $i$ at time $t$ is then represented as follows:

$$
u_{i t}=p_{i t-1} *\left(r_{t}+\delta_{i t}-\zeta_{i t}\right)
$$

where $u_{i t}$ is the user cost of one unit of asset $i$ in period $t, p_{i t-1}$ is the purchase price of asset $i$ at time $t-1, r_{t}$ is the nominal rate of return ${ }^{31}, \zeta_{i t}$ is the expected rate of change of the asset price, and $\delta_{i t}$ is the depreciation rate of a new asset $i$.

With the estimates of the productive capital stocks and the user costs for the different asset types, the growth rate in the aggregate volume of capital services is obtained through a Törnqvist index:

$$
\ln \left(\frac{K S E R_{t}}{K S E R_{t-1}}\right)=\sum_{i} \frac{1}{2}\left(v_{i t}+v_{i t-1}\right) \ln \left(\frac{K S E R_{i t}}{K S E R_{i t-1}}\right)
$$

where $v_{i t}=\frac{u_{i t} K S E R_{i t}}{\sum_{i} u_{i t} K S E R_{i t}}$ and $u_{i t}$ is the user cost of capital of asset $i$ in period $t .^{32}$

The user costs of capital capture the heterogeneity in the productive capacity of capital goods. This constitutes a major difference with the market prices (market values) of capital goods. To illustrate this, one can take the example of short-lived capital assets such as computer hardware. This type of asset typically presents high depreciation rates and a rapid decline in the asset price over time. These will contribute to raise the asset's user cost and the associated user costs' shares relative to their market value shares. Therefore, if the composition of investment shifts towards short-lived assets over time (typically ICT and IPP assets), the aggregate measure of capital services grows faster than the aggregate measures of net (wealth) capital stocks, with the differential reflecting changes in the composition (or "quality") of capital towards more productive assets.

Figure 4.5 highlights the importance of accounting for the heterogeneity in the productive capacity of the different assets. According to the OECD Productivity Statistics database, over the period 19852019, capital services in the United States grew at an annual average rate of 3.8\%, well above the $2.4 \%$ annual average growth rate of the aggregate net (wealth) capital stock over the same period. ${ }^{33}$ The difference is mostly related to ICT assets, which have a higher weight (user cost share) in aggregate capital services than in the aggregate net (wealth) capital stock. Figure 4.6 shows the difference between the growth rate of capital stocks and capital services for selected OECD countries over the period 2010-2019. Capital quality accounted for around $40 \%$ of the total growth of capital services in Austria, Denmark, the Netherlands and the United States, and 50\% in Spain and Germany. Growth in capital quality was nearly the sole contributor to capital services growth in Japan and outweighed the negative contribution of capital stocks in Italy over the same period.

${ }^{31}$ Also referred as nominal discount rate.

32 This is based on the assumption that $K S E R_{i t}=\lambda_{i} * K_{i t}$ where KSER $R_{i t}$ is the flow of capital services of asset $i$ in period $t, K_{i t}$ is the corresponding productive capital stock, and $\lambda_{i}$ is a time-invariant proportionality factor. In this case, the growth rates of capital services and the productive capital stock are equal for each asset: $\frac{d \ln K S E R_{i t}}{d t}=\frac{d \ln K_{i t}}{d t}$. In practice, the proportionality factor $\lambda_{i}$ is set equal to 1 .

${ }^{33}$ For information about the estimation of capital services and other productivity indicators in the OECD Productivity Statistics database see Schreyer et al. (2003) and OECD (2019e). 
Figure 4.5: Capital services vs. net (wealth) capital stocks in the United States Average annual growth rates, percentage

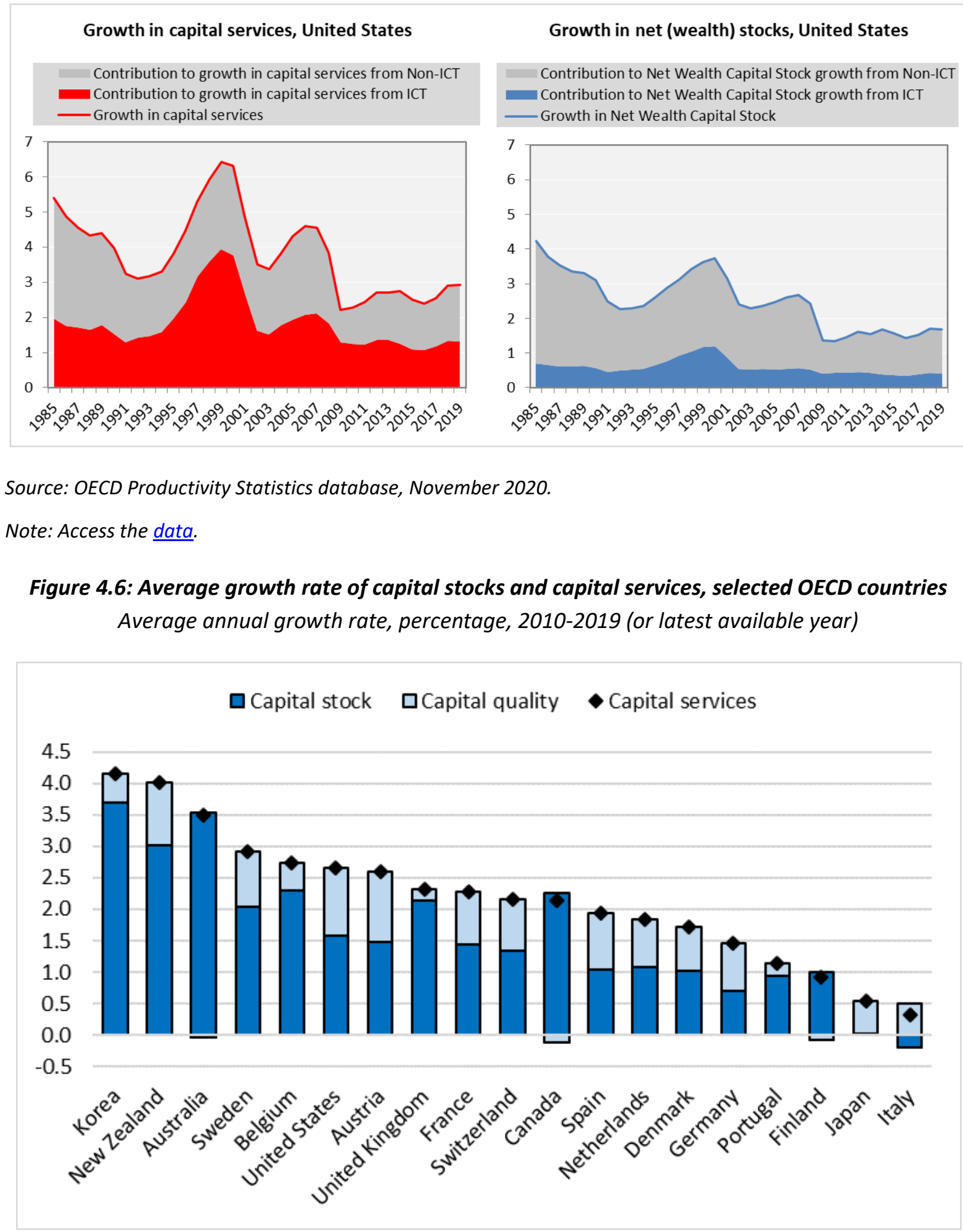

Source: OECD Productivity Statistics database, November 2020.

Note: Access the data. 


\section{c. Multifactor productivity accounting for labour and capital services}

Because measures of labour and capital services account for changes in the composition of the workforce and of capital, their use in the growth accounting framework leads to more accurate measures of MFP growth than derived with the simplified approach in Section 3.d, which accounted for hours worked and net wealth capital stocks. Measuring MFP based on labour and capital services is the recommended approach in the Measuring Productivity OECD Manual (OECD, 2001), and is also the most frequently used nowadays by NSOs and international organisations for productivity analysis.

Estimates of MFP growth accounting for labour and capital services can be derived as follows:

where:

$$
\frac{d \ln M F P}{d t}=\frac{d \ln V A}{d t}-\left(\frac{1}{2}\left(s_{L}^{t}+s_{L}^{t-1}\right) \frac{d \ln L S E R}{d t}+\frac{1}{2}\left(s_{K}^{t}+s_{K}^{t-1}\right) \frac{d \ln K S E R}{d t}\right)
$$

$\frac{d \ln M F P}{d t}$ is the growth rate of MFP;

$\frac{d \ln V A}{d t}$ is the growth rate of value added (in volume terms);

$\frac{d \ln L S E R}{d t}=\sum_{i=1}^{N} \frac{1}{2}\left(\frac{w_{i t} H_{i t}}{w_{t} H_{t}}+\frac{w_{i t-1} H_{i t-1}}{w_{t-1} H_{t-1}}\right) \frac{d \ln H_{i}}{d t}$ is the growth rate of labour services, with $w_{t} H_{t}=$ $\sum_{i=1}^{N} w_{i t} H_{i t}$

$\frac{d \ln K S E R}{d t}=\sum_{j=1}^{M} \frac{1}{2}\left(\frac{u_{j t} K_{j t}}{u_{t} K_{t}}+\frac{u_{j t-1} K_{j t-1}}{u_{t-1} K_{t-1}}\right) \frac{d \ln K_{j}}{d t}$ is the growth rate of capital services, with $u_{t} K_{t}=$ $\sum_{j=1}^{M} u_{j t} K_{j t}$;

$s_{L}^{t}=\frac{w_{t} H_{t}}{w_{t} H_{t}+u_{t} K_{t}}$ and $s_{K}^{t}=\frac{u_{t} K_{t}}{w_{t} H_{t}+u_{t} K_{t}}$ are the shares of labour and capital costs in total production costs.

The construction of labour and capital inputs weights represents another major difference between the MFP measure presented in this section and the MFP measure presented in Section 3.d. In the simplified growth accounting framework underlying the MFP calculations in Section 3.d, inputs weights sum to unity and depend only on the estimation of the labour cost share. However, in the framework presented in the current section for the estimation of MFP growth, the sum of the labour and capital cost shares may sum or not to unity, allowing for differences between the capital costs (i.e. the value of capital services) and gross operating surplus plus the capital element of gross mixed income (Box 4.1).

As shown in Figure 4.7, differences between MFP estimates accounting for labour and capital services and MFP estimates derived using hours worked and net wealth capital stocks matter in practice. In most countries, MFP growth derived with the simplified approach tends to growth faster than MFP measures accounting for labour and capital services. Among the eleven countries shown in Figure 4.7, it is only for Canada and Finland that the opposite is true, partly reflecting a decline in capital quality experienced in these countries since the earlier 2010s. 
Figure 4.7: Accounting for labour and capital services in measured MFP growth, 2004-2014 Average annual percentage change

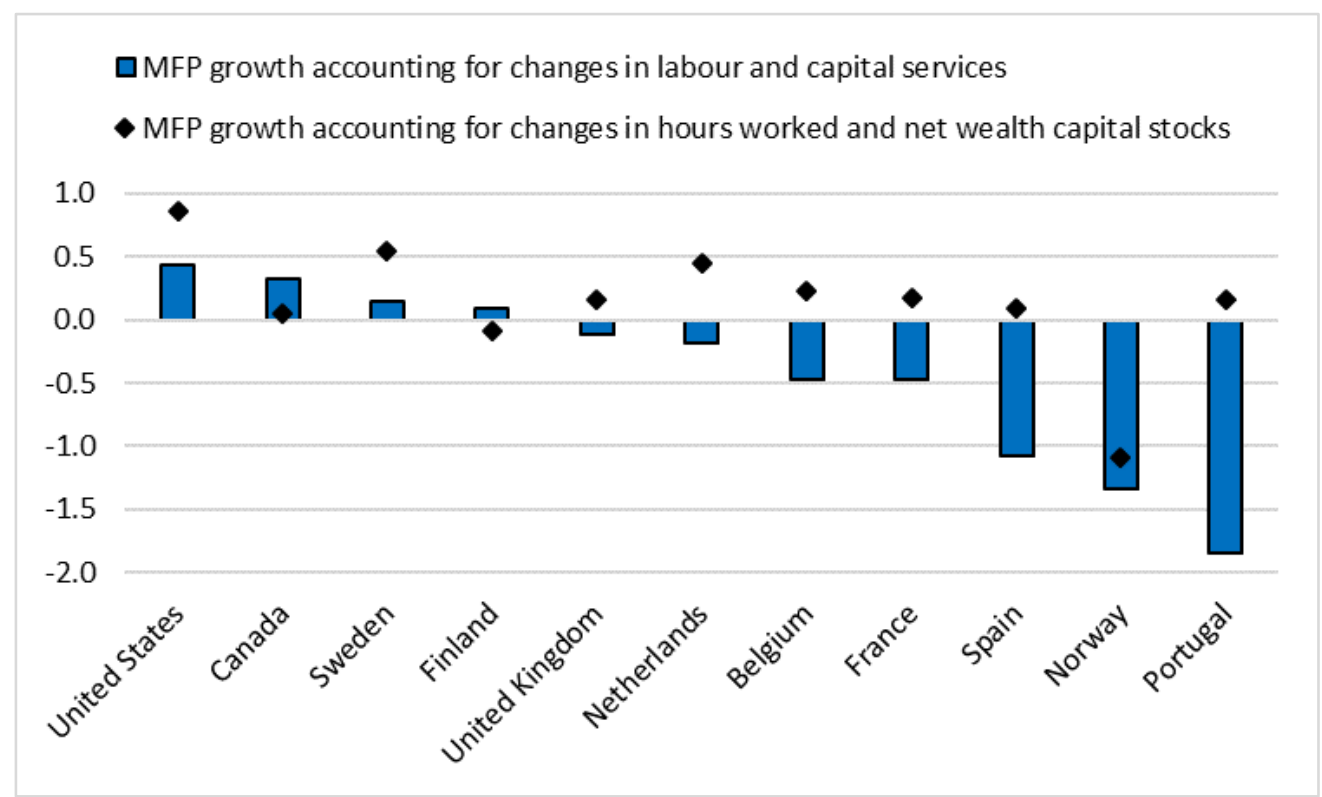

Source: OECD calculations based on the OECD Productivity Statistics (database), November 2020.

Note: Data correspond to the period 2004-2017 for Canada and the United States. MFP growth estimates accounting for labour and capital services rely on input weights that are not constrained to sum to unity because capital costs are estimated using exogenous rates of return. For the computation of labour costs, self-employed workers are assumed to earn the same hourly wage as employees at the total economy level.

Note: Access the data.

In light of their value added for economic analysis as compared to simpler productivity measures, NSOs in APO economies are encouraged to compile MFP estimates accounting for labour and capital services, i.e. taking into account how different types of workers and productive assets contribute to economic growth. In this endeavour, they should pay specific attention to the way self-employed workers are accounted for in total employment and labour compensation. They should also consider the largest possible set of productive assets and closely track the progress made in OECD countries to account for intellectual property assets included and excluded from the SNA asset boundary.

\section{d. Productivity measures accounting for environmental inputs and outputs}

A movement towards sustainable economic growth requires minimising both the contribution of nonrenewable natural resources to production and the emissions of greenhouse gases and other pollutants necessary to achieve a given level of output. The OECD has identified key productivity indicators to measure progress against these aspects (OECD, 2017a), among which energy productivity, material resource productivity, $\mathrm{CO}_{2}$ productivity, and environmentally-adjusted multifactor productivity will be described below. In order to facilitate economic analysis and ensure consistency between the different domains, the environmental and economic statistics used for the compilation of these productivity indicators should ideally be sourced from environmental-economic accounts compiled according to the SEEA Central Framework (Box 4.2). 


\section{Energy productivity}

Energy productivity is defined as the output generated (in terms of real GDP) per unit of total primary energy supply (TPES), expressed as USD per tonne of oil equivalent (USD/TOE). The overall energy productivity of a country depends on its economic specialisation (e.g. share of manufacturing and transport vs. services) and on the energy efficiency of its economic sectors. Compiling energy productivity from SEEA energy accounts, where overall energy consumption is broken down by economic sector using the same industrial classification as in national accounts and where the same (resident) economic units are considered for production and energy consumption, enables the disentanglement of these two factors and facilitates energy productivity comparisons across countries.

Figure 4.8 shows the energy productivity of Japan, China, the Asia $30^{34}$ and the EU15 relative to the United States between 1970 and 2016. Japan's energy productivity was around twice that of the United States towards the start of the period, but dropped in relative terms from the late $1980 \mathrm{~s}$ and observed similar levels to the EU15 at 30-40\% higher than the United States in 2016. Energy productivity in the Asia30 was over $25 \%$ greater than the United States towards the start of the period, moving to about parity from 2005 onwards. China experienced significant growth in energy productivity over the period, from around $25 \%$ to around $75 \%$ of the United States level.

Figure 4.8: Evolution of energy productivity over time

Japan, China, the Asia30 and the EU15, 1970-2016, United States $=100$

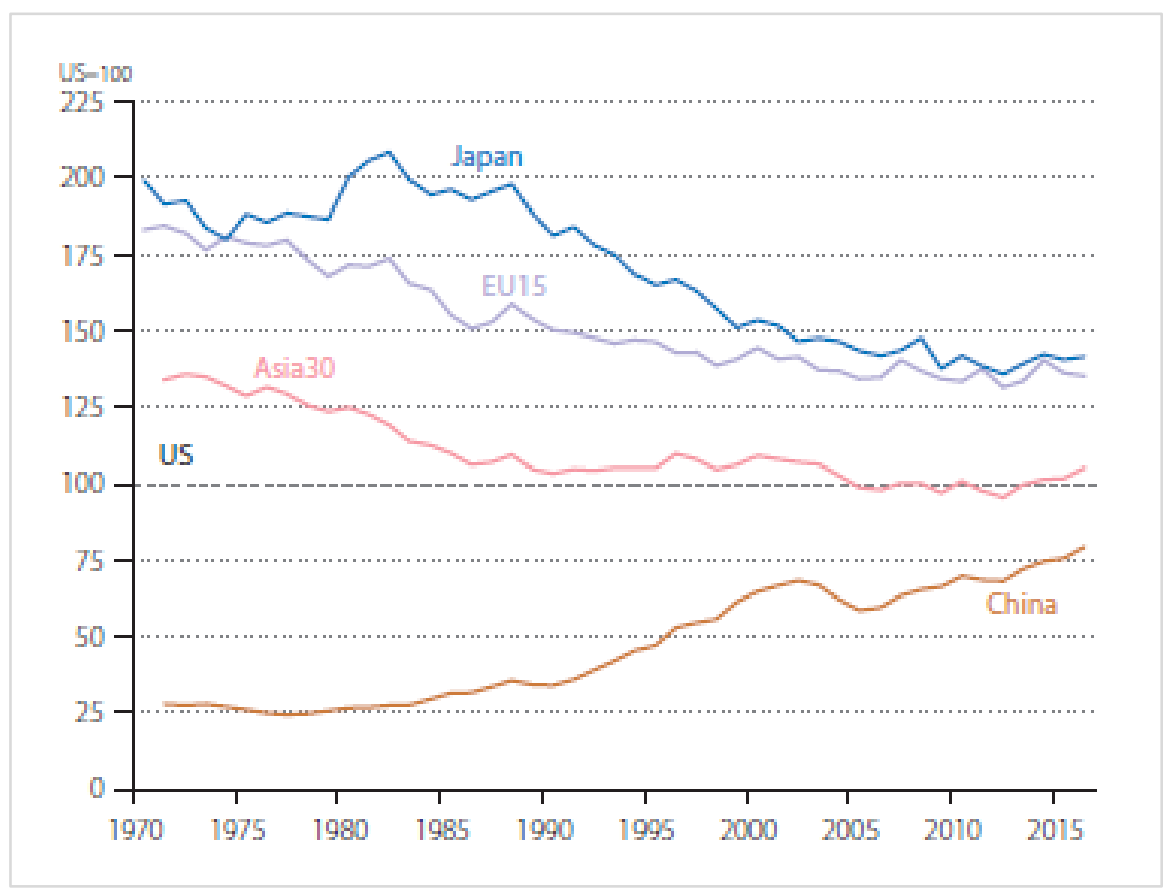

Source: APO (2019), unmodified Figure 50.

Note: Access the data.

${ }^{34}$ Asia30 includes the 20 APO member economies (not including Turkey), plus Bahrain, Bhutan, Brunei Darussalam, China, Kuwait, Myanmar, Oman, Qatar, Saudi Arabia and the United Arab Emirates. 
These data are often available only at the whole economy level. This creates issues for the detailed interpretation of evolutions in these measures, as it is not possible to determine whether changes over time stem from changes in the energy efficiency of certain industries, or from changes in the composition of industries. Sourcing environmental and economic statistics from SEEA environmentaleconomic accounts facilitates structural decompositions and analysis of the drivers of energy, material resource and $\mathrm{CO} 2$ productivity. These decompositions can then contribute to policy discussions on the environmental efficiency of production processes.

\section{Material resource productivity}

Material resource productivity is defined as the output (in terms of real GDP) generated per unit of non-energy materials (i.e. excluding fossil fuel energy carriers) used. Worldwide use of most significant materials has been rising for many years and has caused concerns regarding the environmental effectiveness of their use. Material productivity has been improving in the OECD, especially in some European countries and Korea, but it remains low in the BRIICS. In 2012, OECD economies generated about USD 2400 of income per tonne of non-energy materials used, more than three times the value generated by BRIICS economies (USD 700 per tonne, using purchasing power parities) (OECD, 2017a).

\section{$\underline{\mathrm{CO}}_{2}$ productivity}

$\mathrm{CO}_{2}$ productivity reflects the economic value generated (in terms of real GDP) per unit of $\mathrm{CO}_{2}$ emitted, in terms of gross direct emissions from fossil fuel combustion. $\mathrm{CO}_{2}$ productivity is closely related to energy productivity but also depends on the energy mix that is used as input for production. For example, consider two economic sectors with the same energy productivity. The sector with a larger share of fossil fuels in its energy mix will tend to have a lower $\mathrm{CO}_{2}$ productivity, though the share of coal in fossil fuel use is of particular importance. Here again, using SEEA energy and air emission accounts to compile $\mathrm{CO}_{2}$ productivity allows the disentangling of how economic specialisation, as well as the energy productivity and the energy mix of the different economic sectors contribute to $\mathrm{CO}_{2}$ productivity developments over time and differences in $\mathrm{CO}_{2}$ productivity across countries.

So far, the discussion has covered only production-based energy, material resource and $\mathrm{CO}_{2}$ productivity indicators. Nevertheless, similar demand-based indicators can be defined, taking into account the energy use, the material consumption and the $\mathrm{CO}_{2}$ emissions in the various stages of production of goods and services consumed in domestic final demand. Contrary to production-based indicators that focus on domestic energy use, material consumption and $\mathrm{CO}_{2}$ emissions, demandbased indicators consider energy use, material consumption and $\mathrm{CO}_{2}$ emissions that take place either domestically or abroad, along global value chains.

Production and demand-based productivity indicators complement one another. For example, Figure 4.9 shows that the production-based $\mathrm{CO}_{2}$ productivity of $\mathrm{OECD}$ economies has improved almost uniformly since 1995. Production-based $\mathrm{CO}_{2}$ emissions for many countries have increased at a lower rate than real GDP (relative decoupling), and in half of OECD countries these emissions have decreased in absolute terms (absolute decoupling). This reflects shifts in the industrial structure, in the energy productivity and in the energy mix. Nevertheless, $\mathrm{CO}_{2}$ emissions generated to satisfy domestic final demand in OECD countries have increased faster than emissions from domestic production. Over 1995-2011, only 12 OECD countries have achieved absolute decoupling of demand-based $\mathrm{CO}_{2}$ emissions from real GDP (e.g. Denmark and Germany). In three OECD countries (e.g. Norway) and 
three non-OECD economies (e.g. Indonesia) demand-based $\mathrm{CO}_{2}$ productivity has declined between 1995 and 2011. Differences in production and demand-based $\mathrm{CO}_{2}$ productivity evolutions reflect changing trade patterns and the shift of polluting industries to lower-cost locations, often with less stringent environmental regulations.

Figure 4.9: Evolution of production and demand-based $\mathrm{CO}_{2}$ productivity

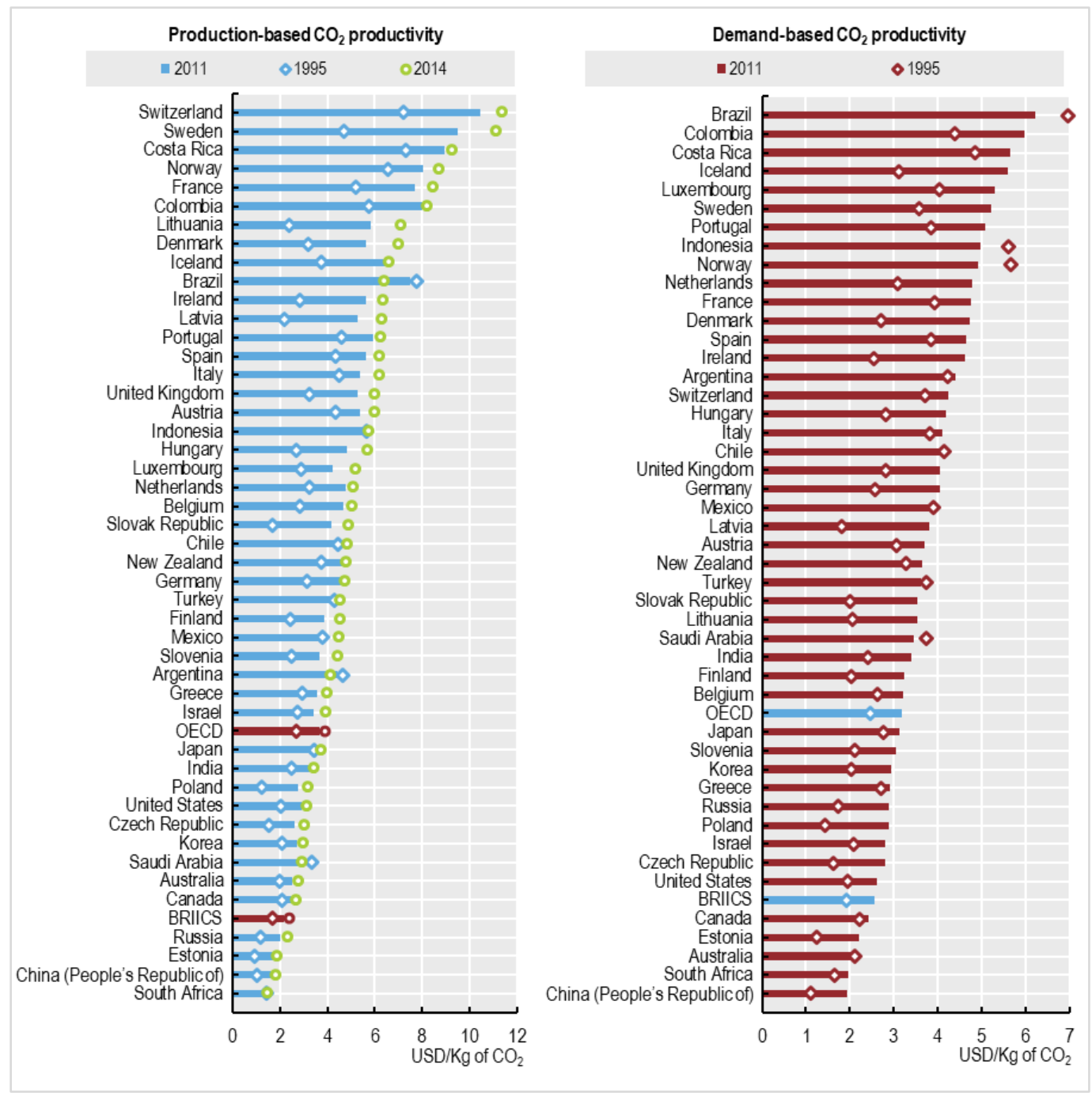

Source: Green Growth Indicators 2017 (OECD, 2017a).

Note: Access the data.

\section{Box 4.2. The System of Environmental-Economic Accounting (SEEA) - Central Framework}

The SEEA central framework is a multipurpose accounting framework that describes the interactions between the environment and the economy, and the stocks and flows of environmental assets (UN, 2014). It was endorsed as an international statistical standard by the UN Statistical Commission (UNSC) in 2012 and can be considered as an extension of the 2008 SNA. Environmental-economic accounts provide a framework in which environmental statistics are fully integrated with national 
accounts, and thus offer an ideal measurement framework for the analysis of interactions between the economy and the environment:

- In providing a framework to combine heterogeneous statistics on the economy and the environment, they ensure that the resulting information is more consistent, and thus of higher quality.

- They allow the combination monetary and physical data in a consistent way, for example for calculating $\mathrm{CO}_{2}$, energy and material resource productivity indicators.

- They provide a unique way to identify how changes in economic structure drive changes in $\mathrm{CO}_{2}$, energy and material resource productivity indicators, and to compile demand-based indicators.

- They ensure that environmental assets are valued in a way that is consistent with the information and the principles of national accounts (Pionnier and Yamaguchi, 2018).

- They provide information on economic opportunities associated with green growth, such as markets for environmentally related products and associated employment, and information on policy signals (e.g. environmentally related taxes and subsidies) to influence the behaviour of economic industries and households, again in a way that is consistent with national accounts.

As of 2019, 45 countries, mostly European OECD member countries, compiled SEEA accounts and had regular funding available to maintain this statistical activity; 38 other countries have at least some experience with SEEA accounts and 22 countries plan to start implementing the SEEA.

Figure 4.10: International progress in the compilation of the SEEA

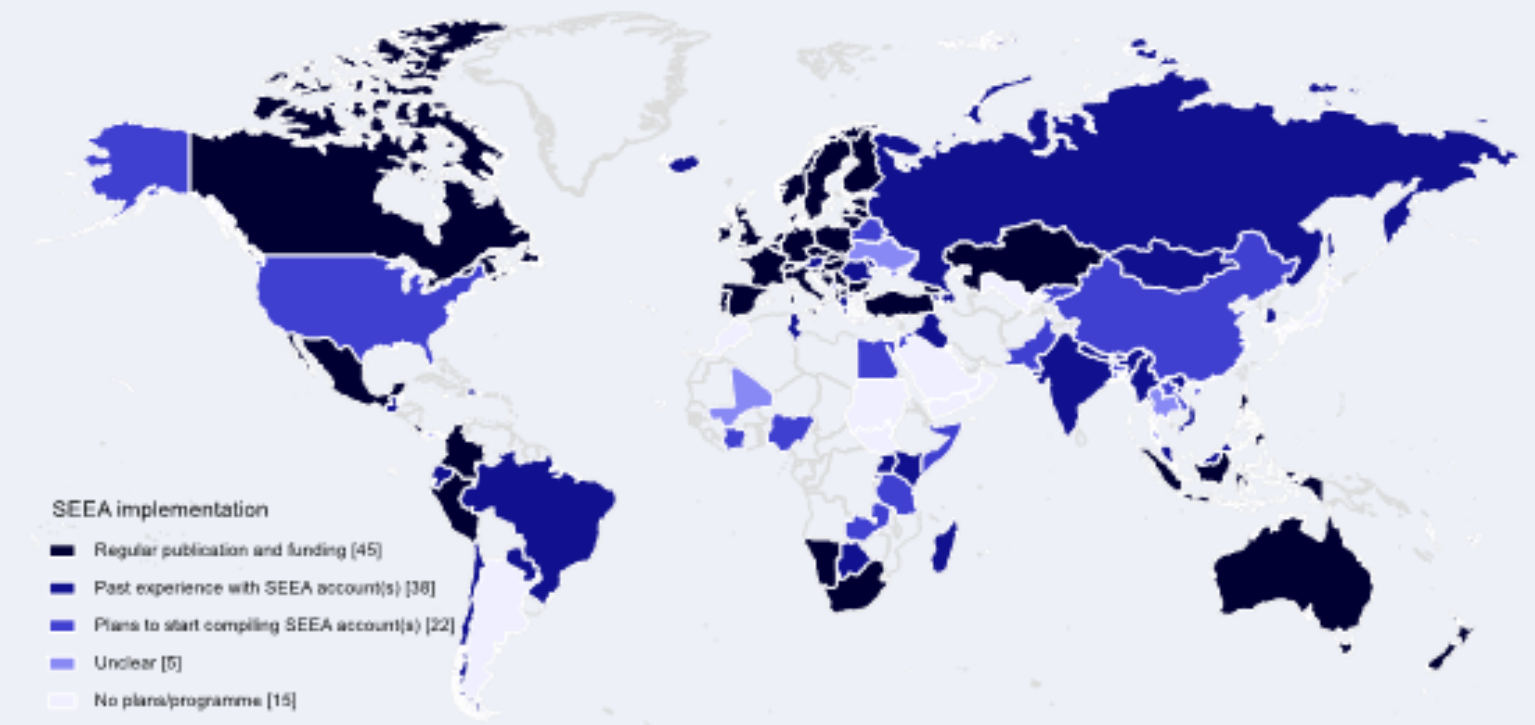

Source: 2017 UN Global Assessment of environment statistics, environmental-economic accounting and related statistics, updated to February 2019. 
Traditional measures of multifactor productivity (MFP), as described in Section 4.c. generally include only produced capital (e.g. machines and transport equipment), ignoring (non-produced) natural capital as an input into the production process. Multiple papers have been produced by the OECD (Brandt et al., 2017; Cárdenas Rodríguez et al., 2018) and different NSOs (Argento and Burnell, 2013; Hann et al., 2014) developing a framework to incorporate natural capital into the growth accounting framework. In doing so, these indicators allow for the sources of economic growth, and its long-run sustainability, to be better assessed.

Brandt et al. (2017) introduce natural assets as an additional input in the growth accounting framework. This method is an extension of the traditional approach where multifactor productivity growth is measured as the weighted difference between output growth and the growth in factor inputs (i.e. labour and produced capital):

$$
\frac{d \ln M F P}{d t} \equiv \frac{d \ln Y}{d t}-\left(\frac{w L}{\gamma^{\prime}} \frac{d \ln L}{d t}+\frac{u_{K} K}{\gamma^{\prime}} \frac{d \ln K}{d t}\right)
$$

In the previous formula $\frac{d \ln X}{d t}$ denotes the logarithmic rate of change of variable $X$ with respect to time, equivalent to its growth rate, $w$ is the wage rate and $u_{K}$ the user cost of produced capital. Total resource costs are defined by $\gamma^{\prime} \equiv w L+u_{K} K$. In what follows, the shorthand $\frac{d \ln Z}{d t}$ will be used to capture the combined rate of growth of labour and produced capital inputs:

$$
\frac{d \ln Z}{d t} \equiv\left(\frac{w L}{\gamma^{\prime}} \frac{d \ln L}{d t}+\frac{u_{K} K}{\gamma^{\prime}} \frac{d \ln K}{d t}\right)
$$

The flow of natural capital inputs, such as minerals, oil, gas and coal, is denoted by $\mathrm{S}$, the vector of quantities of natural capital inputs, $\mathrm{S}=\left(\mathrm{S}_{1}, \ldots, \mathrm{S}_{1}, \ldots, \mathrm{S}_{\mathrm{N}}\right)$, that are used in production. Environmentallyadjusted multifactor productivity growth can be measured as the difference between the growth rates of output and aggregate inputs, where the latter now include natural capital. It should be noted that while produced capital services enter the productivity calculations as the rate of change of the stock of different asset classes weighted by their user cost shares (OECD, 2009), natural capital enters directly as a flow measure corresponding to its annual extraction.

To build an aggregate input growth measure, a user cost for natural capital inputs is needed. In this case, Brandt et al. (2017) rely on unit extraction rents. S should be thought of as an aggregate of different types of natural capital inputs $S_{i}(i=1,2, .$.$) with user costs u_{S_{i}}$. The total value of natural capital input is then $u_{S} S=\sum_{i} u_{S_{i}} S_{i}$ and the growth rate of the volume of natural capital input is $\frac{d \ln S}{d t}=$ $\sum_{i} \frac{u_{S_{i}} S_{i}}{u_{S} S} \frac{d \ln S_{i}}{d t}$. Total input costs including natural capital are defined by $\gamma \equiv w L+u_{K} K+\sum_{i} u_{S_{i}} S_{i}$. It follows that the productivity growth measure then becomes:

$$
\frac{d \ln E A M F P}{d t} \equiv \frac{d \ln Y}{d t}-\left(\frac{w L}{\gamma} \frac{d \ln L}{d t}+\frac{u_{K} K}{\gamma} \frac{d \ln K}{d t}+\sum_{i} \frac{u_{S_{i}} S_{i}}{\gamma} \frac{d \ln S_{i}}{d t}\right)
$$

In this extended framework with natural capital, the cost shares of both labour and produced capital are scaled down to reflect the increase in total costs, and the total costs measure is adjusted to include natural capital costs. The difference between the MFP growth measure accounting for labour and 
capital services and the extended MFP measure, accounting for the contribution of natural capital, will depend on the difference between the growth rate of the original composite input index, and the growth in the use of natural capital S, as well as on the share of natural capital costs. ${ }^{35}$

$$
\frac{d \ln E A M F P}{d t}=\frac{d \ln M F P}{d t}+\sum_{i} \frac{u_{S_{i}} S_{i}}{\gamma}\left(\frac{d \ln Z}{d t}-\frac{d \ln S_{i}}{d t}\right)
$$

$\underline{\text { Data }}$

Compiling such a measure of EAMFP requires both the traditional productivity data and data on natural capital use. Natural capital use is difficult to measure, requiring both information on extractions and unit rents. Both Brandt et al. (2017) and Cárdenas Rodríguez et al. (2018) use similar data sources to account for natural capital use and as a result cover the same 14 types of subsoil assets, including fossil fuels (hard coal, soft coal, gas, oil) and minerals (bauxite, copper, gold, iron ore, lead, nickel, phosphate, silver, tin and zinc)..$^{36}$ In these approaches, data on extractions are taken from the OECD Natural Resource Accounts (OECD, 2015b), and/or from the Changing Wealth of Nations (CWON) database (World Bank, 2014). Unit rent data, obtained from the CWON database, are calculated as the difference between market prices and extraction costs.

\section{$\underline{\text { Results and comparisons }}$}

Results from Brandt et al. (2017) show that the inclusion of natural capital may lead to a notable adjustment to the traditional MFP growth measure accounting for only labour and capital services over the period 1986-2008, especially for economies with significant natural capital endowments, such as Norway ( -0.16 percentage point per annum), Chile ( 0.21 percentage point per annum), Mexico ( 0.12 percentage point per annum) and Russia ( 0.28 percentage point per annum). As can be seen in Table 4.3, the adjustment to MFP growth can be either positive or negative, depending on whether natural capital grew faster or slower than the other factor inputs over the period. For example, in Australia, Denmark, Norway, Finland and New Zealand the adjustment to the traditional MFP growth measure is negative, as natural capital, on average, grew faster than the labour and produced capital input over the period. In Australia, this was due to increased mineral extraction, in Denmark and Norway to oil extraction, and in New Zealand mainly to oil and gas extraction. However, it is not always the case that traditional MFP growth presents an overestimate for countries experiencing natural resource booms. Natural resource booms also bring with them increased investment in produced capital. Hence, natural capital growth can sometimes be outpaced by growth in produced capital. Table 4.3 shows an upward adjustment of the MFP growth measure in Canada, Chile, Mexico, Russia and South Africa, all of which experienced a resource boom over recent years.

\footnotetext{
35 It is important to note that total costs in the traditional framework $\gamma^{\prime}$ presented here do not necessarily equal the value of GDP, so no assumption is made regarding returns to scale or the degree of competitiveness of output markets. Typically, these costs $\gamma^{\prime}$ are smaller than nominal GDP. One interpretation, which suits the extended framework with natural capital, would be that there are unmeasured inputs, such as the natural capital stock.

${ }^{36}$ Cárdenas et al. (2018) account not only for the use of natural resources but also for the costs related to pollution abatement, i.e. undesirable output. See Box 4.3.
} 
Table 4.3: Average productivity growth per year with and without natural capital

\begin{tabular}{|c|c|c|c|c|c|c|}
\hline Country & $\begin{array}{l}\text { Traditional } \\
\text { MFP growth in } \\
\%\end{array}$ & $\begin{array}{l}\text { MFP growth } \\
\text { with natural } \\
\text { resources in } \\
\%\end{array}$ & $\begin{array}{l}\text { GDP growth } \\
\text { in } \%\end{array}$ & $\begin{array}{l}\text { Growth } \\
\text { contribution } \\
\text { of labour } \\
\text { input in } \%\end{array}$ & $\begin{array}{l}\text { Growth } \\
\text { contribution } \\
\text { of capital } \\
\text { input in } \%\end{array}$ & $\begin{array}{l}\text { Growth } \\
\text { contribution } \\
\text { of natural } \\
\text { capital in } \%\end{array}$ \\
\hline & \multicolumn{6}{|c|}{ Based on data from the OECD Productivity Database, 1986-20081 } \\
\hline Australia & 0.92 & 0.88 & 3.34 & 1.26 & 1.05 & 0.15 \\
\hline Austria & 1.43 & 1.44 & 2.60 & 0.57 & 0.57 & 0.00 \\
\hline Belgium & 1.32 & 1.32 & 2.28 & 0.24 & 0.75 & 0.00 \\
\hline Canada & 0.38 & 0.42 & 2.67 & 1.11 & 1.06 & 0.05 \\
\hline Switzerland & 0.06 & 0.06 & 1.46 & 0.60 & 0.82 & 0.00 \\
\hline Germany & 1.10 & 1.11 & 1.48 & -0.21 & 0.58 & 0.00 \\
\hline Denmark & 0.75 & 0.72 & 2.00 & 0.24 & 0.99 & 0.06 \\
\hline Spain & 0.35 & 0.35 & 3.22 & 1.63 & 1.24 & 0.00 \\
\hline Finland & 2.07 & 2.07 & 2.63 & -0.04 & 0.58 & 0.01 \\
\hline France & 1.06 & 1.06 & 2.08 & 0.31 & 0.71 & 0.00 \\
\hline United Kingdom & 1.26 & 1.33 & 2.68 & 0.46 & 0.94 & -0.04 \\
\hline Ireland & 2.84 & 2.86 & 5.25 & 1.52 & 0.87 & -0.01 \\
\hline Italy & 0.45 & 0.45 & 1.64 & 0.39 & 0.81 & 0.00 \\
\hline Japan & 1.46 & 1.46 & 1.99 & -0.36 & 0.88 & 0.00 \\
\hline Korea & 3.93 & 3.93 & 6.39 & 0.72 & 1.74 & 0.00 \\
\hline Netherlands & 0.95 & 1.00 & 2.78 & 0.99 & 0.83 & -0.01 \\
\hline Norway & 1.18 & 1.02 & 2.64 & 0.36 & 0.80 & 0.46 \\
\hline New Zealand & 0.68 & 0.66 & 2.45 & 0.85 & 0.90 & 0.04 \\
\hline Portugal & 1.29 & 1.29 & 2.47 & 0.31 & 0.86 & 0.00 \\
\hline Sweden & 1.03 & 1.03 & 2.33 & 0.30 & 0.95 & 0.00 \\
\hline \multirow[t]{2}{*}{ United States } & 1.03 & 1.05 & 2.84 & 0.94 & 0.89 & -0.01 \\
\hline & \multicolumn{6}{|c|}{ Based on national data, 1996-2008² } \\
\hline Chile & 0.90 & 1.10 & 4.09 & 0.81 & 2.04 & 0.14 \\
\hline Mexico & 0.97 & 1.09 & 3.49 & 0.86 & 1.54 & -0.01 \\
\hline Russia & 2.21 & 2.50 & 4.53 & 0.66 & 0.86 & 0.27 \\
\hline South Africa & 1.62 & 1.70 & 3.61 & 1.00 & 0.93 & -0.01 \\
\hline
\end{tabular}

Source: Adapted from Brandt et al. (2017).

Note: 1. 1996-2007 for Austria, 1986-2004 for Belgium, 1991-2008 for Switzerland, 1992-2008 for Germany, 1986-2007 for the Netherlands, Denmark, United Kingdom, and 1996-2005 for Portugal. 2. 1997-2008 for Chile.

While this approach currently covers only the subsoil assets detailed above, this is only the first step in a complete accounting for natural capital in the growth accounting framework. Further work to cover other natural resources such as land, soils, freshwater, native forests, wild fisheries and other renewable natural capital should be encouraged. The 2019 edition of the APO database and the APO databook introduced, for the first time, the contribution of land into the growth accounting framework. This addition makes a significant difference to the capital-output ratios for APO economies, with land making up over $70 \%$ of the total capital stock in some densely populated economies in 2017, such as Chinese Taipei (78\%), Singapore (77\%) and Hong Kong, China (74\%).

Box 4.3 considers how emissions of greenhouse gases and pollutants could also be taken into account for multifactor productivity measurement. Nevertheless, this approach is still considered as experimental and requires further discussed by the research community. Therefore, implementing it is not considered as a priority in the present report. 


\section{Box 4.3. Accounting for emissions of greenhouse gases and pollutants in multifactor productivity measurement}

The extraction and use of natural assets, particularly the subsoil assets considered above, can lead to negative externalities. That is to say there are costs associated with the production or consumption of those assets that fall on third parties. The most obvious externality in this case is pollution, which is a particularly relevant issue in the APO region. India's population, for instance, is exposed to some of the highest levels of fine particulate matter (PM2.5) in the world, on a similar scale to China (OECD, 2019a). With the increasing policy relevance of climate change and pollution abatement, the measurement of pollution is of particular importance in the statistical policy agenda. Figure 4.11 shows the concentration of air pollution in a selection of countries between 2010 and 2015. China has the highest concentration of air pollution by a wide margin, with Malaysia and Indonesia at the other end of the scale for this group of countries. Thailand, Korea and Turkey have all seen marked increases in air pollution concentration, while Poland has observed a reduction and other countries have remained broadly stable.

Figure 4.11: Developments in air pollution emissions over time Selected countries, 2010-2015

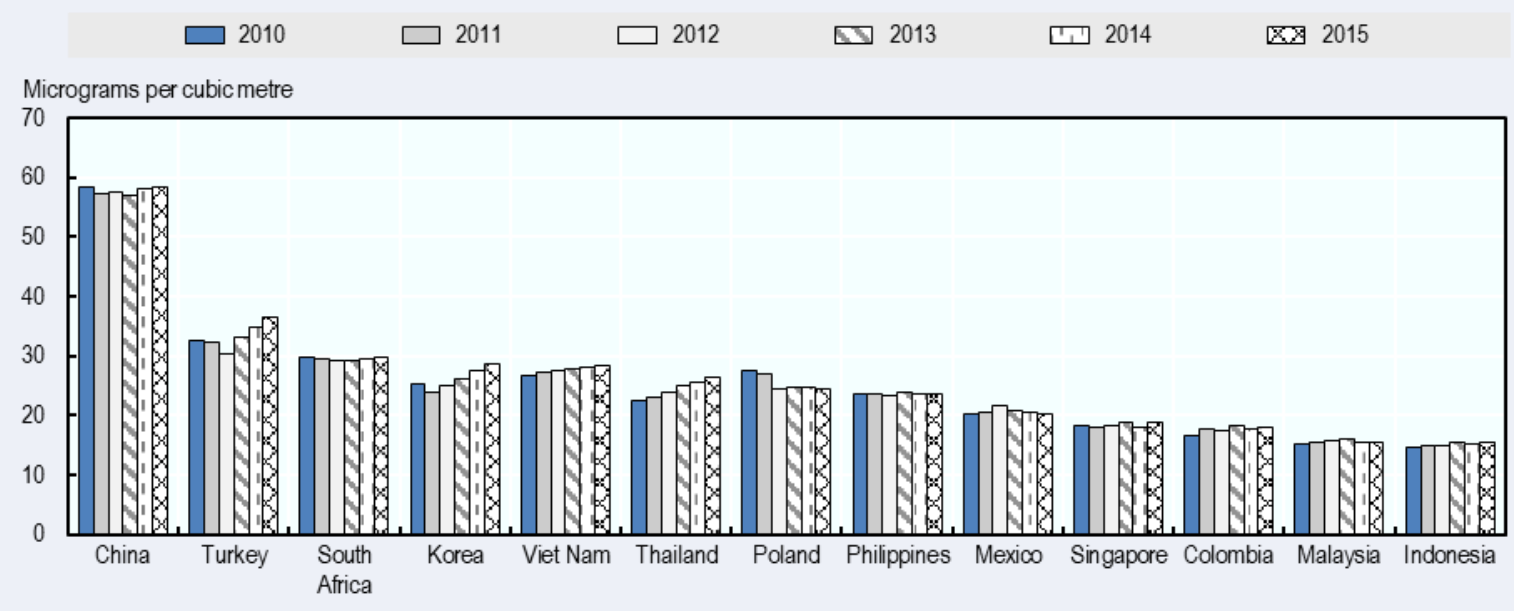

Source: OECD (2018c).

Note: Access the data.

While income generated through the depletion of natural capital (e.g. minerals and fossil fuels) is captured in GDP, neither MFP nor GDP capture the damage created through by-products of the production process, such as greenhouse gas emissions leading to climate change or pollution threatening human health and the environment. Cárdenas Rodríguez et al. (2018) extend the growth accounting framework to account for both natural capital and what they refer to as "undesirable" outputs.

Unlike the capitalisation of natural assets, their approach also adjusts the output side of the production function (GDP) to account not only for income from goods and services, but also for 
"undesirable" outputs resulting from the production process. They account for a relatively complete set of greenhouse gases (CO2, CH4, N2O) and air pollutants (PM10, CO, NMVOC, SOX, NOX).

Their approach is based on an extended production function which dictates the maximum quantity of good outputs, $Y$, and "bad" outputs, $R$, that can be produced using the vector of inputs $X=(L, K, S)$, which consists of labour, produced capital and natural capital, over time $t$.

$$
H(Y, R, X, t)=1
$$

In this framework, the prices of bad outputs are always negative and correspond to the marginal abatement cost of emissions in terms of foregone output of goods and services that would result if one further unit of emissions had to be avoided. In that sense, the relevant price for emissions in a productivity framework is the marginal cost facing producers to achieve the abatement required by different policies constraining emissions.

The main challenge with this approach is that the price of bad outputs can rarely be observed, unless there is an emissions' trading system or tax. While such trading systems or taxes exist in some countries, they generally do not cover all emissions in the economy. Hence, Cárdenas Rodríguez et al. (2018) estimate the corresponding elasticities econometrically.

With this information, the environmentally-adjusted multifactor productivity growth measure $\left(E A M F P^{\prime}\right)$ adjusts the measure of MFP accounting for labour and capital services (defined in Section 4.c) with the addition of natural capital to the vector of inputs, and the subtraction of "bad" outputs from output (GDP):

$$
\frac{d \ln E A M F P^{\prime}}{d t} \equiv \frac{d \ln H}{d t}=\frac{d \ln M F P}{d t}+\frac{u_{S} S}{\gamma}\left(\frac{d \ln Z}{d t}-\frac{d \ln S}{d t}\right)-\frac{P_{R} R}{\rho}\left(\frac{d \ln Y}{d t}-\frac{d \ln R}{d t}\right)
$$

$\mathrm{R}$ should be viewed as an aggregate of different types of emissions $R_{i}(i=1,2, \ldots)$, much like GDP is a composite measure of different goods and services. $P_{R}$ denotes the implied private cost of undesirable output i.e. the marginal cost for producers of complying with environmental regulations. $\rho$ represents the total value of outputs. Notations are otherwise the same as those employed in Brandt et al (2017).

Cárdenas Rodríguez et al. (2018) present results for OECD and G20 countries for the 1990-2013 period. They show that the adjustment to GDP growth for pollution abatement is not negligible, ranging from -1.11 (Turkey) to 0.69 (Germany and the Czech Republic) percentage points per year. It should be noted that the adjustment can be either negative or positive, where countries emissions have increased or decreased, respectively. Given the rising pollution levels in much of the APO over the period, adjustments to GDP for pollution abatement for most of the included APO economies are negative - Korea (-0.89), Indonesia (-0.25) and India (-0.97) -, with only Japan (0.42) experiencing an upwards adjustment. 


\section{e. Statistical recommendations}

\section{KEY MEASUREMENT CHALLENGES}

STATISTICAL RECOMMENDATIONS

\section{Measuring composition-adjusted labour input (CALI)}

For the estimation of MFP, hours worked should be adjusted to account for changes in the skill composition of the workforce. That is, the labour input measure should reflect labour services (i.e. CALI), accounting for both the volume of hours worked and the differing characteristics of workers. The data burden involved in the compilation of CALI measures is significant, requiring microdata on hours worked and on wages, to facilitate the breakdown of workers into distinct groups based on their characteristics. It is often necessary to combine data from multiple microdata sources in order to achieve the intended breakdown for both hours and wages, which are then combined with official estimates from the national accounts.

There have been many attempts to compile measures of labour services, either at a national level or in a centralised cross-country approach. These approaches often differ in the characteristics used to cross-classify workers and, indeed, in the classifications therein. The range of approaches brings into question the international comparability of the resulting indicators. However, for the most part, all approaches utilise the same broad method applied in Jorgerson, Gollop and Fraumeni (1987).

Many approaches, including that of the Asia QALI Database, incorporate sex as a dimension by which to classify workers. While men and women do constitute part of the heterogeneity of the workforce in a country, implementing sex as a dimension presents a unique problem due to the use of wages as a proxy for the productivity of each group of workers. While in theory wages constitute a sound proxy for productivity differentials, in reality, relative wage differences may reflect factors other than productivity differences, including conscious or unconscious bias against specific types of workers, contributing to the gender-pay gap present in many countries across the world. As a result, in the presence of such a gender-pay disparity, a measure of labour services incorporating sex as a dimension would show a reduction in labour services in reaction to increased female participation in the labour market.
This inherent data burden reinforces the argument for the calculation of these measures at the national level. NSOs have access to the necessary data, and the detailed knowledge of their own data sources, to generate high quality estimates of CALI. This does not, however, discount cross-country approaches such as the Asia QALI Project, which are a rich source of data and experience, and should be built upon. Collaboration between NSOs and existing cross-country projects may well be the ideal path towards the development and improvement of labour services measures.

For the purposes of international comparability, not only of the labour input measures but also of the resulting productivity measures, countries should follow the general methods applied in the literature. That is, grouping the hours worked by at least age and education (and possibly other characteristics), and then using the Törnqvist index to create the aggregated growth rate of labour services, weighting each group by their share in total labour compensation.

NSOs and international organisations alike should be cautious in their choice of dimensions to cross-classify workers' hours worked in their labour services methodologies. Specific care should be taken in the interpretation of such measures when sex is included as a dimension, especially when there have been significant movements in female participation in the labour force or in gender pay gaps over time. Notwithstanding the importance of genderdifferentiated data more generally, which is crucial to build a better understanding of gender-pay gaps and other forms of bias based on gender, it is not recommended to include gender as a dimension in measures of CALI.

\section{Measuring productive capital stocks and capital services}

A fundamental characteristic of capital is its dual nature, meaning depending on the purposes of the analysis, the capital measure will reflect the market value of assets in the balance sheets (net wealth capital stock) or the source of productive services provided by capital goods to the production process (capital services).

In the implementation of the PIM at the individual asset level, there exists an important difference between the two capital stock concepts, which is related to the use of an age-price profile when the aim is to estimate net wealth capital stocks, or an ageefficiency profile if the purpose is to estimate productive capital stocks. Nonetheless, the age-price and age-efficiency profiles are not independent from each other, and one can be derived from the other. The geometric pattern constitutes a special case, as both profiles are identical.
While the net (wealth) capital stock is an important indicator for economic analysis, e.g. to assess the level of infrastructure in a country, it is not the most suitable measure of capital input for growth accounting and productivity analysis. In this case, capital input measures should account for the productive capacity of capital goods, rather than their market value, and for the heterogeneity in productive capacity across assets. This is the aim of capital services measures. Capital services are the flow of productive services drawn from the productive capital stock, and constitute the appropriate measure of capital input for production and productivity analysis (OECD, 2009).

Whichever the starting point, age-price or age-efficiency, the choice of the functional form should be made based on empirical evidence regarding the group of assets, or otherwise based on sound logical reasoning about the depreciation or efficiency decline based, for example, on experts' advice. Since geometric profiles tend to be "empirically supported, conceptually correct and easy to implement" (OECD, 2009), NSOs in APO economies with little empirical information on the evolution of asset prices and productive capacity over time are encouraged to use such profiles to measure asset depreciation in their national accounts. 


\section{Measuring multifactor productivity accounting for labour and capital services}

Measures of labour and capital inputs accounting only for the volumes of hours worked and net wealth stocks ignore the skill composition of the workforce and differences in the productive capacity of capital goods. Multifactor productivity measures derived with such labour and capital input measures, will capture the contribution to economic growth arising from changes in the composition of labour and capital inputs, often overestimating multifactor productivity growth.

Assumptions underlying the construction of labour and capital input weights in the growth accounting framework affect derived MFP measures. Labour input weights, i.e. the share of labour costs in total production costs, depend on assumptions made about the compensation of self-employed workers. Capital input weights depend on the underlying asset boundary and the choice made by the productivity analyst to estimate the rate of return of capital assets.
In light of their benefits for economic analysis as compared to simpler productivity measures, NSOs in APO economies are encouraged to compile multifactor productivity growth estimates accounting for labour and capital services, i.e. taking into account how different types of workers and productive assets contribute to economic growth. Measuring multifactor productivity growth accounting for changes in labour and capital services is the recommended approach in the Measuring Productivity OECD Manual (OECD, 2001), and is also the most frequently used approach nowadays by NSOs and international organisations for productivity analysis.

In the estimation of multifactor productivity growth, NSOs should pay specific attention to the incidence of self-employed workers in total employment and make reasonable assumptions about their labour compensation. They should also consider the largest possible set of productive assets and closely track the progress made in OECD countries to account for intellectual property assets included and excluded from the SNA asset boundary.

\section{Measuring productivity accounting for environmental inputs and outputs}

Constructing measures such as $\mathrm{CO}_{2}$ productivity, energy productivity, material resource productivity or environmentally adjusted multifactor productivity brings together indicators from both the economic and environmental measurement domains. It is often the case that these indicators are compiled for different purposes, possibly differing in their coverage, and therefore creating internal inconsistency in their estimation. With many countries attempting to construct such measures, and possibly taking different approaches, this raises questions around the suitability of such estimates for international comparisons.

Measures of, for example, energy productivity, are often available only at the whole economy level. This creates issues for the interpretation of evolutions in these measures, as it is not possible to determine whether changes over time stem from changes in the energy efficiency of certain industries, or from changes in the composition of industries.
In order to facilitate economic analysis and ensure consistency between the different domains, the environmental and economic statistics used for the compilation of productivity indicators accounting for environmental inputs and outputs should be sourced from environmental-economic accounts compiled according to the SEEA Central Framework.

Sourcing environmental and economic statistics from SEEA environmental-economic accounts facilitates structural decompositions and analysis of the drivers of energy, material resource and $\mathrm{CO} 2$ productivity. These decompositions can then contribute to policy discussions on the environmental efficiency of production processes. 
118 | P a g e 


\section{Conclusions and way forward}

This report describes current practices and outstanding challenges in productivity measurement in both OECD and APO countries, illustrating the pros and cons of different productivity indicators for economic analysis based on empirical examples, and making a series of statistical recommendations.

The first recommendation encourages countries to implement the latest national accounting standards, namely the System of National Accounts (SNA) 2008. Other specific recommendations relate to the measurement of output, labour and capital. In particular, special consideration should be given to the measurement of the non-observed economy in APO countries, which otherwise could distort productivity comparisons across countries and over time. Similarly, the increasing scale of transactions facilitated by digitalisation calls for further efforts from NSOs to capitalise on new sources of information, for example, collected by online intermediaries as a by-product of their activities. The construction of digital supply-and-use tables should also be considered by NSOs as a way to track the digitalisation of their economies and account for the scale of e-commerce transactions, digitally delivered services and digitally ordered goods and services (Mitchell, 2019; OECD, WTO and IMF, 2020).

The preferred measure of labour productivity should be the volume of output generated per hour worked. The use of hours worked rather than person or job counts is particularly important for APO countries, as workers tend to work longer hours than in OECD countries. In estimating the total number of hours worked, NSOs should favour the use of a bottom-up approach (component method), exploit the full range of data sources, and fully consider the hours worked by self-employed workers. This avoids the self-reporting bias that affects direct method estimates of hours worked, and reduces measurement errors arising from the use of a single data source and the omission of own-account and unpaid family workers, whose contribution to production is substantial in many APO economies.

For the purposes of multifactor productivity (MFP) calculations, this report advocates the compilation of labour and capital input measures that account for the skill heterogeneity of the workforce and differences in the productive capacity of assets. In other words, the recommendation in this report is to compile MFP using measures of labour and capital services. In contrast with volume measures of labour input, such as the total number of hours worked, labour services (or composition-adjusted labour input) account for both the volume of hours worked and the differing characteristics of workers. Similarly, capital services account for both the volume and composition of the productive capital stock, thus acknowledging differences in the productive capacity of assets, contrary to measures of net wealth capital stocks. This report also shows that the quality of capital measures benefits from long investment time series, with a detailed breakdown by asset category.

Finally, this report discusses how productivity measures can combine economic and environmental indicators, and how to account for the role of natural resources and the production of undesirable outputs, such as carbon dioxide or pollutants, hence addressing the issue of the sustainability of productivity growth.

A consistent theme that runs throughout this report is the importance of engagement with national statistics offices. They are best placed to provide the most reliable inputs for productivity 
measurement given their access to, and knowledge of, the best data sources in their country, which is why the statistical recommendations in this report are first and foremost targeted at NSOs.

However, for many NSOs this requires additional resources, both for the design and collection of new data sources and for the derivation of the productivity measures themselves. Efforts should be also made on this front, and the hope is that this report will provide some momentum in that direction, especially where it is needed most.

At the same time, conscious of these constraints, countries and international organisations should continue to coordinate efforts and push the boundaries of productivity measurement, making the best use of all available data sources and methods to address current measurement challenges and to produce a complete and comparable set of productivity indicators. The APO and the OECD will continue their collaboration to provide their member economies with a better understanding of the drivers of productivity performance and the factors affecting its sustainability. In the current situation, where economies are severely hit by the COVID-19 outbreak and the confinement rules adopted by their governments, creating a better understanding of how productivity indicators are affected by business cycle effects would also be an important contribution. 


\section{References}

Ahmad, N., et al. (2003), Comparing Labour Productivity Growth in the OECD Area: The Role of Measurement, OECD Statistics Working Papers, No. 2003/05, OECD Publishing, Paris, https://doi.org/10.1787/838342850485.

Ahmad, N (2004), Measuring GDP in the Balkans: Experience and Lessons Learned, http://www.oecd.org/sdd/na/39086004.pdf.

Ahmad, N., J. Ribarsky and M. Reinsdorf (2017), Can potential mismeasurement of the digital economy explain the post-crisis slowdown in GDP and productivity growth?, OECD Statistics Working Papers, No. 2017/09, OECD Publishing, Paris, https://doi.org/10.1787/a8e751b7-en.

Ahmad, N. and S. Koh (2011), Incorporating Estimates of Household Production of Non-Market Services into International Comparisons of Material Well-Being, OECD Statistics Working Papers, No. 2011/07, OECD Publishing, Paris, https://doi.org/10.1787/5kg3h0jgk87g-en.

Ahmad, N. and P. Schreyer (2016), Measuring GDP in a Digitalised Economy, OECD Statistics Working Papers, No. 2016/07, OECD Publishing, Paris, https://doi.org/10.1787/5jlwqd81d09r-en.

Akerlof, G (1970), The Market for "Lemons": Quality Uncertainty and the Market Mechanism, Quarterly Journal of Economics 84: 488-500.

APO (Asian Productivity Organization) (2019), APO Productivity Data Book 2019. Tokyo: APO.

Argento, L. and D. Burnell (2013), Australian Valuation of Subsoil Natural Resources and their Inclusion in Productivity Statistics, Presented at the Working Party on National Accounts (WPNA) held on 3-4 October 2013, STD/CSTAT/WPNA(2013)6.

Arnold, J., Garda, P. and Gonzalez-Pandiella, A. (2020) Reaching out to informal workers in Latin America: Lessons from COVID-19, ECOSCOPE blog post, https://oecdecoscope.blog/2020/06/29/reaching-out-to-informal-workers-in-latin-america-lessonsfrom-covid-19/.

Australian Bureau of Statistics (ABS) (2015), Australian System of National Accounts - Concepts, Sources and Methods, ABS Catalogue No. 5216.0, 2015.

Baldwin, J., L. Huju and M. Tanguay, (2015), An Update on Depreciation Rates for the Canadian Productivity Accounts, The Canadian Productivity Review, Catalogue no. 15-206-X, no. 039, January 2015.

Barro, R. and J-W, Lee. (2013), A New Data Set of Educational Attainment in the World, 1950-2010, Journal of Development Economics, vol 104, pp.184-198.

Blades, D., F. Ferreira and M. Ana Lugo (2011), The Informal Economy in Developing Countries: AN Introduction, Review of Income and Wealth, Series 57, Special Issue, May 2011.

Behrman, J., and N. Birdsall (1983). The Quality of Schooling: Quantity Alone is Misleading, The American Economic Review, 73(5), 928-946. 
Bennett, J., R. Kornfeld, D. Sichel and D. Wasshausen (2020), Measuring Infrastructure in BEA's National Economic Accounts, National Bureau of Economic Research, Working Paper 27446, https://www.nber.org/papers/w27446.

Berlemann M. and J. Wesselhöft (2014), Estimating Aggregate Capital Stocks Using the Perpetual Inventory Method - A Survey of Previous Implementations and New Empirical Evidence, Review of Economics, 65 (1), 1-34.

Biatour, B., G. Byron and C. Kegels (2007), Capital services and total factor productivity measurements: impact of various methodologies for Belgium, Federaal PLanbureau, Working Paper 3-07, March 2007.

Blades, D., F. Ferreira and M. Ana Lugo (2011), The Informal Economy in Developing Countries: AN Introduction, Review of Income and Wealth, Series 57, Special Issue, May 2011.

BLS (1993), Labour Composition and U.S. Productivity Growth, 1948-1990, U.S. Department of Labour, Bureau of Labour Statistics, Bulletin 2426.

BLS (2007), Technical Information About the BLS Multifactor Productivity Measures, Bureau of Labour Statistics.

BLS (2017), Overview of Capital Inputs for the BLS Multifactor Productivity Measures, June 2, 2017, accessible online https://www.bls.gov/mfp/mprcaptl.pdf.

Brandt, N., P. Schreyer and V. Zipperer (2017), Productivity Measurement with Natural Capital, Review of Income and Wealth, Series 63, Supplement 1, February 2017.

Bureau of Economic Analysis (2003), Fixed Assets and Consumer Durables Goods in the United States, 1925-97, September 2003, accessible online https://www.bea.gov/system/files/methodologies/Fixed-Assets-1925-97.pdf

Byrne, D. and C. Corrado (2017), ICT prices and ICT services: What do they tell us about productivity and technology?, Finance and Economics Discussion Series, No. 2017-015, Board of Governors of the Federal Reserve System, www.federalreserve.gov/econresdata/feds/2017/files/2017015pap.pdf.

Byrne, D., J. Fernald and M. Reinsdorf (2016), Does the United States have a productivity slowdown or a measurement problem?, Brookings Papers on Economic Activity, Spring 2016, pp. 109-157, https://www.brookings.edu/wp-content/uploads/2016/03/byrnetextspring16bpea.pdf.

Byrne, D., S. Oliner and D. Sichel (2015), How fast are semiconductor prices falling?, NBER Working Paper Series, No. 21074 (July), NBER, Cambridge, Mass, www.nber.org/papers/w21074.pdf.

Cabbanes, P., A. Montaut, and P. Pionnier (2013), Évaluer la productivité globale des facteurs en France : l'apport d'une mesure de la qualité du capital et du travail, INSEE, Direction des Études et Synthèses Économiques, Document de travail, G 2013 / 07. https://www.insee.fr/fr/statistiques/1381116

Cárdenas Rodríguez, M., I. Haščič and M. Souchier (2018), Environmentally Adjusted Multifactor Productivity: Methodology and Empirical results for OECD and G20 countries, OECD Green Growth Papers, No. 2018/02, OECD Publishing, Paris, https://doi.org/10.1787/fdd40cbd-en. 
Cho T., C. Han and Y. Jung (2015), Capital measurement in Korea and findings from the newly compiled national balance sheets, June 2015, https://www.researchgate.net/publication/322386723.

Cho T., K. Do and B. Yi (2012), Measuring Service Lives of Assets in Korean Capital Measurement, Working Paper, June 2012, https://www.researchgate.net/publication/322386181.

Cho, T., S. Hwang and P. Schreyer (2017), Has the Labour Share Declined?: It Depends, OECD Statistics Working Papers, No. 2017/01, OECD Publishing, Paris, http://dx.doi.org/10.1787/2dcfc715-en.

Colecchia, A. and P. Schreyer (2002), ICT Investment and Economic Growth in the 1990s: Is the United States a Unique Case? A Comparative Study of Nine OECD Countries, Review of Economic Dynamics, 5 , issue 2, p. 408-442.

Dang, T. and A. Mourougane (2014), Adjusting Productivity for Pollution in Selected Asian Economies, OECD Green Growth Papers, No. 2014/01, OECD Publishing, Paris, https://doi.org/10.1787/5jxvd5ra5lzv-en.

Diewert, W. (2005), The Measurement of Business Capital, Income and Performance, Chapter 1, The Measurement of Capital: Traditional User Cost Approaches, Tutorial presented at the University Autonoma of Barcelona, Spain, September 21-22, 2005, revised December 2005, available at http://www.econ.ubc.ca/diewert/barc1.pdf.

Elsby, M., B. Hobijn and A. Sahin (2013), The Decline of the U.S. Labor Share, Brookings Papers on Economic Activity, Fall 2013, pp. 1-52.

EPU (2015), The Eleventh Malaysia Plan, 2016-2020, Economic Planning Unit, Prime Minister's Department, Putrajaya.

European Commission (2014), The Production Function Methodology for Calculating Potential Growth Rates \& Output Gaps, Economic Papers 535, November 2014.

Eurostat (2016), Quality Adjusted Labour Input (QALI), Eurostat experimental statistics, https://ec.europa.eu/eurostat/web/experimental-statistics/qali.

Eurostat (2016), Methodological document on labour productivity indicators for the for the EU28 member stats: quality adjusted labour input, https://ec.europa.eu/eurostat/documents/7894008/8915486/Methodology QALI.pdf.

Eurostat (2018a), Eurostat/OECD 2018 questionnaire on the methodology underlying labour input data in national accounts: Croatia.

Eurostat (2018b), Eurostat/OECD 2018 questionnaire on the methodology underlying labour input data in national accounts: France.

Eurostat (2018c), Eurostat/OECD 2018 questionnaire on the methodology underlying labour input data in national accounts: Germany.

Eurostat (2018d), Eurostat/OECD 2018 questionnaire on the methodology underlying labour input data in national accounts: Hungary. 
Eurostat (2018e), Eurostat/OECD 2018 questionnaire on the methodology underlying labour input data in national accounts: Slovenia.

Eurostat (2018f), Eurostat/OECD 2018 questionnaire on the methodology underlying labour input data in national accounts: Israel.

Eurostat (2018g), Eurostat/OECD 2018 questionnaire on the methodology underlying labour input data in national accounts: Italy.

Eurostat (2020), Quality Report of the European Union Labour Force Survey 2018, 2020 Edition, Eurostat Statistical Reports.

Eurostat-OECD (2016), Joint Eurostat-OECD Survey of National Practices in Estimating Net Stocks of Structures, 2016, https://ec.europa.eu/eurostat/documents/24987/4253483/Eurostat-OECD-surveyof-national-practices-estimating-net-stocks-structures.pdf.

Eurostat-OECD (2019), Joint Eurostat-OECD Task Force on Land and Other Non-Financial Assets Report on Intellectual Property Products, 20st Meeting of the Directors of Macro-Economic Statistics, Luxembourg, 18-19 June 2019, https://ec.europa.eu/eurostat/documents/24987/725066/EurostatOECD+Report+on+Intellectual+Property+Products.pdf.

Giandrea, M., R. Kornfeld, P. Meyer and S. Powers, Incorporating Canadian Capital Asset Depreciation Rates into US Capital and Multifactor Productivity Measures: A Collaborative Investigation, Fifth World KLEMS Conference, Cambridge, MA, June 4-5, 2018.

Gyomai, G. and P. van de Van (2014), The Non-Observed Economy in the System of National Accounts, OECD Statistics Brief, https://www.oecd.org/sdd/na/Statistics\%20Brief\%2018.pdf.

Hann, M., E. Veldhuizen., M. Tanriseven and M. van Rooijen-Horsten (2014), The Dutch Growth Accounts: Measuring Productivity with Non-Zero Profits, Review of Income and Wealth Series 60, Supplement Issue, November 2014.

Hulten, Charles R. and Wykoff, Frank C. (1981), The estimation of economic depreciation using vintage asset prices: An application of the Box-Cox power transformation, Journal of Econometrics, Elsevier, Vol. 15(3), pages 367-396, April, 1981.

Hulten, C. (1991), The Measurement of Capital, in Fifty Years of Economic Measurement: The Jubilee of the Conference on Research in Income and Wealth, Ernst R. Berndt and Jack E. Triplett editors, University of Chicago Press, May 12-14, 1988, publication date: 1991.

International Monetary Fund (2018), Turkey: 2018 Article IV Consultations, IMF Country Report No. $18 / 110$.

INEGI (2013), Sistema de Cuentas Nacionales de México - Fuentes y metodología Año Base 2013, 2013, accessible online https://www.inegi.org.mx/app/biblioteca/ficha.html?upc=702825097165

Inklaar, R. (2010), The sensitivity analysis of capital services measurement: measure all assets and the cost of capital, Review of Income and Wealth, Series 56, Number 2, June 2010. 
International Labour Organization (ILO) (1982), Resolution concerning statistics of the economically active population, employment, unemployment and underemployment, adopted by the Thirteenth International Conference of Labour Statisticians, October, 1982.

International Labour Organization (ILO) (1993), Resolution Concerning Statistics of Employment in the Informal Sector, 15th International Conference of Labour Statisticians, Geneva, January 19-28, 1993.

International Labour Organization (ILO) (2003): Guidelines concerning a statistical definition of informal employment, endorsed by the Seventeenth International Conference of Labour Statisticians (November-December 2003); in: Seventeenth International Conference of Labour Statisticians (Geneva, 24 November - 3 December 2003), Report of the Conference; Doc. ICLS/17/2003/R; International Labour Office, Geneva, 2003.

International Labour Organisation (ILO) (2008), Measurement of working time, Publications of the International Labour Office, 18th International Conference of Labour Statisticians (ICLS).

International Labour Organisation (ILO) (2013). Measuring informality: A statistical manual on the informal sector and informal employment, Geneva: ILO, 2013.

International Labour Organization (ILO) (2018). Asia-Pacific Employment and Social Outlook 2018, https://www.ilo.org/wcmsp5/groups/public/---asia/---ro-bangkok/---sro-

bangkok/documents/publication/wcms 649885.pdf.

ISTAT (2019), Misure di produttività, Communicato Stampa, Nota metodologica, November 26, 2019, https://www.istat.it/it/archivio/236114.

Jorgenson, D. (1963), Capital theory and investment behaviour, American Economic Review, Vol. 53, pp. 247-259.

Jorgenson, D. and Z. Griliches (1967), The Explanation of Productivity Change, Review of Economic Studies, Vol. 34, No. 3, pp. 249-283

Jorgenson, D., F. Gollop and B. Fraumeni (1987), Productivity and U.S. Economic Growth, Harvard University Press, Ma.

Lequiller, F. and D. Blades (2014), Understanding National Accounts: Second Edition, OECD Publishing, Paris, https://doi.org/10.1787/9789264214637-en.

Mitchell, J. (2019), Guidelines for Supply-Use tables for the Digital Economy, Prepared for the meeting of the Informal Advisory Group on Measuring GDP in a Digitalised Economy held on July 1-2, 2019, January 2019, accessible online http://www.oecd.org/officialdocuments/publicdisplaydocumentpdf/?cote=SDD/CSSP/WPNA(2019)1 $\angle$ REV1\&docLanguage $=$ En .

Nomura, K. and T. Amano (2012), Labor Productivity and Quality Change in Singapore: Achievements in 1974-2011 and Prospects for the Next Two Decades, KEO Discussion Paper No. 129, KEO, Tokyo.

Nomura, K. and H. Shirane (2014), Measurement of Quality-Adjusted Labor Input in Japan, 1955-2012, KEO Discussion Paper No. 133, KEO, Tokyo. 
Nomura, K. and Akashi, N. (2017), Measuring Quality-adjusted Labour Inputs in South Asia, 1970-2015, KEO Discussion Paper No. 143. KEO: Tokyo.

OECD (2001), Measuring Productivity - OECD Manual: Measurement of Aggregate and Industry-level Productivity Growth, OECD Publishing, Paris, https://doi.org/10.1787/9789264194519-en.

OECD (2002), Measuring the Non-Observed Economy: A Handbook, International Labour Office/International Monetary Fund/International Statistical Committee of the Commonwealth of Independent States/OECD Publishing, www.oecd.org/std/na/measuringthenonobservedeconomyahandbook.htm.

OECD (2009), Measuring Capital - OECD Manual 2009: Second edition, OECD Publishing, Paris, https://doi.org/10.1787/9789264068476-en.

OECD (2012), Closing the Gender Gap: Act Now, OECD Publishing, Paris, https://doi.org/10.1787/9789264179370-en.

OECD (2015a), Government at a Glance 2015, OECD Publishing, Paris, https://doi.org/10.1787/gov glance-2015-en.

OECD (2015b), Mineral and energy natural resources, In: OECD Natural Resource Accounts Statistics Database, http://stats.oecd.org/index.aspx?datasetcode=NAT RES.

OECD (2017a), Green Growth Indicators 2017, OECD Green Growth Studies, OECD Publishing, Paris, https://doi.org/10.1787/9789264268586-en.

OECD (2017b), Entrepreneurship at a Glance 2017, OECD Publishing, Paris, https://doi.org/10.1787/entrepreneur aag-2017-en.

ECD (2017c), Pensions at a Glance 2017: OECD and G20 Indicators, OECD Publishing, Paris, https://doi.org/10.1787/pension glance-2017-en.

OECD (2018a), OECD Economic Surveys: Korea 2018, OECD Publishing, Paris, https://doi.org/10.1787/eco surveys-kor-2018-en.

OECD (2018b), OECD Economic Surveys: Turkey 2018, OECD Publishing, Paris, https://doi.org/10.1787/eco surveys-tur-2018-en.

OECD (2018c), Multi-dimensional Review of Thailand (Volume 1): Initial Assessment, OECD Development Pathways, OECD Publishing, Paris, https://doi.org/10.1787/9789264293311-en.

OECD (2018d), OECD Economic Surveys: Indonesia 2018, OECD Publishing, Paris, https://doi.org/10.1787/eco surveys-idn-2018-en.

OECD (2018e), Economic Outlook for Southeast Asia, China and India 2018: Fostering Growth through Digitalisation, OECD Publishing, Paris, https://doi.org/10.1787/9789264286184-en.

OECD (2019a), OECD Economic Surveys: India 2019, OECD Publishing, Paris, https://doi.org/10.1787/554c1c22-en. 
OECD (2019b), OECD Economic Surveys: Malaysia 2019, OECD Publishing, Paris, https://doi.org/10.1787/eaaa4190-en.

OECD (2019c), OECD Economic Surveys: Japan 2019, OECD Publishing, Paris, https://doi.org/10.1787/fd63f374-en.

OECD (2019d), Southeast Asia Going Digital: Connecting SMEs, OECD, Paris, www.oecd.org/goingdigital/southeast-asia-connecting-SMEs.pdf.

OECD (2019e), OECD Compendium of Productivity Indicators 2019, OECD Publishing, Paris, https://doi.org/10.1787/b2774f97-en.

OECD (2020a), OECD Economic Outlook, Volume 2020 Issue 2, OECD Publishing, Paris, https://doi.org/10.1787/39a88ab1-en.

OECD (2020b), What big data can tell us about women on boards, https://www.oecd.org/gender/data/what-big-data-can-tell-us-about-women-onboards.htm\#: :text=Women\%20make\%20up\%20only\%2016,one\%2Dfifth\%20of\%20the\%20boardro om.

OECD, WTO and IMF (2020), Handbook on Measuring Digital Trade - Version 1, accessible online https://www.oecd.org/sdd/its/Handbook-on-Measuring-Digital-Trade-Version-1.pdf.

Office for National Statistics (ONS) 2019, Changes to the capital stock estimation methods for Blue Book 2019, National Accounts Articles, August 20, 2019.

Ono (2018), Why Do the Japanese Work Long Hours? Sociological Perspectives on Long Working Hours in Japan, Japan Labor Issues, vol.2, no.5, February-March 2018.

Pionnier, P. and E. Guidetti (2015), Comparing profit shares in value-added in four OECD countries: Towards more harmonised national accounts, OECD Statistics Working Papers, No. 2015/03, OECD Publishing, Paris, https://doi.org/10.1787/5js0bsm2g0lt-en.

Reinsdorf, M. and P. Schreyer (2019), Measuring consumer inflation in a digital economy, OECD Statistics Working Papers, No. 2019/01, OECD Publishing, Paris, https://doi.org/10.1787/1d002364en.

Rincon-Aznar, A., R. Riley and G. Young (2017), Academic review of asset lives in the UK, National Institute of Economic and Social Research, NIESR Discussion Paper No. 474, January 2017.

Schmalwasser, O. and M. Schidlowski (2006), Measuring Capital Stock in Germany, National Accounts, Statistisches Bundesamt, Wirtschaft und Statistik 11/2006.

Schreyer, P. (2000), The Contribution of Information and Communication Technology to Output Growth: A Study of the G7 Countries, OECD Science, Technology and Industry Working Papers, No. 2000/02, OECD Publishing, Paris, https://doi.org/10.1787/151634666253.

Schreyer, P. (2002), Computer price indices and international growth and productivity comparisons, Review of Income and Wealth, Series 48, Number 1, March 2002. 
Schreyer, P., P. Bignon and J. Dupont (2003), OECD Capital Services Estimates: Methodology and a First Set of Results, OECD Statistics Working Papers, No. 2003/06, OECD Publishing, Paris, https://doi.org/10.1787/658687860232.

Schreyer, P. (2010), Measuring Multi-Factor Productivity when Rates of Return Are Exogenous, chapter 2, pp. 13-40 in W.E. Diewert, B.M. Balk, D. Fixler, K.J. Fox and A.O. Nakamura (2010), Price and Productivity Measurement: Volume 6 - Index Number Theory. Trafford Press.

Sgaravatti G. (2020), Quality-adjusted labour input (QALI) QMI, United Kingdom Office for National Statistics, Newport.

Singstat (2020), Labour, Employment, Wages and Productivity data, https://www.singstat.gov.sg/finddata/search-by-theme/economy/labour-employment-wages-and-productivity/latest-data.

Sorsa, P., J. Arnold and P. Garda (2020), Informality and weak competition: A deadly cocktail for growth and equity in emerging Latin America, VOXEU article, https://voxeu.org/article/informality-and-weakcompetition-latin-america.

Statistics Canada (2007), Depreciation Rates for the Productivity Accounts, Catalogue no. 15-206-XIE, no. 005, February 2007.

Statistics Netherlands (2019), Gross National Income Inventory 2015, The Hague, January 2019.

Statistics New Zealand (2014), Measuring capital stock in the New Zealand economy, Fourth Edition, 2014.

Stehrer, R., A. Bykova, K. Jäger, O. Reiter and M. Schwarzhappel (2019), Industry Level Growth and Productivity Data with Special Focus on Intangible Assets, Report on methodologies and data construction for the EU KLEMS Release 2019, The Vienna Institute for International Economic Studies (wiiw), Vienna.

Suga, Y. and K. Nomura (2018), Measurement of Depreciation Rates using Microdata from Disposal Survey of Japan, Paper prepared for the 35th IARIW General Conference, Copenhagen, Denmark, August 20-25, 2018.

Timmer, M.P., R. Inklaar, M. O'Mahony and B. van Ark (2010), Economic Growth in Europe. A Comparative Industry Perspective, Cambridge University Press.

United Nations (2008), International Standard Industrial Classification of All Economic Activities (ISIC) Revision 4, Statistical Papers, Series M, No.4/Rev.4.

United Nations (2014), System of Environmental-Economic Accounts: Central Framework, New York, https://seea.un.org/sites/seea.un.org/files/seea of final en.pdf.

United Nations., European Commission., International Monetary Fund., Organisation for Economic Cooperation and Development., \& World Bank. (2009). System of National Accounts 2008. New York: United Nations, https://unstats.un.org/unsd/nationalaccount/docs/sna2008.pdf. 
Van de Ven, P. (2015), New standards for compiling national accounts: what's the impact on GDP and other macroeconomic indicators?, Statistics Brief, February 2015 - No. 20. https://www.oecd.org/sdd/na/new-standards-for-compiling-national-accounts-SNA2008OECDSB20.pdf.

Vries K. and A. Erumban (2017), Total Economy Database, A detailed guide to its sources and methods, The Conference Board, https://www.conference-board.org/data/economydatabase.

Ward, A., M. Zinni and P. Marianna (2018), International productivity gaps: Are labour input measures comparable?, OECD Statistics Working Papers, No. 2018/12, OECD Publishing, Paris, https://doi.org/10.1787/5b43c728-en.

World Bank (2014), The Changing Wealth of Nations Database. The World Bank.

Wyckoff, A. (1995), The Impact of Computer Prices on International Comparisons of Productivity, Economics of Innovation and New Technology, pp. 277-93. 
This report, published in the 60th anniversary of the Asian Productivity Organization (APO) and the Organisation for Economic Co-operation and Development (OECD), is the first outcome of their collaboration to develop improved and more comparable productivity statistics across APO and OECD member economies. It explores current practices and challenges in productivity measurement and provides recommendations to National Productivity Organisations (NPOs), National Statistics Offices (NSOs), and other agencies involved in the compilation and analysis of productivity statistics in APO member economies to improve measurement and cross-country comparability. 